\title{
The old, the new and the ever-changing view of haemorrhoidal disease research
}

Citation for published version (APA):

van Tol, R. (2020). The old, the new and the ever-changing view of haemorrhoidal disease research. [Doctoral Thesis, Maastricht University]. ProefschriftMaken. https://doi.org/10.26481/dis.20200917rt

Document status and date:

Published: 01/01/2020

DOI:

10.26481/dis.20200917rt

Document Version:

Publisher's PDF, also known as Version of record

\section{Please check the document version of this publication:}

- A submitted manuscript is the version of the article upon submission and before peer-review. There can be important differences between the submitted version and the official published version of record.

People interested in the research are advised to contact the author for the final version of the publication, or visit the DOI to the publisher's website.

- The final author version and the galley proof are versions of the publication after peer review.

- The final published version features the final layout of the paper including the volume, issue and page numbers.

Link to publication

\footnotetext{
General rights rights.

- You may freely distribute the URL identifying the publication in the public portal. please follow below link for the End User Agreement:

www.umlib.nl/taverne-license

Take down policy

If you believe that this document breaches copyright please contact us at:

repository@maastrichtuniversity.nl

providing details and we will investigate your claim.
}

Copyright and moral rights for the publications made accessible in the public portal are retained by the authors and/or other copyright owners and it is a condition of accessing publications that users recognise and abide by the legal requirements associated with these

- Users may download and print one copy of any publication from the public portal for the purpose of private study or research.

- You may not further distribute the material or use it for any profit-making activity or commercial gain

If the publication is distributed under the terms of Article $25 \mathrm{fa}$ of the Dutch Copyright Act, indicated by the "Taverne" license above, 


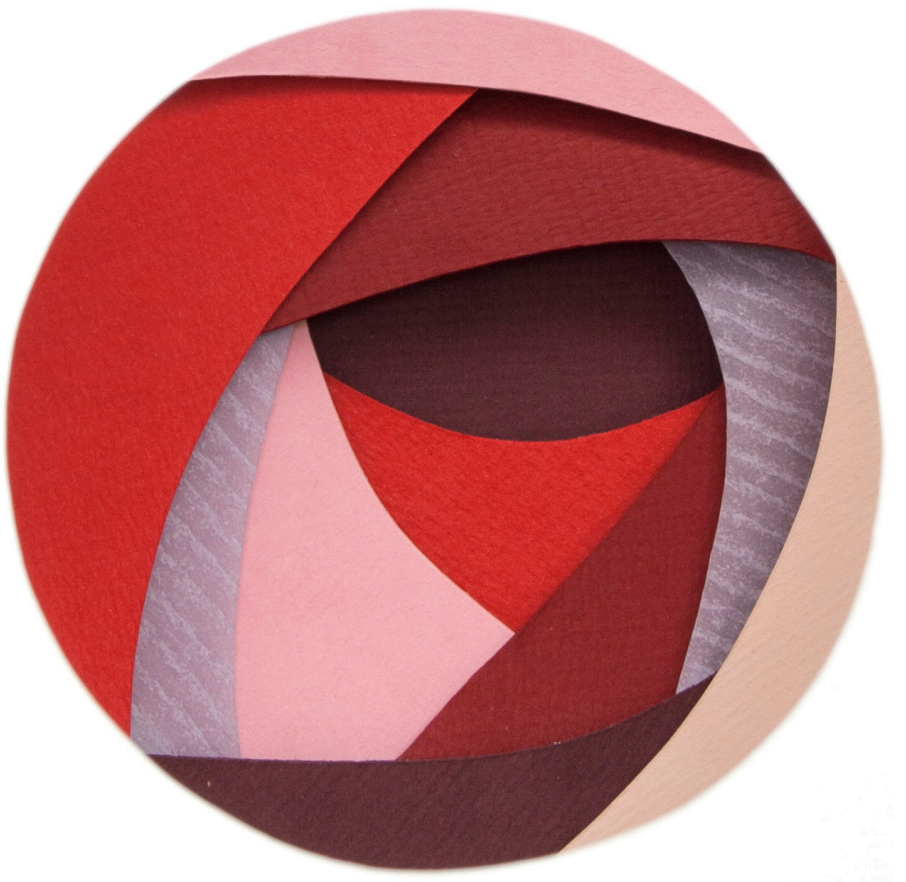

THE OLD, THE NEW AND

THE EVER-CHANGING VIEW OF HAEMORRHOIDAL DISEASE RESEARCH 



\section{The Old, the New and the Ever-Changing View of Haemorrhoidal Disease Research}


Printed by: Proefschrift Maken

(C) Robin Rowan van Tol

All rights reserved. No part of this publication may be reproduced in any form by any electronic or mechanical means (including photocopying, recording, or information storage and retrieval) without the prior permission of the author. 


\title{
The Old, the New and the Ever-Changing View of Haemorrhoidal Disease Research
}

\author{
Proefschrift
}

Ter verkrijging van de graad van doctor aan de Universiteit van Maastricht op gezag van de Rector Magnificus, Prof. dr. Rianne M. Letschert volgens het besluit van het College van Decanen, in het openbaar te verdedigen op donderdag 23 april 2020 om 14.00uur

door

Robin Rowan van Tol

Geboren op 11 maart 1992 te Blaricum 


\section{Promotores}

Prof. dr. L.P.S. Stassen

Prof. dr. C.D. Dirksen

\section{Copromotor}

Dr. S.O. Breukink

\section{Beoordelingscommissie}

Prof. dr. N. Bouvy (voorzitter)

Prof. dr. A. Masclee

Prof. dr. T. van der Weijden

Prof. dr. E. Consten, RU Groningen

Dr. F.J. Vogelaar, VieCurie Venlo 


\section{INDEX}

Chapter 1 General introduction and outline

Chapter 2 Protocol for the development of a Core Outcome Set for haemorrhoidal disease: An international Delphi study

Chapter 3 Towards a Core Outcome Set for haemorrhoidal disease a systematic review of outcomes reported in literature

Chapter 4 European Society of ColoProctology (ESCP) Core

Outcome Set (COS) for haemorrhoidal disease: An international Delphi Study among healthcare professionals

Chapter 5 Experiences of patients with haemorrhoidal disease - a qualitative study

Chapter 6 A national evaluation of the management practices of hemorrhoidal disease in the Netherlands

Chapter 7 European Society of ColoProctology (ESCP): Guideline for Haemorrhoidal Disease

Addendum The development of the European Society of

Coloproctology (ESCP) Guideline for Haemorrhoidal Disease

Chapter 8 Discussion, conclusion, and future perspectives

Chapter 9 Appendices

Summary

Samenvatting

Valorization

Dankwoord

Curriculum Vitae 


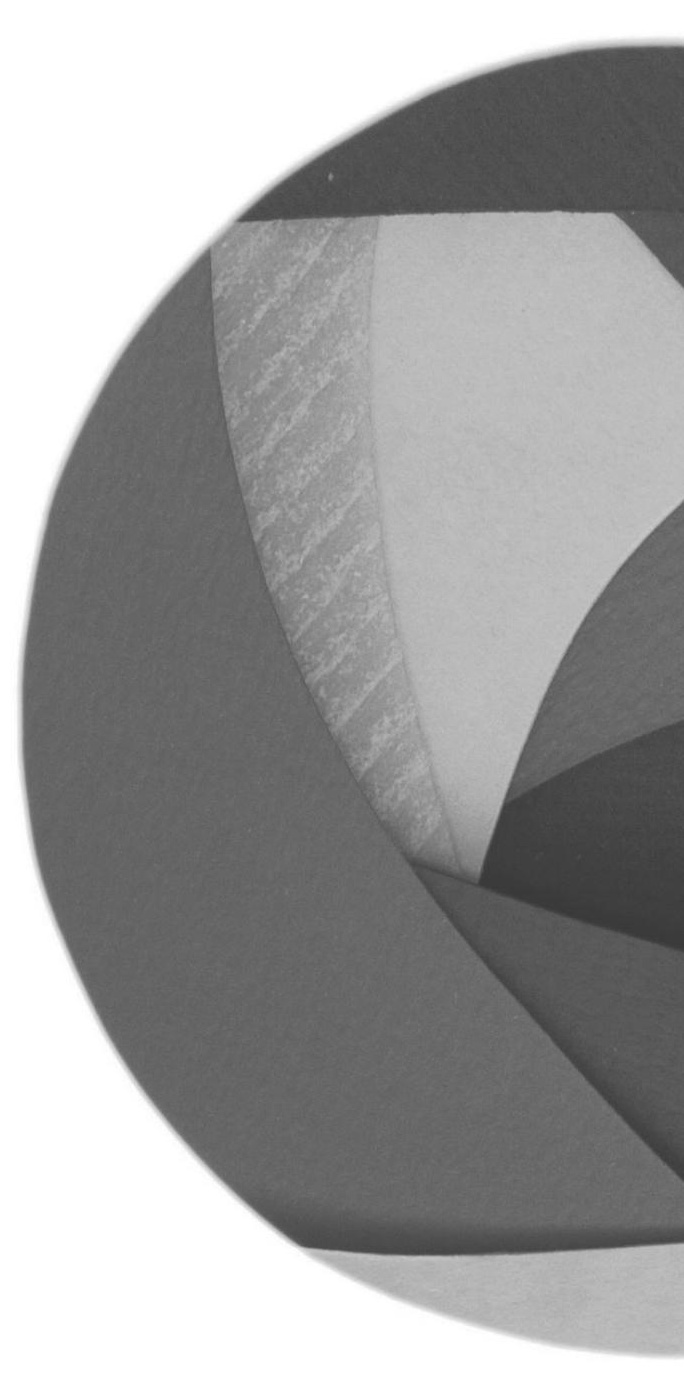




\section{1}

GENERAL INTRODUCTION AND OUTLINE 


\section{General introduction and thesis outline}

\section{Haemorrhoidal disease}

Haemorrhoidal disease (HD) is one of the most frequent anorectal disorders. The true prevalence of haemorrhoids is however not known; hospital-based studies are not representative for the total population with $\mathrm{HD}$ and community-based studies have relied on self-reporting only. This has led to reported prevalence rates varying from 4,4$45 \%$ (1-4).

In the Netherlands, the prevalence is estimated to be around 8.6 per 1000 individuals. The peak incidence seems to be between the ages of 45-65 years $(5,6)$. In the general population, the prevalence of HD is similar between men and women $(2,7)$. High estrogen receptor levels have been identified in haemorrhoids, which may explain haemorrhoidal symptoms during pregnancy (8). There is an increased prevalence amongst higher socioeconomic groups, but this may reflect health-seeking behavior (9).

\section{Anatomy}

Haemorrhoidal cushions are embedded in the sub-epithelial space of the anal canal in connective tissue and smooth muscle fibers which are supportive structures forming a fibro-elastic network. This network is also named the corpus cavernosum recti or plexus haemorrhoidalis interna and is supplied by a complex structure of blood vessels (10). In the non-pathological state the cushions are situated intraluminal proximal to the dentate line. The dentate line is the point at which the squamous anoderm meets the columnar mucosa. With straining and increased abdominal pressure, the cushions fill with blood to prevent leakage of stool, fluid and/or gas. The haemorrhoidal cushions contribute to $15-20 \%$ of the closing pressure of the anal canal (11). In a pathological state, abnormal swelling of the cushions, stretching of the suspensory muscles and dilatation of the submucosal arteriovenous plexus result in prolapse of the haemorrhoidal tissue which can descend distal to the dentate line. This prolapsed tissue is easily traumatized and may cause bleeding. In addition, deposition of mucus produced by the prolapsed haemorrhoids may cause itching of the perianal skin.

Haemorrhoids are mostly classified according to the grading system of Goligher et al. (12-14). In the Goligher classification, grade I describes haemorrhoidal prolapse through the proctoscope, grade II describes haemorrhoidal prolapse during straining which reduces spontaneously, grade III describes haemorrhoidal prolapse occurring during straining and requires manual reduction back into the anal canal and grade IV describes irreducible haemorrhoidal prolapse. 
In literature and daily practice, grade III and IV haemorrhoids are often called external haemorrhoids. However, the wording 'external haemorrhoids' is also used when 'thrombosis of perianal veins' or 'perianal thrombosis' occurs. But thrombosis of perianal veins is a result of a completely different etiology. In the anocutaneous junction there is a external venous plexus, anatomically called 'plexus haemorrhoidalis externa', and here perianal thrombosis may develop, which may cause severe pain and swelling. Therefore, we prefer to use the Goligher classification to indicate severity of the haemorrhoids and healthcare providers should be reluctant to use the term external haemorrhoids to avoid confusing grade III and IV HD with thrombosis of the perianal veins.

\section{Pathology}

The exact pathology of HD is unknown. Consensus exists that frequent straining, constipation and pregnancy are associated with increased abdominal pressure and contribute to the development of HD. However, several studies revealed a hyper perfusion state of the haemorrhoidal plexus in patients with haemorrhoids, suggesting the dysregulation of vascular tone within haemorrhoidal tissue (1). Other studies described that haemorrhoids are a deterioriation of the anchoring connective tissue (15, 16). One study showed a fundamental disorder of collagen metabolism in patients with haemorrhoidal disease (17). Other histopathologic studies showed that haemorrhoidal tissue contained some inflammatory cells and newly-formed micro vessels $(18,19)$. In case of circumferential prolapsing haemorrhoids, there might be a relation to internal rectal prolapse (20).

Although the true pathophysiology of HD is unknown, it is likely that the etiology is multifactorial including sliding of the anal cushion, hyper perfusion of haemorrhoid plexus, vascular abnormality, tissue inflammation and internal rectal prolapse (rectal redundancy).

\section{Symptoms}

HD is mostly associated with the following symptoms $(21,22)$ :

o bleeding after passing stool

o pain

o prolapse, a lump hanging down outside of the anus, which may need to be pushed back in the anus

o itching

o soiling/mucus discharge after passing stool 


\section{Diagnosis}

Diagnosis starts with a medical history to identify the symptoms suggestive of HD (21, 22). Besides, the following risk factors should be evaluated: hard stools (constipation), the use of opioids or other medication causing constipation, increased intra-abdominal pressure (obesity, prolonged sitting on the toilet and pregnancy), low fiber diets and limited fluid intake $(9,23-25)$. In addition, a surgical history of previous anorectal procedures must be obtained.

A detailed physical examination should include external inspection of the anus and a digital rectal examination. Rectal examination could be performed in the left lateral position, knee-chest- or lithotomy (22). The rectal examination should include inspection, palpation for masses and tenderness and characterization of the anal sphincter tone. The initial examination should also include asking the patient to strain the pelvic floor down. Haemorrhoids are generally not palpable on digital examination in the absence of thrombosis.

\section{Treatment algorithm}

Numerous techniques are available, ranging from basic treatment including topical and medical therapies to outpatient treatments and surgical interventions. Treatment options mainly depend on the type and severity of haemorrhoids (according to the Goligher classification), patient's preference, and the expertise of the healthcare professional.

\section{Basic treatment}

When a patient visits the outpatient clinic with anorectal symptoms which may include bleeding, pain, prolapse, itching and/or soiling and the healthcare provider makes a diagnosis of $\mathrm{HD}$, the first management step consists of basic treatment. Basic treatment can be used for symptom relief and to prevent prolapse and includes toilet training, dietary changes (specifically high fiber diet), topical and pharmacological treatments (which may include phlebotonics such as flavonoids) (26-28).

These interventions are given in addition to advice about adequate water intake, healthy diet and encouraging physical activity.

\section{Outpatient procedures}

In patients in whom basic treatment has not resulted in satisfactory symptom reduction, outpatient procedures should be considered including Rubber Band Ligation (RBL), Infrared Coagulation (IRC) or Sclerotherapy (SCL).

With RBL, a device applies a rubber band to the base of each haemorrhoidal cushion by using an anoscope. This band constricts the blood supply of the haemorrhoidal cushion 
causing ischaemia. The ischaemic haemorrhoidal cushion will shrink and scar tissue is formed with subsequent repositioning of the prolapsing part of the cushion higher up in the anal canal. RBL can be applied for several times for different haemorrhoidal cushions during the same session. If necesarry this procedure can be repeated after a couple of weeks (29) to get an optimal treatment result.

Using IRC, the tissue is coagulated with infrared light. The infrared photo coagulator produces infrared light that penetrates the tissue and converts to heat, promoting coagulation of vessels that will result in local ischaemia and the formation of scar tissue which causes repositioning of the prolapsing part of the cushion higher up in the anal canal. The amount of tissue destruction depends on the intensity and duration of the application. The infrared probe is applied for 0.9 to 1.5 seconds to the apex of each haemorrhoid cushion, and this could be repeated three times on each haemorrhoidal cushion.

With SCL, an agent (i.e. polidocanol or aluminium potassium sulfate) is injected into the haemorrhoidal cushions. Local infiltration leads to inflammation of the haemorrhoidal tissue and scar tissue is formed with subsequent fixation of mucosa to the submucosa (30).

\section{Surgical treatment}

In patients in whom basic treatment or outpatient procedures have not resulted in an acceptable outcome or in case of grade III and/or IV HD, surgical procedures can be considered. These include Doppler-Guided Haemorrhoidal Artery ligation (DGHAL) +/- mucopexy or Mucopexy alone, Stapled Haemorrhoidopexy (SH) and Haemorrhoidectomy.

During a DG-HAL procedure, an ultrasound system enables accurate detection and targeted suture ligation of the haemorrhoidal arteries. DG-HAL is often combined with a modification mucopexy which serve to lift and secure the protruding haemorrhoid cushions to its original place. Many descriptive terms are used, such as 'recto anal repair' (RAR)' (31-33), 'transanal haemorrhoid mucopexy' (34) and 'anal lifting' (35). In this thesis, we use the term 'mucopexy'. Since the DG-HAL is being questioned, the mucopexy may also be described as a single procedure for treatment of $\operatorname{HD}(36,37)$.

$\mathrm{SH}$ is also known as circumferential stapled mucosectomy or 'procedure for prolapse and haemorrhoids' (PPH). With SH, a transanal circular stapler is used to excise a complete circular strip of rectal mucosa approximately four centimeters proximal to the dentate line removing the redundant mucosa (including a part of the proper muscle layer of the lower rectum) and to staple off the end of the branches of the superior haemorrhoidal artery. In this way, the prolapsed haemorrhoidal tissue is intended to be lifted to its position proximal to the dentate line. 
Haemorrhoidectomy involves excision of the haemorrhoidal tissue. There are technical variants depending on the treatment of the bridges of tissue that remain between the excised cushions and/or the addition of a posterior mucosal anoplasty. In Europe, the open (Milligan-Morgan) method is most commonly used. In an open Haemorrhoidectomy according to Milligan-Morgan, a Y-shaped incision is made at the mucocutaneous junction and the vascular pedicle is ligated. Afterwards the wound is not closed. The Closed Haemorrhoidectomy (Ferguson) consists of excision of three vascular pedicles with complete wound closure using absorbable sutures. This technique is often used in the United States.

\section{Challenges in haemorrhoid research}

With the continuing evolution of different treatments for HD, it is key that the effectiveness of (surgical) treatments is analysed in a systematic way. Clinical trials investigating the effectiveness of interventions for HD have used a wide variety of outcomes and outcome measures. Reviews highlighted the lack of uniformity of outcome definition, measurement, and reporting [11-13]. Consequently, optimal evidence synthesis is hampered and high-quality guidelines are lacking (38-40). A solution to improve homogeneity in outcome reporting on HD is to develop and use a Core Outcome Set (COS). A COS represents a consensus-derived minimum set of outcome parameters that should be reported in all studies that report on a particular condition (41). An agreed COS will enhance the ability to compare future studies and to develop an optimal treatment algorithm for HD. Since no COS for HD existed yet, an important step for improving HD research is the development of a COS for such research.

The last ten years, several national guidelines reporting on HD are published (3537). The most recently updated guideline is of the American Society of Colon and Rectal Surgeons (ASCRS) (42). The methodological quality of these guidelines could be improved by being much more specific about the methods used to formulate their recommendations. Therefore, we need to develop an international, multidisciplinary, high quality guideline in collaboration with the European Society of Coloproctology (ESCP) addressing both diagnostic and therapeutic modalities in the management of HD.

\section{Outline and aims of the thesis}

This thesis has two aims. The first aim is to address heterogeneity in study outcomes in HD research and to describe solutions to improve homogeneity in outcome reporting. The second aim is to prepare and develop an international, high quality guideline for HD. 
The aims are reflected in the following chapters:

Aim I

chapter 2: a protocol for the development of a Core Outcome Set (COS) for HD defining a minimum outcome-reporting standard.

chapter 3: a literature review to list systematically the types of outcomes used in HD studies.

chapter 4: a Delphi process to develop an international COS for HD.

chapter 5: a qualitative study on patient experiences of $\mathrm{HD}$.

\section{Aim 2}

chapter 6: a national survey on current practices regarding management of HD in the Netherlands.

chapter 7: an ESCP guideline for the treatment of HD.

addendum: a rigorous process of the development of the ESCP guideline for HD.

For the development of a COS, a stepwise approach needs to be undertaken which will be described in a protocol (chapter 2). One of the earliest attempts to standardize outcomes was conducted by the World Health Organisation in the 1970s, relating to cancer trials. This resulted in a WHO Handbook of guidelines recommending the minimum requirements for data collection in cancer trials (43). The most notable work to date relating to outcome standardization since has been conducted by the OMERACT (Outcome Measures in Rheumatology) collaboration (44). Since OMERACT, there have been other examples (i.e. HOME, IMMPACT) of similar COS initiatives to develop recommendations about the outcomes that should be measured in clinical trials $(45,46)$. However, the OMERACT community recently published the OMERACT Filter 2.0 which provides a careful explanation of how it can be implemented in other subspecialties (47). In this thesis, we decided to follow this method.

Following the OMERACT initiative, the first phase in developing a COS is a literature review on the types of outcomes and outcome measures used in previously published HD research (chapter 3). In HD research, several outcomes are used (e.g. prolapse, recurrence, complications and duration of operation) (48-50) as primary and secondary endpoints. This heterogeneity in reporting outcomes hampers the proper comparison between trials. Even in two recently conducted high level of evidence randomised controlled trials from the UK different primary endpoints were used. In the first study, the HubBLe trial, RBL was compared with DG-HAL. The authors used recurrence at one year post procedure as primary outcome (51). The second study of Watson et al., the eTHoS trial, comparing stapled haemorrhoidopexy with the traditional 
haemorrhoidectomy, an area under the quality-of-life curve was measured as primary outcome using the EQ-5D-3L descriptive system (48).

The second phase in developing a COS is a Delphi process. First the outcomes identified in the literature review will be operationalized into a questionnaire for healthcare professionals and a separate questionnaire for patients. Then two sequential rounds of the questionnaire will follow to prioritize these outcomes. Phase three consists of a faceto-face consensus meeting with healthcare professionals to agree on the final endpoints of the COS. This Delphi process will be described in chapter 4 .

However, by developing a COS for $\mathrm{HD}$ we need to be cautious that treatment preferences and outcomes may differ substantially between patients with HD (52). Qualitative interviews in patients with HD could be performed to gain a deeper understanding and obtain information directly from the patients about their experiences with $\mathrm{HD}$ and treatment preferences $(53,54)$ (chapter 5).

Guidelines serve the purpose to support clinical (shared) decision-making regarding treatment choices, following best available evidence. Several national HD guidelines are published $(42,55,56)$. The Dutch guideline was published in 2015.

To explore current practice in the treatment of HD in the Netherlands before the introduction of an international guideline, we need to perform a national survey among Dutch colorectal consultants, fellows and residents (chapter 6). These results could serve as direction for the next phase of developing an international guideline for HD. Several initiatives (i.e. NICE, GIN-McMaster) developed guideline development checklists and described that a guideline should be developed according to a process that starts from the topic being chosen and extends to future guideline updates. The AGREE Enterprise developed the AGREE Instrument, an online tool to assess the quality and reporting of practice guidelines (57). Existing HD guidelines do not describe a rigorous development method as suggested by the AGREE checklist. They often do not report their review questions and methods for formulating their recommendations. In collaboration with the European Society of Coloproctology (ESCP) an international high quality guideline for $\mathrm{HD}$ will be designed. In addendum the development processes and methods following the AGREE II instrument will be described. In chapter 7 the results of the final ESCP guideline for the treatment of HD will be presented. 


\section{General introduction and outline}

\section{References}

1. Lohsiriwat V. Hemorrhoids: from basic pathophysiology to clinical management. World J Gastroenterol. 2012;18(17):2009-17.

2. Riss S, Weiser FA, Schwameis K, Riss T, Mittlbock M, Steiner G, et al. The prevalence of hemorrhoids in adults. Int J Colorectal Dis. 2012;27(2):215-20.

3. Haas PA, Haas GP. The prevalence of hemorrhoids and chronic constipation. Gastroenterology. 1990;99(6):1856-7.

4. Johanson JF, Sonnenberg A. The prevalence of hemorrhoids and chronic constipation. An epidemiologic study. Gastroenterology. 1990;98(2):380-6.

5. Medich DS, Fazio VW. Hemorrhoids, anal fissure, and carcinoma of the colon, rectum, and anus during pregnancy. Surg Clin North Am. 1995;75(1):77-88.

6. Madoff RD, Fleshman JW, Clinical Practice Committee AGA. American Gastroenterological Association technical review on the diagnosis and treatment of hemorrhoids. Gastroenterology. 2004;126(5):1463-73.

7. Haas PA, Haas GP, Schmaltz S, Fox TA, Jr. The prevalence of hemorrhoids. Dis Colon Rectum. 1983;26(7):435-9.

8. Pares D, Iglesias M, Pera M, Pascual M, Torner A, Baro T, et al. Expression of estrogen and progesterone receptors in the anal canal of women according to age and menopause. Dis Colon Rectum. 2010;53(12):1687-91.

9. Burkitt DP. Varicose veins, deep vein thrombosis, and haemorrhoids: epidemiology and suggested aetiology. Br Med J. 1972;2(5813):556-61.

10. Stelzer H. [Experiences with Sedapon in obstetrics and gynecology]. Med Welt. 1962;6:321-2.

11. Lestar B, Penninckx F, Kerremans R. The composition of anal basal pressure. An in vivo and in vitro study in man. Int J Colorectal Dis. 1989;4(2):118-22.

12. Banov L, Jr., Knoepp LF, Jr., Erdman LH, Alia RT. Management of hemorrhoidal disease. J S C Med Assoc. 1985;81(7):398-401.

13. Gaj F, Trecca A, Busotti A, Brugiotti C, Carboni M. The new classification of hemorrhoids: PATE 2000-Sorrento. History of the scientific debate. Minerva Chir. 2002;57(3):331-9.

14. Elbetti C, Giani I, Novelli E, Fucini C, Martellucci J. The single pile classification: a new tool for the classification of haemorrhoidal disease and the comparison of treatment results. Updates Surg. 2015;67(4):421-6.

15. Scheyer M, Antonietti E, Rollinger G, Mall H, Arnold S. Doppler-guided hemorrhoidal artery ligation. Am J Surg. 2006;191(1):89-93.

16. Arnold S, Antonietti E, Rollinger G, Scheyer M. [Doppler ultrasound assisted hemorrhoid artery ligation. A new therapy in symptomatic hemorrhoids]. Chirurg. 2002;73(3):269-73.

17. Willis S, Junge K, Ebrahimi R, Prescher A, Schumpelick V. Haemorrhoids - a collagen disease? Colorectal Dis. 2010;12(12):1249-53.

18. Morgado PJ, Suarez JA, Gomez LG, Morgado PJ, Jr. Histoclinical basis for a new classification of hemorrhoidal disease. Dis Colon Rectum. 1988;31(6):474-80. 


\section{Chapter I}

19. Chung YC, Hou YC, Pan AC. Endoglin (CD105) expression in the development of haemorrhoids. Eur J Clin Invest. 2004;34(2):107-12.

20. Corman ML, Gravie JF, Hager T, Loudon MA, Mascagni D, Nystrom PO, et al. Stapled haemorrhoidopexy: a consensus position paper by an international working party - indications, contra-indications and technique. Colorectal Dis. 2003;5(4):304-10.

21. Pucher PH, Qurashi M, Howell AM, Faiz O, Ziprin P, Darzi A, et al. Development and validation of a symptom-based severity score for haemorrhoidal disease: the Sodergren score. Colorectal Dis. 2015;17(7):612-8.

22. Kuehn HG, Gebbensleben O, Hilger Y, Rohde H. Relationship between anal symptoms and anal findings. Int J Med Sci. 2009;6(2):77-84.

23. Loder PB, Kamm MA, Nicholls RJ, Phillips RK. Haemorrhoids: pathology, pathophysiology and aetiology. Br J Surg. 1994;81(7):946-54.

24. Todd IP. Aetiology, management and prognosis of haemorrhoids. Curr Med Drugs. 1961;2:1-5.

25. Lorenzo-Rivero S. Hemorrhoids: diagnosis and current management. Am Surg. 2009;75(8):63542.

26. Alonso-Coello P, Guyatt G, Heels-Ansdell D, Johanson JF, Lopez-Yarto M, Mills E, et al. Laxatives for the treatment of hemorrhoids. Cochrane Database Syst Rev. 2005(4):CD004649.

27. Perera N, Liolitsa D, Iype S, Croxford A, Yassin M, Lang P, et al. Phlebotonics for haemorrhoids. Cochrane Database Syst Rev. 2012(8):CD004322.

28. Alonso-Coello P, Zhou Q, Martinez-Zapata MJ, Mills E, Heels-Ansdell D, Johanson JF, et al. Meta-analysis of flavonoids for the treatment of haemorrhoids. Br J Surg. 2006;93(8):909-20.

29. Alshreef A, Wailoo AJ, Brown SR, Tiernan JP, Watson AJM, Biggs K, et al. Cost-Effectiveness of Haemorrhoidal Artery Ligation versus Rubber Band Ligation for the Treatment of Grade IIIII Haemorrhoids: Analysis Using Evidence from the HubBLe Trial. Pharmacoecon Open. 2017;1(3):175-84.

30. Yuksel BC, Armagan H, Berkem H, Yildiz Y, Ozel H, Hengirmen S. Conservative management of hemorrhoids: a comparison of venotonic flavonoid micronized purified flavonoid fraction (MPFF) and sclerotherapy. Surg Today. 2008;38(2):123-9.

31. Hoyuela C, Carvajal F, Juvany M, Troyano D, Trias M, Martrat A, et al. HAL-RAR (Doppler guided haemorrhoid artery ligation with recto-anal repair) is a safe and effective procedure for haemorrhoids. Results of a prospective study after two-years follow-up. Int J Surg. 2016;28:39-44.

32. Testa A, Torino G, Gioia A. DG-RAR (Doppler-guided recto-anal repair): a new mini invasive technique in the treatment of prolapsed hemorrhoids (grade III-IV): preliminary report. Int Surg. 2010;95(3):265-9.

33. Walega P, Krokowicz P, Romaniszyn M, Kenig J, Salowka J, Nowakowski M, et al. Doppler guided haemorrhoidal arterial ligation with recto-anal-repair (RAR) for the treatment of advanced haemorrhoidal disease. Colorectal Dis. 2010;12(10 Online):e326-9.

34. Pakravan F, Helmes C, Baeten C. Transanal open hemorrhoidopexy. Dis Colon Rectum. 2009;52(3):503-6. 


\section{General introduction and outline}

35. Zagriadskii EA. [Trans-anal disarterization of internal hemorrhoids under Doppler control with mucopexy and lifting in treatment of stage III-IV hemorrhoids]. Khirurgiia (Mosk). 2009(2):52-8.

36. Aigner F, Kronberger I, Oberwalder M, Loizides A, Ulmer H, Gruber L, et al. Doppler-guided haemorrhoidal artery ligation with suture mucopexy compared with suture mucopexy alone for the treatment of Grade III haemorrhoids: a prospective randomized controlled trial. Colorectal Dis. 2016;18(7):710-6.

37. Gupta PJ, Kalaskar S, Taori S, Heda PS. Doppler-guided hemorrhoidal artery ligation does not offer any advantage over suture ligation of grade 3 symptomatic hemorrhoids. Tech Coloproctol. 2011;15(4):439-44.

38. Shanmugam V, Thaha MA, Rabindranath KS, Campbell KL, Steele RJ, Loudon MA. Systematic review of randomized trials comparing rubber band ligation with excisional haemorrhoidectomy. Br J Surg. 2005;92(12):1481-7.

39. Shao WJ, Li GC, Zhang ZH, Yang BL, Sun GD, Chen YQ. Systematic review and metaanalysis of randomized controlled trials comparing stapled haemorrhoidopexy with conventional haemorrhoidectomy. Br J Surg. 2008;95(2):147-60.

40. Simillis C, Thoukididou SN, Slesser AA, Rasheed S, Tan E, Tekkis PP. Systematic review and network meta-analysis comparing clinical outcomes and effectiveness of surgical treatments for haemorrhoids. Br J Surg. 2015;102(13):1603-18.

41. Klokker L, Tugwell P, Furst DE, Devoe D, Williamson P, Terwee CB, et al. Developing an OMERACT Core Outcome Set for Assessing Safety Components in Rheumatology Trials: The OMERACT Safety Working Group. J Rheumatol. 2017;44(12):1916-9.

42. Davis BR, Lee-Kong SA, Migaly J, Feingold DL, Steele SR. The American Society of Colon and Rectal Surgeons Clinical Practice Guidelines for the Management of Hemorrhoids. Dis Colon Rectum. 2018;61(3):284-92.

43. Miller AB, Hoogstraten B, Staquet M, Winkler A. Reporting results of cancer treatment. Cancer. 1981;47(1):207-14.

44. Boers M, Brooks P, Strand CV, Tugwell P. The OMERACT filter for Outcome Measures in Rheumatology. J Rheumatol. 1998;25(2):198-9.

45. Turk DC, Dworkin RH, McDermott MP, Bellamy N, Burke LB, Chandler JM, et al. Analyzing multiple endpoints in clinical trials of pain treatments: IMMPACT recommendations. Initiative on Methods, Measurement, and Pain Assessment in Clinical Trials. Pain. 2008;139(3):485-93.

46. Schmitt J, Spuls PI, Thomas KS, Simpson E, Furue M, Deckert S, et al. The Harmonising Outcome Measures for Eczema (HOME) statement to assess clinical signs of atopic eczema in trials. J Allergy Clin Immunol. 2014;134(4):800-7.

47. Boers M, Kirwan JR, Wells G, Beaton D, Gossec L, d'Agostino MA, et al. Developing core outcome measurement sets for clinical trials: OMERACT filter 2.0. J Clin Epidemiol. 2014;67(7):745-53.

48. Watson AJ, Hudson J, Wood J, Kilonzo M, Brown SR, McDonald A, et al. Comparison of stapled haemorrhoidopexy with traditional excisional surgery for haemorrhoidal disease (eTHoS): a pragmatic, multicentre, randomised controlled trial. Lancet. 2016;388(10058):2375-85. 


\section{Chapter I}

49. Brown SR, Bradburn M. The HubBle trial: a word of caution - Authors' reply. Lancet. 2016;388(10063):2996.

50. Leung ALH, Cheung TPP, Tung K, Tsang YP, Cheung H, Lau CW, et al. A prospective randomized controlled trial evaluating the short-term outcomes of transanal hemorrhoidal dearterialization versus tissue-selecting technique. Tech Coloproctol. 2017;21(9):737-43.

51. Brown SR, Tiernan JP, Watson AJM, Biggs K, Shephard N, Wailoo AJ, et al. Haemorrhoidal artery ligation versus rubber band ligation for the management of symptomatic second-degree and thirddegree haemorrhoids (HubBLe): a multicentre, open-label, randomised controlled trial. Lancet. 2016;388(10042):356-64.

52. Brown SR, Watson A. Comments to 'Rubber band ligation versus excisional haemorrhoidectomy for haemorrhoids'. Tech Coloproctol. 2016;20(9):659-61.

53. Wu YP, Thompson D, Aroian KJ, McQuaid EL, Deatrick JA. Commentary: Writing and Evaluating Qualitative Research Reports. J Pediatr Psychol. 2016;41(5):493-505.

54. Keeley RD, West DR, Tutt B, Nutting PA. A qualitative comparison of primary care clinicians' and their patients' perspectives on achieving depression care: implications for improving outcomes. BMC Fam Pract. 2014;15:13.

55. Altomare DF, Roveran A, Pecorella G, Gaj F, Stortini E. The treatment of hemorrhoids: guidelines of the Italian Society of Colorectal Surgery. Tech Coloproctol. 2006;10(3):181-6.

56. Higuero T, Abramowitz L, Castinel A, Fathallah N, Hemery P, Laclotte Duhoux C, et al. Guidelines for the treatment of hemorrhoids (short report). J Visc Surg. 2016;153(3):213-8.

57. Cartabellotta A. [AGREE II: assessing the quality of practice guidelines]. Recenti Prog Med. 2011;102(5):217-9. 
General introduction and outline 


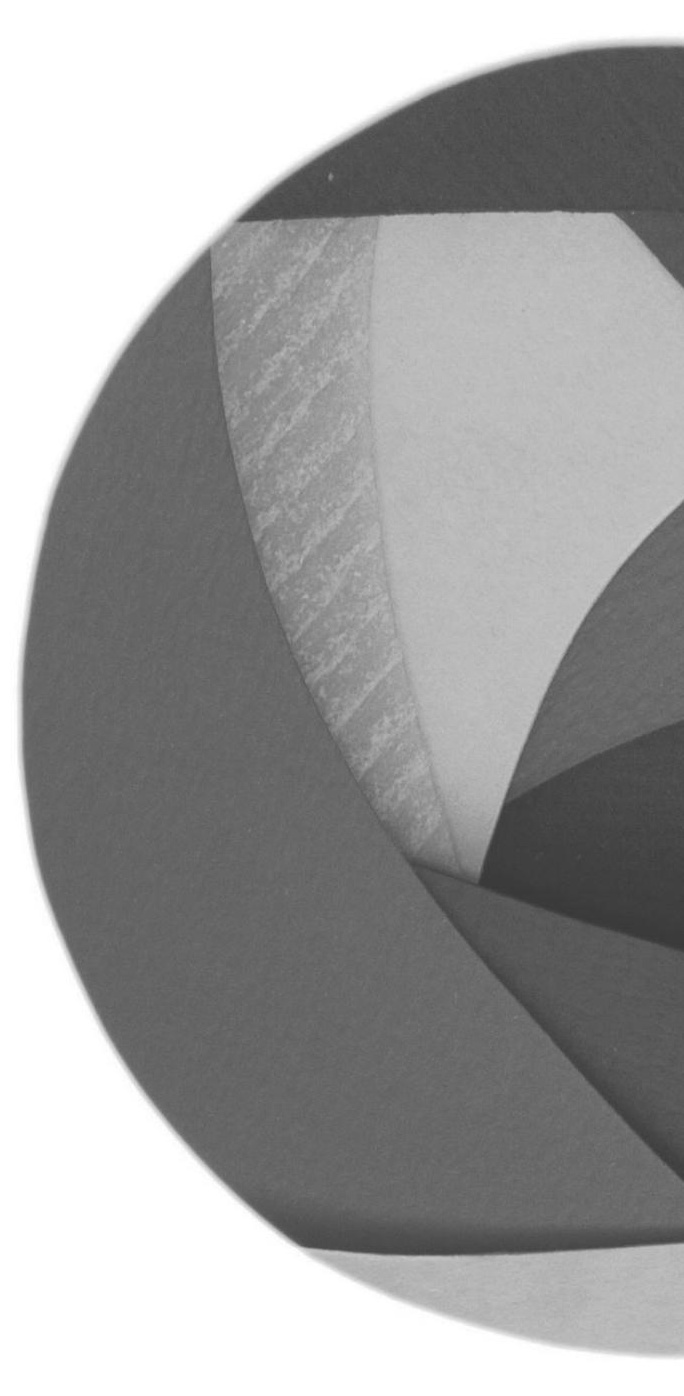





\section{Abstract}

Purpose Over the last decade, many studies were performed regarding treatment options for hemorrhoidal disease (HD). Randomised controlled trials (RCTs) should have welldefined primary and secondary outcomes. However, the reported outcome measures are numerous and diverse. The heterogeneity of outcome definition in clinical trials limits transparency and paves the way for bias. The development of a Core Outcome Set (COS) helps minimizing this problem. A COS is an agreed minimum set of outcomes that should be measured and reported in all clinical trials of a specific disease. The aim of this project is to generate a COS regarding the outcome of treatment after HD.

Methods A Delphi study will be performed by an international steering group healthcare professionals and patients with the intention to create a standard outcome set for future clinical trials for the treatment of HD. First, a literature review will be conducted to establish which outcomes are used in clinical trials for HD. Secondly, both healthcare professionals and patients will participate in several consecutive rounds of online questionnaires and a face-to-face meeting to refine the content of the COS.

Discussion Development of a COS for HD defines a minimum outcome reporting standard and will improve the quality of research in the future. 


\section{Background}

Hemorrhoidal disease (HD) is one of the most common anorectal disorders presenting to coloproctological units, with a prevalence of $5-35 \%$ in the overall population [1, 2]. The true incidence of HD is difficult to estimate, as many patients are reluctant to seek medical therapy for various personal, cultural, and socio economic reasons. Hemorrhoids are enlarged vascular cushions in the anal canal, which can bleed because of both degenerative effects of aging and the repeated passage of hard stool [1]. People experience the following most common complaints: blood loss, prolapse, pain, itching, and pruritus. Conservative and/or medical treatment, including diet, lifestyle changes, and application of topical ointments, is often offered first [3]. When these treatment options fail, a common next treatment step is Rubber Band Ligation (RBL) [4, 5]. Grade III and IV HD is often directly treated by more invasive surgical interventions including the sutured hemorrhoidopexy [6], the stapled hemorrhoidopexy [7, 8], the Doppler-guided Hemorrhoidal Artery Ligation (DGHAL) [9-11], and the traditional hemorrhoidectomy $[12,13]$. The ability to compare findings between studies and synthesize data in meta-analysis is limited because the outcomes are inconsistently defined and reported in clinical trials. This hampers interpreting treatment effect and making evidence-based healthcare decisions $[14,15]$.

The Outcome Measures in Rheumatology (OMERACT) [16] and Core Outcome Measures in Effective Trials (COMET) [17] (http://www.comet-initiative.org/) initiatives responded to the problem by developing a guideline for the creation of a core outcome set (COS). This paper describes the study protocol developing a COS that should be considered mandatory for inclusion in all future clinical trials on treatment of HD.

\section{Methods}

Development of a COS incorporates the Delphi methodology and exists of a stepwise approach [18]. The guideline on the usage of the Delphi technique and the checklist will be followed [19]. First, a systematic literature review will be performed to identify potential outcomes. Secondly, several rounds of online questionnaires will be conducted involving researchers and healthcare professionals.

\section{Search strategy}

A broad-search strategy will be conducted to identify all published guidelines, reviews, systematic reviews, meta-analyses and protocols regarding HD. The search will be limited to English language articles published in fulltext. 
Searches will be performed in the following database: PubMed, EMBASE, and Cochrane between January 2012 and December 2016 [Appendix 1].

\section{Selection of articles}

The review will be performed by two researchers (RT and JM) to identify all possible clinical outcomes reported in treatment studies for HD. First, the identified abstract will be screened. Studies where the outcomes are not treatment related (e.g. health policy) will be excluded. In order to ensure accuracy of exclusion, a proportion of the excluded abstracts will be reviewed by a third reviewer (SB).

\section{Data extraction}

For each trial, we will assess the author, date of publication, study design, compared treatments/interventions, primary and secondary outcomes, definition of these outcomes, and Patient Reported Outcomes (PROs).

\section{Participants}

We will involve healthcare professionals and patients. We found no guidelines for the sample sizes of this study $[18,20]$. However, having more stakeholders will increase the reliability of the group judgment $[19,20]$. Healthcare professionals will be selected from a diverse range of international institutions and organizations. We will select healthcare professionals who have multiple cited publications in the field of proctology and/or who are familiar with the development of a COS. Further, we will use the 'snowball sampling' approach. This method gives the healthcare professionals the opportunity to add someone they want to be included as panel member. We aim to recruit around 30 healthcare professionalsby e-mail.

Patients will be invited to participate when they visit the outpatient clinic for the first time. Participants have to be diagnosed with HD and have to agree to participate in all Delphi rounds needed for this COS. We expect to recruit about 20 patients in total.

\section{Online Survey}

The list of outcomes, originating from the systematic review, will be formatted into questions with a Likert response design [21, 22], an evaluation scale from 1 to 9 , to identify outcomes of importance to both healthcare professionals and patients. Questionnaires in the Delphi survey will be pilot tested by at least two members of the steering group (SB and LS). Currently, there is no consensus in literature regarding the cut offs for inclusion and exclusion of outcomes in this process. Therefore, a flexible and pragmatic approach will be employed. "Consensus in" (information essential to the core set) will be defined as greater than 70\% of participants scoring as 7-9 and less than $15 \%$ of participants scoring as $1-3$. "Consensus out " (information should not be included in core set) will be defined as greater than $70 \%$ of participants scoring as $1-3$ and less 
than $15 \%$ of participants scoring as 7-9. "Disagreement" will occur when $33 \%$ or more score $1-3$ and $33 \%$ or more score $7-9$ for a particularitem. All other combinations will be considered "Equivocal", which means that these items are open to more than one interpretation [23]. Over the course of several rounds, the expectation is that the range of items will decrease and the group converges toward a consensus opinion. This part of the process will end when the list of items is reduced to ten or less; or on completion of the second round voting [Appendix 2].

\section{Round 1}

In the first round, the panel members will be approached by a personalized e-mail with a link to a web based survey (Monkey Survey). Once participants have registered for the survey, names and email addresses will be stored in the system. This will allow identification of participants completing all rounds of the Delphi survey.

Initially, the panel members will be provided with one page background information on the rationale of the development of the COS. Then, they will be asked to list all items that they consider important or relevant in the COS.

All items included in Delphi round 1 will be assigned to one of the four categories and "consensus in" and "consensus out" domains will be brought forward for the second round. Items designated "Disagreement" will undergo further analysis: mean scores will be calculated, and if the mean is above or below 5 (i.e. tending towards "consensus in" or "consensus out") the item will be included in the second round. Items designated "Equivocal" will not be carried forward.

\section{Round 2}

The panel members from round 1 will then be invited to undertake round 2 of the process. During the second round the stakeholders will be asked to review their initial responses in the light of groups' responses [Appendix 3]. The responses of round 1 will be aggregated and send back to the panel members anonymously in a feedback report. The participants do not know the identities of other individuals in the panel group to make sure that the views of participants are obtained by a method that gives equal influence. This report will include the panel members' ratings on the several questions/ items, including the median scores, the interquartile ranges, their comments and suggestions. Descriptive statistics summarising the results of round 1 will be available for the panel members to review [Appendix 4]. Participant will also be provided with an option to add additional items that they think are missing.

\section{Round 3}

The third round will only be undertaken if significant numbers of outcomes remain in the short list after round 2 . The results of round 2 will again be send back to all panel 


\section{Chapter 2}

members in a feedback report. Then, the panel members will be asked to re-rate the items in view of the groups' response.

\section{Consensus meeting}

If consensus has not been reached after the three Delphi rounds or there is significant disagreement between the stakeholders, we will conduct a face-to-face meeting with the panel members initially invited.

By the end of the process we should have identified 'what' COS should be measured in clinical trials for HD. However, we may not be clear on 'how' we should measure these.

\section{Discussion}

The aim of this project is the development of a COS for HD. At the time of writing, there is no published COS for HD. The development of COS for the management of HD will facilitate evidence synthesis by reducing heterogeneity between trials. The Delphi method $[18,24]$ is the appropriate instrument in decision-making processes in groups as feedback can be provided in a controlled anonymous manner. A major drawback is that the results of a Delphi study are highly dependent upon the composition of the panel and the selection of its members. To provide the highest possible input, we will include the healthcare professionals from a diverse range of international institutions and organizations. We must actively engage with triallists and those that fundand publish trials to ensure that our COS is used in the rest of the academic world. With help from the panel members, we will identify how to reach relevant audience, including people using services, carers, the public, practitioners, and providers. 


\section{References}

1. Loder PB, Kamm MA, Nicholls RJ, Phillips RK (1994) Haemorrhoids: pathology, pathophysiology and aetiology. Br JSurg 81(7):946-954

2. Lohsiriwat V (2012) Hemorrhoids: from basic pathophysiology toclinical management. World J Gastroenterol 18(17):2009-2017

3. Alonso-Coello P, Mills E, Heels-Ansdell D, Lopez-Yarto M, ZhouQ, Johanson JF et al (2006) Fiber for the treatment of hemorrhoidscomplications: a systematic review and meta-analysis. Am JGastroenterol 101(1):181-188

4. Brown S, Tiernan J, Biggs K, Hind D, Shephard N, Bradburn Met al (2016) The HubBLe trial: haemorrhoidal artery ligation (HAL)versus rubber band ligation (RBL) for symptomatic secondandthird-degree haemorrhoids: a multicentre randomised controlled tri-al and health-economic evaluation. Health Technol Assess 20(88):1-150

5. Gaj F, Biviano I, Sportelli G, Candeloro L (2015) Rubber bandligation in treatment of hemorrhoids: our experience. Clin Ter166(4):162-167

6. Pakravan F, Helmes C, Baeten C (2009) Transanal openhemorrhoidopexy. DisColon rectum52(3):503-506

7. Corsale I, Rigutini M, Francioli N, Panicucci S, Mori PA, Aloise F(2014) Stapled anopexy and STARR in surgical treatment ofhaemorrhoidal disease. Updat Surg 66(3):217-222

8. Nisar PJ, Acheson AG, Neal KR, Scholefield JH (2004) Stapledhemorrhoidopexy compared with conventional hemorrhoidectomy: systematic review of randomized, controlled trials. DisColonrectum47(11):1837-1845

9. Faucheron JL, Poncet G, Voirin D, Badic B, Gangner Y (2011) Doppler-guided hemorrhoidal artery ligation and rectoanal repair(HAL-RAR) for the treatment of grade IV hemorrhoids: longterm results in 100 consecutive patients. DisColon rectum54(2):226-231

10. Hoyuela C, Carvajal F, Juvany M, Troyano D, Trias M, Martrat Aet al (2016) HAL-RAR (Doppler guided haemorrhoid artery liga-tion with recto-anal repair) is a safe and effective procedure forhaemorrhoids. Results of a prospective study after two-years fol-low-up. Int J Surg 28:39-44

11. Zagriadskii EA [Transanal Doppler-guided desarterization withmucopexy (HAL-RAR) for the treatment of hemorrhoids stageIII-IV]. Khirurgiia (Mosk). 2013(4):59-64

12. Shanmugam V, Thaha MA, Rabindranath KS, Campbell KL, SteeleRJ, Loudon MA(2005) Systematic review of randomized trialscomparing rubber band ligation with excisionalhaemorrhoidectomy. $\mathrm{Br}$ J Surg. 92(12):1481-1487

13. Watson AJ, Hudson J, Wood J, Kilonzo M, Brown SR, McDonaldA et al (2016) Comparison of stapled haemorrhoidopexy withtraditional excisional surgery for haemorrhoidal disease (eTHoS):a pragmatic, multicentre, randomised controlled trial. Lancet388(10058):2375-2385

14. Clarke M (2008) Standardising outcomes in Paediatric clinical tri-als. PLoS Med 5(4):e102

15. Boonen A, Stucki G, Maksymowych W, Rat AC, Escorpizo R,Boers M et al (2009) The OMERACT-ICF reference group: inte-grating the ICF into the OMERACT process: opportunities andchallenges. J Rheumatol 36(9):2057-2060 


\section{Chapter 2}

16. Boers M, Brooks P, Strand CV, Tugwell P (1998) The OMERACTfilter for outcome measures in rheumatology. J Rheumatol 25(2):198-199

17. Prinsen CA, Vohra S, Rose MR, King-Jones S, Ishaque S, Bhaloo Zet al (2014) Core outcome measures in effectiveness trials(COMET) initiative: protocol for an international Delphi study toachieve consensus on how to select outcome measurement instru-ments for outcomes included in a'core outcome set'. Trials 15:247

18. Steurer J (2011) The Delphi method: an efficient procedure to gen-erate knowledge. Skelet Radiol 40(8):959-961

19. Sinha IP, Smyth RL, Williamson PR (2011) Using the Delphi tech-nique to determine which outcomes to measure in clinical trials: recommendations for the future based on a systematic review ofexisting studies. PLoS Med 8(1):e1000393

20. Boers M, Kirwan JR, Wells G, Beaton D, Gossec L, d'Agostino MAet al (2014) Developing core outcome measurement sets for clinicaltrials: OMERACT filter 2.0. J Clin Epidemiol 67(7):745753

21. Ogden J, Lo J (2012) How meaningful are data from Likert scales? An evaluation of how ratings are made and the role of the responseshift in the socially disadvantaged. J Health Psychol 17(3):350 361

22. van Laerhoven H, van der Zaag-Loonen HJ, Derkx BH (2004) Acomparison of Likert scale and visual analogue scales as responseoptions in children's questionnaires. Acta Paediatr 93(6):830-835

23. Schunemann HJ, Mustafa R, Brozek J, Santesso N, Alonso-CoelloP, Guyatt G et al (2016) GRADE guidelines: 16. GRADE evidenceto decision frameworks for tests in clinical practice and publichealth. J Clin Epidemiol 76:89-98

24. Boulkedid R, Abdoul H, Loustau M, Sibony O, Alberti C (2011) Using and reporting the Delphi method for selecting healthcarequality indicators: a systematic review. PLoS One 6(6):e20476 


\section{Supplementary material}

\section{Appendix I}

\section{Search strategies}

\section{Pubmed:}

1. \#13,"Search $(((($ hemorrhoid* $[$ Title/Abstract] $)$ OR $((((($ haemorrhoid*[Title/ Abstract]) OR hemorhoid*[Title/Abstract]) OR haemorhoid*[Title/ Abstract]) OR hemorroid*[Title/Abstract]) OR haemorroid*[Title/Abstract]) OR hemoroid*[Title/Abstract])) OR hemorrhoid[MeSH Terms])) AND ((()((()(((() surgery[MeSH Subheading]) OR surgery) OR surgical procedures, operative[MeSH Terms]) OR surgical) AND procedures) AND operative) OR operative surgical procedures) OR surgery) OR general surgery[MeSH Terms]) OR general) AND surgery) OR general surgery)) OR ((((treatment $[\mathrm{MeSH}$ Subheading]) OR therapy) OR treatment) OR therapeutics[MeSH Terms]) OR therapeutics $)))$ AND (((((recurrence[MeSH Terms]) OR recurrence)) OR ((((diagnosis[MeSH Subheading]) OR diagnosis) OR symptoms) OR diagnosis[MeSH Terms]) OR symptoms)) OR (((()outcome assessment health care[MeSH Terms]) OR patient outcome assessment[MeSH Terms]) OR treatment outcome[MeSH Terms]) OR clinical effectiveness) OR treatment effectiveness))",2707,06:22:16

2. (\#10 AND \#11 AND \#12)

3. \#12,"Search $(((($ recurrence$[\mathrm{MeSH}$ Terms] $) \quad$ OR recurrence $))$ OR (((((diagnosis[MeSH Subheading]) OR diagnosis) OR symptoms) OR diagnosis[MeSH Terms]) OR symptoms)) OR (((()outcome assessment health care[MeSH Terms]) OR patient outcome assessment[MeSH Terms]) OR treatment outcome[MeSH Terms]) OR clinical effectiveness) OR treatment effectiveness)",9328185,06:21:54

4. (\#7 OR \#8 OR \#9)

5. \#11,"Search $\quad(((()((()(($ surgery[MeSH $\quad$ Subheading $]) \quad$ OR surgery) OR surgical procedures, operative[MeSH Terms]) OR surgical) AND procedures) AND operative) OR operative surgical procedures) OR surgery) OR general surgery[MeSH Terms]) OR general) AND surgery) OR general surgery)) OR $(((($ treatment[MeSH Subheading]) OR therapy) OR treatment) OR therapeutics[MeSH Terms]) OR therapeutics)",10554636,06:21:22

6. (\#5 OR \#6) 
7. \#10,"Search ((hemorrhoid* [Title/Abstract]) OR (((((haemorrhoid*[Title/ Abstract]) OR hemorhoid*[Title/Abstract]) OR haemorhoid*[Title/Abstract]) OR hemorroid*[Title/Abstract]) OR haemorroid*[Title/Abstract]) OR hemoroid*[Title/Abstract])) OR hemorrhoid[MeSH Terms]",6602,06:21:03

8. (\#2 OR \#3 OR \#4)

9. \#9,"Search ((((outcome assessment health care[MeSH Terms]) OR patient outcome assessment[MeSH Terms]) OR treatment outcome[MeSH Terms]) OR clinical effectiveness) OR treatment effectiveness",1197546,06:19:38

10. \#8,"Search ((((diagnosis[MeSH Subheading]) OR diagnosis) OR symptoms) OR diagnosis[MeSH Terms]) OR symptoms",8982014,06:17:16

11. \#7,"Search (recurrence[MeSH Terms]) OR recurrence",406696,06:16:22

12. \#6,"Search ((((treatment[MeSH Subheading]) OR therapy) OR treatment) OR therapeutics[MeSH Terms]) OR therapeutics",9498187,06:16:05

13. \#5,"Search $((((()(((($ surgery$[\mathrm{MeSH}$ Subheading]) OR surgery) OR surgical procedures, operative[MeSH Terms]) OR surgical) AND procedures) AND operative) OR operative surgical procedures) OR surgery) OR general surgery[MeSH Terms]) OR general) AND surgery) OR general surgery",4051959,06:15:19

14. \#4,"Search hemorrhoid[MeSH Terms]",4871,06:12:15

15. \#3,"Search $(((($ haemorrhoid*[Title/Abstract] $)$ OR hemorhoid*[Title/Abstract] $)$ OR haemorhoid*[Title/Abstract]) OR hemorroid*[Title/Abstract]) OR haemorroid*[Title/Abstract]) OR hemoroid*[Title/Abstract]", 1761,06:11:16

16. \#2,"Search hemorrhoid* [Title/Abstract]",4116,06:08:55

\section{Cochrane:}

1. \#1, "hemorrhoid*":ti,ab,kw (Word variations have been searched)

2. \#2, haemorrhoid*

3. \#3, hemorrhoid*

4. \#4, haemorroid*

5. \#5, hemorroid*

6. \#6, haemorhoid*

7. \#7, hemorhoid*

8. \#8, haemoroid*

9. \#9, hemoroid*

10. $\# 1$ or $\# 2$ or $\# 3$ or $\# 4$ or $\# 5$ or $\# 6$ or $\# 7$ or $\# 8$ or $\# 9$

11. \#11, surgery

12. \#12, surgical procedures

13. \#13, general surgery

14. \#14, procedures

15. \#15, treatment 
16. \#16, therapy

17. \#17, therapeutics

18. \#11 or \#12 or \#13 or \#14 or \#15 or \#16 or \#17

19. \#19, recurrence

20. \#20, outcome assessment

21. \#21, treatment outcome

22. $\# 19$ or $\# 20$ or $\# 21$

23. \#10 and \#18 and \#22

\section{Embase:}

1. \#1, hemorrhoid*.mp. or exp hemorrhoid/

2. \#2, haemorrhoid.mp. or exp hemorrhoid/

3. \#3, hemorroid.mp.

4. \#4, haemorroid.mp.

5. \#5, hemoroid.mp.

6. \#6, haemorhoid.mp.

7. \#7, hemorhoid.mp.

8. $\# 1$ or $\# 2$ or $\# 3$ or $\# 4$ or $\# 5$ or $\# 6$ or $\# 7$

9. \#9, exp general surgery/ or exp surgery/ or surgery.mp.

10. \#10, surgical procedures.mp. or exp surgical technique/

11. \#11, treatment.mp.

12. \#12, exp therapy/or therapy.mp.

13. \#13, exp therapy/ or therapy.mp.

14. $\# 9$ or $\# 10$ or $\# 11$ or $\# 12$ or \#13

15. \#15, recurrence.mp. or exp recurrent disease/

16. \#16, exp diagnosis/ or diagnosis.mp.

17. \#17, exp symptom assessment/ or exp symptom/ or symptoms.mp.

18. \#18, outcome assessment.mp. or exp outcome assessment/

19. \#19, treatment outcome.mp. or exp treatment outcome/

20. \#20, exp treatment outcome/ or exp outcome assessment/ or outcome.mp.

21. 15 or 16 or 17 or 18 or 19 or 20

22. $\# 8$ and $\# 14$

23. \#21 and \#22 
Chapter 2

\section{Appendix 2}

Schema for the development of a Core Outcome Set

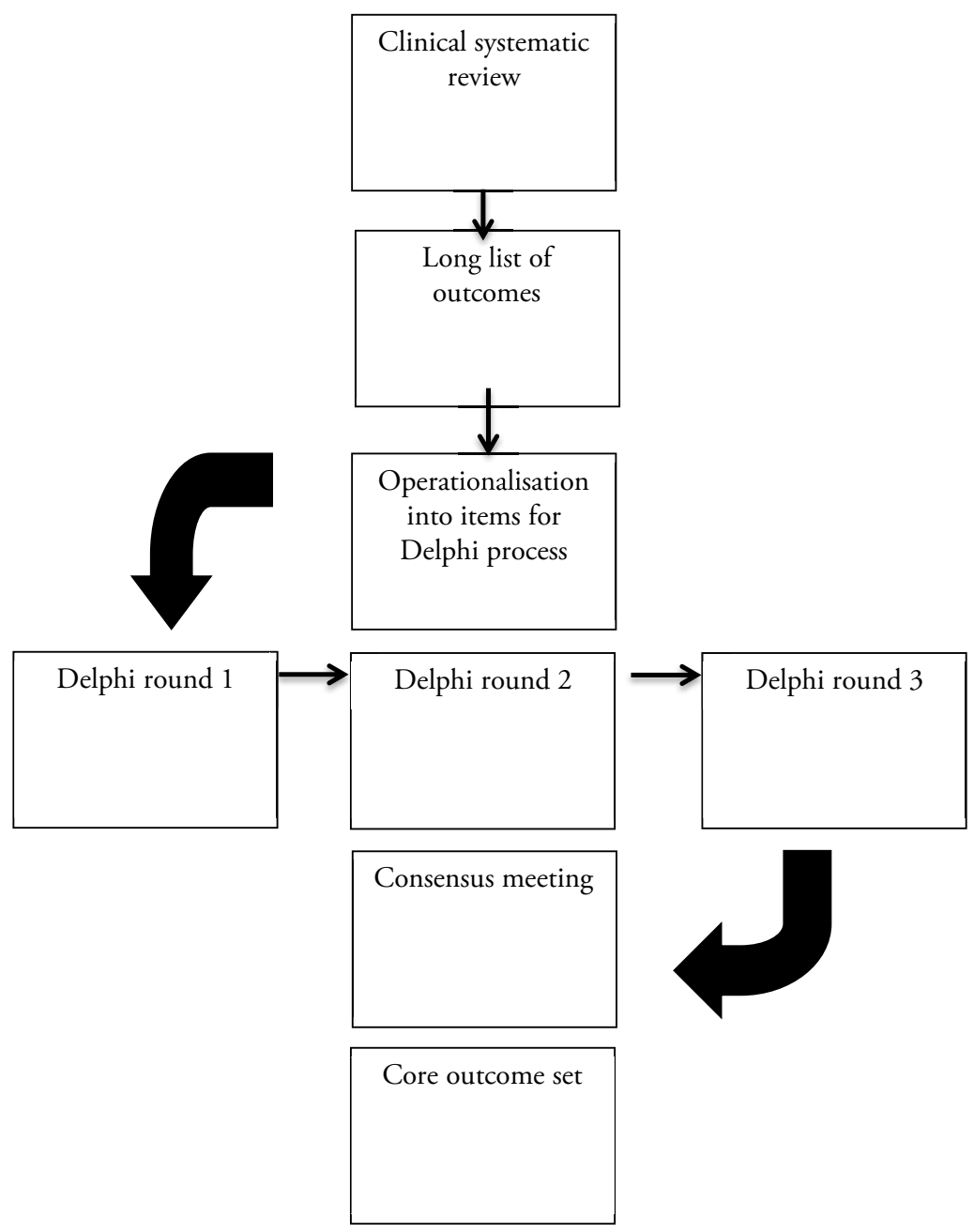




\section{Appendix 3}

\section{Overview for Delphi round 2}

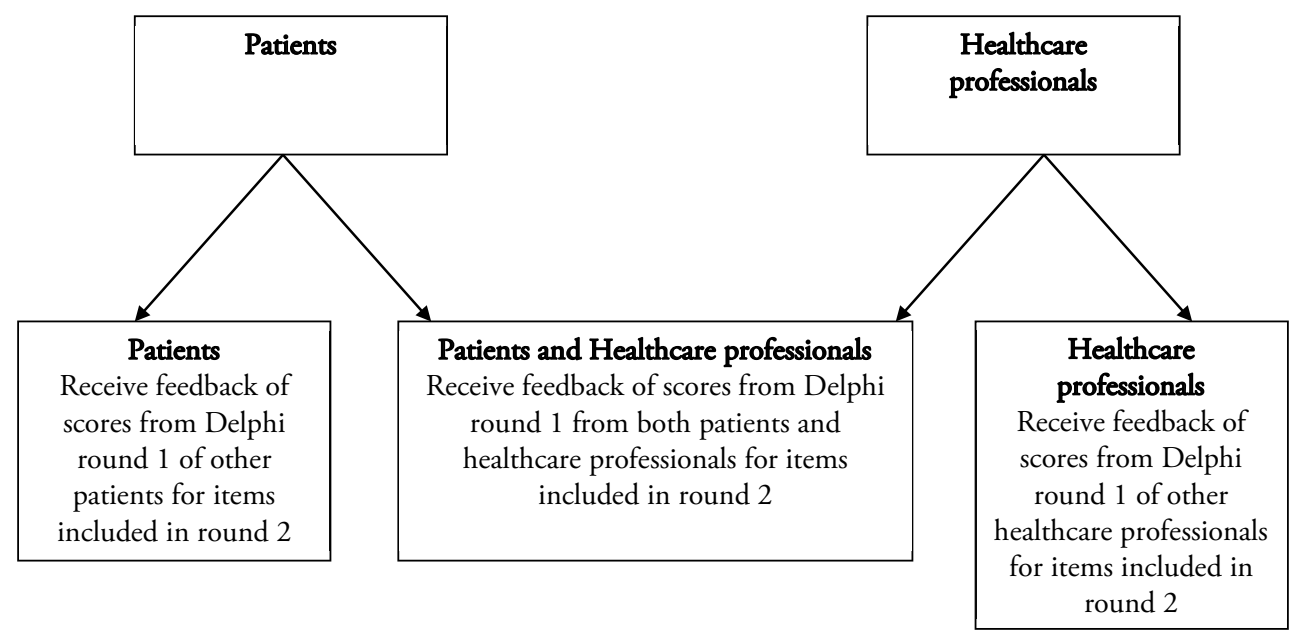




\section{Appendix 4}

\section{Analysis of questionnaire results}

\begin{tabular}{ll}
\hline Table A. MS Excel 2010 formulas used to assess appropriateness and disagreement. \\
\hline Median of panel rating & $=$ MEDIAN $(x: x)$ \\
$\mathbf{3 0}^{\text {th }}$ percentile & $=$ PERCENTILE.EXC $(x: x ; 0,3)$ \\
$\mathbf{7 0}^{\text {th }}$ percentile & $=$ PERCENTILE.EXC $(x: x ; 0,7)$ \\
Interpercentile range $\mathbf{3 0}^{\text {th }}-\mathbf{7 0}^{\text {th }}$ & $=\left[70^{\text {th }}\right.$ percentile $]\left[30^{\text {th }}\right.$ percentile $]$ \\
Central point IPR & $=\left(\left[70^{\text {th }}\right.\right.$ percentile $]+\left[30^{\text {th }}\right.$ percentile $\left.]\right) / 2$ \\
Asymmetry Index & $=A B S(5-[$ central point IPR $])$ \\
IPRAS & $=2,35+\left(1,5^{*}[\right.$ Asymmetry index $\left.]\right)$ \\
IPRAS-IPR & $=[$ IPRAS $]-[$ IPR $]$ \\
\hline
\end{tabular}

Panel members score each item on a nine-point scale, where 1 equals "Very inappropriate" and 9 equals "Very appropriate". Analysis of rating of events was conducted using MS Excel 2010. The formulas that were used are listed in Table A.

Consensus was defined as a panel median between 1 and 3 (Inappropriate) or between 7 and 9 (Appropriate) without disagreement. Inversely, this means that consensus did not exist if the panel median was between 4 and 6 (Uncertain), or if the answers varied so much that the definition of disagreement was met.

Disagreement was assessed according to the IPRAS Method as described in the RAND/ UCLA Appropriateness Method Manual. Traditionally, the Appropriateness Method defined disagreement based on the amount of panel members that voted outside the 3 -point range that contained the median. However, for panels consisting of more than nine members, another method, based on the InterPercentile Range (IPR), is recommended. A smaller IPR of the panel's answers reflects more agreement. The $30^{\text {th }}$ $70^{\text {th }}$ percentile range is used because it most accurately reflects the traditional RAND/ UCLA definition of disagreement. However, the IPR in itself is not sufficient to assess agreement. One also needs to adjust for symmetry of the answers, because the IPR in itself does not take into account if the answers are at the same side of the rating scale of if there are extreme differences between panel members (reflected in answers distributed symmetrically on both sides of the rating scale). To illustrate the importance of correcting for symmetry, an example for a nine-member panel is shown in table B. The IPR is the same for both samples, although it is clear that panel members did not agree as much on question 1 as they did on question 2. To correct for this problem, 
RAND/UCLA developed a formula called IPRAS (InterPercentile Range Adjusted for Symmetry). In short, the IPRAS method determines if disagreement is present, based on the IPR of the ratings of the panel members, adjusted for symmetry.

\begin{tabular}{|c|c|c|c|c|c|c|c|c|c|c|c|}
\hline & & & & Par & $1 \mathrm{ra}$ & ing & & & & IPR 30\%-70\% & IPRAS-IPR \\
\hline & $a$ & $b$ & $c$ & $d$ & $e$ & $f$ & $g$ & $b$ & $i$ & & \\
\hline Item 1 & 1 & 1 & 3 & 5 & 5 & 5 & 7 & 9 & 9 & 4 & -1,65: disagreement \\
\hline Item 2 & 1 & 1 & 1 & 3 & 3 & 3 & 5 & 5 & 5 & 4 & 1,35: agreement \\
\hline
\end{tabular}

The IPRAS formula (see Table A) contains fixed variables and a measure of asymmetry, the Asymmetry Index. As the answers of the panel (and therefore the symmetry of the answers) differ per item, every item has its own Asymmetry Index. The IPRAS reflects the broadest IPR that would constitute agreement at a certain Asymmetry Index. Next, the IPRAS can be compared to the actual IPR of the ratings of the panel. If the actual IPR is larger than the calculated IPRAS, this means disagreement is present taking into account the asymmetry of the answers. Therefore, IPRAS-IPR is $<0$ if the actual IPR of the ratings is larger than the range that would be the threshold for disagreement at the particular level of asymmetry of the answers. Thus, IPRAS-IPR indicates agreement if $>0$ and disagreement if $<0$.

In the example in Table B, scores on both items have a 30\%-70\% IPR of 4. For item 1, the calculated IPRAS minus the observed IPR results in disagreement, reflecting the fact that in question 1, panel members answered on both extremes of the scale, whereas in question 2, there was some uncertainty but answers were generally on the low side of the rating scale, which was recognized as in this case IPRAS-IPR does indicate agreement. 


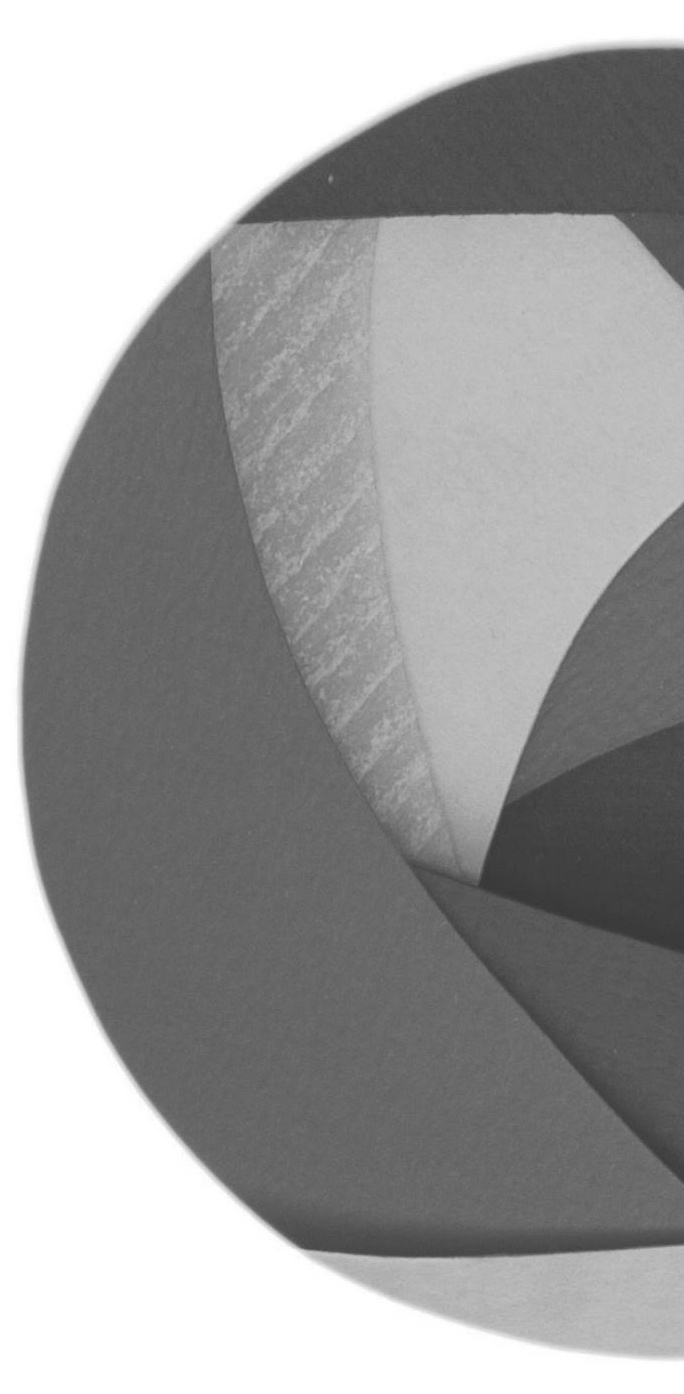




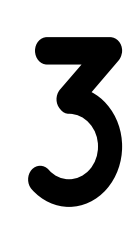

\section{TOWARDS A CORE OUTCOME SET FOR HAEMORRHOIDAL DISEASE - A SYSTEMATIC REVIEW OF OUTCOMES REPORTED IN LITERATURE}

R.R. van Tol, E. van Zwietering, J. Kleijnen,

J. Melenhorst, L.P.S. Stassen, C.D. Dirksen,

S.O. Breukink

Int J Colorectal Disease (2018) 33: 849-856 


\section{Abstract}

Purpose Previously published literature regarding treatment of hemorrhoidal disease (HD) revealed a lack of uniform defined outcomes. These differences between outcomes among studies limit transparency and lead to incomparability of results. The aim of this study was to systematically list the types of outcomes used in HD studies. This list will be used to develop a Core Outcome Set (COS).

Methods We searched Medline (Pubmed), Embase (OVID), and Cochrane for interventional studies for adult patients with HD. Two authors independently identified and reviewed eligible studies. This resulted in a list of outcomes reported by each clinical trial. All outcomes were categorized using the conceptual framework OMERACT filter 2.0.

Results A total of 34 randomized controlled trials and prospective observational studies were included in this study. A total of 59 different types of outcomes were identified. On average, 5.8 different outcomes (range 2-8) were used per study. The outcomes were structured into three core areas and ten domains. The most commonly reported core area was pathophysiological manifestations including the domain symptoms, complications and recurrence. The most frequently reported outcomes were pain (91\%), blood loss (94\%), prolapse (71\%) and incontinence (56\%). There was a high variation in definitions of the common outcomes. And often there was no definition at all.

Conclusion This study shows a substantial heterogeneity in the types of outcomes in HD studies. We provided an overview of the types of outcomes reported in HD studies and identified a list of potentially relevant outcomes required for the development of a COS. 


\section{Introduction}

Hemorrhoidal disease (HD) is the commonest anorectal problem. It affects $5-10 \%$ of the population with the highest prevalence in people being 45-65 years of age [1]. HD is usually classified by their location and by the severity of prolapse. The most widely accepted classification is Golighers' classification [2]. There is considerable variation in the way that HD is managed due to the lack of strong recommendations in treatment guidelines [3, 4]. Basic treatment of HD consists of diet, lifestyle changes, and application of topical ointments [5]. The next treatment modality is often an office-based procedure like Rubber Band Ligation (RBL), sclerotherapy, or radiofrequency therapy [6-9]. In case of persistent symptoms and higher grade of HD, patients are usually treated with surgical solutions (e.g. a Doppler-guided hemorrhoidal artery ligation (DGHAL) [10], with or without Recto-Anal-Repair (RAR) [11-13], stapled hemorrhoidopexy (SH) $[14,15]$ or traditional hemorrhoidectomy [16].

Ideally, a meta-analysis will answer the question what the best current treatment option is for HD. This requires that the same types of outcomes are reported and assessed in the same way. However, previously published literature regarding HD highlighted the lack of uniform outcome definition, measurement, and reporting in research data $[6,17,18]$. In order to overcome this, the European Society of Coloproctology (ESCP) recognized the need to define a Core Outcome Set (COS) for HD. A COS is an agreed standardized set of outcomes that should be assessed and reported in clinical trials for a specific clinical area [19].

Since 1992, the Outcome Measures in Rheumatology (OMERACT) group developed many COSs according to a framework and methodology (i.e., the OMERACT Filter) for the identification and validation of core outcome measurement sets for use in clinical trials for any health condition [20]. Also, Core Outcome Measures in Effectiveness Trials (COMET) [21] and the International Consortium for Health Outcomes Measurement (ICHOM) [22, 23] initiatives developed a guideline for developing a COS. We chose to follow the OMERACT working group, since their OMERACT filter resulted in successful development and implementation of core domain and measurement sets for many different diseases [24-30]. In addition, they recently provided the OMERACT Filter 2.0, a practical framework to develop and validate domains and measures for any health condition [31]. The aim of this systematic review was to provide an overview of the types of outcomes reported in studies regarding HD and to identify a list of potentially relevant outcomes for development of a COS. 


\section{Methods}

\section{Literature search}

We conducted a search of standard electronic databases such as Medline (Pubmed), Embase (OVID), and Cochrane for relevant studies regarding HD. Boolean operators (AND, OR) were used to narrow and widen the search results. In addition, the reference list of the included studies was also searched for additional studies that were not identified in the database searches. Reviews were cross-checked to identify missing studies.

The search was limited to recent published studies between January 2012 and December 2016 representatively for all published studies. No language restrictions were imposed. The full search query is described in Appendix 1.

\section{Study selection}

For inclusion in the review, a study had to meet the following criteria: (1) both randomized controlled trials and (prospective) observational studies since outcomes may have not been reported in RCTs due to selective reporting bias, (2) studies had to assess basic treatment (i.e., diet, lifestyle, and physical therapy), office-based procedures (i.e., RBL, sclerotherapy, and infrared coagulation) or surgical treatment (i.e., DG-HAL with or without mucopexy, stapled haemorrhoidopexy, and the traditional hemorrhoidectomy) regarding $\mathrm{HD}$ and (3) reporting at least one outcome.

\section{Data extraction}

Two authors (RT and EZ) independently screened the titles, abstracts, and full papers regarding the in- and exclusion criteria. Studies without data for retrieval or duplicate publications were excluded. Any disagreement in study selection was resolved by consensus or by discussion with a third reviewer (SB).

The same two authors independently extracted data from the included studies:

study name, design, size, intervention(s), outcome, and outcome assessment (e.g. instrument). After completing the data extraction, the two independent reviewers discussed the results, and if discrepancy was present, a consensus was reached.

\section{Data synthesis}

Outcomes were categorized according to the framework of the OMERACT 2.0 filter [32, 33]. The framework consisted of four levels including life impact, pathophysiological manifestations, resource use/economic impact, and death. See Fig. 1 for the conceptual framework. 
Fig. I Conceptual framework OMERACT filter 2.0 [32]
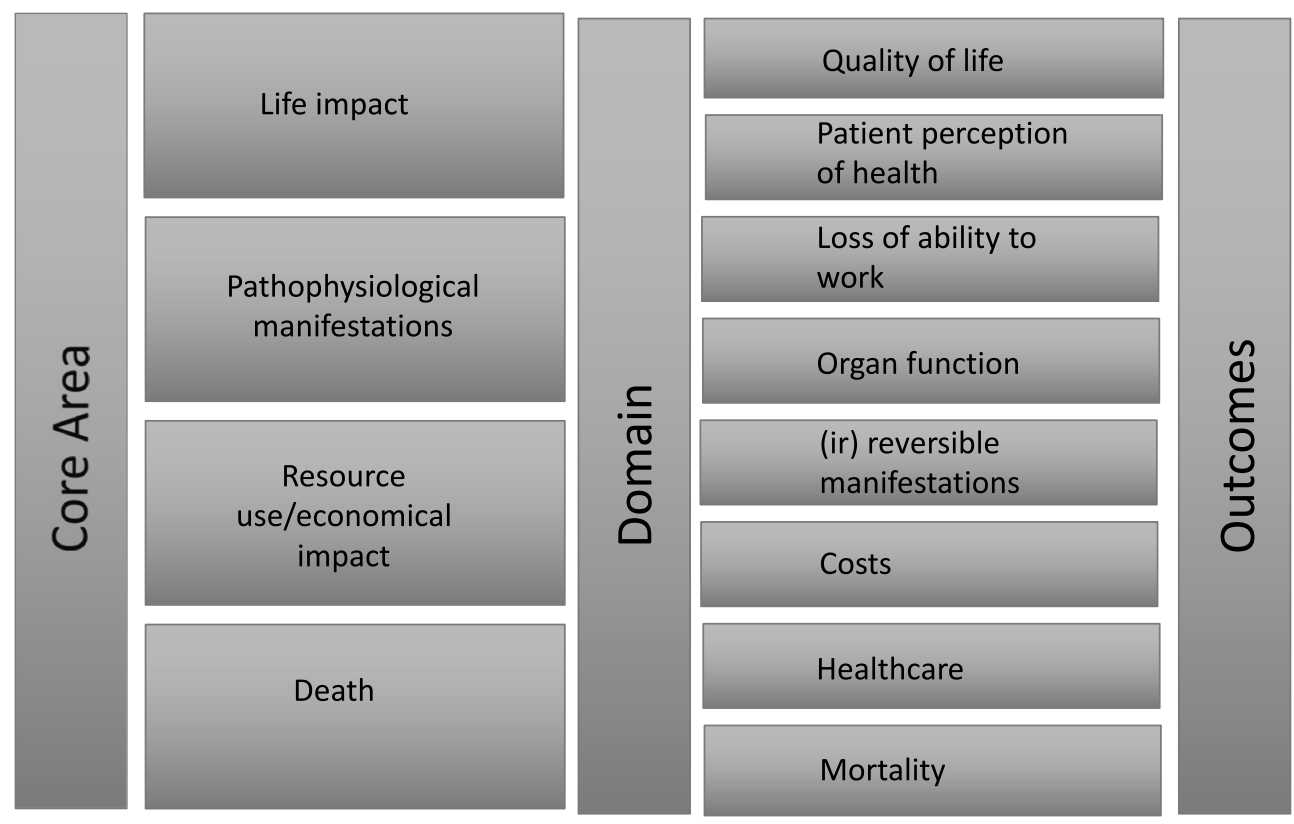

\section{Results}

\section{Study selection}

The literature search resulted in 4863 abstracts (PubMed, 2717; Ovid, 2084; Cochrane, 62). After deduplication, 4295 records remained and were included in title and abstract screening. Title and abstract screening resulted in the inclusion of 216 articles for full-text screening. After this first step, 34 studies were included in the review. A PRISMA flow diagram of screening and inclusion of studies is shown in Fig. 2. The summary of the characteristics of the included studies according to their year of publication is shown in Appendix 2. 


\section{Chapter 3}

Fig. 2 PRISMA flow diagram [34]

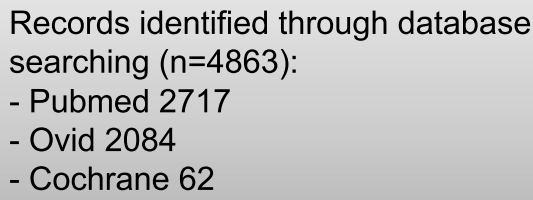

- Ovid 2084

- Cochrane 62

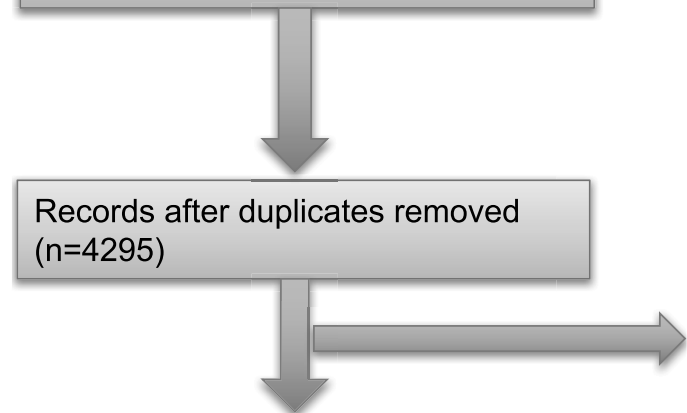

Excluded based on title and abstract $(n=4079)$ :

- Year of publication 3047

- Outcome report 690

- Intervention 30

- $\quad$ Study type 134

- $\quad$ No full tekst 178

Full-tekst articles assessed for eligibility $(n=216)$

Excluded based on full tekst $(n=101)$ :

- Outcome report 52

- Study type 44

- Intervention 6

Included in quality appraisal $(n=115)$

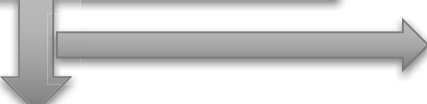

Excluded in quality appraisal $(n=81)$

Included in review $(n=34)$

\section{Study characteristics}

Baseline characteristics of the included studies are displayed in Table 1. We identified 24 randomized controlled trials (RCTs) and ten observational studies. Most studies assessed the effectiveness of surgical techniques (92\%). In total, 59 different outcomes were used in the 34 included studies. On the average, 5.8 different outcomes [1-6, 32] were assessed per study. 
Table 1: Baseline characteristics of the included studies

Baseline characteristics of the included studies

\begin{tabular}{ll} 
& $\mathbf{N}(\%)$ \\
\hline Total included studies & $34(100)$ \\
\hline Study type & $24(71)$ \\
Randomized controlled trials & $10(29)$ \\
\hline
\end{tabular}

Treatment

$\underline{\text { Surgical treatment }}$

Haemorrhoidectomy

Haemorrhoidectomy

Haemorrhoidectomy

Stapled haemorrhoidopexy

DG-HAL (with suture mucopexy)

$\mathrm{H}(\mathrm{a})$ emorrhoidectomy

Stapled haemorrhoidopexy

DG-HAL (+ RAR or suture mucopexy)

Surgical vs office-based procedures

Hemorrhoidectomy

DG-HAL

DG-HAL

\section{Offece-based procedure}

Sclerotherapy

\section{Basic treatment}

Diltiazam gel

Flavenoids

\section{Control}

Haemorrhoidectomy

$4(12)$

Stapled haemorrhoidopexy

$5(15)$

DG-HAL (with suture mucopexy)

DG-HAL (with suture mucopexy) 3 (9)

Suture mucopexy

$6(18)$

Sclerotherapy

Rubber band ligation

Infrared coagulation

Placebo

$1(3)$

Placebo

$1(3)$

Total different reported outcomes 59

Average number of outcomes per study 5.8 (range 3-8) 


\section{Categorization of outcomes}

The 59 different types of outcomes were categorized into three core areas and 10 domains [Appendix 3: Outcomes structured into potential domains and core areas according to OMERACT Filter 2.0]. The core area life impact included the following three domains: patient satisfaction, quality of life, and time to return to normal. The core area pathophysiological manifestations consisted of four domains: symptoms, complications, and recurrence. The core area resource use/ economical impact included four domains: duration of operation, duration of hospitalization, re-operation, and costs. No outcome could be placed into the core area death. Apparently, death was not an outcome of interest in hemorrhoidal studies. Therefore, this core area was excluded.

Tables 2, 3, and 4 summarize the number of outcomes reported within each domain and the number of studies reporting these outcomes in each core area.

The most reported domains were symptoms (100\%), complications (91\%), recurrence (59\%), and patient satisfaction (41\%).

In office-based procedure and basic treatment studies, the most reported domains were similar including symptoms, complications, and patient satisfaction. Recurrence, time to return to normal, quality of life, duration of operation, re-operation, and costs, however, were no outcomes in these studies [Table 5].

Table 2: Outcome Domains in 42 studies included according to OMERACT 2.0 filter Core "Life impact"

\begin{tabular}{lcc}
\hline Domain & $\begin{array}{c}\text { Number of outcomes reported } \\
\text { within Domain }\end{array}$ & $\begin{array}{c}\text { Number of studies reporting } \\
\text { outcomes in Domain (\%) }\end{array}$ \\
\hline Patient satisfaction & 1 & $14(41)$ \\
Time to return to normal & 6 & $12(35)$ \\
Quality of life & 2 & $8(24)$ \\
\hline
\end{tabular}

Table 3: Outcome Domains in 42 studies included according to OMERACT 2.0 filter Core "Pathophysiological manifestations"

\begin{tabular}{lcc}
\hline Domain & $\begin{array}{c}\text { Number of outcomes reported } \\
\text { within domain }\end{array}$ & $\begin{array}{c}\text { Number of studies reporting } \\
\text { outcomes in Domain (\%) }\end{array}$ \\
\hline Symptoms & 22 & $34(100)$ \\
Complications & 18 & $31(91)$ \\
Recurrence & 2 & $20(59)$ \\
\hline
\end{tabular}


Table 4: Outcome Domains in 42 studies included according to OMERACT 2.0 filter Core "Resource use/ economical impact"

\begin{tabular}{lcc}
\hline Domain & $\begin{array}{c}\text { Number of outcomes reported } \\
\text { within domain }\end{array}$ & $\begin{array}{c}\text { Number of studies reporting } \\
\text { outcomes in Domain (\%) }\end{array}$ \\
\hline Duration of operation & 3 & $10(29)$ \\
Duration of hospitalization & 2 & $13(38)$ \\
Re-operation & 2 & $13(38)$ \\
Costs & 1 & $5(15)$ \\
\hline
\end{tabular}

Table 5: Comparison Outcome Domains between surgical treatment, office-based procedures and basic treatment studies according to OMERACT 2.0 Filter.

\begin{tabular}{lccc}
\hline & $\begin{array}{c}\text { Number of surgical } \\
\text { studies reporting } \\
\text { outcomes in Domain } \\
(\%)\end{array}$ & $\begin{array}{c}\text { Number of studies } \\
\text { comparing surgical vs } \\
\text { office-based procedures } \\
\text { reporting outcomes in } \\
\text { Domain (\%) }\end{array}$ & $\begin{array}{c}\text { Number of basic } \\
\text { treatment and office- } \\
\text { based procedure studies } \\
\text { reporting outcomes in } \\
\text { Domain (\%) }\end{array}$ \\
\hline Domain & $11(39)$ & $1(33)$ & $2(67)$ \\
\hline Patient satisfaction & $12(43)$ & 0 & 0 \\
$\begin{array}{l}\text { Time to return to } \\
\text { normal }\end{array}$ & $7(25)$ & $1(33)$ & 0 \\
Quality of life & $28(100)$ & $3(100)$ & $3(100)$ \\
Symptoms & $26(93)$ & $2(67)$ & $3(100)$ \\
Complications & $19(68)$ & $1(33)$ & 0 \\
Recurrence & $10(36)$ & 0 & $1(33)$ \\
\hline $\begin{array}{l}\text { Duration of operation } \\
\text { Duration of } \\
\text { hospitalization }\end{array}$ & $11(39)$ & $1(33)$ & 0 \\
\hline Re-operation & $11(39)$ & $2(67)$ & 0 \\
\hline Costs & $3(11)$ & $2(67)$ & 0 \\
\hline
\end{tabular}




\section{Defining of outcomes}

Many outcomes were not clearly defined and assessed using non-validated questionnaires [Appendix 4: describes the type of outcome measurement and the used instruments].

\section{Core area life impact}

Patient satisfaction Patient satisfaction was used in 14 studies (41\%) and all studies used non-validated questionnaires.

Time to return to normal Time to return to normal was used in 12 studies (35\%) and was defined as days off to work $(n=1)$, return to work $(n=2)$, resumption of social and working activity $(n=1)$, patients' time off everyday activity $(n=1)$, time to return to normal activity $(n$ $=1)$, and sick leave $(n=1)$.

Quality of life The outcome quality of life or well-being was reported in eight studies (24\%). This domain was assessed by using a Visual Analog Scale $(n=1)$, SF-12 $(n=2)$, or the EQ- 5D (QALY) $(n=1)$. In three other studies, assessment was not clear.

\section{Core area pathophysiological manifestations}

Symptoms Twenty-two different outcomes were used in a 'symptom score'. More than one outcome was used in each study (100\%). Most reported symptoms were pain $(91 \%)$, blood loss (94\%), and prolapse (71\%). Pain was assessed either by a visual analogue scale $(n=18)$, numeric rating scale (NRS) $(n=2)$, brief pain inventory $(B P I),(n=2)$, PATE $2000(n=1)$, or not clear $(n=8)$. Blood loss was assessed using a 4-point scale from 'not at all' to 'blood dripping in toilet' $(n=1)$, 5-point scale $(n=1)$, visual analog scale (VAS) ( $n=$ $1)$, Hemorrhoid symptom score (HSS) $(n=1)$, requiring a re-intervention (transfusion, re-operation) $(n=3)$, or not clear $(n=25)$. Prolapse was assessed using a 4-point scale: not at all/spontaneously/manual replacement/prolapse remains $(n=1), 5$-pointscale $(n=1)$, PATE $2000(n=1)$, or not clear $(n=21)$.

Complications Eighteen different outcomes were used in a 'complication score'. In $91 \%$ of the studies, more than one outcome was used. The outcome incontinence was the most reported complication and assessed using 5-point scale $(\mathrm{n}=1)$, Fecal Incontinence Quality of Life (Rockwood) Scale (FIQOL) $(n=2)$, the Wexner Incontinence Score $(\mathrm{n}=2)$, Cleveland Clinic Florida Score $(\mathrm{n}=2)$, Fecal Incontinence Quality-of-Life $(\mathrm{n}=$ 20 , the Vaizey Incontinence Score $(n=2)$, or not clear $(n=11)$. Two studies provided a definition of complications: (1) deviation from normal perioperative course and (2) non-resolving adverse advents related to surgery. 
Recurrence Recurrence was used in 20 studies (59\%). In nine studies, recurrence was assessed using non-validated questionnaires. One study assessing recurrent prolapse used anoscopic or proctoscopic examination $(n=1)$. In ten studies, the assessment of recurrence was not clear. However, eleven studies (32\%) provided a definition, which varied considerably over studies: 'recurrent prolapse and pain' $(n=2)$, 'recurrent prolapse' $(\mathrm{n}=1)$, 'recurrence is based on patient's complaints and surgeon's examination' $(\mathrm{n}=1)$, 'physical examination' ( $\mathrm{n}=1)$, 'relapse symptoms', 'rectal bleeding and impression by the patient of recurrent prolapse' $(\mathrm{n}=1)$, 'internal hemorrhoids diagnosed onproctoscopy' $(\mathrm{n}=1)$, ' 1 year patient's self-reported assess-ment in combination with resource use from their general practitioner and hospital records' $(\mathrm{n}=1)$, 'clinical evident grade III at 1 year' $(n=1)$, 'recurrent prolapse or bleeding' or 'PATE (recurrence of prolapse, acute symptoms, anal tone and external pill)' $(\mathrm{n}=1)$ or 'reappearance of the condition at an equal or lower grade than before' $(\mathrm{n}=1)$

\section{Core area resource use/economical impact}

Duration of operation was used as outcome in ten studies (29\%). Two studies assessed this outcome as incision to application of dressings $(n=1)$ and time between the incision and suturing the skin $(n=1)$. Duration of hospitalization was used in 13 studies $(38 \%)$. In all studies, this outcome was not specified. Re-operation was used in 13 studies (38\%). In none of the studies this outcome was specified. Costs were used in five studies (15\%). In none of the studies, this outcome was specified. 


\section{Discussion}

This systematic review showed a wide heterogeneity of outcomes in studies reporting on hemorrhoidal disease (HD). Furthermore, a lack of a standardized definition for commonly reported outcomes was observed.

The most commonly reported core area was pathophysiological manifestations including the domain symptoms, complications, and recurrence. All studies reported symptoms as an outcome (100\%). However, 22 different outcomes were used in this category alone, hence making direct comparison between studies difficult. Most reported symptoms were pain (91\%), blood loss (94\%), and prolapse (71\%). Pain and blood loss were the two pre-eminent symptoms that were addressed by asking the patient. Prolapse was assessed by asking both the patient $(51 \%)$ and by physical examination by the clinician (49\%). This disparity strengthens the case for the development of a COS which embraces the patient voice, as well as those from clinicians. Since patients are fulfilling a more central role in the consulting room, more areas of healthcare intent to develop patient-reported outcomes [35-37]. Until know, there are several non-validated symptom questionnaires developed for HD scoring the frequencies of five outcomes (i.e., pain, blood loss, prolapse, itching, and soiling), for example, the Sodergren score [38]. Besides symptoms, complications were reported in $91 \%$ of the studies. This Domain included 18 different outcomes. Again, heterogeneity of outcomes was seen within the studies. Registrations of complications are mandatory since reliable outcome data are crucial to improve outcome of care and gather credible data for benchmarking. In 1992, the Clavien-Dindo classification was introduced offering the possibility to combine grades of complications [39] which enables comparisons to be made between studies. Recurrence was the next frequently reported outcome in the studies (59\%) for the core area pathophysiological manifestations. Remarkable, only 11 studies (32\%) provided a definition, which varied considerably over studies.

The core area life impact capturing the domain patient satisfaction, time to return to normal, and quality of life was less often used in studies than pathophysiological manifestations. Patient satisfaction was the most reported domain in this core area. This domain was used in $41 \%$ of the studies and was always assessed by using non-validated questionnaires. In literature, no validated instrument for assessing patient satisfaction with HD treatment could be found. However, we think this domain is important as we know that dissatisfied patients often have worse clinical outcomes [40-43]. Time to return to normal was reported in 35\% of the studies. Several definitions were provided in the studies. Quality of life was assessed in eight studies (24\%) and only three studies used a validated questionnaire (i.e., SF-12/36 and EQ- 5D).

The core area resource use/economical impact including duration of operation, duration of hospitalization, re-operation, and costs were also often used in studies. Duration of hospitalization was the most reported domain in this core area. Duration of hospitalization was used in 13 studies (38\%). In none of the studies, a definition was provided. Duration 
of operation was used as outcome in ten studies (29\%). Re-operation was used in 13 studies (38\%), but without providing a definition. Costs were used in five studies (15\%).

The OMERACT handbook states that the core area resource use is only recommended for inclusion if stakeholders decide that this core area is mandatory [33].

The core area death was not an outcome of interest in HD studies. Patients with HD are generally healthy patients undergoing elective medical therapy and therefore mortality due to treatment of HD is very rare.

Although HD is the most common anorectal problem, there is no COS for this condition. This study supports the need to develop a COS for HD to ensure that study results can be compared and combined in the future. Next step will be a consensus study with both patients and healthcare professionals using the Delphi methodology [22]. With this review study, we have derived potentially relevant outcome domains for the development of such COS for HD (47). Treating HD in daily practice includes often a combination of basic treatment, office-based procedures and surgical treatment, depending on the grade of severity of the disease. Therefore, we included all interventional studies in this review ranging from life styles and diet advices till surgical interventions. We recognize that in doing so, some outcomes (e.g. prolapse) may not be relevant for all types of treatment for HD, especially in low grade HD. Further, most domains were similar between the studies; however, the domains time to return to normal, quality of life, recurrence, duration of operation, reoperation, and costs were not reported in studies investigating only basic treatment or office-based procedures. This review can serve as a basis for developing a COS for all grades of HD; however, one should be aware of these findings.

The main limitation of our study is that in our search for outcomes, it has been limited to those reported in the existing literature, potentially missing outcomes that are important to other stakeholder groups, in particular patients. The importance of engaging patients in research is being increasingly recognized [44-46]. By asking patients which outcomes should be assessed, we can be confident that treatment interventions are investigated in a way that is relevant to the target population. Therefore, patients will be included in the consensus study. Secondly, the OMERACT Filter may have some limitations. It was developed primarily for trials within the field of rheumatology. Hence, there may be specialty- specific factors that affect the suitability of the filter for other fields. Thirdly, in assigning outcomes to OMERACT core areas, we encountered several examples where an outcome term could potentially be assigned to more than one core area. For example, requirement of repeat procedure could be considered in the context of (ongoing) "Pathophysiological Manifestations", or within "Resource Use". 


\section{Conclusion}

In conclusion, this systematic review showed a wide heterogeneity of outcomes in studies reporting on HD and a lack of a standardized definition for commonly reported outcomes. To improve transparency between studies and facilitate the ability to compare and combine (future) studies, we need to develop a COS for HD. This study, in which we identified a list of potentially relevant outcomes, is the first step towards the development of a COS for HD.

\section{Compliance with ethical standards}

Ethical approval None declared.

Conflict of interest The authors declare that they have no conflict of interest.

Open Access This article is distributed under the terms of the Creative Commons Attribution 4.0 International License (http:// creativecommons.org/licenses/by/4.0/), which permits unrestricted use, distribution, and reproduction in any medium, provided you give appropriate credit to the original author(s) and the source, provide a link to the Creative Commons license, and indicate if changes were made. 


\section{References}

1. Lohsiriwat V (2012) Hemorrhoids: from basic pathophysiology to clinical management. World J Gastroenterol 18(17):2009-2017

2. Gerjy R, Lindhoff-Larson A, Nystrom PO (2008) Grade of pro- lapse and symptoms of haemorrhoids are poorly correlated: result of a classification algorithm in 270 patients. Color Dis 10(7):694-700

3. Higuero T, Abramowitz L, Castinel A, Fathallah N, Hemery P, Laclotte Duhoux C, Pigot F, Pillant-le Moult H, Senéjoux A, Siproudhis L, Staumont G, Suduca JM, Vinson-Bonnet B (2016) Guidelines for the treatment of hemorrhoids (short report). J Visc Surg. 153(3):213-218

4. Altomare DF, Roveran A, Pecorella G, Gaj F, Stortini E (2006) The treatment of hemorrhoids: guidelines of the Italian Society of Colorectal Surgery. Tech Coloproctol 10(3):181-186

5. Alonso-Coello P, Guyatt GH, Heels-Ansdell D, Johanson JF, Lopez-Yarto M, Mills E, Zhuo Q (2005) Laxatives for the treatment of hemorrhoids. Cochrane Database Syst Rev (4):CD004649. https://doi.org/10.1002/14651858.CD004649

6. Shanmugam V,Thaha MA, Rabindranath KS, Campbell KL, Steele RJ, Loudon MA (2005) Systematic review of randomized trials comparing rubber band ligation with excisional haemorrhoidectomy. $\mathrm{Br} \mathrm{J}$ Surg 92(12):1481-1487

7. Brown S, Tiernan J, Biggs K, Hind D, Shephard N, Bradburn M, Wailoo A, Alshreef A, Swaby L, Watson A, Radley S, Jones O, Skaife P, Agarwal A, Giordano P, Lamah M, Cartmell M, Davies J, Faiz O, Nugent K, Clarke A, MacDonald A, Conaghan P, Ziprin P, Makhija R (2016) The HubBLe trial: haemorrhoidal artery ligation (HAL) versus rubber band ligation (RBL) for symptomatic secondand third-degree haemorrhoids: a multicentre randomised con- trolled trial and health-economic evaluation. Health Technol Assess 20(88):1-150

8. Tokunaga Y, Sasaki H, Saito T (2010) Evaluation of sclerotherapy with a new sclerosing agent and stapled hemorrhoidopexy for pro- lapsing internal hemorrhoids: retrospective comparison with hemorrhoidectomy. Dig Surg 27(6):469-472

9. Gupta PJ (2005) Ambulatory hemorrhoid therapy with radiofre- quency coagulation. Clinical practice paper. Rom J Gastroenterol 14(1):37-41

10. Pucher PH, Sodergren MH, Lord AC, Darzi A, Ziprin P (2013) Clinical outcome following Doppler-guided haemorrhoidal artery ligation: a systematic review. Color Dis 15(6):e284-e294

11. Hoyuela C, Carvajal F, Juvany M, Troyano D, Trias M, Martrat A, Ardid J, Obiols J (2016) HAL-RAR (Doppler guided haemorrhoid artery ligation with recto-anal repair) is a safe and effective procedure for haemorrhoids. Results of a prospective study after two-years follow- up. Int J Surg 28:39_44

12. Faucheron JL, Trilling B, Reche F (2015) HAL-RAR(R) procedure: a safe operation for hemorrhoids. J Visc Surg 152(2):143-144

13. Faucheron JL, Poncet G, Voirin D, Badic B, Gangner Y (2011) Doppler-guided hemorrhoidal artery ligation and rectoanal repair (HAL-RAR) for the treatment of grade IV hemorrhoids: longterm results in 100 consecutive patients. Dis Colon rectum 54(2): 226-231 


\section{Chapter 3}

14. Giordano P, Gravante G, Sorge R, Ovens L, Nastro P (2009) Long- term outcomes of stapled hemorrhoidopexy vs conventional hemorrhoidectomy: a meta-analysis of randomized controlled trials. Arch Surg 144(3):266-272

15. Porrett LJ, Porrett JK, Ho YH (2015) Documented complications of staple hemorrhoidopexy: a systematic review. Int Surg 100(1):44- 57

16. Xu L, Chen H, Lin G, Ge Q (2015) Ligasure versus Ferguson hemorrhoidectomy in the treatment of hemorrhoids: a meta- analysis of randomized control trials. Surg Laparosc Endosc Percutan Tech 25(2):106-110

17. Shao WJ, Li GC, Zhang ZH, Yang BL, Sun GD, Chen YQ (2008) Systematic review and metaanalysis of randomized controlled tri- als comparing stapled haemorrhoidopexy with conventional haemorrhoidectomy. Br J Surg 95(2):147-160

18. Simillis C, Thoukididou SN, Slesser AA, Rasheed S, Tan E, Tekkis PP (2015) Systematic review and network meta-analysis comparing clinical outcomes and effectiveness of surgical treatments for haemorrhoids. Br J Surg 102(13):1603-1618

19. Klokker L, Tugwell P, Furst DE, Devoe D, Williamson P, Terwee CB et al (2016) Developing an OMERACT core outcome set for assessing safety components in rheumatology trials: the OMERACT safety working group. J Rheumatol. https://doi.org/ 10.3899/jrheum.161105

20. Boers M, Brooks P, Strand CV, Tugwell P (1998) The OMERACT filter for outcome measures in rheumatology. J Rheumatol 25(2): 198-199

21. Prinsen CA, Vohra S, Rose MR, King-Jones S, Ishaque S, Bhaloo Z et al (2014) Core outcome measures in effectiveness trials (COMET) initiative: protocol for an international Delphi study to achieve consensus on how to select outcome measure- ment instruments for outcomes included in a Bcore outcome set^. Trials 15:247

22. Ong WL, Schouwenburg MG, van Bommel ACM, Stowell C, Allison KH, Benn KE, Browne JP, Cooter RD, Delaney GP, Duhoux FP, Ganz PA, Hancock P, Jagsi R, Knaul FM, Knip AM, Koppert LB, Kuerer HM, McLaughin S, Mureau MAM, Partridge AH, Reid DP, Sheeran L, Smith TJ, Stoutjesdijk MJ, Vrancken Peeters MJTFD, Wengström Y, Yip CH, Saunders C (2017) A standard set of value-based patient-centered outcomes for breast cancer: the international consortium for health outcomes measure- ment (ICHOM) initiative. JAMA Oncol 3(5):677-685

23. McNamara RL, Spatz ES, Kelley TA, Stowell CJ, Beltrame J, Heidenreich P et al (2015) Standardized outcome measurement for patients with coronary artery disease: consensus from the inter- national consortium for health outcomes measurement (ICHOM). J Am Heart Assoc 4(5):e001767

24. Hall NJ, Kapadia MZ, Eaton S, Chan WW, Nickel C, Pierro A et al (2015) Outcome reporting in randomised controlled trials and meta- analyses of appendicitis treatments in children: a systematic review. Trials 16:275

25. Schmitt J, Spuls PI, Thomas KS, Simpson E, Furue M, Deckert S, Dohil M, Apfelbacher C, Singh JA, Chalmers J, Williams HC, HOME initiative collaborators (2014) The Harmonising outcome measures for eczema (HOME) statement to assess clinical signs of atopic eczema in trials. J Allergy Clin Immunol 134(4):800-807 
26. Mackie SL, Twohig H, Neill LM, Harrison E, Shea B, Black RJ, Kermani TA, Merkel PA, Mallen CD, Buttgereit F, Mukhtyar C, Simon LS, Hill CL, on behalf of the OMERACT PMR Working Group (2017) The OMERACT core domain set for outcome mea- sures for clinical trials in polymyalgia rheumatica. J Rheumatol 44: 1515-1521

27. Toupin-April K, Barton J, Fraenkel L, Li LC, Brooks P, De Wit M et al (2017) Toward the development of a core set of outcome domains to assess shared decision-making interventions in rheuma- tology: results from an OMERACT Delphi survey and consensus meeting. J Rheumatol 44:1544-1550

28. Hatemi G, Meara A, Ozguler Y, Direskeneli H, Mahr A, Easley E, Gurcan M, Davis T, Gul A, Yazici Y, Zottenberg K, Esatoglu SN, Erer B, Kamali S, Yazici H, Cronholm PF, Merkel PA (2017) Developing a core set of outcome measures for Behcet disease: report from OMERACT 2016. J Rheumatol 44:1750-1753

29. Singh JA, Dowsey M, Choong PF (2017) Patient endorsement of the outcome measures in rheumatology (OMERACT) total joint replacement (TJR) clinical trial draft core domain set. BMC Musculoskelet Disord 18(1):111

30. Singh JA, Dowsey MM, Dohm M, Goodman SM, Leong AL, Scholte Voshaar MM et al (2017) Achieving consensus on total joint replacement trial outcome reporting using the OMERACT filter: endorsement of the final core domain set for total hip and total knee replacement trials for endstage arthritis. J Rheumatol 44: 1723-1726

31. Boers M, Kirwan JR, Wells G, Beaton D, Gossec L, d'Agostino MA, Conaghan PG, Bingham CO III, Brooks P, Landewé R, March L, Simon LS, Singh JA, Strand V, Tugwell P (2014) Developing core outcome measurementsets for clinical trials: OMERACT filter 2.0. J Clin Epidemiol 67(7):745-753

32. Kirwan JR, Boers M, Tugwell P (2014) Updating the OMERACT filter at OMERACT 11. J Rheumatol 41(5):975-977

33. Kirwan JR, Boers M, Hewlett S, Beaton D, Bingham CO 3rd, Choy E et al (2014) Updating the OMERACT filter: core areas as a basis for defining core outcome sets. J Rheumatol 41(5):994-999

34. Stovold E, Beecher D, Foxlee R, Noel-Storr A (2014) Study flow diagrams in Cochrane systematic review updates: an adapted PRISMA flow diagram. Syst Rev 3:54

35. Liu N, Lv J, Liu J, Zhang Y (2017) The PU-PROM: a patient- reported outcome measure for peptic ulcer disease. Health Expect 20:1350-1366

36. Most SP, Moubayed SP (2017) Patient-reported outcome measures for facial plastic surgery: a specialty finally gets to go to the PROM. JAMA Facial Plast Surg 19(2):101

37. Klingels K, Mayhew AG, Mazzone ES, Duong T, Decostre V, Werlauff U, Vroom E, Mercuri E, Goemans NM, The Upper Limb Clinical Outcome Group (2017) Development of a patientreported outcome measure for upper limb function in Duchenne muscular dystrophy: DMD upper limb PROM. Dev Med Child Neurol 59(2):224-231

38. Pucher PH, Qurashi M, Howell AM, Faiz O, Ziprin P, Darzi A, Sodergren MH (2015) Development and validation of a symptom-based severity score for haemorrhoidal disease: the Sodergren score. Color Dis 17(7):612-618 


\section{Chapter 3}

39. Clavien PA, Barkun J, de Oliveira ML, Vauthey JN, Dindo D, Schulick RD, de Santibañes E, Pekolj J, Slankamenac K, Bassi C, Graf R, Vonlanthen R, Padbury R, Cameron JL, Makuuchi M (2009) The Clavien-Dindo classification of surgical complications: five-year experience. Ann Surg 250(2):187-196

40. Mancuso CA, Salvati EA, Johanson NA, Peterson MG, Charlson ME (1997) Patients' expectations and satisfaction with total hip arthroplasty. J Arthroplast 12(4):387-396

41. Mahajan ST, Elkadry EA, Kenton KS, Shott S, Brubaker L (2006) Patient-centered surgical outcomes: the impact of goal achievement and urge incontinence on patient satisfaction one year after surgery. Am J Obstet Gynecol 194(3):722-728

42. Rao JK, Weinberger M, Kroenke K (2000) Visit-specific expecta- tions and patient-centered outcomes: a literature review. Arch Fam Med 9(10):1148-1155

43. Lochman JE (1983) Factors related to patients' satisfaction with their medical care. J Community Health 9(2):91-109

44. Bredart A, Marrel A, Abetz-Webb L, Lasch K, Acquadro C (2014) Interviewing to develop patientreported outcome (PRO) measures for clinical research: eliciting patients' experience. Health Qual Life Outcomes 12:15

45. Black N (2013) Patient reported outcome measures could help transform healthcare. BMJ (Clinical research ed) 346:f167

46. Marshall S, Haywood K, Fitzpatrick R (2006) Impact of patient- reported outcome measures on routine practice: a structured review. J Eval Clin Pract 12(5):559 


\section{Supplementary material}

\section{Appendix I}

\section{Search strategies}

\section{Medline (Pubmed):}

\#1,"Search $(((($ haemorrhoid*[Title/Abstract] $)$ OR hemorhoid*[Title/Abstract]) OR haemorhoid*[Title/Abstract]) OR hemorroid*[Title/Abstract]) OR haemorroid*[Title/Abstract]) OR hemoroid*[Title/Abstract]",

$1761,06: 11: 16$

\#2,"Search hemorrhoid[MeSH Terms]",

$4871,06: 12: 15$

\#3,"Search $((((()(((($ surgery[MeSH Subheading] $))$ OR surgery) OR surgical procedures, operative[MeSH Terms]) OR surgical) AND procedures) AND operative) OR operative surgical procedures) OR surgery) OR general surgery[MeSH Terms]) OR general)

4051959,06:15:19

\#4,"Search ((((treatment[MeSH Subheading]) OR therapy) OR treatment) OR therapeutics[MeSH Terms]) OR therapeutics"

$9498187,06: 16: 05$

\#5,"Search (recurrence[MeSH Terms]) OR recurrence",

406696,06:16:22

\#6,"Search ((((diagnosis[MeSH Subheading]) OR diagnosis) OR symptoms) OR diagnosis[MeSH Terms]) OR symptoms",

$8982014,06: 17: 16$

\#7,"Search ((((outcome assessment health care[MeSH Terms]) OR patient outcome assessment[MeSH Terms]) OR treatment outcome[MeSH Terms]) OR clinical effectiveness) OR treatment effectiveness",

1197546,06:19:38

(\#1 OR \#2)

\#8,"Search ((hemorrhoid* [Title/Abstract]) OR $\quad((((($ haemorrhoid*[Title/ Abstract]) OR hemorhoid*[Title/Abstract]) OR haemorhoid*[Title/Abstract]) OR hemorroid*[Title/Abstract]) OR haemorroid*[Title/Abstract]) OR hemoroid*[Title/Abstract])) OR hemorrhoid[MeSH Terms]",

$6602,06: 21: 03$

$(\# 2$ OR \#3)

\#),"Search $(((()(((()($ surgery[MeSH Subheading]) OR surgery) OR surgical procedures, operative[MeSH Terms]) OR surgical) AND procedures) AND operative) OR operative surgical procedures) OR surgery) OR general surgery[MeSH Terms]) OR general) AND surgery) OR general surgery)) OR ((((treatment[MeSH Subheading]) OR therapy) OR treatment) OR therapeutics[MeSH Terms]) OR therapeutics)”,

$10554636,06: 21: 22$

(\#5 OR \#6 OR \#7) 


\section{Chapter 3}

\#10,"Search $\quad(((($ recurrence$[\mathrm{MeSH} \quad$ Terms] $) \quad$ OR recurrence $)) \quad$ OR (((() diagnosis[MeSH Subheading]) OR diagnosis) OR symptoms) OR diagnosis[MeSH Terms] ) OR symptoms)) OR (((((outcome assessment health care[MeSH Terms]) OR patient outcome assessment[MeSH Terms]) OR treatment outcome[MeSH Terms]) OR clinical effectiveness) OR treatment effectiveness)"

(\#8 AND \#9 AND \#10)

\#11,"Search $\left(\left(\left(\left((\right.\right.\right.\right.$ hemorrhoid* [Title/Abstract] $)$ OR $\left(\left(\left(\left(\left(\right.\right.\right.\right.\right.$ haemorrhoid*[Title/ $^{*}$ Abstract]) OR hemorhoid*[Title/Abstract]) OR haemorhoid*[Title/ Abstract]) OR hemorroid*[Title/Abstract]) OR haemorroid*[Title/Abstract]) OR hemoroid*[Title/Abstract])) OR hemorrhoid[MeSH Terms])) AND (((()((()((((surgery[MeSH Subheading]) OR surgery) OR surgical procedures, operative[MeSH Terms]) OR surgical) AND procedures) AND operative) OR operative surgical procedures) OR surgery) OR general surgery[MeSH Terms]) OR general) AND surgery) OR general surgery)) OR ((((treatment $[\mathrm{MeSH}$ Subheading]) OR therapy) OR treatment) OR therapeutics[MeSH Terms]) OR therapeutics) $))$ AND (((((recurrence[MeSH Terms]) OR recurrence)) OR ((((diagnosis[MeSH Subheading]) OR diagnosis) OR symptoms) OR diagnosis[MeSH Terms] ) OR symptoms)) OR (((()outcome assessment health care[MeSH Terms]) OR patient outcome assessment[MeSH Terms]) OR treatment outcome[MeSH Terms]) OR clinical effectiveness) OR treatment effectiveness))",

$2717,06: 22: 16$

\section{Cochrane:}

1. \#1, "hemorrhoid*":ti,ab,kw (Word variations have been searched)

2. \#2, haemorrhoid*

3. \#3, hemorrhoid*

4. \#4, haemorroid*

5. \#5, hemorroid*

6. \#6, haemorhoid*

7. \#7, hemorhoid*

8. \#8, haemoroid*

9. $\# 9$, hemoroid*

10. $\# 1$ or $\# 2$ or $\# 3$ or $\# 4$ or $\# 5$ or $\# 6$ or $\# 7$ or \#8 or \#9

11. \#11, surgery

12. \#12, surgical procedures

13. \#13, general surgery

14. \#14, procedures

15. \#15, treatment

16. \#16, therapy

17. \#17, therapeutics

18. \#11 or \#12 or \#13 or \#14 or \#15 or \#16 or \#17

19. \#19, recurrence

20. \#20, outcome assessment

21. \#21, treatment outcome 
22. \#19 or \#20 or \#21

23. \#10 and \#18 and \#22

\section{Ovid (Embase):}

1. \#1, hemorrhoid*.mp. or exp hemorrhoid/

2. \#2, haemorrhoid.mp. or exp hemorrhoid/

3. \#3, hemorroid.mp.

4. \#4, haemorroid.mp.

5. \#5, hemoroid.mp.

6. \#6, haemorhoid.mp.

7. \#7, hemorhoid.mp.

8. \#1 or \#2 or \#3 or \#4 or \#5 or \#6 or \#7

9. \#9, exp general surgery/ or exp surgery/ or surgery.mp.

10. \#10, surgical procedures.mp. or exp surgical technique/

11. \#11, treatment.mp.

12. \#12, exp therapy/or therapy.mp.

14. \#9 or \#10 or \#11 or \#12

15. \#14, recurrence.mp. or exp recurrent disease/

16. \#15, exp diagnosis/ or diagnosis.mp.

17. \#16, exp symptom assessment/ or exp symptom/ or symptoms.mp.

18. \#17, outcome assessment.mp. or exp outcome assessment/

19. \#18, treatment outcome.mp. or exp treatment outcome/

20. \#19, exp treatment outcome/ or exp outcome assessment/ or outcome.mp.

21. 14 or 15 or 16 or 17 or 18 or 19

22. \#8 and \#14

23. \#21 and \#22 


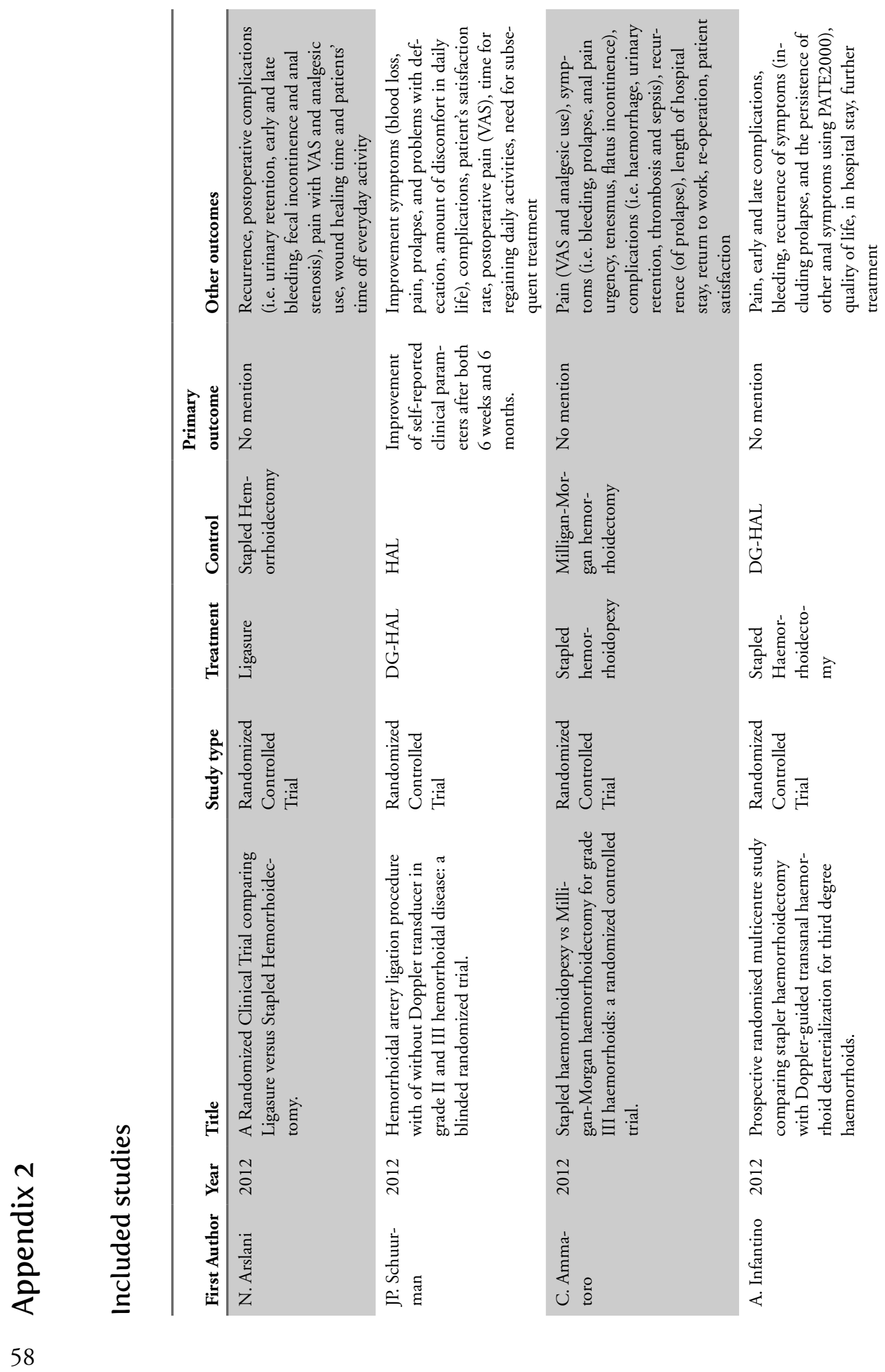




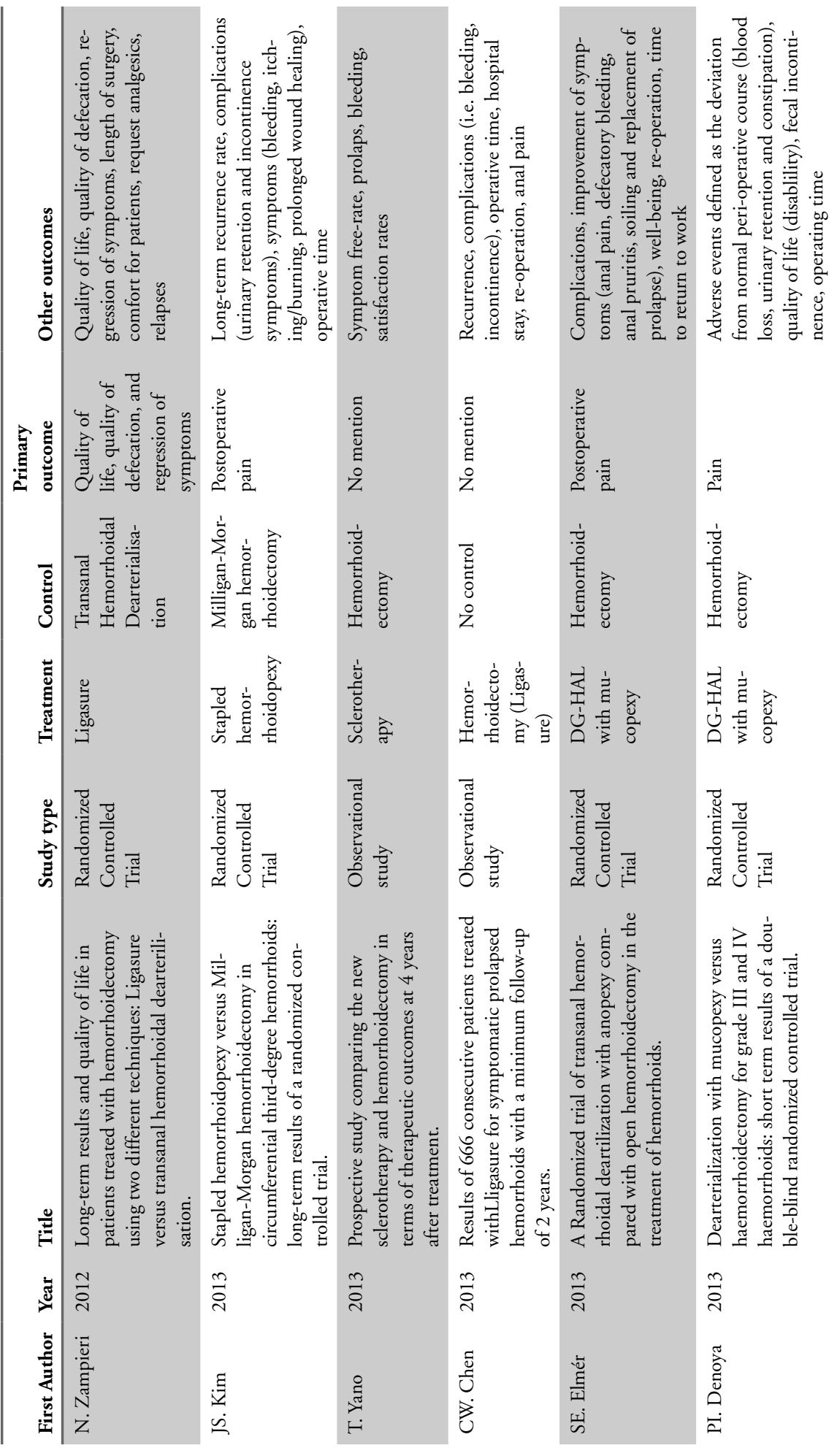




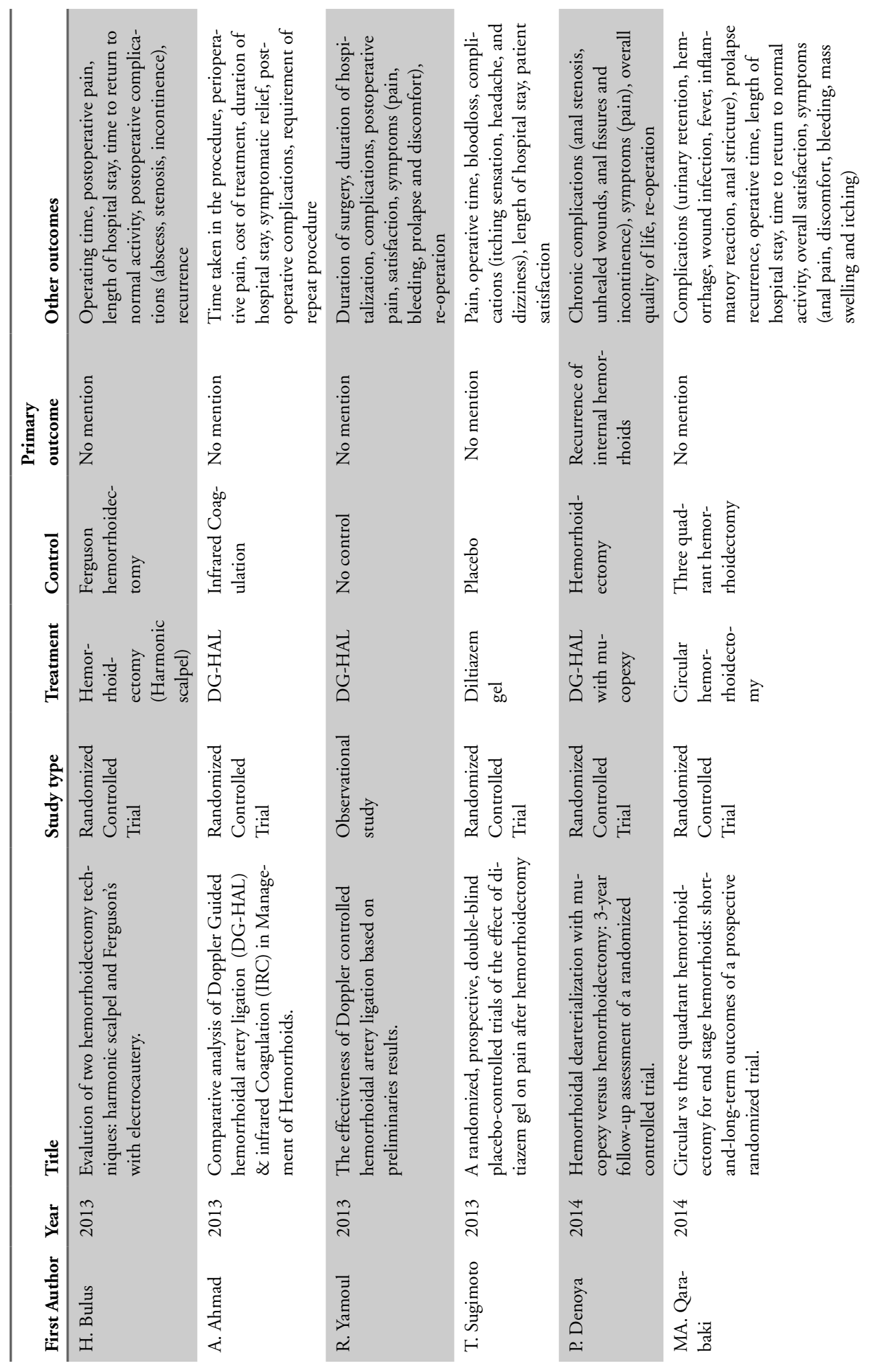




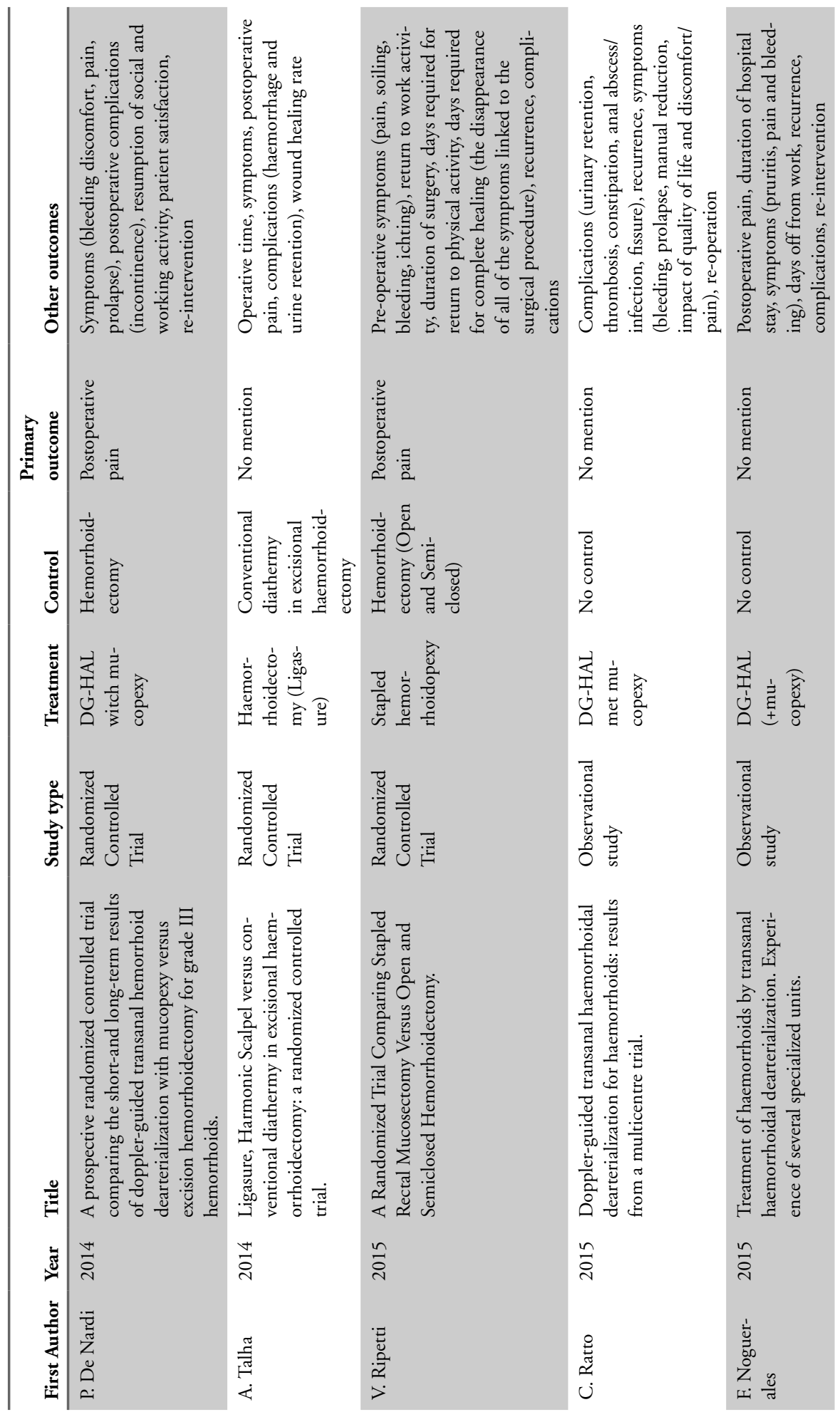




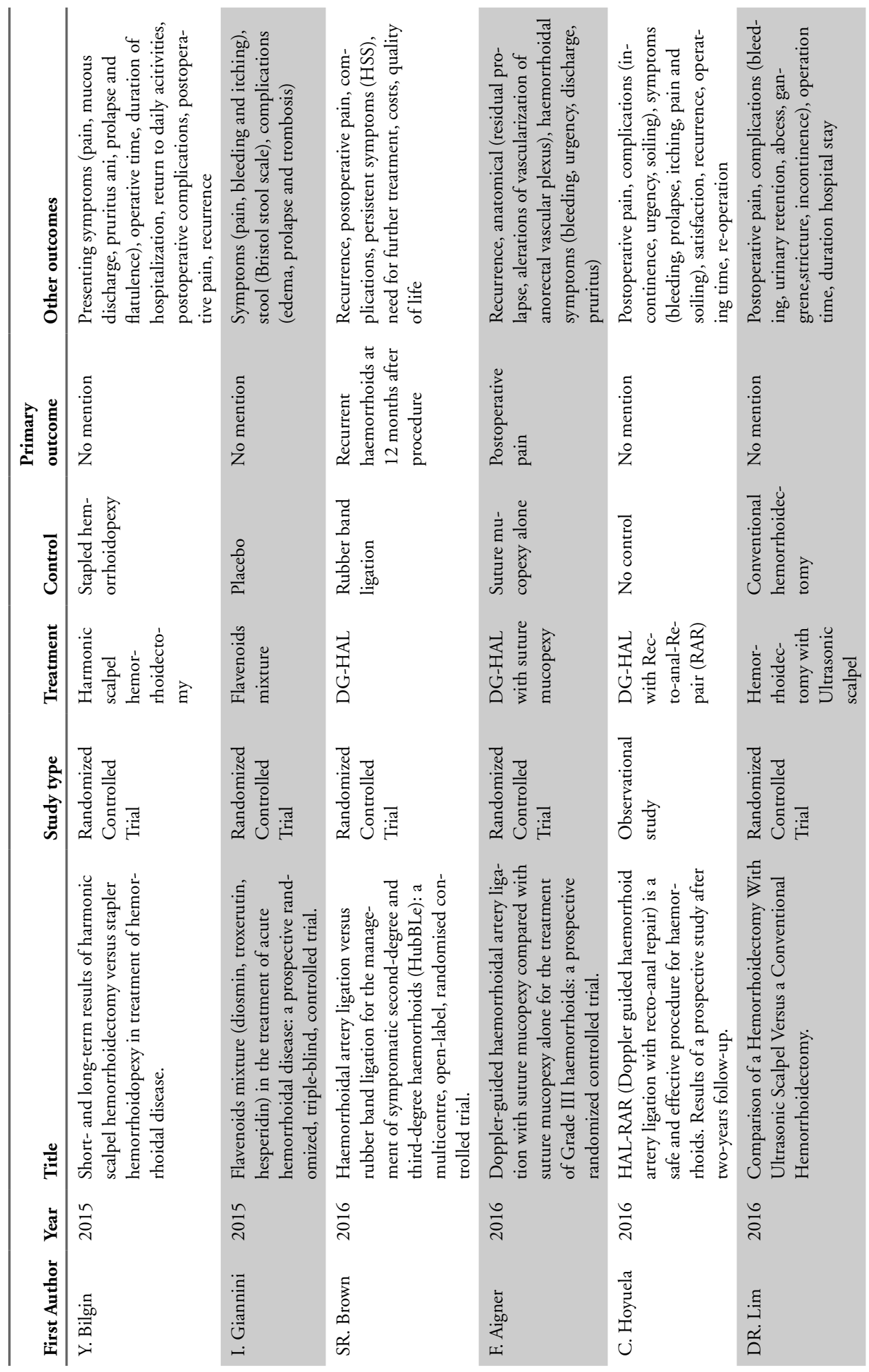




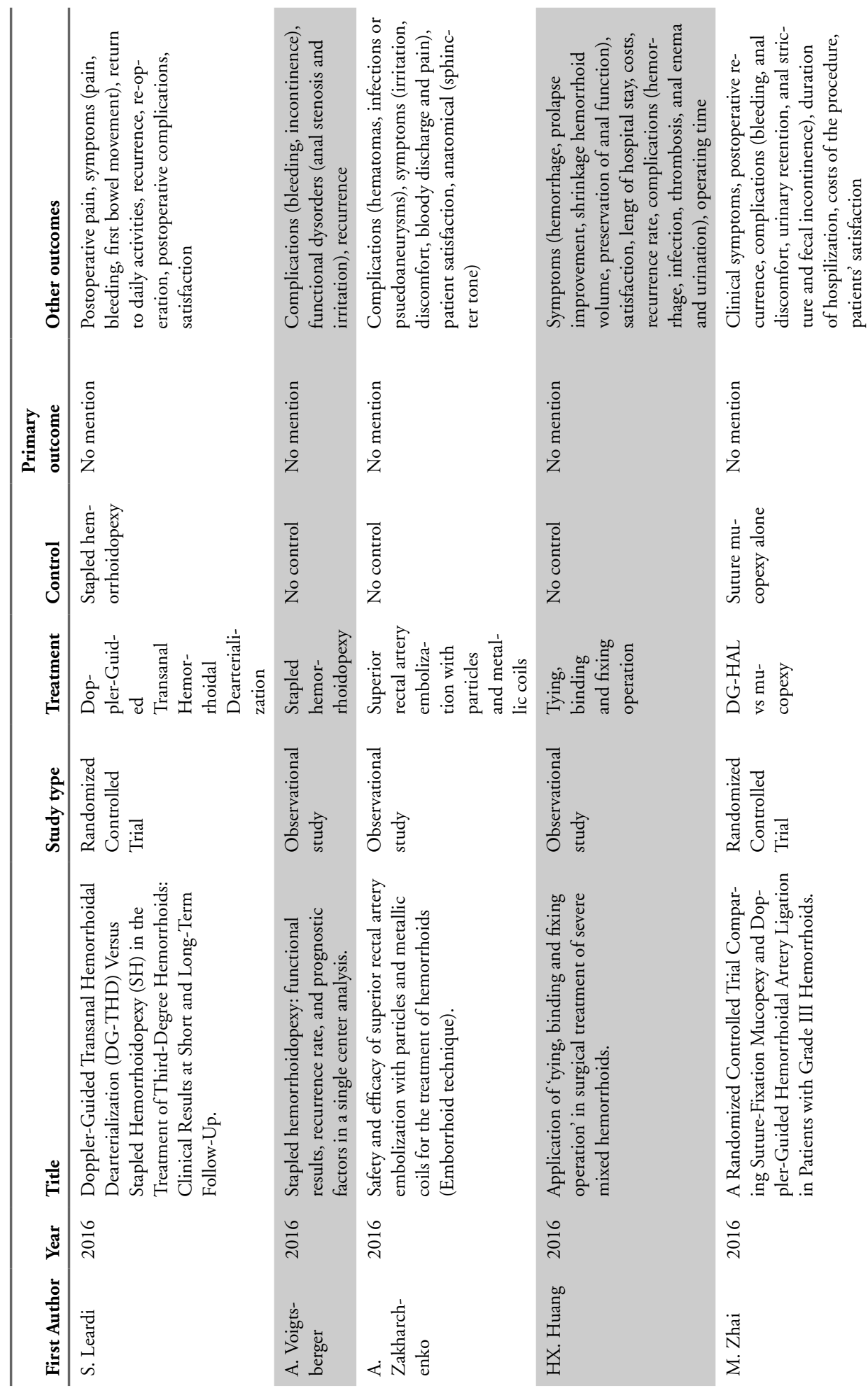


Chapter 3

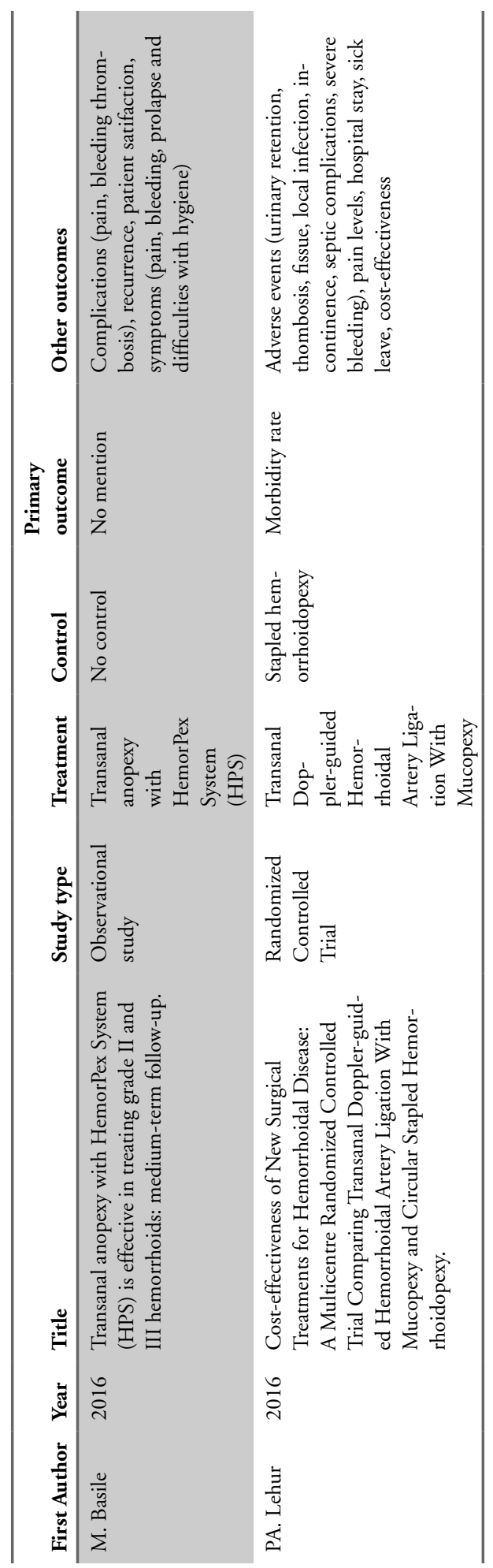




\section{Appendix 3}

Outcomes structured into potential domains and core areas according to OMERACT Filter 2.0

\begin{tabular}{|c|c|c|}
\hline Outcomes & Domains & Core areas \\
\hline$(\mathrm{n}=59)$ & $(\mathrm{n}=10)$ & $(\mathrm{n}=3)$ \\
\hline Patient satisfaction & Satisfaction & Life impacts \\
\hline Quality of life & \multirow[t]{2}{*}{ Quality of life } & \\
\hline Well-being & & \\
\hline Days off to work & \multirow{6}{*}{$\begin{array}{l}\text { Time to return to } \\
\text { 'normal' }\end{array}$} & \\
\hline Return to work & & \\
\hline Resumption social and working activity & & \\
\hline Patients' time off everyday activity & & \\
\hline Time to return to normal activity & & \\
\hline Sick leave & & \\
\hline Prolapse & \multirow[t]{22}{*}{ Symptoms } & \multirow[t]{22}{*}{ Pathophysiological manifestations } \\
\hline Pain & & \\
\hline Bleeding/ blood loss & & \\
\hline Itching & & \\
\hline Pruritus & & \\
\hline Soiling & & \\
\hline Discomfort & & \\
\hline Urgency & & \\
\hline Mucous discharge & & \\
\hline Tenesmus & & \\
\hline Burning & & \\
\hline Mass swelling & & \\
\hline Constipation & & \\
\hline Hygiene problems & & \\
\hline Quality of defecation & & \\
\hline Passage of gas/feces & & \\
\hline Flatus incontinence & & \\
\hline Wound healing & & \\
\hline Irritation & & \\
\hline Anal function & & \\
\hline Anatomical difference & & \\
\hline Anal tone & & \\
\hline
\end{tabular}




\section{Chapter 3}

\begin{tabular}{|c|c|c|}
\hline Fecal incontinence & \multirow[t]{18}{*}{ Complications } & \\
\hline Outlet obstruction & & \\
\hline External pil & & \\
\hline Severe pain & & \\
\hline Severe bleeding & & \\
\hline Gangrene & & \\
\hline Edema & & \\
\hline Sepsis & & \\
\hline Local infection & & \\
\hline Haemorrhage & & \\
\hline Hematomas & & \\
\hline Thrombosis & & \\
\hline Anal fissure & & \\
\hline Abscess & & \\
\hline Urinary retention & & \\
\hline Anal stricture & & \\
\hline Unhealed wounds & & \\
\hline Anal stenosis & & \\
\hline Recurrent prolapse & \multirow[t]{2}{*}{ Recurrence } & \\
\hline Recurrent haemorrhoidal symptoms & & \\
\hline Time taken in the procedure & \multirow[t]{3}{*}{ Duration of operation } & Resource use/Economical impact \\
\hline Duration of surgery & & \\
\hline Operative time & & \\
\hline Hospital stay & \multirow{2}{*}{$\begin{array}{l}\text { Duration of } \\
\text { hospitalization }\end{array}$} & \\
\hline Duration or length of hospitalization & & \\
\hline Cost of treatment & Costs & \\
\hline Requirement of repeat procedure & \multirow[t]{2}{*}{ Re-operation } & \\
\hline (Surgical) re-intervention & & \\
\hline
\end{tabular}




\section{Appendix 4}

Measurement of outcomes and measurement tools used

\begin{tabular}{|c|c|c|c|c|c|}
\hline \multirow[b]{2}{*}{ Outcomes } & \multicolumn{4}{|c|}{ Measurement type used (N) } & \multirow[b]{2}{*}{ Measurement tools used } \\
\hline & . & 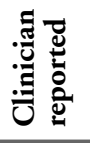 & 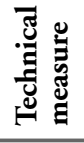 & 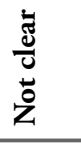 & \\
\hline \multicolumn{6}{|l|}{ Life impact } \\
\hline $\begin{array}{l}\text { Patient } \\
\text { satisfaction }\end{array}$ & 14 & 0 & 0 & 0 & Questionnaire nd $(\mathrm{n}=14)$ \\
\hline Quality of life & 7 & 0 & 0 & 0 & $\begin{array}{l}\text { Visual Analog Scale }(n=1), \text { SF-12 }(n=2), \text { EQ-5D } \\
(n=1) \text {, not clear }(n=3)\end{array}$ \\
\hline Well-being & 1 & 0 & 0 & & Questionnaire nd $(\mathrm{n}=1)$ \\
\hline Days off to work & 0 & 0 & 0 & 1 & Not specified $(\mathrm{n}=1)$ \\
\hline Return to work & 0 & 0 & 0 & 2 & Not specified $(\mathrm{n}=2)$ \\
\hline $\begin{array}{l}\text { Resumption } \\
\text { social and } \\
\text { working activity }\end{array}$ & 0 & 0 & 0 & 1 & Not specified $(\mathrm{n}=2)$ \\
\hline $\begin{array}{l}\text { Patients' time off } \\
\text { everyday activity }\end{array}$ & 0 & 0 & 0 & 3 & Not specified $(\mathrm{n}=3)$ \\
\hline $\begin{array}{l}\text { Time to return to } \\
\text { normal activity }\end{array}$ & 0 & 0 & 0 & 4 & Not specified nd $(\mathrm{n}=4)$ \\
\hline Sick leave & 0 & 0 & 0 & 1 & Not specified $(\mathrm{n}=1)$ \\
\hline \multicolumn{6}{|c|}{ Pathophysiological manifestations } \\
\hline Prolapse & 12 & 11 & 0 & 1 & $\begin{array}{l}\text { 4-point scale }(n=1), 5 \text {-point scale }(n=1) \text {, PATE } 2000 \\
(n=1) \text {, not clear }(n=21)\end{array}$ \\
\hline Pain & 31 & 0 & 0 & 0 & $\begin{array}{l}\text { Visual Analog Scale (VAS) }(\mathrm{n}=18) \text {, NRS }(\mathrm{n}=2) \text {, BPI } \\
(\mathrm{n}=2) \text {, PATE2000 }(\mathrm{n}=1) \text {, not clear }(\mathrm{n}=8)\end{array}$ \\
\hline $\begin{array}{l}\text { Bleeding/ blood } \\
\text { loss }\end{array}$ & 29 & 3 & 0 & 0 & $\begin{array}{l}\text { 4-point scale from 'not at all' to 'blood dripping } \\
\text { in toilet' }(n=1), 5 \text {-point scale ( } n=1) \text {, VAS }(n=1) \text {, } \\
\text { Haemorrhoid Symptom Score (HSS) }(n=1) \text {, } \\
\text { requiring a re-intervention }(n=3) \text {, not clear }(n=25)\end{array}$ \\
\hline Itching & 6 & 0 & 0 & 0 & Not clear $(n=6)$ \\
\hline Pruritis & 4 & 0 & 0 & 0 & Not clear $(n=4)$ \\
\hline Soiling & 8 & 0 & 0 & 0 & Not clear $(\mathrm{n}=8)$ \\
\hline Discomfort & 8 & 0 & 0 & 0 & Not clear $(\mathrm{n}=8)$ \\
\hline Urgency & 3 & 0 & 0 & 0 & Not clear $(\mathrm{n}=3)$ \\
\hline $\begin{array}{l}\text { (Mucous) } \\
\text { discharge }\end{array}$ & 3 & 0 & 0 & 0 & Not clear $(\mathrm{n}=3)$ \\
\hline
\end{tabular}


Measurement type used (N)

\begin{tabular}{|c|c|c|c|c|c|}
\hline Outcomes & 氖苞 & 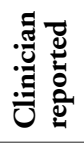 & 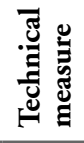 & $\begin{array}{l}\frac{\mathscr{J}}{0} \\
\stackrel{0}{0}\end{array}$ & Measurement tools used \\
\hline Tenesmus & 1 & 0 & 0 & 0 & Not clear $(\mathrm{n}=1)$ \\
\hline Burning & 1 & 0 & 0 & 0 & Not clear $(\mathrm{n}=1)$ \\
\hline Mass swelling & 1 & 0 & 0 & 1 & Not clear $(\mathrm{n}=1)$ \\
\hline Constipation & 1 & 0 & 0 & 0 & Not clear $(\mathrm{n}=1)$ \\
\hline $\begin{array}{l}\text { Hygiene } \\
\text { problems }\end{array}$ & 1 & 0 & 0 & 0 & Not clear $(\mathrm{n}=1)$ \\
\hline $\begin{array}{l}\text { Quality of } \\
\text { defecation }\end{array}$ & 1 & 0 & 0 & 0 & Bristol stool scale $(\mathrm{n}=1)$ \\
\hline $\begin{array}{l}\text { Passage of gas } \\
\text { and feces }\end{array}$ & 1 & 0 & 0 & 0 & Not clear $(\mathrm{n}=1)$ \\
\hline $\begin{array}{l}\text { Flatus } \\
\text { incontinence }\end{array}$ & 1 & 0 & 0 & & Not clear $(\mathrm{n}=1)$ \\
\hline Wound healing & 1 & 1 & 0 & 1 & $\begin{array}{l}\text { Time in weeks needed for complete epithelization } \\
(\mathrm{n}=1) \text {, not clear }(\mathrm{n}=2)\end{array}$ \\
\hline Irritation & 1 & 0 & 0 & 0 & Not clear $(\mathrm{n}=1)$ \\
\hline Anal function & 0 & 0 & 0 & 1 & Not clear $(\mathrm{n}=1)$ \\
\hline $\begin{array}{l}\text { Anatomical } \\
\text { difference }\end{array}$ & 0 & 0 & 1 & 0 & Not clear $(\mathrm{n}=1)$ \\
\hline Anal tone & 0 & 0 & 1 & 0 & Sphincter tone $(\mathrm{n}=1)$ \\
\hline $\begin{array}{l}\text { Fecal } \\
\text { incontinence }\end{array}$ & 19 & 0 & 0 & 0 & $\begin{array}{l}\text { 5-point scale }(\mathrm{n}=1) \text {, Cleveland incontinence score } \\
(\mathrm{n}=2) \text {, Fecal Incontinence Quality-of-Life }(\mathrm{n}=2) \text {, } \\
\text { Vaizey }(\mathrm{n}=2) \text {, Wexner incontinence score }(\mathrm{n}=2) \text {, not } \\
\text { clear }(\mathrm{n}=11)\end{array}$ \\
\hline $\begin{array}{l}\text { Outlet } \\
\text { obstruction }\end{array}$ & 0 & 0 & 0 & 1 & Not clear $(n=1)$ \\
\hline External pil & 0 & 0 & 0 & 0 & Not clear $(\mathrm{n}=1)$ \\
\hline Gangrene & 0 & 0 & 0 & 1 & Not clear $(\mathrm{n}=1)$ \\
\hline Edema & 0 & 2 & 0 & 0 & Not clear $(\mathrm{n}=2)$ \\
\hline Sepsis & 0 & 1 & 0 & 0 & Not clear $(n=2)$ \\
\hline Local infection & 0 & 1 & 0 & 0 & Not clear $(\mathrm{n}=1)$ \\
\hline Hemorrhage & 0 & 1 & 0 & 0 & Not clear $(\mathrm{n}=1)$ \\
\hline Hematomas & 0 & 1 & 0 & 0 & Not clear $(\mathrm{n}=1)$ \\
\hline Thrombosis & 0 & 5 & 0 & 0 & Not clear $(\mathrm{n}=5)$ \\
\hline Anal fissure & 0 & 1 & 0 & 0 & Not clear $(\mathrm{n}=1)$ \\
\hline Abscess & 0 & 2 & 0 & 0 & Not clear $(n=2)$ \\
\hline
\end{tabular}


Measurement type used (N)

\begin{tabular}{|c|c|c|c|c|c|}
\hline Outcomes & 总 & 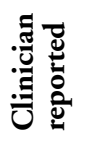 & 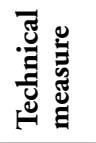 & $\begin{array}{l}\frac{\tilde{J}}{0} \\
\dot{0} \\
z\end{array}$ & Measurement tools used \\
\hline Urinary retention & 0 & 9 & 0 & 0 & Not clear $(n=9)$ \\
\hline Anal stricture & 0 & 3 & 0 & 0 & Not clear $(\mathrm{n}=3)$ \\
\hline $\begin{array}{l}\text { Unhealed } \\
\text { wounds }\end{array}$ & 0 & 0 & 0 & 5 & Not clear $(n=5)$ \\
\hline Anal stenosis & 0 & 4 & 0 & 0 & Not clear $(n=4)$ \\
\hline $\begin{array}{l}\text { Recurrent } \\
\text { prolapse }\end{array}$ & 1 & 6 & 0 & 0 & $\begin{array}{l}\text { Anoscopic or proctoscopic examination }(n=1) \text {, not } \\
\text { clear }(n=6)\end{array}$ \\
\hline $\begin{array}{l}\text { Recurrent } \\
\text { haemorrhoidal } \\
\text { symptoms }\end{array}$ & 8 & 1 & 0 & 4 & Questionnaire nd $(n=9)$, not clear $(n=4)$ \\
\hline
\end{tabular}

Resource use/ economical impact

\begin{tabular}{lllllll}
$\begin{array}{l}\text { Time taken in } \\
\text { the procedure }\end{array}$ & 0 & 0 & 2 & 0 & $\begin{array}{l}\text { From incision to application of dressings }(\mathrm{n}=1) \text {, time } \\
\text { between the incision and suturing the skin }(\mathrm{n}=1)\end{array}$ \\
$\begin{array}{l}\text { Duration of } \\
\text { surgery }\end{array}$ & 0 & 0 & 2 & 0 & Not specified $(\mathrm{n}=2)$ \\
$\begin{array}{l}\text { Operative time } \\
\begin{array}{l}\text { Hospital stay } \\
\text { Duration }\end{array}\end{array}$ & 0 & 0 & 0 & 10 & 0 & Not specified $(\mathrm{n}=10)$ \\
$\begin{array}{l}\text { or length of } \\
\text { hospitalization }\end{array}$ & 0 & 0 & 3 & 0 & Not specified $(\mathrm{n}=11)$ \\
$\begin{array}{l}\text { Cost of } \\
\text { treatment }\end{array}$ & 0 & 0 & 4 & 0 & Not specified $(\mathrm{n}=4)$ \\
$\begin{array}{l}\text { Requirement of } \\
\text { repeat procedure }\end{array}$ & 0 & 8 & 0 & 0 & Not specified $(\mathrm{n}=8)$ \\
$\begin{array}{l}\text { Surgical } \\
\text { reintervention }\end{array}$ & 0 & 6 & 0 & 0 & Not specified $(\mathrm{n}=6)$ \\
\hline
\end{tabular}




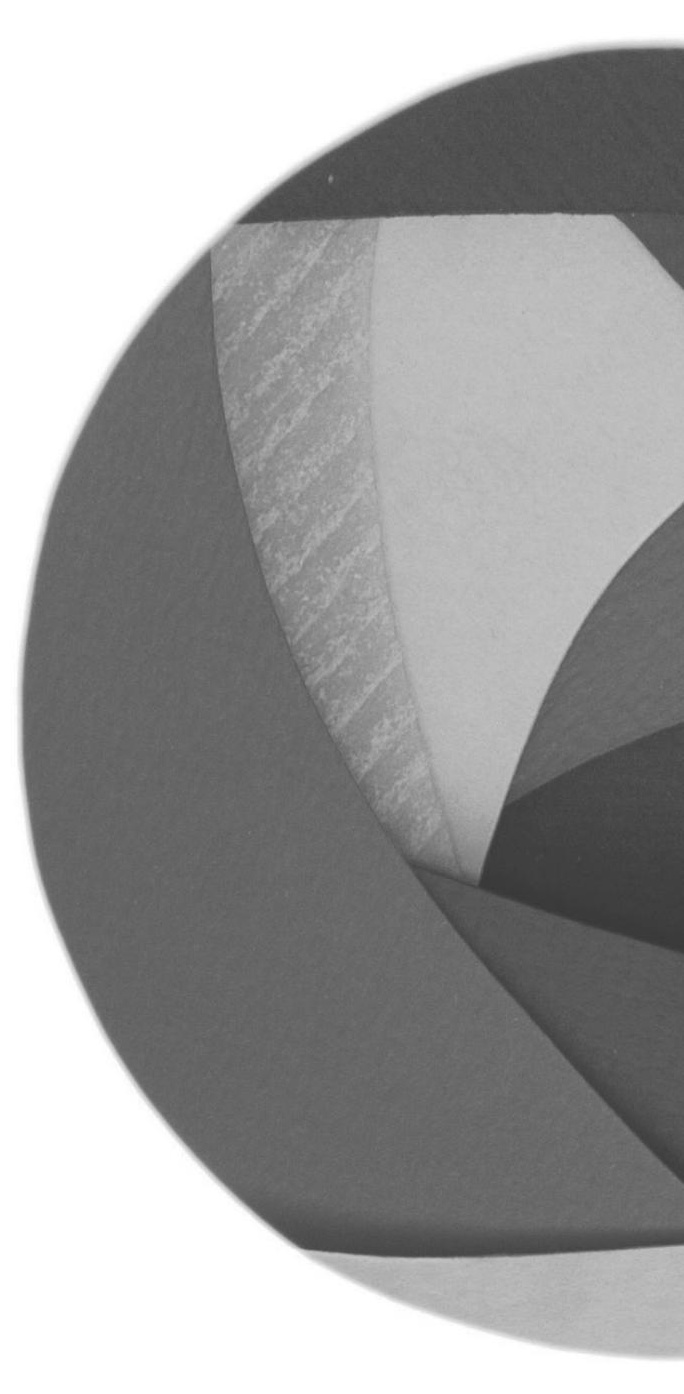




\section{4}

\section{EUROPEAN SOCIETY OF COLOPROCTOLOGY (ESCP) CORE OUTCOME SET (COS) FOR HAEMORRHOIDAL DISEASE: AN INTERNATIONAL DELPHI STUDY AMONG HEALTHCARE PROFESSIONALS}

R.R. van Tol, ML Kimman, J. Melenhorst, L.P.S. Stassen, C.D. Dirksen, S.O. Breukink

*Members of the steering group are co-authors of this study and can be found under the heading Collaborators 


\section{Abstract}

Aim There is considerable heterogeneity in Outcomes in studies reporting on treatment of haemorrhoidal disease (HD). The aim of this study was to develop a Core Outcome Set (COS) for HD in cooperation with the European Society of ColoProctology (ESCP). Method A Delphi study was performed according to the OMERACT methodology. In total 38 healthcare professionals (56\%) and 30 patients (44\%) were invited in the panel. Previously, 10 outcome Domains and 59 Outcomes were identified through a systematic literature review. In this study these Domains and Outcomes were operationalized into a questionnaire for healthcare professionals and a separate questionnaire for patients. Sequential questionnaire rounds prioritizing the Domains and Outcomes were conducted. Panel members were asked to rate the appropriateness of each Domain and Outcome on a 9-point Likert scale. During a face-to-face meeting, healthcare professionals agreed on the primary and secondary endpoints of the COS for HD. Finally, a short survey was sent to the healthcare professionals in order to reach consensus on 'how' the chosen endpoints should be assessed and at which time points.

Results The response rate in questionnaire round 1 for healthcare professionals was $44.7 \%(n=17)$. Sixteen out of seventeen healthcare professionals also completed the questionnaire in round 2. The response rate for the patient questionnaire was $60 \%$ $(\mathrm{n}=18)$. Seventeen healthcare professionals participated in the face-to-face meeting. The questionnaire rounds did not result in a clear-cut selection of the primary and secondary endpoints. Most Domains and Outcomes were considered important and only three Outcomes were excluded. During the face-to-face meeting, agreement was reached to select the Domain 'symptoms' as primary endpoint, and 'complications', 'recurrence' and 'patient satisfaction' as secondary endpoints in the COS for HD. Furthermore, consensus was reached that the Domain 'symptoms' should be a Patient Reported Outcome Measure and include the Outcomes 'pain' and 'prolapse', 'itching', 'soiling' and 'blood loss'. The Domain 'complications' should include the Outcomes 'incontinence', 'abscess', 'urinary retention', 'anal stenosis' and 'fistula'. Consensus was reached to use "reappearance of initial symptoms" as reported by the patient to define recurrence.

During an additional short survey consensus was reached that 'incontinence' should be assessed by the Wexner Fecal Incontinence Score, 'abscess' by physical examination, 'urinary retention' by ultrasonography, 'anal stenosis' by physical examination, and 'fistula' by MR-imaging after inconclusive physical examination. During follow-up, the Outcome 'symptoms' should be assessed at baseline, 7 days, 6 weeks and one year postprocedure. The Outcomes 'abscess' and 'urinary retention' should be assessed 7 days post-procedure and 'incontinence', 'anal stenosis' and 'fistula' one year post-procedure. Conclusions We developed the first European Society of ColoProctology (ESCP) 
COS for HD based on an international Delphi study among healthcare professionals. The next step is to incorporate the patients' perspective in the COS. Use of this COS can improve the quality and uniformity of future research and enhance evidence synthesis. 


\section{Introduction}

Haemorrhoidal disease (HD) is common with a prevalence around 5\% [1-4]. HD is usually classified according to the grading system of Goligher et al. [5-7] and therapeutic options are generally based on the HD grade. Numerous techniques are described, ranging from simple treatment including topical and medical therapies to outpatient treatments and surgical interventions.

There are several national guidelines for HD including treatment algorithms [8-10]. Nevertheless, there remains debate regarding the best treatment option for each grade of HD. Clinical trials investigating the effectiveness of interventions for HD have used a wide variety of Outcomes and outcome measures. Consequently, evidence analysis within the systematic reviews is hampered and high-quality guidelines are lacking [1113].

A solution to improve homogeneity in outcome reporting on HD is to develop and use a Core Outcome Set (COS). An agreed COS will enhance the ability to compare future studies in order to produce optimal treatment guidelines. A COS represents a consensus derived minimum set of outcome parameters that should be reported in all studies that report on a particular condition [14]. Until now, there is no established COS for HD. Therefore, the aim of this study was to develop a COS for HD in cooperation with the European Society of Coloproctology (ESCP). This COS covers all types of treatment including simple treatment (e.g. fibre intake), outpatient treatment (i.e. rubber band ligation, sclerotherapy, infrared coagulation) and surgical procedures (i.e. Doppler-guided haemorrhoidal artery ligation, stapled haemorrhoidopexy and haemorrhoidectomy).

The aim of this Delphi process was to develop an international COS for HD which will recommend which minimal endpoints should be assessed in future trials to assess the effectiveness of all surgical (operative and outpatient based) and nonsurgical interventions. 


\section{Methods}

This study is registered on the COMETdatabase (http://www.comet-initiative. org/studies/searchre sults) and a detailed study protocol defining objectives, the Delphi process and criteria for participant selection has been published previously [15].

Since the Outcome Measures in Rheumatology (OMERACT) Filer 2.0 resulted in successful development and implementation of COSs for many other diseases, we used their methodology [16-22]. The OMERACT Filter is a conceptual framework which encompasses the entire content of what is measureable in a study. Following this initiative, the first phase in developing the COS was a literature review [23]. Fiftynine Outcomes for HD treatment were categorized into 10 Domains according to the OMERACT Filter 2.0 [24]. For example, the Outcomes pain, blood loss and soiling were included in the Domain 'symptoms'.

The next step was the Delphi process to reach a consensus on the primary and secondary endpoints. The Delphi process involved four phases and consisted of a panel including healthcare professionals and patients. Healthcare professionals were involved in three phases and patients in one phase of the COS development. In phase 1, the Outcomes, which were identified in the literature review [23], were formed into a questionnaire for healthcare professionals with a separate questionnaire for patients. Phase 2 involved two sequential rounds of the questionnaire for healthcare professionals and one round for patients, aiming at prioritizing these Outcomes [25]. Phase 3 consisted of a face-to-face consensus meeting with healthcare professionals to agree on the final endpoints of the COS. In phase 4 a short survey was sent to the healthcare professionals in order to reach consensus on how the selected endpoints should be assessed and at which time points pre- and post procedure.

Ethics clearance for this study was obtained from the hospital's ethical review board (METC 16-4-078). All participants in the Delphi study were asked to provide informed consent to have their responses included in further analysis and dissemination of the results and were informed about confidentiality of the data. 


\section{Phase I: Questionnaire development}

\section{Healthcare professionals}

In the literature review, 59 Outcomes were categorized into 10 Domains according to the OMERACT Filter 2.0. The most frequently reported Domains and Outcomes were created into a web-based questionnaire. Twenty-three Outcomes were used. The other 36 Outcomes were reported only once or twice in the systematic reviews and were discarded. The four most commonly reported Domains were 'symptoms', 'complications', 'recurrence' and 'patient satisfaction'. The most commonly reported Outcomes were 'pain', 'prolapse', 'blood loss', 'itching, 'soiling', 'urgency', 'constipation', 'abscess', 'incontinence', 'anal stenosis', 'stricture', 'urinary retention', 'thrombosis' and 'oedema'. In the literature, the Outcomes 'prolapse' and 'pain' were often used as primary endpoints in studies. Therefore, 'prolapse' and 'pain' were also included as Domains. In addition, the Outcomes 'fistula', 'nodule' and 'severe pain' and 'bleeding' were added to the Domain complications based on clinical expert experience.

No agreed definition exists in the literature regarding 'recurrence' for HD. Therefore, we asked healthcare professionals to select one of the following options as the definition which best reflects 'recurrence': 'reappearance of prolapse after symptom-free period', 'reappearance of initial symptoms', 'further intervention necessary', 'residual symptoms in relation to degree of satisfaction' or 'histological proven recurrence'.

The questionnaire included an option to add missing Outcomes, because it was possible that an outcome important to patients or healthcare professionals was not reported in the literature or was previously excluded due to infrequent reporting.

The questionnaire for healthcare professionals was divided into two parts (Appendix S1). The first part consisted of the question 'What Domains should be included as the primary endpoint and what Domains as secondary endpoints in the COS for HD?' In the second part, healthcare professionals were asked: 'Which Outcomes should be included in these Domains?' For example, for the Domain 'complications' the following Outcomes could be selected: 'incontinence', 'urinary retention', 'stricture', 'abscess' etc.

\section{Patients}

A questionnaire was developed specifically for patients, focusing on their symptoms because some questions in the questionnaire for healthcare professionals were not relevant to patients. Patients were asked to rate the following items on a Likert-type scale: (1) suffering from symptoms (e.g. blood loss, pain, prolapse, soiling and itching), (2) distress of these symptoms in daily life, (3) treatment success (i.e. having no blood loss, no pain, no prolapse, no itching or no soiling), (4) symptom relief after treatment, (5) items to discuss during the outpatient visit (i.e. symptoms, patient satisfaction, complications, prolapse and pain) and 6) a definition of recurrence. 
The questionnaires were piloted with both healthcare professionals $(n=2)$ and patients $(\mathrm{n}=2)$ to check understanding and acceptability. Healthcare professionals and patients were told the questionnaires were different. Healthcare professionals reviewed the patient questionnaire but not vice versa. Minor changes were made to improve the clarity and understanding of both questionnaires.

\section{Phase 2: Questionnaire rounds}

\section{Participants}

Initially we contacted the international representatives $(n=43)$ of the ESCP. However, most representatives did not treat HD. On their recommendation (i.e. Snowball method) only healthcare professionals with an in depth understanding, who have multiple cited publications in the field of proctology and/or who are familiar with the development of a COS were invited. This resulted in a smaller sample than defined in the protocol. Dutch-speaking male and female participants (aged $>18$ years) diagnosed with HD (by their general practitioner) who visited the outpatient clinic of an academic hospital (Maastricht University Medical Centre) for treatment were invited by their treating colorectal consultant (SB or JM) to participate. To ensure a variety of patients, those treated with rubberband ligation and surgical treatment were included. The colorectal consultant (SB) informed eligible patients about the study and gave them a patient information sheet. If the patient agreed, one of two researchers (RT or SK) contacted the patient explaining the purpose of the study and the procedures in depth. If the patient was willing to participate, written consent was obtained. They were not informed of the identities of other panel members. Insufficient language proficiency was an exclusion criterion.

The aim was to include as many panel members and patients as possible $[18,20]$, since this increases the reliability of the group judgement [24,26]. All 43 representatives of the ESCP and a total of 30 patients were approached.

\section{Questionnaires}

Healthcare professionals and patients were invited by email to complete the web-based questionnaire using the online software Survey Monkey (SurveyMonkey, Palo Alto, California, USA). Healthcare professionals were invited to complete two Delphi rounds. Patients received only one questionnaire parallel to the first round of the healthcare professionals.

The survey was kept online for 5 weeks and reminder emails were sent 2 and 4 weeks after the initial invitation. The first questionnaire round ran from 13 June to 27 July 2016. Healthcare professionals who completed the first questionnaire were invited to the subsequent round, unless they decided to opt out. The second questionnaire 
round for healthcare professionals ran from 25 August to 8 September 2016. Healthcare professionals were not informed of the identities of other panel members.

Both healthcare professionals and patients were asked to rate the questionnaire items on a nine-point Likert scale. All items rated as 'appropriate' and/or 'unsure' (median score $\geq 4$ ) were carried forward to the second round including additional items suggested by the participants. Items rated as 'inappropriate' (i.e. medium score $\leq 4$ ) were omitted. In the second round, healthcare professionals were also shown their first scores and the distribution of the scores for these Outcomes per participant. Participants were invited to re-score the Domains and Outcomes. All Domains and Outcomes that had a median score of $\geq 4$ were carried forward to the face-to-face meeting including additional items suggested by the participants. There were no agreed methods to remove criteria and therefore the criteria were chosen according to other consensus studies [27,28].

\section{Phase 3: Face-to-face meeting}

The third phase involved a face-to-face meeting during the 11th annual meeting of the ESCP in September 2016 with the aim of agreeing on a final COS. Healthcare professionals who had completed at least one questionnaire round were invited to attend this meeting. Two independent facilitators (SB, RT), who did not participate in the questionnaire rounds, were informed of the results and chaired the meeting.

First, the results of the patient questionnaire, presented in a Powerpoint presentation, were discussed extensively. Then the retained items (i.e. Domains and Outcomes) of the second questionnaire from the healthcare professionals were presented. There was opportunity for an open discussion regarding the remaining items and dissenting views were actively sought. Thereafter, healthcare professionals were asked to vote on both primary and secondary endpoints as 'yes' or 'no' for inclusion in the final COS. A Domain or Outcome was included in the COS when $\geq 70 \%$ of healthcare professionals voted 'yes' in this final vote [29]. After all Domains and Outcomes had been voted on, and the total COS had been reviewed, the healthcare professionals were given another opportunity to comment on included items. After being sent a summary of the meeting by email, healthcare professionals believed the COS was comprehensive. They were asked if they had additional comments.

\section{Phase 4: short survey}

After reaching consensus on the endpoints during the face-to-face meeting we discussed how we should measure these endpoints. We first checked which instruments were most commonly reported in the literature. This showed that for some Outcomes several instruments were used, e.g. the St Marks or Wexner Fecal Incontinence Scale for the outcome 'incontinence'. However, for most Outcomes 
there was a gold standard, e.g. MR-imaging for fistula [30,31]. Based on a literature review, we were able to make a short list of the selected Outcomes for the COS and the evidence-based instruments currently used to assess these Outcomes. This list was sent to the healthcare professionals and they were asked to vote 'yes' or 'no' for the proposed instrument. We also asked the group to fill in at what time points the Outcomes should be assessed.

\section{Results}

The response rate in the first round for healthcare professionals was 44.7\% $(n=17)$. Sixteen out of 17 healthcare professionals also completed the second questionnaire (Fig. 1). The group consisted of colorectal residents with an indepth understanding of Outcomes relevant for the treatment of $\mathrm{HD}$ and experience with the development of a COS. The following countries were represented: Germany $(n=4)$, Denmark $(n=3)$, England $(\mathrm{n}=2)$, Italy $(\mathrm{n}=3)$, The Netherlands $(\mathrm{n}=2)$, Greece, $(\mathrm{n}=3)$ Israel $(\mathrm{n}=1)$ and Austria $(n=3)$.

Figure I: Delphi process.

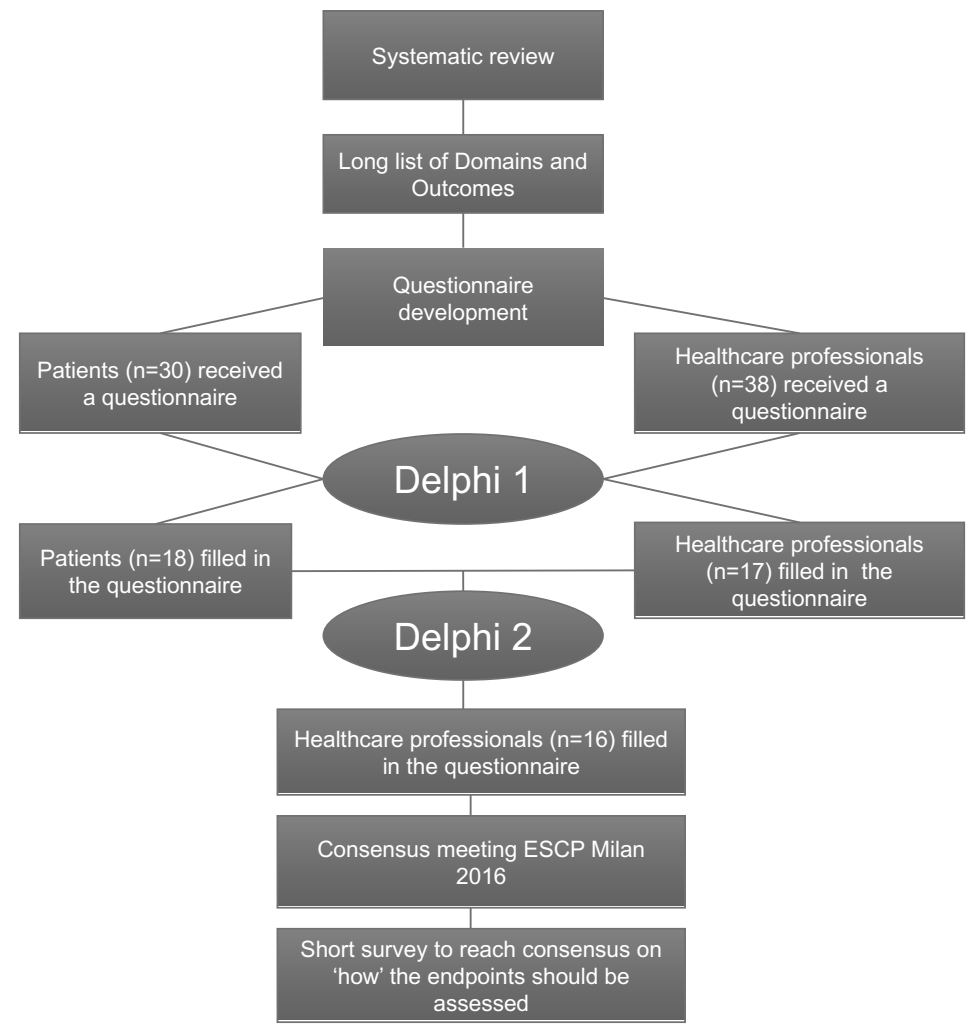




\section{First questionnaire}

In the first part of the questionnaire regarding the question 'What Domains should we use as primary and secondary endpoints in the COS for HD', the Domains (in order of level of appropriateness) 'symptoms', 'patient satisfaction', 'recurrence', 'complications', 'prolapse' and 'pain' were rated appropriate as primary endpoint options. As secondary endpoints, the Domains 'patient satisfaction', 'complications' and 'recurrence' were rated as appropriate and 'symptoms', 'prolapse' and 'pain' were rated as unsure.

In the second part of the questionnaire, regarding the question 'Which Outcomes should be included in the Domains', most Outcomes (i.e. 'pain', 'prolapse', 'itching', 'soiling', 'blood loss', 'abscess', 'incontinence', 'anal stenosis', 'stricture', 'fistula', 'severe bleeding', 'severe pain', 'urinary retention', 'thrombosis') were rated as appropriate. The Outcomes 'urgency' and 'constipation' were rated as unsure. The Outcomes 'oedema' and 'nodule' were rated as inappropriate and were omitted.

The following definitions of recurrence were rated as appropriate: 'recurrent prolapse after a symptom-free period', 'reappearance of initial symptoms' and 'further intervention necessary'. The definition 'residual symptoms in relation to degree of satisfaction' was rated as unsure. 'Histological proven recurrence' was rated as inappropriate.

\section{Second questionnaire}

In the second questionnaire healthcare professionals rated (in order of level of appropriateness) 'symptoms', 'patient satisfaction', 'recurrence' and 'complications' as appropriate primary endpoint options and 'prolapse' and 'pain' as unsure. As secondary endpoint options, 'patient satisfaction', 'recurrence', 'prolapse', 'complications', 'symptoms' and 'pain' were all rated as appropriate.

Regarding the question 'Which Outcomes should be included in the Domains', 'constipation', 'urgency', 'urinary retention' and 'thrombosis' were rated as unsure. 'Pain', 'prolapse', 'itching', 'soiling', 'blood loss', 'abscess', 'incontinence', 'anal stenosis', 'fistula', 'stricture', 'severe pain' and 'severe bleeding' were rated as appropriate Outcomes (Appendix S2).

To define recurrence the following options were rated as appropriate: 'further intervention necessary', 'recurrent prolapse after symptom-free period', 'reap- pearance of initial symptoms' and 'residual symptoms in relation to degree of satisfaction'.

In conclusion, based on the two questionnaire rounds, no obvious selection emerged regarding the primary and secondary Outcomes. Some Domains which were rated as appropriate in the first questionnaire were rated as unsure in the second questionnaire, and vice versa. Only two Outcomes and one definition of recurrence were excluded based on the questionnaire rounds. 


\section{Patient questionnaire}

The response rate for patients was $60 \%(n=18)$ with a mean age of $55(35-77)$ of whom seven were females. Regarding prior treatment, $70 \%$ of the patients had received rubber band ligation and the remaining $30 \%$ a mucopexy.

In response to the first question, 'How much do you suffer from the following symptoms on a scale from 0 (not at all) to 9 (a lot)', they rated as medium 'a lump near your anus (prolapse)', 'pain' and 'blood loss' (score between 4 and 7) and as less or not at all 'itching' and 'soiling' (mean score < 2) (Fig. 2). In response to the second question, 'How much do these symptoms bother you in daily life from 0 (no bother at all) to 9 (very bothersome)', 'a lump near your anus' was rated as moderately bothersome (mean score 5.5) and 'pain', 'blood loss', 'itching' and 'soiling' as little or no bother in daily life (mean score < 3) (Fig. 3). In response to the third question, 'When is treatment successful from 0 (not successful at all) to 9 (very successful)', they rated 'no blood loss', 'no pain' and 'no lump' as a successful outcome (mean score between 7 and 9) and 'no itching' and 'no soiling' as reasonably successful (mean score < 7) (Fig. 4). In response to the fourth question, 'What should have been treated by a surgical intervention on a scale from 0 (not important) to 9 (very important)', patients rated 'blood loss' and 'a lump near your anus' as very important (mean score $>8$ ), 'pain' and 'itching' as unsure and 'soiling' less important $($ mean $<6)$. In response to the fifth question, 'What is important to be discussed by your clinician during the outpatient visit -0 (not important) and 9 (very impor- tant)', patients rated 'symptoms', 'patient satisfaction', 'complications', 'a lump near your anus' and 'pain' as important (mean $>7)$. In response to the final question, 'How would you describe the term recurrence', 'reappearance of initial symptoms' was rated as the most appropriate definition (mean of 7) and 'reappearance of prolapse after a symptom-free period' and 're-intervention necessary' as moderately appropriate (mean of 5) (Appendix S3). 
Chapter 4

Figure 2: Results patient questionnaire.

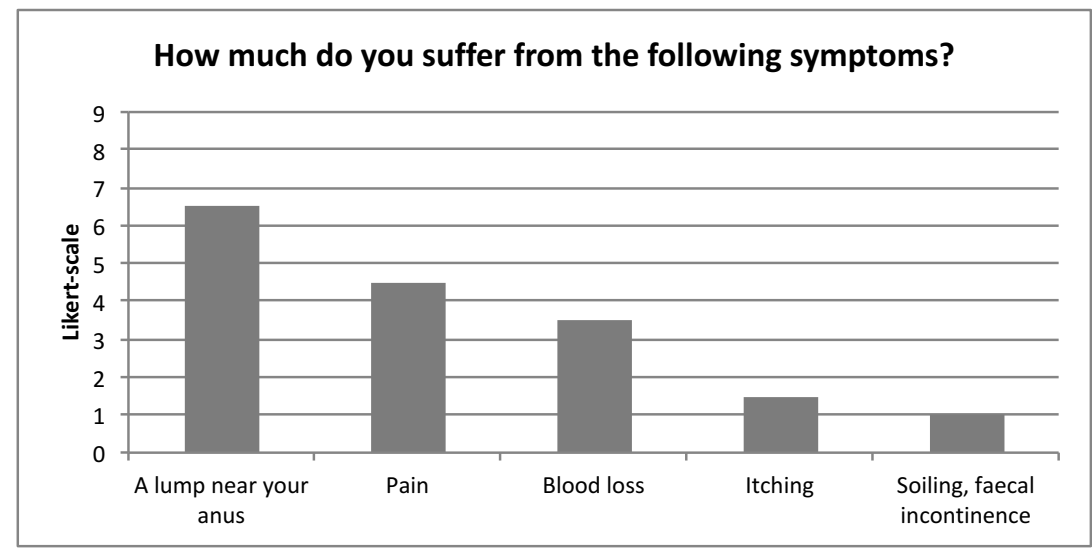

Figure 3: Results patient questionnaire.

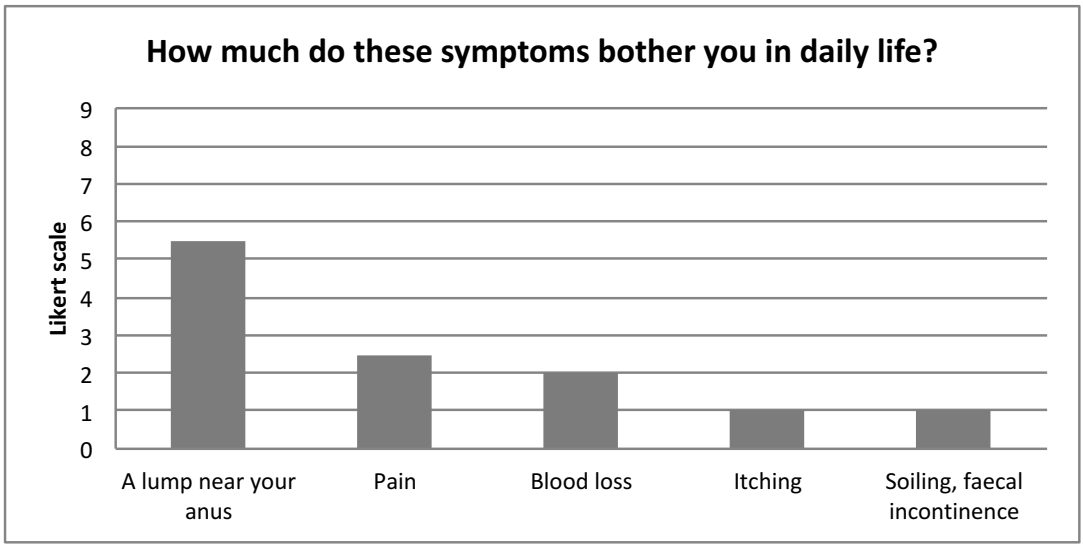

Figure 4: Results patient questionnaire.

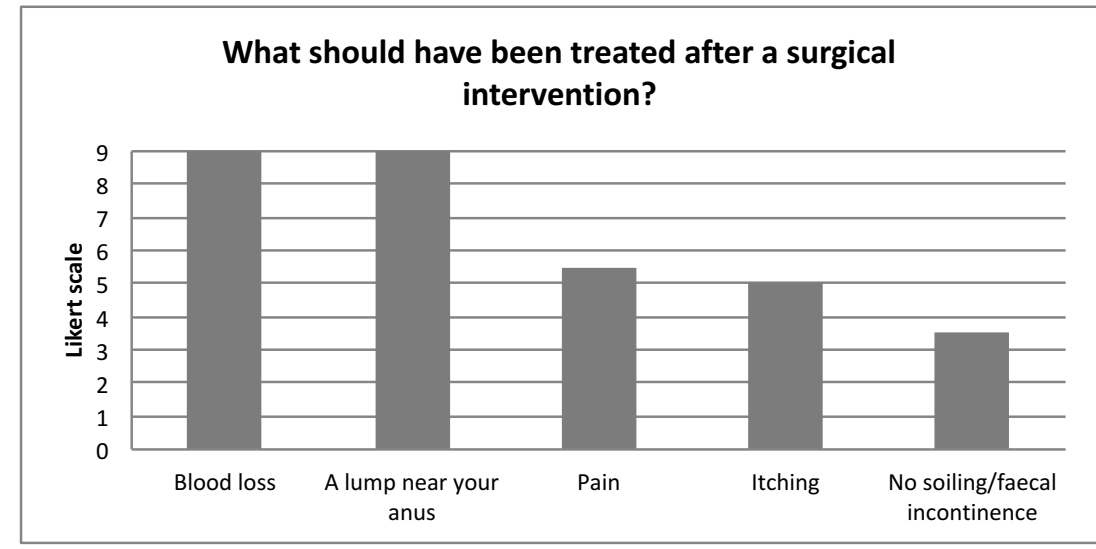




\section{Face-to-face meeting}

Seventeen healthcare professionals attended the meeting, of whom 16 had responded to both questionnaires. The patient questionnaires were discussed extensively. The following complaints were reported: 'pain', 'prolapse', 'itching', 'soiling' and 'blood loss'. These symptoms were the most important to be discussed during the outpatient clinic. With these results healthcare professionals rated the Domain 'symptoms' as the most appropriate primary endpoint in the COS. Further, healthcare professionals reached consensus that the Domains 'complications', 'recurrence' and 'patient satisfaction' should all be used as secondary endpoints in the COS for HD (Table 1).

Healthcare professionals agreed that the Domain 'symptoms' should be a patient reported outcome measure (PROM) and should include the Outcomes 'pain', 'prolapse', 'itching', 'soiling' and 'blood loss'.

The Domain 'complications' should include the Outcomes 'incontinence', 'abscess', 'urinary retention', 'anal stenosis' and 'fistula'.

During the face-to-face meeting the definition of recurrence was discussed extensively. Consensus was reached to use 'reappearance of initial symptoms' as reported by the patient to define recurrence.

\section{Short survey}

In total 15 healthcare professionals completed the short survey. Consensus was reached that 'incontinence' should be assessed by the Wexner Fecal Incontinence Score [32], 'abscess' by physical examination, 'urinary retention' by ultrasonography, 'anal stenosis' by physical examination and 'fistula' by MR-imaging after inconclusive physical examination. During follow-up, the outcome 'symptoms' should be assessed at baseline (i.e. before the procedure) and 7 days, 6 weeks (possibly by telephone) and at 1 year post-procedure. The Outcomes 'abscess' and 'urinary retention' should be assessed 7 days post-procedure, and 'rectal stenosis', 'incontinence' and 'fistula' at 1 year postprocedure (Table 2). 


\section{Chapter 4}

Table I: Summary of the core Domains for haemorrhoidal disease

\begin{tabular}{ll}
\hline Core Outcome Set & \\
\hline PRIMARY OUTCOME & Patient Reported Outcome Measure (PROM) \\
$\begin{array}{l}\text { Patient reported symptoms } \\
\text { Blood loss }\end{array}$ & \\
Pain & \\
Prolapse & \\
Itching & \\
Soiling & \\
SECONDARY OUTCOME & \\
Complications & Wexner Fecal Incontinence Score \\
Incontinence & Physical examination \\
Abscess & MR imaging after inconclusive physical \\
Fistula & examination \\
& Ultrasonography \\
Urinary retention & Physical examination \\
Anal stenosis & The reappearance of initial symptoms \\
Recurrence & This endpoint will be included in the PROM. \\
\hline Patient satisfaction & \\
\hline
\end{tabular}

Table 2: Follow-up scheme.

\begin{tabular}{llcccc}
\hline & Outcomes & Baseline & 7 days & 6 weeks & 1 year \\
\hline Primary endpoint & Symptoms (PROM) & $\mathrm{X}$ & $\mathrm{X}$ & $\mathrm{X}$ & $\mathrm{X}$ \\
Secondary endpoints & Abscess & & $\mathrm{X}$ & & \\
& Urinary retention & & $\mathrm{X}$ & & \\
& Anal stenosis & & & $\mathrm{X}$ \\
& Incontinence & & & $\mathrm{X}$ \\
& Fistula & & & $\mathrm{X}$ \\
\hline
\end{tabular}


European Society of Coloproctology Core Outcome Set for haemorrhoidal disease: an international Delphi study among healthcare professionals

\section{Discussion}

This consensus study presents the first ESCP COS for HD based on a systematic review of the literature and an international Delphi study among healthcare professionals. As the primary endpoint, the Domain 'symptoms' was selected. The three Domains 'complications', 'recurrence' and 'patient satisfaction' were chosen as secondary endpoints. Eventually healthcare professionals agreed that the Domain 'symptoms' should be a PROM and should include the Outcomes 'pain' and 'prolapse', 'blood loss', 'itching' and 'soiling'. The Domain 'complications' should include the Outcomes 'incontinence', 'abscess', 'urinary retention', 'anal stenosis' and 'fistula'. Consensus was also reached on how the primary and secondary Outcomes should be measured and at which time points pre- and post procedure. Further, consensus was reached to define 'recurrence' as 'reappearance of initial symptoms'.

With the continuing evolution of different treatments for HD, the effectiveness of treatments needs to be analysed in a systematic way. Reviews of the published literature highlighted the lack of uniformity of outcome definition, measurement and reporting [11-13]. This resulted in wide variation in Outcomes between studies using the same techniques but which used different definitions for the same Outcomes and/or various Outcomes for the same treatment modalities. As a result, HD studies cannot inform directly an optimal treatment algorithm. This may hamper efficient use of healthcare resources [33]. The standardization of Outcomes and outcome measurement in HD studies is mandatory to support the development of effective patient care.

Besides uniformity in reporting, this Delphi study underlined the need to integrate PROMs with traditional clinical Outcomes. PROMs have become an increasingly important component of assessing treatment response [34]. Several HD-specific symptom scores and quality of life Outcomes are developed for use in clinical practice. Examples include the Symptom-based Severity Score [35] and the Haemorrhoid Severity Score [36]. These symptom scores offer a potential solution to simplify the various symptoms of haemorrhoids. However, the lack of fully validated instruments is a limitation to incorporating them in future HD studies. At the moment, we are developing a disease-specific PROM for haemorrhoids that will be based on the results of this Delphi study. We will also incorporate the results of a qualitative study with patients in this PROM. We recently conducted individual interviews with 15 patients to obtain a more in-depth understanding of patients' experiences with HD, impact on daily life and results of treatment.

We suggest that future studies evaluating interventions for HD should assess and report the primary and secondary endpoints of the COS reported here. Additional Outcomes may be included if appropriate for the specific intervention or setting. Furthermore, especially for research purposes, it is advisable that the primary outcome 'symptoms' is also measured at baseline, i.e. before the procedure. 
To our knowledge, our project is the first Delphi process to develop a COS for HD. We started with an in-depth literature review which identified 10 Domains, 59 Outcomes and several different instruments. Subsequently, as described in this paper, the minimum COS was compiled from the perspectives of 17 healthcare professionals and 18 patients with HD using a Delphi process. The extensive process following OMERACT and the broad consensus reached are the main strengths of this study.

However, several limitations remain present. First, although Delphi processes have been recommended as an ideal approach to identify which Outcomes to measure in clinical trials [26], they have also been criticized. One of the major critiques is assuring methodological rigour which is often cited as a weakness, because there are 10 different types of Delphi methods [37]. We chose to follow OMERACT Filter 2.0 since their guideline resulted in successful development and implementation of COSs for many other diseases.

A second limitation of this study was that patients were only partially involved in the development of this COS. Patients received a modified questionnaire, because some questions posed to the healthcare professional were deemed irrelevant for patients. The modified questionnaire focused on symptoms they experienced in daily life and how much they were bothered by them. As a result, patients were not asked specifically what Outcomes they consider most important in a research setting. For example, the question 'What Domains should be included as the primary endpoint and what Domains as secondary endpoints in the COS for HD?' was not posed to patients. However, patient input regarding the most important symptoms of $\mathrm{HD}$ resulted in the selection of the five symptoms that make up the primary outcome in the COS. Furthermore, while we conducted qualitative interviews to get more input from the patients' point of view to be able to develop a PROM, these interviews should have been performed prior to the Delphi study to ensure patient views were adequately represented in the Delphi surveys. Patients also did not participate in the face-to-face meeting. However, the results and comments on the patient questionnaire were presented to the healthcare professionals. These results were discussed extensively during the meeting. There was opportunity for open discussion and dissenting views regarding the patients' results were actively sought. A third limitation was that the questionnaires used in the Delphi rounds were not validated. It is therefore possible that some Outcomes may have been missed. Further, we made a selection of the Domains and Outcomes that were identified in the literature review, based on the frequency of reporting, because we felt that 59 Outcomes were too many to present to the panel in a Delphi survey. However, by doing so we may have overlooked Outcomes that may be important to patients. It would have been better to organize a consensus meeting to reduce the Outcomes to a manageable number for the Delphi questionnaire. 
Fourth, while we contacted all 43 representatives of the ESCP, most representatives did not treat HD regularly and could not therefore take part in the Delphi survey. This resulted in fewer healthcare professionals on the panel than was initially planned (and stated in the protocol) [38]. Finally, there may be a concern that 18 Dutch patients may not represent fully the views of HD patients across Europe. Unfortunately, our resources were limited and we were unable to conduct patient interviews in other countries. However, by testing the COS and validating the PROM (that has been developed based on patient views) in an international setting, we expect that, if present, diverging views will emerge and it will be possible to adapt them. It is important to emphasize that a COS is dynamic and can (and should) be reviewed regularly. Future work should ensure a more prominent role of the patient in COS development.

In conclusion, this study presents the first ESCP COS for HD based on an international Delphi study among healthcare professionals. This COS will be useful for future intervention trials in this condition, encouraging a more coordinated approach than currently exists to interventional research in the future and facilitating more meaningful analysis of research findings.

\section{Acknowledgements}

This work was undertaken with support of the European Society of Coloproctology. The project received no funding.

\section{Conflicts of interest}

No conflicts of interest. 


\section{Collaborators}

National representatives of the European Society of Coloproctology are collaborators in the study: 1) Andreas Salat, 2) Andreas Ommer, 3) Pasquale Giordano, 4) Lilli Lundby, 5) Paola de Nardi, 6) Raimund Strouhal, 7) Martina Lemmerer, 8) Konstantinos M. Stamou, 9) Georgius Pechli- vanidis, 10) Nikolaos Gouvas, 11) Evaghelos Xynos, 12) Alexander Herold, 13) Ingo Alldinger, 13) Faramarz Pakravan, 14) Corrado R. Asteria, 15) Dimitri Christoforidis, 16) Niels Qvist, 16) Gunnar Baatrup, 17) Nir Wasserberg.

1. Department of Surgery, Medical University of Vienna, Waehringer Guertal 1820, 1090 Vienna, Austria

2. End- und Dickdarm-Zentrum Essen, Rüttenschei- der Strasse 66, 45130 Essen, Germany

3. Barts Health NHS Trust, Whitechapel, Turner St, Whitechapel, London E1 $1 \mathrm{BB}, \mathrm{UK}$

4. Department of Surgery P, Aarhus University Hospital, Tage-Hansens Gade 2, 8000 Aarhus C, Denmark

5. Department of Surgery, San Raffaele Scientific Institute, Milan, Italy

6. General Surgery, Krankenhaus Oberndorf, Paracelsusstrasse 37, 5110 Oberndorf bei Salzburg, Austria

7. Department of General and Visceral Surgery, Medical University Clinic Graz, Auenbruggerplatz 29, A-8036 Graz, Austria

8. Department of Colorectal Surgery, Peritoneal Sur- face Malignancy Program, Bioclinic, Athens, Greece

9. General Surgery, Metropolitan Hospital of Pir- aeus, Ethnarchou Makariou 9, Pireas 185 47, Greece

10. Worcestershire Acute Hospitals NHS Trust, Charles Hastings Way, Worcester WR5 1DD, UK

11. Creta Inter-Clinic Hospital, Heraklion, Crete, Greece

12. End- und Dickdarm-Zentrum Mannheim, Bis- marckpl. 1, 68165 Mannheim, Germany

13. CPZ-Coloproktologisches Zentrum Düsseldorf, Schadowstraße 11B, 40212 Düsseldorf, Germany

14. Department of Surgery and Orthopaedics, ASST, Mantova, Str Lago Paiolo,10 I-46100 Mantova, Italy

15. Ospedale Regionale di Lugano, Via Tesserete 46, 6900 Lugano, Italy

16. University of Southern Denmark, Campusvej 55, 5230 Odense M, Danmark

17. Department of Surgery, Herzliya Medical Centre, 7 Ramat Yam St Herzliya, Israel 


\section{References}

1. Yang, J., et al., Meta-analysis of stapled hemorrhoidopexy vs LigaSure hemorrhoidectomy. World J Gastroenterol, 2013. 19(29): p. 4799-807.

2. Burkitt, D.P., Varicose veins, deep vein thrombosis, and haemorrhoids: epidemiology and suggested aetiology. Br Med J, 1972. 2(5813): p. 556-61.

3. Alonso-Coello, P., et al., Meta-analysis of flavonoids for the treatment of haemorrhoids. Br J Surg, 2006. 93(8): p. 909-20.

4. Gencosmanoglu, R., et al., Hemorrhoidectomy: open or closed technique? A prospective, randomized clinical trial. Dis Colon Rectum, 2002. 45(1): p. 70-5.

5. Banov, L., Jr., et al., Management of hemorrhoidal disease. J S C Med Assoc, 1985. 81(7): p. 398401.

6. Gaj, F., et al., The new classification of hemorrhoids: PATE 2000-Sorrento. History of the scientific debate. Minerva Chir, 2002. 57(3): p. 331-9.

7. Elbetti, C., et al., The single pile classification: a new tool for the classification of haemorrhoidal disease and the comparison of treatment results. Updates Surg, 2015. 67(4): p. 421-6.

8. Rivadeneira, D.E., et al., Practice parameters for the management of hemorrhoids (revised 2010). Dis Colon Rectum, 2011. 54(9): p. 1059-64.

9. Higuero, T., et al., Guidelines for the treatment of hemorrhoids (short report). J Visc Surg, 2016. 153(3): p. 213-8.

10. Altomare, D.F., et al., The treatment of hemorrhoids: guidelines of the Italian Society of Colorectal Surgery. Tech Coloproctol, 2006. 10(3): p. 181-6.

11. Shanmugam, V., et al., Systematic review of randomized trials comparing rubber band ligation with excisional haemorrhoidectomy. Br J Surg, 2005. 92(12): p. 1481-7.

12. Shao, W.J., et al., Systematic review and meta-analysis of randomized controlled trials comparing stapled haemorrhoidopexy with conventional haemorrhoidectomy. Br J Surg, 2008. 95(2): p. 147-60.

13. Simillis, C., et al., Systematic review and network meta-analysis comparing clinical Outcomes and effectiveness of surgical treatments for haemorrhoids. Br J Surg, 2015. 102(13): p. 1603-18.

14. Klokker, L., et al., Developing an OMERACT Core Outcome Set for Assessing Safety Components in Rheumatology Trials: The OMERACT Safety Working Group. J Rheumatol, 2017. 44(12): p. 19161919.

15. van Tol, R.R., et al., Protocol for the development of a Core Outcome Set (COS) for hemorrhoidal disease: an international Delphi study. Int J Colorectal Dis, 2017.

16. Hall, N.J., et al., Outcome reporting in randomised controlled trials and meta-analyses of appendicitis treatments in children: a systematic review. Trials, 2015. 16: p. 275.

17. Schmitt, J., et al., The Harmonising Outcome Measures for Eczema (HOME) statement to assess clinical signs of atopic eczema in trials. J Allergy Clin Immunol, 2014. 134(4): p. 800-7.

18. Mackie, S.L., et al., The OMERACT Core Domain Set for Outcome Measures for Clinical Trials in Polymyalgia Rheumatica. J Rheumatol, 2017. 


\section{Chapter 4}

19. Toupin-April, K., et al., Toward the Development of a Core Set of Outcome Domains to Assess Shared Decision-making Interventions in Rheumatology: Results from an OMERACT Delphi Survey and Consensus Meeting. J Rheumatol, 2017.

20. Hatemi, G., et al., Developing a Core Set of Outcome Measures for Behcet Disease: Report from OMERACT 2016. J Rheumatol, 2017.

21. Singh, J.A., M. Dowsey, and P.F. Choong, Patient Endorsement of the Outcome Measures in Rheumatology (OMERACT) Total Joint Replacement (TJR) clinical trial draft core Domain set. BMC Musculoskelet Disord, 2017. 18(1): p. 111.

22. Singh, J.A., et al., Achieving Consensus on Total Joint Replacement Trial Outcome Reporting Using the OMERACT Filter: Endorsement of the Final Core Domain Set for Total Hip and Total Knee Replacement Trials for Endstage Arthritis. J Rheumatol, 2017.

23. van Tol, R.R., et al., Towards a core outcome set for hemorrhoidal disease-a systematic review of Outcomes reported in literature. Int J Colorectal Dis, 2018.

24. Boers, M., et al., Developing core outcome measurement sets for clinical trials: OMERACT filter 2.0. J Clin Epidemiol, 2014. 67(7): p. 745-53.

25. Steurer, J., The Delphi method: an efficient procedure to generate knowledge. Skeletal Radiol, 2011. 40(8): p. 959-61.

26. Sinha, I.P., R.L. Smyth, and P.R. Williamson, Using the Delphi technique to determine which Outcomes to measure in clinical trials: recommendations for the future based on a systematic review of existing studies. PLoS Med, 2011. 8(1): p. e1000393.

27. McNair, A.G., et al., Core Outcomes for Colorectal Cancer Surgery: A Consensus Study. PLoS Med, 2016. 13(8): p. e1002071.

28. Potter, S., et al., Development of a core outcome set for research and audit studies in reconstructive breast surgery. Br J Surg, 2015. 102(11): p. 1360-71.

29. Moossdorff, M., et al., Maastricht Delphi consensus on event definitions for classification of recurrence in breast cancer research. J Natl Cancer Inst, 2014. 106(12).

30. Sudol-Szopinska, I., et al., Endosonography and magnetic resonance imaging in the diagnosis of high anal fistulae - a comparison. J Ultrason, 2014. 14(57): p. 142-51.

31. Lunniss, P.J., et al., Magnetic resonance imaging of anal fistulae. Lancet, 1992. 340(8816): p. 394-6.

32. Seong, M.K., et al., Comparative analysis of summary scoring systems in measuring fecal incontinence. J Korean Surg Soc, 2011. 81(5): p. 326-31.

33. in Guide to the Processes of Technology Appraisal. 2014: London.

34. Speight, J. and S.M. Barendse, FDA guidance on patient reported Outcomes. BMJ, 2010. 340: p. c2921.

35. Pucher, P.H., et al., Development and validation of a symptom-based severity score for haemorrhoidal disease: the Sodergren score. Colorectal Dis, 2015. 17(7): p. 612-8.

36. Brown, S., et al., The HubBLe Trial: haemorrhoidal artery ligation (HAL) versus rubber band ligation (RBL) for symptomatic second-and third-degree haemorrhoids: a multicentre randomised controlled trial and health-economic evaluation. Health Technol Assess, 2016. 20(88): p. 1-150.

37. Beretta, R., A critical review of the Delphi technique. Nurse Res, 1996. 3(4): p. 79-89. 
European Society of Coloproctology Core Outcome Set for haemorrhoidal disease: an international Delphi study among healthcare professionals

38. van Tol, R.R., et al., Protocol for the development of a Core Outcome Set (COS) for hemorrhoidal disease: an international Delphi study. Int J Colorectal Dis, 2017. 32(7): p. 1091-1094. 


\section{Appendix I}

\section{Questionnaire I: healthcare professionals}

What should we use as primary endpoint in the Core Outcome Set (COS) for haemorrhoidal disease?

- Patients satisfaction

- Symptoms

- Complications

- Recurrence

- Pain

- Prolapse

- Open answer option

What should we use as secondary endpoint(s) in the Core Outcome Set (COS) for haemorrhoidal disease?

- Patients satisfaction

- Symptoms

- Complications

- Recurrence

- Pain

- Prolapse

- Open answer option

Which of the following Outcomes should be included in a symptom score?

- Blood loss

- Pain

- Itching

- Soiling

- Prolapse

- Urgency

- Constipation

- Open answer option 
Which of the following Outcomes should be included in a 'complication score'?

- Incontinence

- Severe pain

- Stricture

- $\quad$ Severe bleeding

- Fistula

- Thrombosis

- Abscess

- Urinary retention

- Anal Stenosis

- Edema

- Nodule

- Open answer option

How should recurrence be defined?

- $\quad$ Recurrent prolapse after symptom free period

- $\quad$ Reappearance of initial symptoms

- $\quad$ Further intervention necessary

- Residual symptoms in relation to degree of satisfaction

- Histological proved recurrence

- Open answer option 


\section{Appendix 2}

Healthcare professionals scoring the Domains and Outcomes on a nine-point scale, where I-3 equals "inappropriate" (out) and 4-6 equals "unsure"(vote again)

\section{Round 1}

\begin{tabular}{|c|c|c|c|c|c|}
\hline Primary endpoint & Panel ratings & $\begin{array}{l}\text { Consensus } \\
\text { definition }\end{array}$ & Secondary endpoint & Panel ratings & $\begin{array}{l}\text { Consensus } \\
\text { definition }\end{array}$ \\
\hline Symptoms & $9(8-9)$ & Appropriate & Patient satisfaction & $9(8-9)$ & Appropriate \\
\hline Patient satisfaction & $8(7-9)$ & Appropriate & Complications & $7(5.5-8)$ & Appropriate \\
\hline Recurrence & $8(6-9)$ & Appropriate & Recurrence & $7(3.2-8)$ & Appropriate \\
\hline Complications & $7(5-8.2)$ & Appropriate & Symptoms & $6(5-7.5)$ & Unsure \\
\hline Prolapse & $7(5-7)$ & Appropriate & Prolapse & $5.5(5-7)$ & Unsure \\
\hline Pain & $7(5-8)$ & Appropriate & Pain & $5(5-6.5)$ & Unsure \\
\hline
\end{tabular}




\section{Round 1}

Second part: Which Outcomes should be included in the Domains for the COS?

Panel ratings

Consensus definition

Domain "symptoms"

\begin{tabular}{|lll}
\hline Pain & $9(8-9)$ & Appropriate \\
\hline Prolapse & $7.5(6-8.5)$ & Appropriate \\
\hline Soiling & $7(6-8)$ & Appropriate \\
\hline Itching & $7(6-7)$ & Appropriate \\
\hline Blood loss & $7(3-9)$ & Appropriate \\
\hline Urgency & $6.5(6-7)$ & Unsure \\
\hline Constipation & $4.5(3-5)$ & Unsure \\
\hline Domain "complications" & & \\
\hline Abscess & $9(9-9)$ & Appropriate \\
\hline Incontinence & $9(9-9)$ & Appropriate \\
\hline Anal stenosis & $9(9-9)$ & Appropriate \\
\hline Stricture & $9(9-9)$ & Appropriate \\
\hline Fistula & $9(8.5-9)$ & Appropriate \\
\hline Severe bleeding & $8.5(7.5-9)$ & Appropriate \\
\hline Severe pain & $8.5(7-9)$ & Appropriate \\
\hline Urinary retention & $7.5(6.5-9)$ & Appropriate \\
\hline Thrombosis & $7(5.5-8)$ & Appropriate \\
\hline Edema & $3(3.2-3.9)$ & Inappropriate \\
\hline Nodule & $3(2-4.5)$ & Inappropriate \\
\hline Domain "recurrence" & & \\
\hline Recurrent prolapse after symptom free period & $8.5(8-9)$ & Appropriate \\
\hline Reappearance of initial symptoms & $8(5.5-9)$ & Appropriate \\
\hline Further intervention necessary & $8(5.5-9)$ & Appropriate \\
\hline Residual symptoms in relation to degree of satisfaction & $6(6-7)$ & Unsure \\
\hline Histological proved recurrence & $1.5(1-3)$ & Inappropriate \\
\hline & & \\
\hline
\end{tabular}

\section{Round 2}

First part: Which Domains should be included as primary- and secondary endpoints?

\begin{tabular}{lllllll} 
Primary endpoint & Panel ratings & $\begin{array}{l}\text { Consensus } \\
\text { definition }\end{array}$ & Secondary endpoint & $\begin{array}{l}\text { Panel } \\
\text { ratings }\end{array}$ & $\begin{array}{l}\text { Consensus } \\
\text { definition }\end{array}$ \\
\hline Symptoms & $9(8-9)$ & Appropriate & Patient satisfaction & $9(8-9)$ & Appropriate \\
\hline Patient satisfaction & $8(7-8)$ & Appropriate & Recurrence & $8(7-9)$ & Appropriate \\
\hline Recurrence & $8(7-9)$ & Appropriate & Prolapse & $7.5(6.1-8)$ & Appropriate \\
Complications & $7.5(6-8)$ & Appropriate & Complications & $7(6.1-8)$ & Appropriate \\
\hline Prolapse & $6(6-7.5)$ & Unsure & Symptoms & $7(6-8)$ & Appropriate \\
Pain & $6(6-7)$ & Unsure & Pain & $7(6-7)$ & Appropriate \\
\hline
\end{tabular}




\section{Chapter 4}

\section{Round 2}

Second part: Which Outcomes should be included in the Domains for the COS?

Domain "symptoms"

\begin{tabular}{|lll}
\hline Pain & Panel ratings & Consensus definition \\
\hline Prolapse & $9(8-9)$ & Appropriate \\
\hline Blood loss & $8(7-8)$ & Appropriate \\
\hline Itching & $7(5.1-8)$ & Appropriate \\
\hline Soiling & $7(6-7)$ & Appropriate \\
\hline Urgency & $7(6-8)$ & Appropriate \\
\hline Constipation & $6.5(6-7)$ & Unsure \\
\hline Domain "complications" & $4(3-4.9)$ & Unsure \\
\hline Abscess & & \\
\hline Incontinence & $9(9-9)$ & Appropriate \\
\hline Fistula & $9(9-9)$ & Appropriate \\
\hline Stricture & $9(8-9)$ & Appropriate \\
\hline Anal stenosis & $9(8-9)$ & Appropriate \\
\hline Severe pain & $9(8-9)$ & Appropriate \\
\hline Severe bleeding & $8.5(7-9)$ & Appropriate \\
\hline Urinary retention & $8(7-9)$ & Appropriate \\
\hline Thrombosis & $6(4-8)$ & Unsure \\
\hline Domain "recurrence" & $6(4-7)$ & Unsure \\
\hline Recurrent prolapse after symptom free period & $8(8-9)$ & \\
\hline Further intervention necessary & $8(7-9)$ & Appropriate \\
\hline Reappearance of initial symptoms & $8(7-8)$ & Appropriate \\
\hline Residual symptoms in relation to degree of & $7(5-8)$ & Appropriate \\
\hline satisfaction & & Appropriate \\
\hline & & \\
\hline
\end{tabular}




\section{Appendix 3}

\section{Translated patient questionnaire}

\section{Patients}

How much do you suffer from the following symptoms on a scale from 0 (no suffer at all) to 9 (a lot of suffer)?

\begin{tabular}{|c|c|}
\hline & Panel ratings \\
\hline A lump near your anus & $6.5(5-8.3)$ \\
\hline Pain & $4.5(2-5)$ \\
\hline Blood loss & $3.5(1-7)$ \\
\hline Itching & $1.5(1-4.3)$ \\
\hline Soiling, faecal incontinence & $1(1-1.3)$ \\
\hline \multicolumn{2}{|c|}{ How much do these symptoms bother you in daily life on a scale from 0 (no bother at all) to 9 (very bothered)? } \\
\hline A lump near your anus & $5.5(3.7-7)$ \\
\hline Pain & $2.5(1-6)$ \\
\hline Blood loss & $2(1-4)$ \\
\hline Itching & $1(1-1.3)$ \\
\hline Soiling, faecal incontinence & $1(1-4)$ \\
\hline \multicolumn{2}{|c|}{ When is treatment successful for you on a scale from 0 (not successful at all) to 9 (very successful)? } \\
\hline Having no blood loss & $8.5(5-9)$ \\
\hline No pain & $8(6-9)$ \\
\hline No lump near your anus or swelling & $7.5(3-9)$ \\
\hline No itching & $6.5(3-9)$ \\
\hline No soiling of undergarments or faecal incontinence & $4(1-9)$ \\
\hline \multicolumn{2}{|c|}{$\begin{array}{l}\text { What should have been remedied after a surgical intervention for haemorrhoidal disease on a scale from } 0 \text { (not } \\
\text { important) to } 9 \text { (very important)? }\end{array}$} \\
\hline Blood loss & $8.5(5-9)$ \\
\hline A lump near your anus & $8.5(5-9)$ \\
\hline Pain & $5.5(3-9)$ \\
\hline Itching & $5(2-7)$ \\
\hline Soiling, faecal incontinence & $3.5(1-9)$ \\
\hline \multicolumn{2}{|c|}{$\begin{array}{l}\text { What is important that the clinician discusses with the patient during the outpatient visit with } 0 \text { (not important) to } \\
9 \text { (very important)? }\end{array}$} \\
\hline Symptoms/ complaints (blood loss, pain etc.) & $9(9-9)$ \\
\hline Patient satisfaction & $8.5(8-9)$ \\
\hline Complications & $8.5(7-9)$ \\
\hline A lump near your anus & $8(7-9)$ \\
\hline Pain & $7(5-8)$ \\
\hline \multicolumn{2}{|c|}{ How would you describe the term recurrence of hemorrhoidal disease? } \\
\hline Reappearance of initial symptoms & $7(5-8)$ \\
\hline Reappearance prolapse after symptom free period & $5(4-7)$ \\
\hline Re-intervention necessary & $5(3-8)$ \\
\hline
\end{tabular}




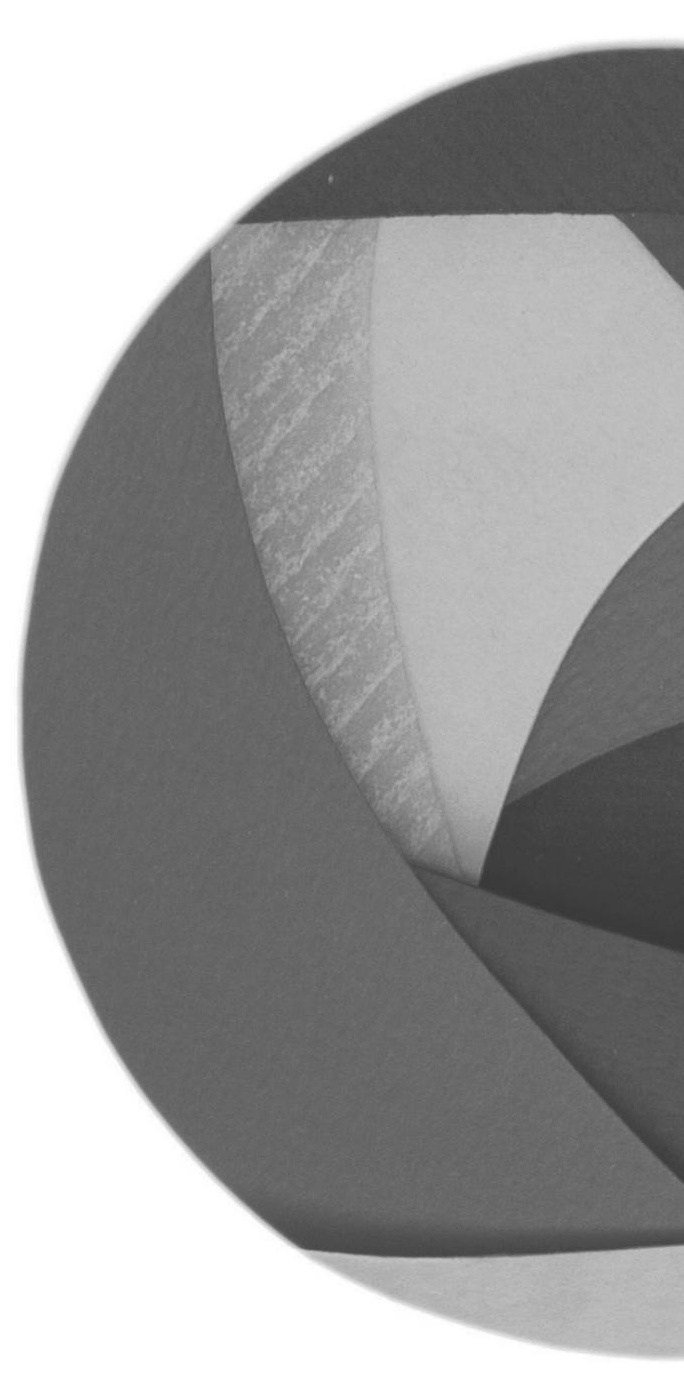




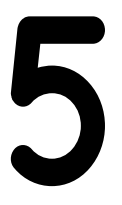

\section{EXPERIENCES OF} PATIENTS WITH HAEMORRHOIDAL DISEASE - A QUALITATIVE STUDY

R.R. Van Tol, M.L. Kimman, S.O. Breukink,

S.Z. Kuiper, J. Melenhorst, L.P.S. Stassen,

C.D. Dirksen

J Coloproctology (RIO J). 2019; 39 (1): 41-47 


\section{Abstract}

Purpose To obtain a better understanding of the patients' experiences with HD, impact on their daily life and results of treatment by performing a qualitative study.

Method Individually interviews were conducted among patients with HD between 2016-2017. Each interview was recorded using an audio recorder and transcribed verbatim. A semi-structured interview guide was used with prespecified topics, based on a previous conducted literature review. Transcripts were coded and the analysis consisted highlighting passages in the text and assigning each passage a code representing the predefined themes from the interview guide. This resulted in a three-level theme hierarchy: overarching theme, midlevel subtheme and issues.

Results Fifteen participants underwent individual interviews of whom thirteen were conducted by telephone. The mean age was 60.7 years (35-78); five of them were female (33.3\%). Pain and blood loss were the most frequently reported symptoms. Participants indicated that these symptoms were directly associated with emotional burden, daily adjustments and social impact. Before diagnosis with HD blood loss resulted in feelings of fear and next in embarrassment during social activities. In daily life participants needed to get up early, used sanitary pads for blood loss and anal ice sticks to reduce pain. Participants were often not completely satisfied with the process and outcome of treatment.

Conclusion This first qualitative study provides detailed insight into the patients' experiences with HD, impact on daily life and results of treatment. This information may be used in daily practice to create awareness among clinicians. 


\section{Backround}

Haemorrhoidal disease (HD) is one of the most common anorectal pathologies affecting a large number of people in the western world. The prevalence can vary from $4.4 \%$ in the general population to $36 \%$ in general practice (1-5).

HD concerns a swelling of the submucosal veins in the anal canal that results in prolapse. It is hypothesized that it is caused by an increased abdominal pressure and/or the degenerative effects in aging (6-8). This prolapsed tissue is easily traumatised which may result in bleeding and the deposition of mucus on the perianal skin may cause itching $(9,10)$.

Haemorrhoids are mostly classified according to the grading system of Goligher et al. (11-13). This grading system is important since the best therapeutic option is directed by the location and severity of the haemorrhoids. However, while many patients have reported benefits of specific treatments for different grades of HD, consensus on the ideal treatment option for each grade of HD has not been reached yet (14-16). This may be partly explained by the lack of consensus on what constitutes treatment success. In the majority of HD studies treatment success is based on quantitative measurement of parameters such as prolapse, recurrence, complications and duration of operation (17-19). However, these traditional clinical outcomes - mostly selected by healthcare professionals - may not include all relevant benefits and harms as experienced by patients. There is some evidence that treatment preferences may differ substantially between healthcare professionals and patients (20). However, differences in such preferences are difficult to predict and may vary for a given condition (21-25).

Conducting qualitative interviews can function as groundwork to gain a deeper understanding and obtain information directly from the patients about their experiences with a disease and treatment preferences $(26,27)$. Qualitative research has established that patients' experiences and health beliefs are important factors in determining treatment success $(21)$.

To obtain a more in-depth understanding of patients' experiences with HD, impact on daily life and results of treatment a qualitative study was conducted. 


\section{Methods}

\section{Study design \& participants}

The study was a qualitative study involving individual interviews. Dutch-speaking, male and female participants (aged $>18$ years) already diagnosed with HD (by their GP) who visited the outpatient clinic of an academic hospital (Maastricht University Medical Centre) for treatment were invited by their treating colorectal consultant (SB or JM). The colorectal consultant (SB) informed eligible patients regarding the study and handed out a patient information sheet. If the patient agreed, one of two researchers (RT and SK) contacted the patient explaining the study purpose and procedures in depth. If the patient was willing to participate, written consent was obtained. Insufficient language proficiency was an exclusion criterion. Patients were included between June 2016 and March 2017. The sample size was based on the concept of 'saturation' defined as the point at which no new information or themes emerged from the data (28).

\section{Semi-structured interviews}

An interview guide supported the collection of data. Review of the literature resulted in a number of topics and open ended questions, exploring three target themes: (1) experience of HD, (2) impact on daily life and (3) treatment (appendix 1).

The indepth interviews were conducted by telephone or by face-to-face meeting in the outpatient clinic, dependent on the participants' preferences. One hour was scheduled for each interview. The interviews were conducted by two researchers (SK and RT). One researcher (SK) was a medical student and the other a clinical investigator (RT). Both interviewers had no prior treatment relationship with the participants.

During the interview, participants were encouraged to describe their experiences and symptoms they encountered concerning HD. For example, the following question was used 'how do you experience having haemorrhoids?' Symptoms were not predefined and the interviewer probed for details on the HD symptoms reported by participants. Subsequent questions could be, 'What do you mean?' or/and 'Could you tell me more about that?'

The same strategy was followed for the themes daily life impact and treatment.

\section{Data analysis}

All interviews were audio recorded and transcribed verbatim. To protect the anonymity of participants, all personal data were removed. The data were subjected to manual qualitative analysis by two data coders (RT and SK). Analysis consisted of two steps. First, coding was carried out by highlighting passages in the text and assigning each passage a code representing the predefined themes from the interview guide: (1) experience of HD (2) impact on daily life and (3) treatment. In the second step the data coders catalogued the passages into main issues expressed by patients. The analysis resulted in a 
three-level theme hierarchy: (1) overarching theme (the broadest category), (2) midlevel subtheme and (3) issues (the finest level of theme detail). RT and SK compared codes and identified issues for consistency and discussed discrepancies with CD. Refinement of the issues continued with the other co-authors until the structure was perceived to adequately capture the observed data.

\section{Results}

\section{Study participants}

Fifteen patients with HD participated in the study. Twelve out of fifteen interviews were conducted by telephone and three were conducted face-to-face. The majority of patients $(60 \%)$ had previously received rubberband ligation and presented with recurrent symptoms. Six participants received (GP-initiated) basic treatment (i.e. toilet training, high fibre diet and/or topical ointment) and visited the outpatient clinic to discuss rubberband ligation. At time of the interview, treatment (e.g. RBL or a haemorrhoidopexy) for all participants was scheduled. Participants' characteristics are presented in table 1.

Table I: Participant characteristics ( $\mathrm{n}=\mathrm{I5}$ )

\begin{tabular}{ll}
\hline Characteristics & \\
\hline Age (in years), mean (range) & $61(35-78)$ \\
Female, $\mathrm{n}(\%)$ & $5(33)$ \\
Classification of haemorrhoids, n (\%) & \\
Grade I & $4(27)$ \\
Grade II & $8(53)$ \\
Grade III & $3(20)$ \\
Prior treatment (100\%) & \\
$\quad$-basic treatment & $6(40 \%)$ \\
$\quad$-rubber band ligation & $7(47 \%)$ \\
$\quad$-haemorrhoidopexy & $2(13 \%)$ \\
Years since diagnosis, median (range) & $8.5(0.5-20)$ \\
\hline
\end{tabular}




\section{Themes}

An overview of the issues related to HD extracted from the interviews is provided in Table 2.

Table 2: Summary of responses extracted from the individual interviews $(n=15)$

\begin{tabular}{|c|c|c|}
\hline Themes & Sub-themes & Issues \\
\hline Experience of $H D$ & N/A & $\begin{array}{l}\text { Blood loss, pain, prolapse, itching, soiling } \\
\text { Fear/panic } \\
\text { Delay } \\
\text { Embarrassment } \\
\text { Seeking help }\end{array}$ \\
\hline \multirow[t]{3}{*}{ Impact on daily life } & Emotional burden & Stigma/identity \\
\hline & $\begin{array}{l}\text { Restrictions and } \\
\text { adjustment }\end{array}$ & Impact on daily functioning (e.g. planning) \\
\hline & Social support & $\begin{array}{l}\text { Daily adjustments (e.g. sanitary pads) } \\
\text { Sharing with partner } \\
\text { Support in environment }\end{array}$ \\
\hline \multirow[t]{2}{*}{ Treatment } & Procedure responses & Communication \\
\hline & Treatment outcome & $\begin{array}{l}\text { Treatment outcomes } \\
\text { Patient information } \\
\text { Recurrence } \\
\text { Satisfaction }\end{array}$ \\
\hline
\end{tabular}

\section{Experience of HD}

Blood loss and prolapse were the most commonly reported complaints [Table 3]. Other complaints included pain, itching and soiling. "The itching is very annoying, I'd rather be in pain than have that itch" (ID 2, female). On average, participants reported one to two symptoms.

Table 3: Frequency of symptoms reported by participants

\begin{tabular}{ll}
\hline Symptom & $\mathrm{n}(\%)$ \\
\hline Blood loss & $10(67)$ \\
Prolapse & $5(33)$ \\
Pain & $4(27)$ \\
Itching & $3(20)$ \\
Soiling & $2(13)$ \\
\hline
\end{tabular}


The presence of blood was sometimes associated with the thought of having a malignant condition by the patient. "Of course you are scared, [...] at first you always think that it might be cancer", (ID 1, male). "At first, I did not know where [the blood] came from, it scared me" (ID 6, male). Going to the general practitioner or undergoing a clinical colonoscopy ablated these feelings of fear. Other patients reported they never had any concerns regarding possible malignancy. "No, I was never worried that it might be cancer. [...] The difference is also quite clear, it is such fresh blood and I know where it comes from" (ID 13, female).

Most patients suffered from HD for a long period of time and were reluctant to seek help. Many patients felt ashamed or embarrassed resulted in a hesitation going to the general practitioner. "It started when I was sixteen, so I have been suffering [from haemorrhoidal disease] for the past twenty years. (...) It is a familiar phenomenon in the family, so at first I thought it was not necessary to seek help, but the pain worsened and I overcame my shame" (ID 3, male). "You do not talk about it, nowadays I do, but back then, I did not, because it is embarrassing. You also postpone the hospital visits. It is a painful area, so you postpone it" (ID 13, female).

After seeking treatment, most patients expressed they wished they had turned to the doctor sooner. "I know now: the result outweighs the pain" (ID 5, female).

\section{Impact on daily life}

\section{Emotional burden}

Many patients experienced a feeling of embarrassment regarding their haemorrhoidal disease. Haemorrhoids are considered as unhygienic and unclean. “(...). You feel ashamed because everyone else thinks it is embarrassing, that is society's opinion (ID 13, female). Another patient stated the same thing: “(...) the shame comes from talking about it. It is as if you're talking about your penis. Look, the meniscus or the heart or something like that, that does not matter, but this does" (ID 10, male). Other patients shared the following: "I do feel ashamed. Recently, I went to an athletics club and I took a shower with a white towel, after using it, the towel was covered in blood. I felt really ashamed then, because I am concerned about what others will think of me now" (ID 7, male). Despite the sentiments mentioned above, three other respondents stated that they did not experience feelings of shame.

Another feeling patients often experience is worry due to a relapse of the condition. "Yes, of course you think about that. In the past they have also relapsed." (ID 9, male).

\section{Restrictions and daily adjustments}

Asking patients if they felt restricted by their $\mathrm{HD}$, all participants said 'no'. After probing this question, however, respondents reported several restrictions or adjustments in daily 
life. For example, one respondent reported: "Because of the massive blood loss, I could not function normally any more. I did not dare to go anywhere, not to a party, not to my son's soccer match" (ID 13, female). Another respondent claimed that his condition affected his sex life. "(...) my sex life, I do think it is difficult, because of the flap coming out of my anus" (ID 4, male). Examples of daily adjustments were getting up early in the morning to have sufficient time to pass stool at home and clean their bottom. "I did make changes [in my life], I have to get up one hour earlier to go to the bathroom. If I do this hastily, or not at all, I know I will have trouble with my stool" (ID 3, male). "Nowadays I eat early in the morning, go to the toilet and shower afterwards to clean my bottom, all before work" (ID 4, male).

To reduce the impact of frequent blood loss, patients often needed to use sanitary pads. "In the beginning you feel ashamed while admitting you have this problem and then your sister says 'I have some sanitary pads if you want'. Normally, these are used by women, which makes it even worse because I am a man." (ID 7, male).

To relieve the pain, a few patients used lidocaine cream. One patient was prescribed anal ice sticks by her general practitioner. This seemed to help the pain, although she stated that she was uncomfortable with the feeling of it (ID 13, female). Another patient created a tool against prolapse; "I have moments that I cannot sit down, so I have to sit on a frozen plastic bottle to push the haemorrhoids back inside" (ID 3, male). One patient also used an old household remedy by applying cold whipped egg whites to the affected areas. "I tried egg whites, whipped and stored in the fridge. (...) It helped for a while, but at a certain point my haemorrhoids seemed to get used to it and the effect disappeared" (ID 2, female). Another patient said he benefited from meditation. "[Meditation] helped me a lot. (...) I have managed to create a sensation that makes the haemorrhoids bearable" (ID 3, male).

\section{Social support}

All respondents reported that they shared their complaints about having HD with their partner. "Of course I did not hide this [haemorrhoidal disease] from my wife and of course we talked about this from time to time" (ID 9, male). Another patient quoted "(...) I have been with my wife for the past 20 years. We share everything; we do not have secrets from each other" (ID 3, male). Another participant also explained that it was her own self-perception that was altered and not the way her partner reacted to it. "No, no, it is not a problem for my partner (...) Of course it bothers me, because I don't think that it is aesthetically pleasing" (ID 13, female). In some cases, the partner of the patient took care of some aspects of the HD, and provided active support. "My partner salves my [haemorrhoidal] folds. I am really grateful for that, because not every partner does this. He also checks for changes in colour and thickness" (ID, 2, female).

Some respondents discovered that more people in their environment were struggling with haemorrhoidal disease. "If you start talking about it, you will find out that many 
people experience [haemorrhoidal disease]. At a certain point, I thought 'I am not going to make it embarrassing for myself anymore, other people have something else and, coincidently, I have this" (ID 13, female). Participants were receiving support from their personal environment.

\section{Treatment}

\section{Procedure responses}

The experiences of patients regarding haemorrhoidal procedures were diverse; they ranged from positive to negative and were mostly related to the information provided to the patient. "Quite pleasant, so relaxed, and also telling what they were doing. I worked in education all my life, it was an A+, and I felt in good hands" (ID 5, female). "It happens really quickly, just bend over, elastic around it, snap, snap, and go!" (ID 15, male).

However, several participants had expected more clarification concerning the interference and information regarding the post treatment care. "I had no idea [what to expect], nobody told me anything about it, I just sort of went with it" (ID 6, male). "I went to the surgeon for the haemorrhoids and prolapsed rectum, but all he treated was the rectum. I have not heard anything about the haemorrhoids; I think that is a disadvantage" (ID 2, female). "Think of pain, costs, etc. They could have been more transparent and open about these things in the time leading up to the procedure" (ID 4, male). "[Expectations] were formed by the information provided by other people I spoke with, who had already undergone the operation" (ID 3, male).

\section{Treatment outcomes}

A respondent defined treatment success as: "the moment when I do not have to make adjustments in life anymore" (ID 3, male). "It is such a difference, now that I do not need to be aware of going to the toilet anymore when I am on my way to clients" (ID 6 , male). Respondents reported that after treatment blood loss and/or prolapse should be resolved (ID 7, male and ID 13, female). A respondent even said "I can imagine that there is a discrepancy between the expectations of the patient, on the one hand, and the opinion of the surgeon on the other. Therefore, treatment considerations should be discussed openly with a patient (ID 4, male).

Further, many patients conveyed that they worried about a relapse of the condition. "Yes, of course you think about that. In the past they have also relapsed, but if I touch that area now it feels different than the last time, so I have more faith this time" (ID 9, male).

\section{Discussion}


This is the first qualitative study that gives an insight into patients' experiences having HD. Blood loss and anal pain were the most commonly reported symptoms. Participants indicated that these symptoms were directly associated with emotional burden, daily adjustments and social impact. For example, in patients having blood loss before the diagnosis was known, this symptom resulted in feelings of fear. Besides blood loss resulted in embarrassment, and avoidance of social activities. Furthermore, participants used a variety of tricks and adjustments in their daily life to cope with HD (e.g. getting up early, sanitary pads, use of anal ice sticks to reduce pain). Participants were not always completely satisfied with the process and / or outcome of treatment. They appreciated greater openness and exchange of information regarding the different treatment options and the expected outcomes from their healthcare professionals.

We are not aware of other studies that have comprehensively investigated the symptoms and impacts of HD from the patient perspective. Nevertheless, the reported symptoms by our participants are in line with HD symptoms that are commonly evaluated in clinical trials $(29,30)$. No studies were found regarding the impact on daily life and treatment experiences of HD.

This is the first study that showed that certain aspects relevant to the patient are overlooked when HDtreatment effectiveness is assessed by only traditional endpoints such as prolapse, recurrence and complications. This study showed that, besides the traditional endpoints, patients are also concerned about the bothersomeness of the symptoms and the impact on their daily life. Furthermore, patients may have different preferences regarding the treatment options than the clinician has. This issue is an important reason why clinicians should ask patients what treatment they prefer and what they consider as treatment success.

This approach where clinicians and patients discuss the best treatment option is defined as Shared Decision Making (SDM) (31). An important advantage of this approach by both taking in account the experiences of the patients as SDM, is that patients are more likely to be satisfied with the clinician-patient contact and the decision $(32,33)$.

Nowadays next to traditional clinical outcomes, literature shows more and more the importance of using Patient Reported Outcome Measures (PROMs) for assessing treatment outcome (34). PROMs are questionnaires that measure the patient's experiences regarding health (outcomes) and sense of well-being. This study may contain clinical relevant information, which could be incorporated in the development of a future PROM for HD.

We acknowledge that a qualitative study has a number of limitations. First, the small number of participants may be considered as a limitation. Although, 15 participants are relatively common for this kind of study and further data collection and/or analysis was unnecessary since this provided us no new information. Secondly, only patients visiting the outpatient clinic with persistent $\mathrm{HD}$ were included in this study. This may resulted in an overrepresentation of respondent's with more severe HD and less 
treatment satisfaction. Thirdly, researchers' understanding and interpretation of the data may influence the results that could be different from that of others. Fourthly, socially desirable responses regarding treatment satisfaction or the lack of reporting of sensitive issues cannot be ruled out. However, two researchers conducted the interviews with no prior treatment relation with the participants. Finally, conducting the interview by telephone can create a distance between researcher and patient and corrode the trust. Nevertheless, the distance created by the telephone can also help the patient to narrate more easily regarding their complaint experience and personal life. We tried to make participants feel as comfortable and safe as possible and ensured their responses would be anonymised and not shared with anyone else. It appears that highly sensitive topics such as sexual barriers were openly addressed.

In conclusion, this is the first qualitative study that provided detailed insight into the patient's experiences with HD. This information may be used in clinical practice to create awareness among clinicians to take the patient's experiences and values into account when making HD treatment decisions. In addition, this study contains clinical relevant information, which could be incorporated in the development of a PROM for HD. 


\section{References}

1. Yang J, Cui PJ, Han HZ, Tong DN. Meta-analysis of stapled hemorrhoidopexy vs LigaSure hemorrhoidectomy. World J Gastroenterol. 2013;19(29):4799-807.

2. Burkitt DP. Varicose veins, deep vein thrombosis, and haemorrhoids: epidemiology and suggested aetiology. Br Med J. 1972;2(5813):556-61.

3. Alonso-Coello P, Zhou Q, Martinez-Zapata MJ, Mills E, Heels-Ansdell D, Johanson JF, et al. Meta-analysis of flavonoids for the treatment of haemorrhoids. Br J Surg. 2006;93(8):909-20.

4. Gencosmanoglu R, Sad O, Koc D, Inceoglu R. Hemorrhoidectomy: open or closed technique? A prospective, randomized clinical trial. Dis Colon Rectum. 2002;45(1):70-5.

5. Johanson JF, Sonnenberg A. The prevalence of hemorrhoids and chronic constipation. An epidemiologic study. Gastroenterology. 1990;98(2):380-6.

6. Alonso-Coello P, Marzo-Castillejo M, Mascort JJ, Hervas AJ, Vina LM, Ferrus JA, et al. [Clinical practice guideline on the treatment of hemorrhoids and anal fissure (update 2007)]. Gastroenterol Hepatol. 2008;31(10):668-81.

7. Cirocco WC. A matter of semantics: hemorrhoids are a normal part of human anatomy and differ from hemorrhoidal disease. Gastrointest Endosc. 2000;51(6):772-3.

8. Jacobs D. Clinical practice. Hemorrhoids. N Engl J Med. 2014;371(10):944-51.

9. Guttenplan M. The Evaluation and Office Management of Hemorrhoids for the Gastroenterologist. Curr Gastroenterol Rep. 2017;19(7):30.

10. Butters M. [Hemorrhoids--etiology, symptoms and therapy]. Ther Umsch. 1997;54(4):185-9.

11. Banov L, Jr., Knoepp LF, Jr., Erdman LH, Alia RT. Management of hemorrhoidal disease. J S C Med Assoc. 1985;81(7):398-401.

12. Gaj F, Trecca A, Busotti A, Brugiotti C, Carboni M. The new classification of hemorrhoids: PATE 2000-Sorrento. History of the scientific debate. Minerva Chir. 2002;57(3):331-9.

13. Elbetti C, Giani I, Novelli E, Fucini C, Martellucci J. The single pile classification: a new tool for the classification of haemorrhoidal disease and the comparison of treatment results. Updates Surg. 2015;67(4):421-6.

14. Shanmugam V, Thaha MA, Rabindranath KS, Campbell KL, Steele RJ, Loudon MA. Systematic review of randomized trials comparing rubber band ligation with excisional haemorrhoidectomy. Br J Surg. 2005;92(12):1481-7.

15. Shao WJ, Li GC, Zhang ZH, Yang BL, Sun GD, Chen YQ. Systematic review and metaanalysis of randomized controlled trials comparing stapled haemorrhoidopexy with conventional haemorrhoidectomy. Br J Surg. 2008;95(2):147-60.

16. Simillis C, Thoukididou SN, Slesser AA, Rasheed S, Tan E, Tekkis PP. Systematic review and network meta-analysis comparing clinical outcomes and effectiveness of surgical treatments for haemorrhoids. Br J Surg. 2015;102(13):1603-18.

17. Watson AJ, Hudson J, Wood J, Kilonzo M, Brown SR, McDonald A, et al. Comparison of stapled haemorrhoidopexy with traditional excisional surgery for haemorrhoidal disease (eTHoS): a pragmatic, multicentre, randomised controlled trial. Lancet. 2016;388(10058):2375-85. 
18. Brown SR, Tiernan JP, Watson AJM, Biggs K, Shephard N, Wailoo AJ, et al. Haemorrhoidal artery ligation versus rubber band ligation for the management of symptomatic second-degree and thirddegree haemorrhoids (HubBLe): a multicentre, open-label, randomised controlled trial. Lancet. 2016;388(10042):356-64.

19. Leung ALH, Cheung TPP, Tung K, Tsang YP, Cheung H, Lau CW, et al. A prospective randomized controlled trial evaluating the short-term outcomes of transanal hemorrhoidal dearterialization versus tissue-selecting technique. Tech Coloproctol. 2017;21(9):737-43.

20. Brown SR, Watson A. Comments to 'Rubber band ligation versus excisional haemorrhoidectomy for haemorrhoids'. Tech Coloproctol. 2016;20(9):659-61.

21. Montgomery A, Fahey T, Protheroe J, Peters TJ. More on patients' preferences in treating atrial fibrillation. West J Med. 2001;175(6):379.

22. Charles C, Whelan T, Gafni A. What do we mean by partnership in making decisions about treatment? BMJ. 1999;319(7212):780-2.

23. Montgomery AA, Fahey T. How do patients' treatment preferences compare with those of clinicians? Qual Health Care. 2001;10 Suppl 1:i39-43.

24. Montgomery AA, Harding J, Fahey T. Shared decision making in hypertension: the impact of patient preferences on treatment choice. Fam Pract. 2001;18(3):309-13.

25. Protheroe J, Fahey T, Montgomery AA, Peters TJ. Effects of patients' preferences on the treatment of atrial fibrillation: observational study of patient-based decision analysis. West J Med. 2001;174(5):311-5.

26. Wu YP, Thompson D, Aroian KJ, McQuaid EL, Deatrick JA. Commentary: Writing and Evaluating Qualitative Research Reports. J Pediatr Psychol. 2016;41(5):493-505.

27. Keeley RD, West DR, Tutt B, Nutting PA. A qualitative comparison of primary care clinicians' and their patients' perspectives on achieving depression care: implications for improving outcomes. BMC Fam Pract. 2014;15:13.

28. Francis JJ, Johnston M, Robertson C, Glidewell L, Entwistle V, Eccles MP, et al. What is an adequate sample size? Operationalising data saturation for theory-based interview studies. Psychol Health. 2010;25(10):1229-45.

29. Brown S, Tiernan J, Biggs K, Hind D, Shephard N, Bradburn M, et al. The HubBLe Trial: haemorrhoidal artery ligation (HAL) versus rubber band ligation (RBL) for symptomatic secondand third-degree haemorrhoids: a multicentre randomised controlled trial and health-economic evaluation. Health Technol Assess. 2016;20(88):1-150.

30. Pucher PH, Qurashi M, Howell AM, Faiz O, Ziprin P, Darzi A, et al. Development and validation of a symptom-based severity score for haemorrhoidal disease: the Sodergren score. Colorectal Dis. 2015;17(7):612-8.

31. Chang A, Bowen JL, Buranosky RA, Frankel RM, Ghosh N, Rosenblum MJ, et al. Transforming primary care training--patient-centered medical home entrustable professional activities for internal medicine residents. J Gen Intern Med. 2013;28(6):801-9.

32. Barry CA, Bradley CP, Britten N, Stevenson FA, Barber N. Patients' unvoiced agendas in general practice consultations: qualitative study. BMJ. 2000;320(7244):1246-50. 
33. Kinnersley P, Stott N, Peters TJ, Harvey I. The patient-centredness of consultations and outcome in primary care. Br J Gen Pract. 1999;49(446):711-6.

34. Wiering B, de Boer D, Delnoij D. Patient involvement in the development of patient-reported outcome measures: a scoping review. Health Expect. 2017;20(1):11-23.

\section{Appendix I}

\section{INTERVIEW GUIDE}

\section{Characteristics of the interview}

$\checkmark \quad$ Individual interview

$\checkmark \quad$ Informal and convenient location

$\checkmark \quad$ Direct approach: participant informed about the purpose of the interview

$\checkmark \quad$ Semi-structured interviews: main questions with potential sub-questions

$\checkmark \quad$ Duration between 30-60 minutes

$\checkmark \quad$ Audio recorded

\section{Aims of the interview}

To inform the development of the patient-reported outcome measure, with a focus on disease-specific items, by gaining knowledge and information about:

$\checkmark \quad$ Patient experiences and perceptions of haemorrhoidal disease (HD)

$\checkmark \quad$ Diagnosis of HD

$\checkmark \quad$ The impact of HD on daily life

$\checkmark \quad$ Experience, expectations and satisfaction with treatment

\section{Main questions and potential sub-questions}

$\checkmark \quad$ Would you please briefly introduce yourselves? Tell us your name, when you were diagnosed with haemorrhoidal disease (HD)?

$\checkmark \quad$ What are your main symptoms or complaints of HD?

o Are there symptoms we haven't discussed yet?

$\checkmark \quad$ Do these symptoms bother you?

$\checkmark \quad$ How do they impact on your daily life?

$\checkmark \quad$ Do you feel hindered in daily activities by these symptoms?

$\checkmark \quad$ Where you informed by your health care professional (specialist nurse or medical specialist) about the expected efficacy of the treatment?

o What were your expectations?

o Were your expectations met?

$\checkmark \quad$ Do you have the feeling that treatment is effective? And if so, how do you notice? 
o It is possible that treatment reduces your blood loss, pain etc. Have you experienced this?

o Do you feel that your general quality of life has improved? If so, how do you notice?

$\checkmark \quad$ To what extent are you happy with your treatment?

o What are you most satisfied about?

$\checkmark \quad$ Does the treatment live up to your expectations?

$\checkmark$ Are there any issues that we haven't discussed that you would like to tell me about?Do you have any final questions? 


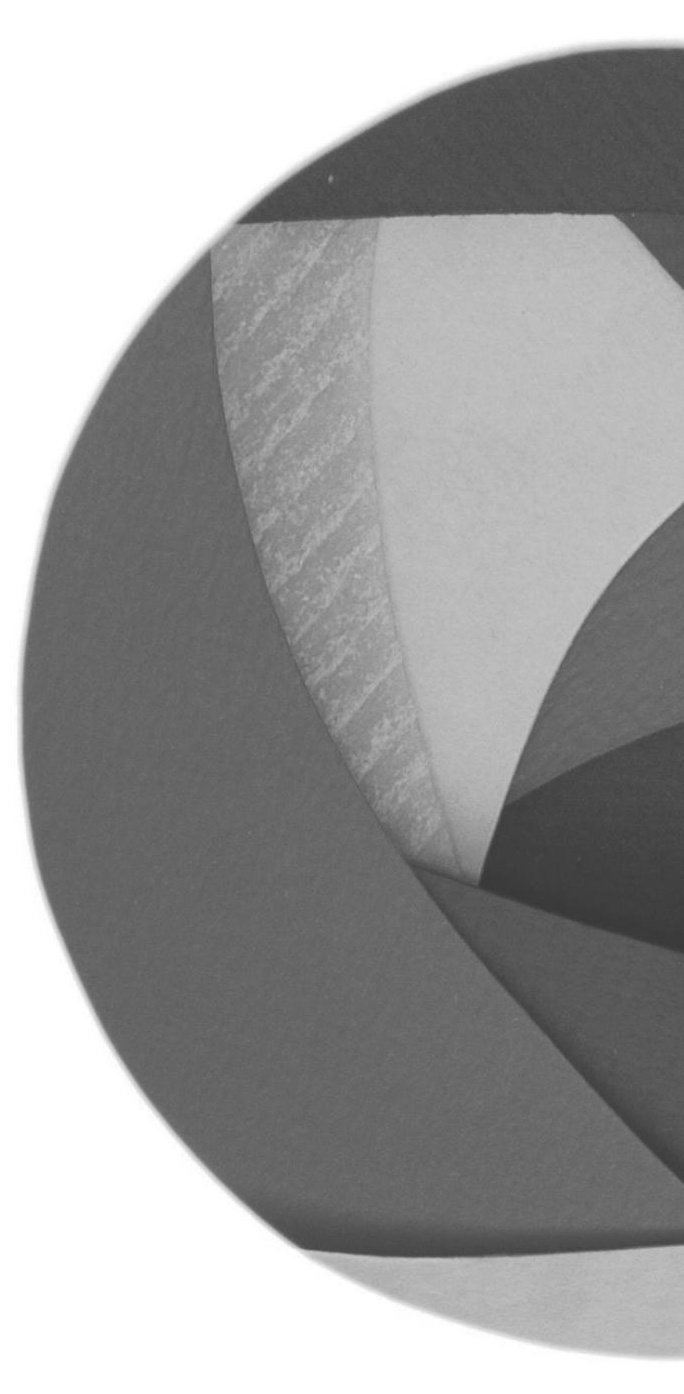




\section{Abstract}

Purpose In this study, we describe current practices in the management of hemorrhoidal disease in the Netherlands.

Methods A validated online survey was performed among Dutch surgeons and residents treating hemorrhoidal disease. Contact details were retrieved from the Dutch Association for Surgery resulting in 619 contacts. Only doctors who were treating hemorrhoidal disease regularly were asked to complete the questionnaire. The following items were assessed: initial treatment, recurrence, complications, and follow-up.

Results In total, 133 respondents completed the survey. Ninety percent of the respondents started with rubber band ligation (RBL) as the first treatment in low-grade hemorrhoidal disease. In case of recurrence, $64 \%$ of the respondents repeated RBL three times before switching to a more invasive treatment modality. In grade III hemorrhoidal disease, the respondents preferred more invasive techniques: a sutured hemorrhoidopexy was performed in 24\%, Doppler-guided hemorrhoidal artery ligation (DG- HAL) in $9 \%$, stapled hemorrhoidopexy in 19\%, and the traditional hemorrhoidectomy in $31 \%$ of the patients, respectively. The majority of the respondents (39\%) reported a mild complication in $5-10 \%$ of the patients. The most reported complication was pain. Nearly all the respondents (98\%) reported a major complication in less than $5 \%$ of the patients. The majority of the patients (57\%) were seen in outpatient clinics 6 weeks' post-treatment.

Conclusion This Dutch survey showed areas of common practice for primary treatment of hemorrhoidal disease. However, it also demonstrated varying practices regarding recurrent hemorrhoidal disease. Practical guidelines are required to support colorectal surgeons in the Netherlands. 


\section{Introduction}

Hemorrhoidal disease (HD) is a common pathology with prevalence rates of up to $44 \%$ within the general population [1-3]. Hemorrhoids are usually classified by their location and by the presence and severity of prolapse. The most widely accepted classification is the Goligher classification [4]. Initial treatment of grades I-II HD is quite uniform.

Conservative treatment including diet, lifestyle changes, and application of topical ointments is mostly offered as a first step [5-7]. In case of persistent symptoms, patients are usually treated with Rubber Band Ligation (RBL) [8]. However, it is still unclear what the best next treatment modality is in case of recurrence after several failed RBL attempts.

Grades III and IV HD is often treated in a more invasive way, thereby skipping the first two steps. Similar to recurrence after RBL for grade I and II disease, there remains a debate what the best (surgical) treatment option is in case of recurrence.

Over the past two decades, knowledge of the anatomy of hemorrhoids has improved, leading to the introduction of new surgical technologies. This was accompanied by many studies comparing several surgical treatments including the Doppler- guided hemorrhoidal artery ligation (DG-HAL) with or without recto-anal repair (RAR) [911], a sutured hemorrhoidopexy [12, 13], the stapled hemorrhoidopexy (SH) [14-16], and the traditional hemorrhoidectomy [17-20].

However, systematic reviews [21, 22] and guidelines [23, 24] including a Dutch guideline of Dunker et al. (published in a Dutch guideline database) highlighted the lack of a high level of evidence which is mandatory to develop an optimal treatment algorithm. Recently, two high-quality RCTs have been published [25, 26]. Results of these studies may not have been implemented in clinical practice yet.

Besides, as many studies use different outcomes assessing treatment effect, data of these studies cannot easily be compared or pooled into a single inference. As a result, it is difficult to determine what treatment yields the highest clinical benefit for each grade or what treatment is advocated in case of recurrence.

The aim of the present study was to assess current practice in (surgical) treatment of HD using a national survey among officially registered Dutch colorectal consultants, fellows, and residents in the Netherlands. Besides the complications for each treatment and outcome, parameters to determine treatment success were recorded. 


\section{Materials and methods}

\section{Design of the survey}

Two surgical residents (RS, RT) formulated the questions of the survey. These questions were edited by a colorectal surgeon (SB). After making adjustments, the survey was reviewed by a second colorectal surgeon (LS).

The survey was created using a validated web-based program [27]. The survey consisted of 30 items: 13 multiple- choice questions, 14 optional questions, and three open ended questions with a total word count of 1144 words. The questionnaire was developed in Dutch [see Appendix 1 for a version translated to English]. In order to check comprehensibility and content validity of the survey, several rounds of pilot testing were conducted before its actual distribution.

\section{Survey distribution}

We distributed the survey among officially registered Dutch colorectal consultants, fellows and residents. Contact details were retrieved from the Dutch Association for Surgery resulting in 619 contacts. Only doctors who were treating patients with HD regularly at the time of the questionnaire, irrespective of the number of years of experience with the treatment, were asked to complete the questionnaire. A personalized e-mail with a link to the web-based survey was sent to each of them, and a reminder was sent 1 week later.

\section{Data analysis}

Only completed surveys were included in the analysis. Characteristics of the doctors, treatments used for primary and recurrent disease stratified by grade, and the outcome parameters were all described using absolute value and percentage. The complications were estimated as cumulative incidence. All analyses were performed in IBM SPSS version 22.0.

\section{Definitions}

Conservative treatment consisted of diet, lifestyle changes, and application of topical ointments. Minimally invasive treatment consisted of laser therapy, Doppler-guided hemorrhoidal artery ligation (DG-HAL) (with recto-anal repair (RAR)) or a sutured hemorrhoidopexy. The term 'sutured hemorrhoidopexy' we used in this manuscript is similar to RAR or suture mucopexy described in the literature. However, the term sutured hemorrhoidopexy reflects more precisely the surgical technique; a suture is used for lifting the hemorrhoidal complex to its origin.

Invasive treatment consisted of the stapled hemorrhoidopexy and traditional hemorrhoidectomy. 
We asked two questions regarding complications. First, we asked the respondents 'how often did you see a mild or severe complication after treatment for HD?' The respondents could choose between 1 and $5 \%$ or $5-10 \%$ or $10-20 \%$ or more than $20 \%$. The second question was: 'did you experience 'no' or 'mild' or 'severe' complications after use of either RBL, minimally invasive treatment, or invasive treat- ment?' This question allowed respondents to select more than one answer.

\section{Results}

\section{Characteristics respondents}

Background features of the respondents are shown in Table 1. A total of 100 participants returned a completed survey. The majority of $\mathrm{HD}$ was treated by the department of surgery $(82.4 \%)$. Patients were mostly seen in outpatient clinics for the first time by a resident $(44.2 \%)$ or consultant $(37 \%)$. 


\section{Chapter 6}

Table I Background features respondents

\begin{tabular}{|c|c|c|}
\hline Background features & $\mathrm{N}$ & $(\%)$ \\
\hline \multicolumn{3}{|l|}{ Gender } \\
\hline Male & 76 & $76 \%$ \\
\hline Female & 24 & $24 \%$ \\
\hline \multicolumn{3}{|l|}{ Function participants } \\
\hline Consultant & 84 & $84 \%$ \\
\hline Fellow & 5 & $5 \%$ \\
\hline Resident & 11 & $11 \%$ \\
\hline \multicolumn{3}{|c|}{ Years of experience hemorrhoid treatment } \\
\hline $1-5$ years & 11 & $11 \%$ \\
\hline $5-10$ years & 26 & $26 \%$ \\
\hline $10-20$ years & 39 & $39 \%$ \\
\hline$>20$ years & 24 & $24 \%$ \\
\hline \multicolumn{3}{|l|}{ Type of hospital } \\
\hline District & 85 & $85 \%$ \\
\hline University & 12 & $12 \%$ \\
\hline Private clinic & 3 & $3 \%$ \\
\hline \multicolumn{3}{|c|}{ Treatment by the department } \\
\hline Surgery & 82 & $82 \%$ \\
\hline Gastroenterology & 9 & $9 \%$ \\
\hline Dermatology & 9 & $9 \%$ \\
\hline \multicolumn{3}{|c|}{ Contact first visit outpatient clinic } \\
\hline Consultant & 38 & $38 \%$ \\
\hline Fellow & 12 & $12 \%$ \\
\hline Resident & 44 & $44 \%$ \\
\hline Nurse practitioner & 6 & $6 \%$ \\
\hline
\end{tabular}




\section{Treatment for primary disease}

\section{Primary treatment of grade I disease}

Respondents used RBL in $90 \%$ of the patients as first treatment modality. Regarding minimally invasive treatment, respondents used laser therapy in $<1 \%$ and the sutured hemorrhoidopexy in 3\% of the patients. Regarding invasive treatment, respondents used the stapled hemorrhoidopexy in $1 \%$ of the patients (Figs. 1 and 2 ).

\section{Primary treatment of grade II disease}

Fifty-nine percent of the respondents treated their patients with RBL. Regarding minimally invasive treatment, respondents used laser therapy in $4 \%$, the sutured hemorrhoidopexy in $10 \%$, and the DG-HAL in $10 \%$ of the patients. Regarding invasive treatment, respondents used the stapled hemorrhoidopexy in $2 \%$ and the traditional hemorrhoidectomy in $9 \%$ of the patients (Figs. 1 and 2).

\section{Primary treatment of grade III disease}

Six percent of the respondents used RBL for grade III HD. Regarding minimally invasive treatment, respondents used laser therapy in $4 \%$, sutured hemorrhoidopexy in $24 \%$, and the DG-HAL in $15 \%$ of the patients. Regarding invasive treatment, respondents used the stapled hemorrhoidopexy in 19\% and traditional hemorrhoidectomy in $31 \%$ of the patients (Figs. 1 and 2).

\section{Primary treatment of grade IV disease}

Ninety percent of the respondents performed a (minimally) invasive treatment consisting of laser therapy in $2 \%$, sutured hemorrhoidopexy in $21 \%$, DG-HAL in $10 \%$, stapled hemorrhoidopexy in $21 \%$, and traditional hemorrhoidectomy in $37 \%$ of the patients (Figs. 1 and 2). 


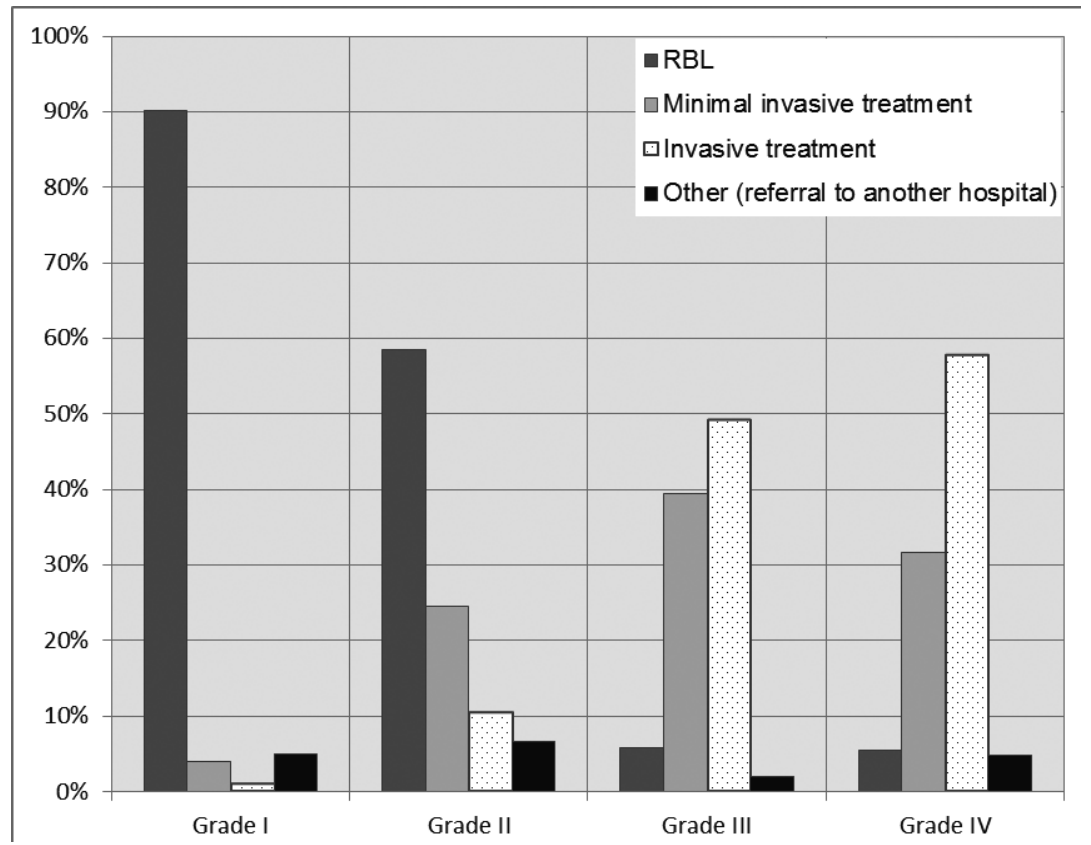

Figure I: The use of Rubber band ligation (RBL), minimal invasive treatment (laser therapy or sutured hemorrhoidopexy or Doppler-guided hemorrhoidal artery ligation (DG-HAL)) or invasive treatment (stapled hemorrhoidopexy or traditional hemorrhoidectomy) for grade I-IV hemorrhoidal disease according to the Goligher classification.

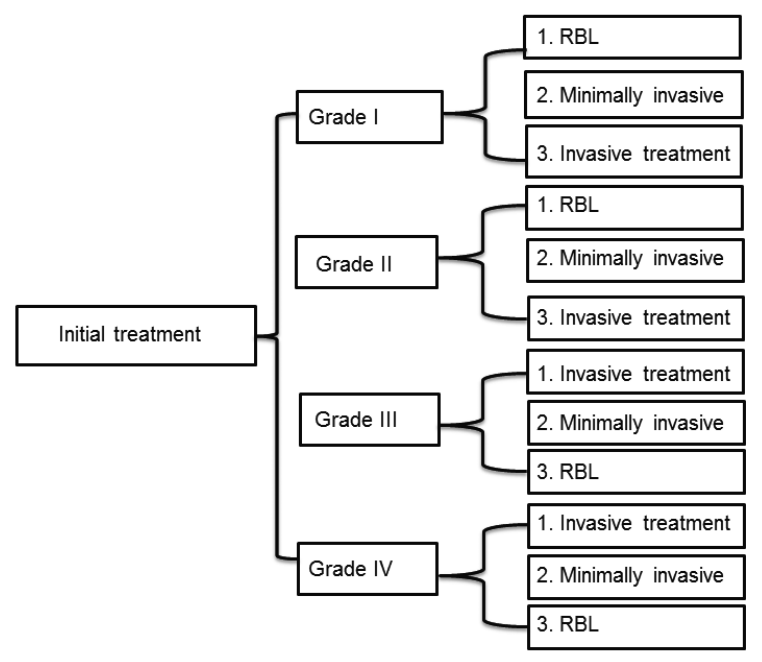

Figure 2: Flow diagram: initial treatment for grade I-IV hemorrhoids (RBL=rubber band ligation, minimal invasive treatment= laser therapy or sutured hemorrhoidopexy or DGHAL and invasive treatment $=$ stapled hemorrhoidopexy and traditional hemorrhoidectomy) 


\section{Treatment for recurrence after initial therapy}

\section{Recurrence after primary treatment of grade I disease}

If complaints persisted in grade I HD, $65 \%$ of the respondents used conservative treatment. Twenty-eight percent of the respondents performed RBL. Regarding minimally invasive treatment, laser therapy is used $<1 \%$ and the sutured hemorrhoidopexy in $2 \%$ of the patients (Figs. 3 and 4).

\section{Recurrence after primary treatment of grade II disease}

Respondents chose for conservative treatment in 32\% and for RBL in $46 \%$ of the patients. Regarding minimally invasive treatment, laser therapy was used in $1 \%$, the sutured hemorrhoidopexy in $8 \%$ and DG-HAL in $4 \%$ of the patients. Regarding invasive treatment, respondents used the stapled hemorrhoidopexy in $2 \%$ and the traditional hemorrhoidectomy in $4 \%$ of the patients (Figs. 3 and 4).

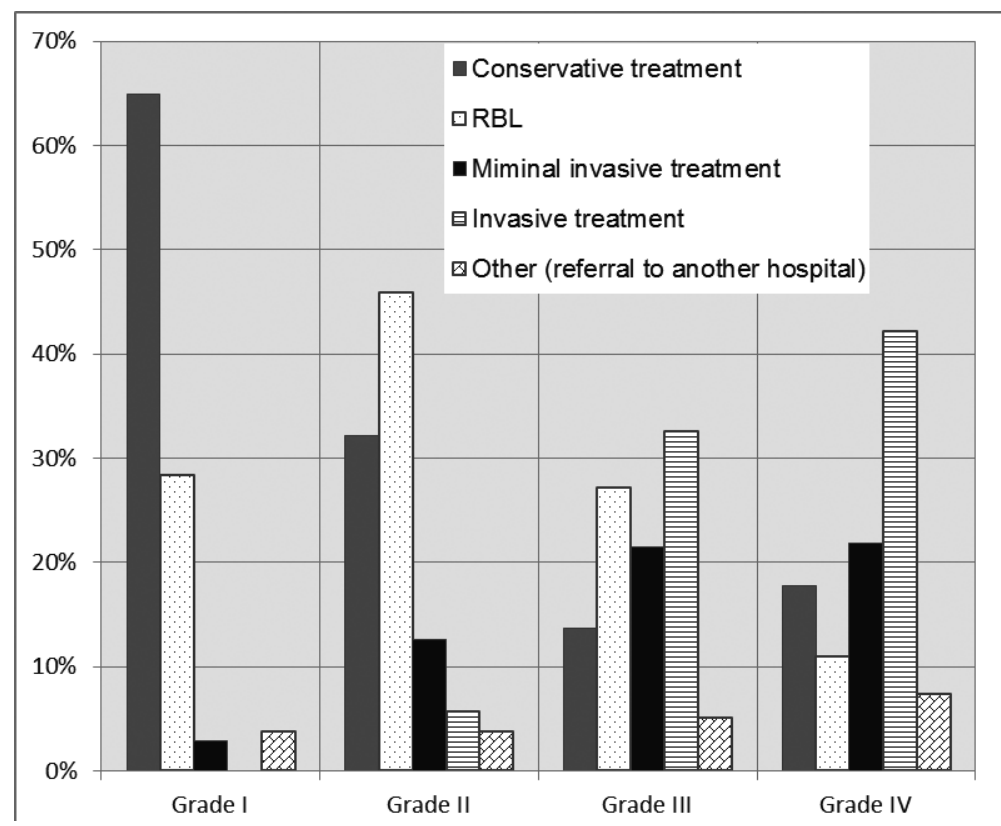

Figure 3: The use of conservative treatment, Rubber band ligation (RBL), minimal invasive treatment (laser therapy or sutured hemorrhoidopexy or DG-HAL) or invasive treatment (stapled hemorrhoidopexy or traditional hemorrhoidectomy) in recurrent grade I-IV hemorrhoidal disease according to the Goligher classification. 


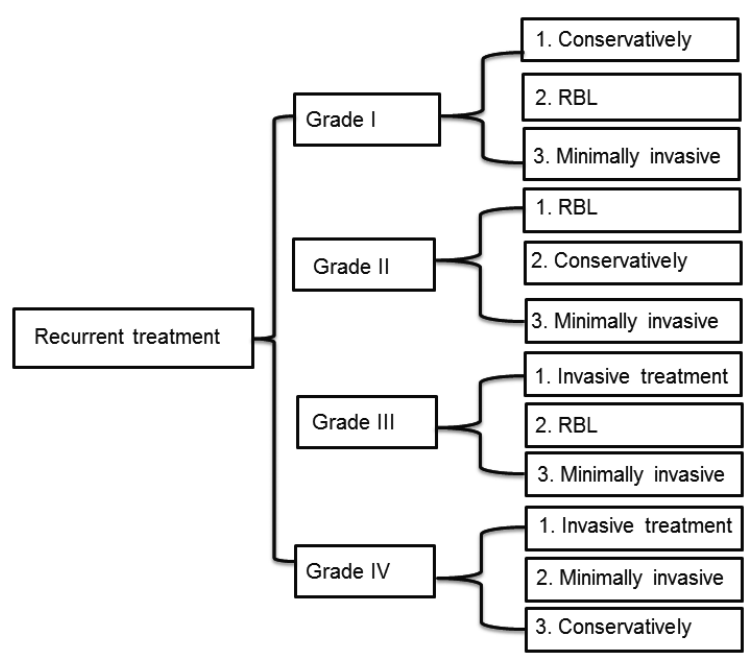

Figure 4: Flow diagram: treatment in case of recurrent hemorrhoids for grade I-IV hemorrhoids $(\mathrm{RBL}=$ rubber band ligation, minimally invasive treatment = laser therapy, sutured hemorrhoidopexy or DG-HAL and invasive treatment = stapled hemorrhoidopexy and traditional hemorrhoidectomy).

\section{Recurrence after primary treatment of grade III disease}

Respondents used conservative treatment in $14 \%$ and RBL in $27 \%$ of the patients. Regarding minimally invasive treatment, respondents used laser therapy in $2 \%$, the sutured hemorrhoidopexy in 13\%, and DG-HAL in $6 \%$ of the patients. Regarding invasive treatment, respondents used the stapled hemorrhoidopexy in $11 \%$ and traditional hemorrhoidectomy in $21 \%$ of the patients (Figs. 3 and 4).

\section{Recurrence after primary treatment of grade IV disease}

Recurrence in grade IV HD was treated conservatively by the respondents in $18 \%$ and RBL in $11 \%$ of the patients. Regarding minimally invasive treatment, respondents used laser therapy in 2\%, the sutured hemorrhoidopexy in $14 \%$ and DG-HAL in $5 \%$ of the patients. Regarding invasive treatment, respondents used the stapled hemorrhoidopexy in $14 \%$ and traditional hemorrhoidectomy in $28 \%$ of the patients (Figs. 3 and 4 ).

In case RBL failed, $80 \%$ of the respondents reported that a patient underwent a new RBL after a mean of 6.4 weeks. Sixty-four percent of the respondents performed two to three attempts of RBL before switching to another treatment option. In $41 \%$ of the cases a RBL was performed by residents. 


\section{Complications}

The majority of respondents (39\%) reported a mild complication in 5-10\% of the patients after any treatment for HD. In Fig. 5, the cumulative reported mild complications are shown for RBL, minimally invasive treatment, and invasive treatment.

Ninety-eight of the respondents reported major complications. Major complications occurred in less than 5\% of the patients after any treatment for HD. In Fig. 6 the cumulative reported severe complications are shown for RBL, minimally invasive treatment, and invasive treatment.

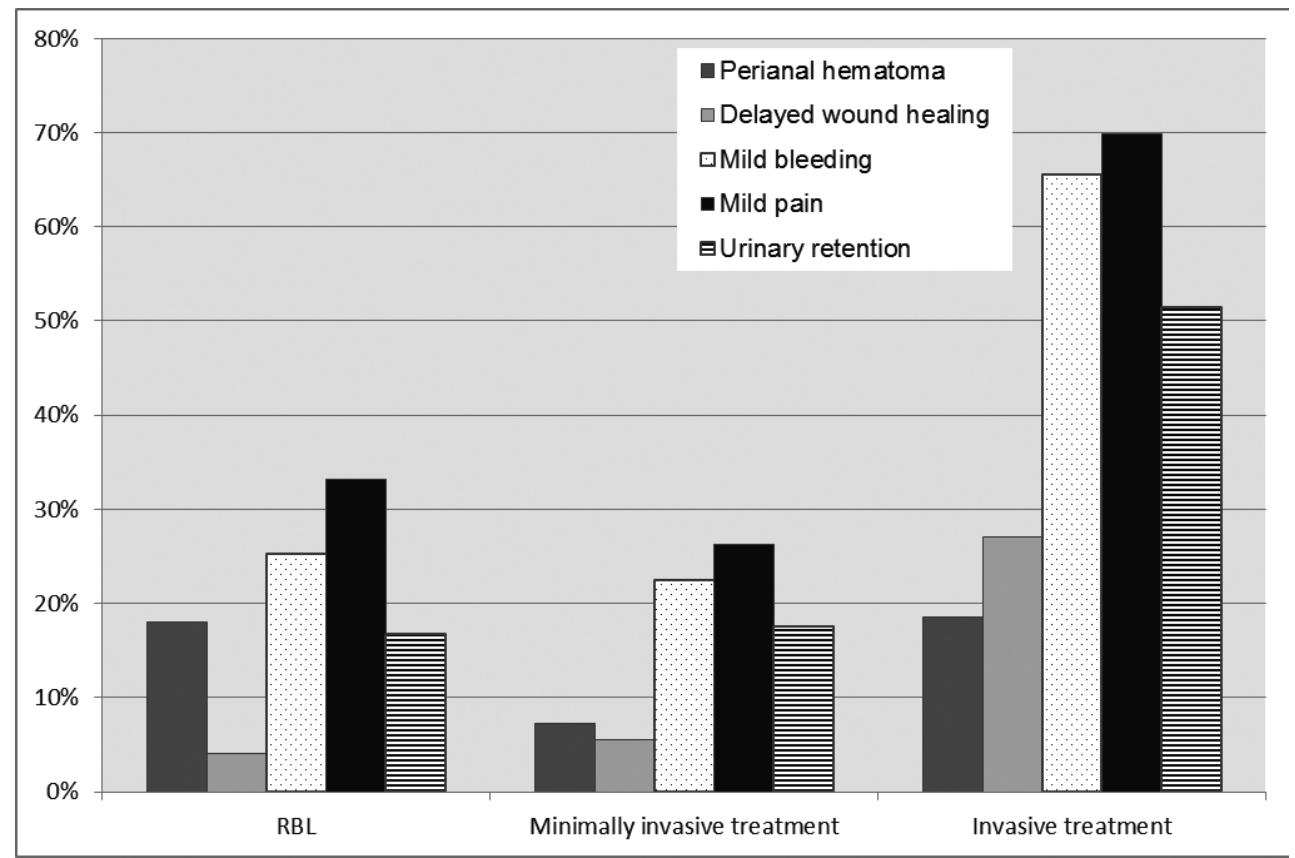

Figure 5: Cumulative reported mild complications (Clavien-dindo I-2) after RBL (Rubber band ligation), minimal invasive treatment (laser therapy or sutured hemorrhoidopexy or DG-HAL) and invasive treatment (stapled hemorrhoidopexy and traditional hemorrhoidectomy). 


\section{Chapter 6}

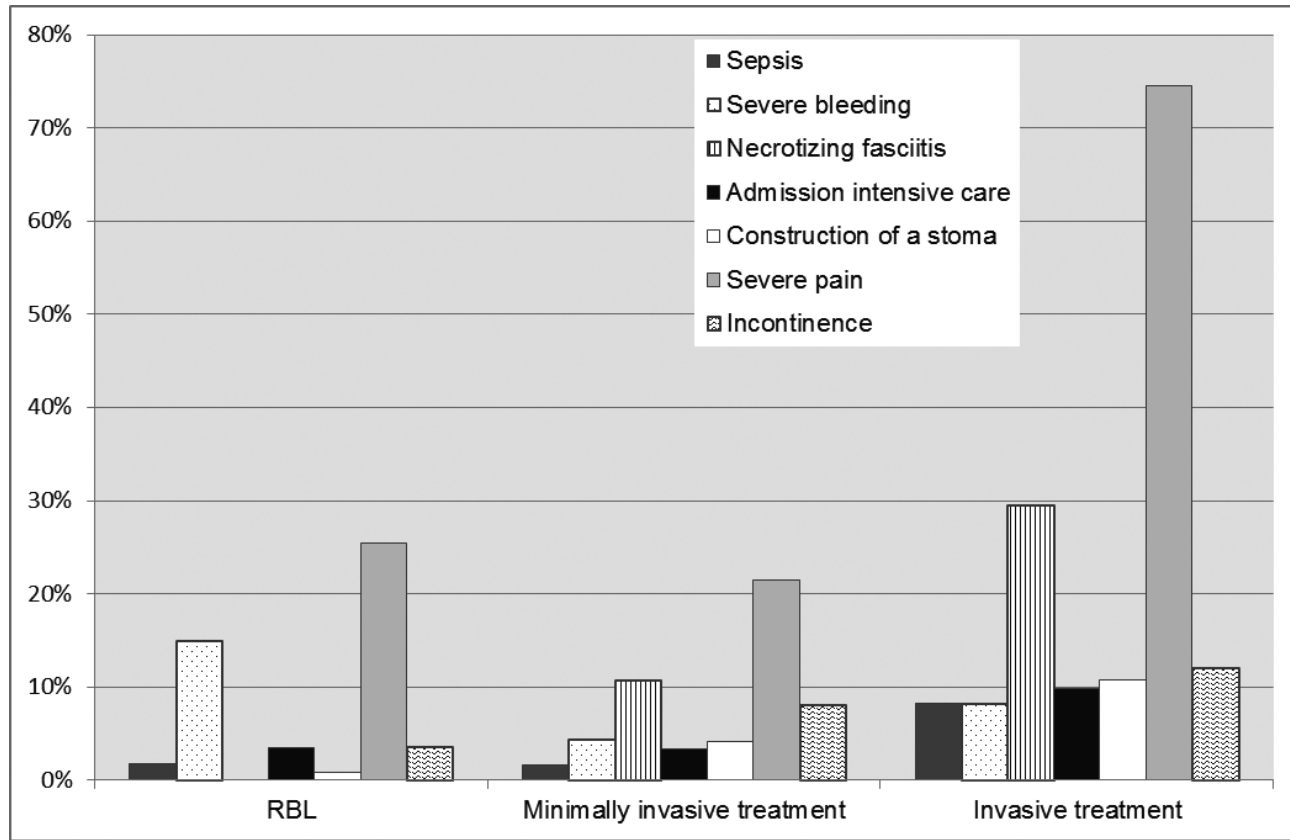

Figure 6: Cumulative reported severe complications (Clavien-dindo 3-5) after RBL (Rubber band ligation), minimal invasive treatment (laser therapy or sutured hemorrhoidopexy or DG-HAL) and invasive treatment (stapled hemorrhoidopexy or traditional hemorrhoidectomy).

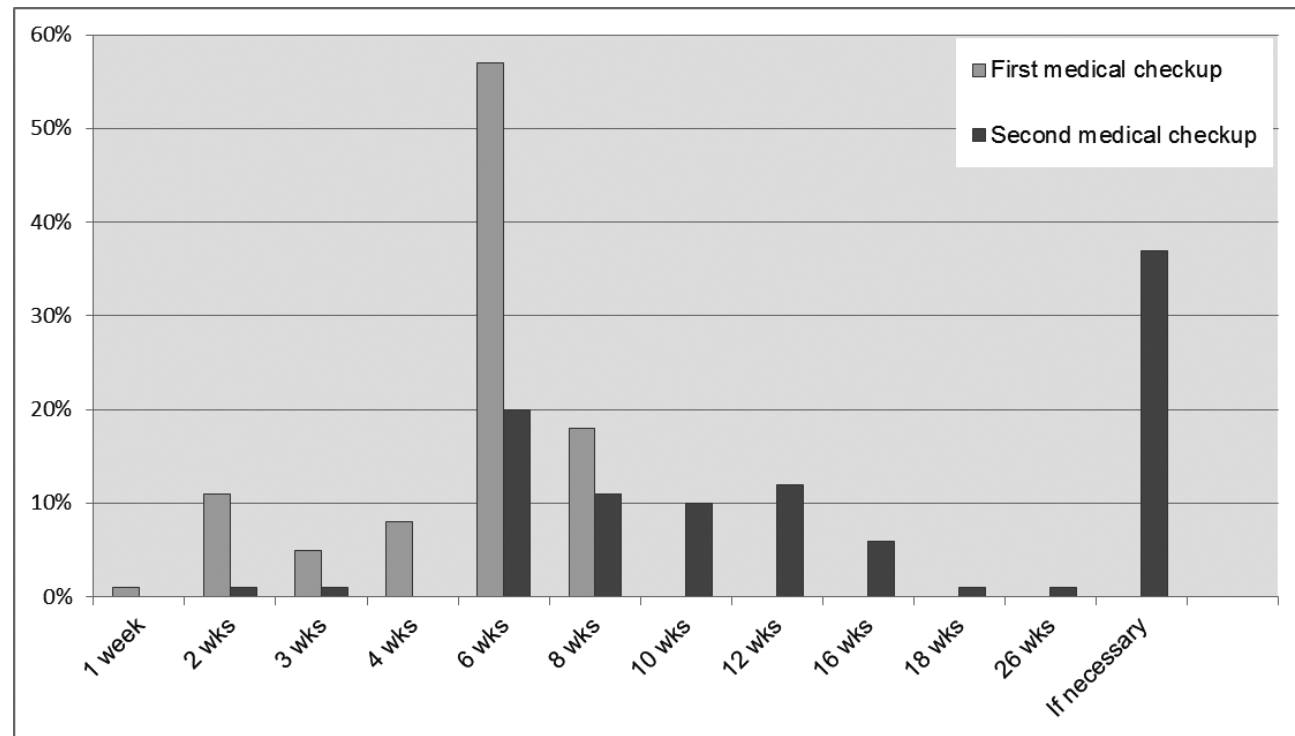

Figure 7: First and second outpatient visit after initial treatment for grade I-IV hemorrhoidal disease. 


\section{Follow-up}

Follow up schedules were quite uniform. Eighty-five percent of the patients were seen six weeks after treatment [Fig. 7]. As primary outcome of success, several definitions were used: $42.5 \%$ of the respondents used 'patient satisfaction' and $36.7 \%$ 'absence of complaints'.

\section{Discussion}

This Dutch survey showed areas of common practice for primary treatment of HD. However, it also demonstrated more varying practices regarding recurrent HD.

Grades I and II HD were mostly treated conservatively or with RBL according to the respondents. This is in accordance with several studies and guidelines describing the optimal treatment for low-grade HD [28-30]. A review, describing seven RCTs with a total number of 378 patients, confirmed better outcome in patients with grades III HD who used increased fiber intake [31]. In a recent RCT, comparing RBL with hemorrhoidal artery ligation (HAL) in 370 patients with grades II and III HD, they showed that HAL resulted in fewer recurrences. However, recurrence was similar to repeat RBL [32]. In grades III and IV HD, most respondents preferred (minimally) invasive treatment instead of RBL as the first treatment option. Recently, two RCTs compared the minimally invasive treatment options Doppler- guided hemorrhoidal artery ligation (DG-HAL) combined with a suture mucopexy versus a suture mucopexy alone. They showed low recurrence rates of $2-10 \%$ after $12-24$ months follow-up for the suture mucopexy group $[12,13,33]$. However, long-term results of the suture mucopexy are limited: only one RCT fulfilled a follow-up of 2 years [13]. Despite the good results, the recurrence rate was high for grade IV $\operatorname{HD}(11-59 \%)[22,34]$.

Respondents used the stapled hemorrhoidopexy or traditional hemorrhoidectomy more often in patients with grades III and IV HD than in patients with grades II and III HD. A meta-analysis of almost 1000 patients demonstrated a higher long-term recurrence rate of $42 \%$ in patients undergoing a stapled hemorrhoidopexy compared to the traditional hemorrhoidectomy $(25 \%)[26,35]$. Recently, Watson et al. conducted a multicenter RCT, comparing stapled hemorrhoidopexy to traditional excisional surgery in 777 patients with grade III HD. The overall quality of life was significantly better after traditional hemorrhoidectomy with a follow-up of 24 months. They concluded that the traditional hemorrhoidectomy is superior for the primary management of grades II-IV hemorrhoidal disease compared to the stapled hemorrhoidopexy [26].

In case of recurrent grades I and II HD, most respondents used conservative treatment or performed RBL. For recurrent grades III and IV HD, respondents used more often invasive treatments. As there are to our knowledge no studies focusing on what to do in 
case of recurrent $\mathrm{HD}$, there remains a debate what the next step should be in these patients. Ideally, an international guideline will be conducted for primary and recurrent treatment of HD. A barrier for such treatment algorithm is the lack of a known uniformly accepted core outcome set (COS). Comparing data and pooling results of clinical trials used in evidence-based health care, can only be conducted if outcomes are comparable. Therefore, we started the development of a COS assessing the treatment for HD in clinical trials [36].

Some limitations of this study should be noted. Firstly, the grading of hemorrhoids can be surgeon dependent. This may result in a wide variation in classification of the severity of hemorrhoids. Secondly, the frequency of grade IV hemorrhoids is less common than the grades I, II, and III hemorrhoids. Some respondents may not have clinical experience in the treatment of grade IV hemorrhoids. Thirdly, due to the lack of a central database comprising detailed information of Dutch surgeons, the survey was sent to all Dutch colorectal consultants, fellows, and surgical residents of the Dutch Association for Surgery. They were requested to reply only in case the respondent was treated for HD regularly. This approach lacks insight in the exact response of the target population. Fourthly, due to the nature of surveys: respondents represent an intrinsic selection bias and answer options may be interpreted differently by different responders. Fifthly, the study surveyed only Dutch colorectal consultants and residents; therefore, the results cannot be generalized to surgeons worldwide. In most countries, daily care for patients with HD is conducted by surgeons. Therefore, in our survey we only assessed the surgical point of view regarding HD treatment. But we are aware that in some countries other healthcare professionals like gastroenterologists and dermatologists are involved in daily care for these patients.

\section{Conclusion}

This survey showed that there remains considerable variation in the treatment of HD, especially in case of recurrence, in the Netherlands. This implies a need for an evidencebased (international) guideline regarding the treatment of HD. 


\section{A national evaluation of the management practices of hemorrhoidal disease in the Netherlands}

\section{References}

1. Russell, MMG, Ko CY (2012) Management of hemorrhoids: main- stay of treatment remains diet modification and office-based proce- dures July 16, 2012

2. Loder PB, Kamm MA, Nicholls RJ, Phillips RKS (1994) Haemorrhoids: pathology, pathophysiology and aetiology. Br J Surg 81(7):946-954

3. Riss S, Weiser FA, Schwameis K, Riss T, Mittlböck M, Steiner G, Stift A (2012) The prevalence of hemorrhoids in adults. Int J Color Dis 27(2):215-220

4. Elbetti C, Giani I, Novelli E, Fucini C, Martellucci J (2015) The single pile classification: a new tool for the classification of haemorrhoidal disease and the comparison of treatment results. Updat Surg 67(4):421-426

5. Alonso-Coello P et al (2005) Laxatives for the treatment of hemor- rhoids. Cochrane Database Syst Rev 4:CD004649

6. Alonso-Coello P, Zhou Q, Martinez-Zapata MJ, Mills E, Heels- Ansdell D, Johanson JF, Guyatt G (2006) Meta-analysis of flavo- noids for the treatment of haemorrhoids. Br J Surg 93(8):909-920

7. Perera N et al (2012) Phlebotonics for haemorrhoids. Cochrane Database Syst Rev 8:CD004322

8. MacRae HM, McLeod RS (1997) Comparison of hemorrhoidal treatments: a meta-analysis. Can J Surg 40(1):14-17

9. Hoyuela C, Carvajal F, Juvany M, Troyano D, Trias M, Martrat A, Ardid J, Obiols J (2016) HALRAR (Doppler guided haemorrhoid artery ligation with recto-anal repair) is a safe and effective proce- dure for haemorrhoids. Results of a prospective study after two- years follow-up. Int J Surg 28:39-44

10. Faucheron JL, Trilling B, Reche F (2015) HAL-RAR(R) procedure: a safe operation for hemorrhoids. J Visc Surg 152(2):143-144

11. Faucheron JL, Poncet G, Voirin D, Badic B, Gangner Y (2011) Doppler-guided hemorrhoidal artery ligation and rectoanal repair (HAL-RAR) for the treatment of grade IV hemorrhoids: longterm results in 100 consecutive patients. Dis Colon Rectum 54(2): 226-231

12. Aigner F, Kronberger I, Oberwalder M, Loizides A, Ulmer H, Gruber L, Pratschke J, Peer S, Gruber H (2016) Doppler-guided haemorrhoidal artery ligation with suture mucopexy compared with suture mucopexy alone for the treatment of grade III haemorrhoids: a prospective randomized controlled trial. Color Dis 18(7):710-716

13. Zhai $\mathrm{M}$ et al (2016) A randomized controlled trial comparing suture-fixation mucopexy and Doppler-guided hemorrhoidal artery ligation in patients with grade III hemorrhoids. Gastroenterol Res Pract 2016:8143703

14. Shanmugam V, Muthukumarasamy G, Cook JA, Vale L, Watson AJ, Loudon MA (2010) Randomized controlled trial comparing rubber band ligation with stapled haemorrhoidopexy for grade II circumferential haemorrhoids: long-term results. Color Dis 12(6): 579-586

15. Longo A (2002) Stapled anopexy and stapled hemorrhoidectomy: two opposite concepts and procedures. Dis Colon Rectum 45(4): 571-572 author reply 572 


\section{Chapter 6}

16. Burch J et al (2008) Stapled haemorrhoidectomy (haemorrhoidopexy) for the treatment of haemorrhoids: a systematic review and economic evaluation. Health Technol Assess 12(8): p. iii-iv, ix-x, 1-193

17. Majeed S et al (2015) Comparison of open and closed techniques of haemorrhoidectomy in terms of post-operative complications. J Ayub Med Coll Abbottabad 27(4):791-793

18. Arroyo A, Pérez F, Miranda E, Serrano P, Candela F, Lacueva J, Hernández H, Calpena R (2004) Open versus closed day-case haemorrhoidectomy: is there any difference? results of a prospec- tive randomised study. Int J Colorectal Dis 19(4):370-373

19. Bouchard D, Abramowitz L, Castinel A, Suduca JM, Staumont G, Soudan D, Devulder F, Pigot F, Varastet M, Ganansia R, Groupe de Recherche En Proctologie de la Société Nationale Française de Colo-Proctologie (GREP), Club de Réflexion des cabinets et Groupe d'Hépato-Gastroentérologie (CREGG) (2013) One-year outcome of haemorrhoidectomy: a prospective multicentre French study. Color Dis 15(6):719-726

20. Shanmugam V, Thaha MA, Rabindranath KS, Campbell KL, Steele RJC, Loudon MA (2005) Systematic review of ran- domized trials comparing rubber band ligation with excision- al haemorrhoidectomy. Br J Surg 92(12):1481-1487

21. Pucher PH, Sodergren MH, Lord AC, Darzi A, Ziprin P (2013) Clinical outcome following Doppler-guided haemorrhoidal artery ligation: a systematic review. Color Dis 15(6):e284-e294

22. Giordano P, Overton J, Madeddu F, Zaman S, Gravante G (2009) Transanal hemorrhoidal dearterialization: a systematic review. Dis Colon Rectum 52(9):1665-1671

23. Rivadeneira DE, Steele SR, Ternent C, Chalasani S, Buie WD, Rafferty JL, Standards Practice Task Force of The American Society of Colon and Rectal Surgeons (2011) Practice parameters for the management of hemorrhoids (revised 2010). Dis Colon Rectum 54(9):1059-1064

24. Cataldo P, Ellis CN, Gregorcyk S, Hyman N, Buie WD, Church J, Cohen J, Fleshner P, Kilkenny J 3rd, Ko C, Levien D, Nelson R, Newstead G, Orsay C, Perry WB, Rakinic J, Shellito P, Strong

S, Ternent C, Tjandra J, Whiteford M, Standards Practice Task Force, The American Society of Colon and Rectal Surgeons, USA (2005) Practice parameters for the management of hemorrhoids (revised). Dis Colon Rectum 48(2):189-194

25. Brown S, Tiernan J, Biggs K, Hind D, Shephard N, Bradburn M, Wailoo A, Alshreef A, Swaby L, Watson A, Radley S, Jones O, Skaife P, Agarwal A, Giordano P, Lamah M, Cartmell M, Davies J, Faiz O, Nugent K, Clarke A, MacDonald A, Conaghan P, Ziprin P, Makhija R (2016) The HubBLe trial: haemorrhoidal artery ligation (HAL) versus rubber band ligation (RBL) for symptomatic second- and third-degree haemorrhoids: a multicentre randomised con- trolled trial and healtheconomic evaluation. Health Technol Assess 20(88):1-150

26. Watson AJ, Hudson J, Wood J, Kilonzo M, Brown SR, McDonald A, Norrie J, Bruhn H, Cook JA, eTHoS study group (2016) Comparison of stapled haemorrhoidopexy with traditional exci- sional surgery for haemorrhoidal disease $(\mathrm{eTHoS})$ : a pragmatic, multicentre, randomised controlled trial. Lancet 388(10058): 2375-2385

27. Shaw HM, Milton GW, Farago G, McCarthy WH (1978) Endocrine influences on survival from malignant melanoma. Cancer 42(2): 669-677 


\section{A national evaluation of the management practices of hemorrhoidal disease in the Netherlands}

28. Rivadeneira DE, Steele SR, Ternent C, Chalasani S, Buie WD, Rafferty JL (2011) Practice parameters for the management of hem- orrhoids (revised 2010). Dis Colon Rectum 45:10591064

29. Cataldo P, Ellis CN, Gregorcyk S, Hyman N, Buie WD, Church J et al (2005) Practice parameters for the management of hemorrhoids (revised). Dis Colon Rectum 48:189-194

30. dr. M.S. Dunker, d.D.D.E.Z., dr. N.A.T. Wijffels, dr. M.J. Lahaye, dr. O. van Ruler, dr. E. Mitalas, dr. R.J.F. Felt-Bersma, drs. M.T. Bousema, dr (2015) P.G. Doornebosch, Richtlijn Proctologie

31. Alonso-Coello P, Mills E, Heels-Ansdell D, Lopez-Yarto M, Zhou Q, Johanson JF, Guyatt G (2006) Fiber for the treatment of hemor- rhoids complications: a systematic review and meta-analysis. Am J Gastroenterol 101(1):181-188

32. Brown SR, Tiernan JP, Watson AJM, Biggs K, Shephard N, Wailoo AJ, Bradburn M, Alshreef A, Hind D, HubBLe Study team (2016) Haemorrhoidal artery ligation versus rubber band ligation for the management of symptomatic second-degree and third-degree haemorrhoids (HubBLe): a multicentre, open-label, randomised controlled trial. Lancet 388(10042):356-364

33. Schuurman JP, Borel Rinkes IH, Go PM (2012) Hemorrhoidal ar-tery ligation procedure with or without Doppler transducer in grade II and III hemorrhoidal disease: a blinded randomized clinical trial. Ann Surg 255(5):840-845

34. Infantino A (2010) Transanal haemorrhoidal artery echodoppler ligation and anopexy (THD) is effective for II and III degree haemorrhoids. A prospective multicentre study. Color Dis 12(12): 1274

35. Nisar PJ, Acheson AG, Neal KR, Scholefield JH (2004) Stapled hemorrhoidopexy compared with conventional hemorrhoidectomy: systematic review of randomized, controlled trials. Dis Colon Rectum 47(11):1837-1845

36. van Tol RR et al (2017) Protocol for the development of a core outcome set (COS) for hemorrhoidal disease: an international Delphi study. Int J Color Dis 32(7):1091-1094 


\section{Appendix I: Questionnaire}

\section{PERSONAL DATA}

- $\quad$ You are a:

- Consultant

- Fellow

- Resident

- $\quad$ Experience in surgery:

- $1-5$ years

- 5-10 years

- 10-20 years

- $>20$ years

- $\quad$ Gender: male/ female

- Do you work fulltime or part time?

\section{DATA HOSPITAL}

- Do you work in an Academic/ non-academic/ private hospital?

- When a patient with hemorrhoids visits the outpatient clinic, he is seen by:

- Consultant

- Fellow

- Resident

- Nurse practitioner

- Other

- Department of treatment:

- Surgery department

- Gastroenterology department

- Dermatology department

- Otherwise

\section{INTERNAL HEMORRHOIDS}

- Classification internal hemorrhoids:

- Goligher classification

- Otherwise

- $\quad$ Treatment of hemorrhoids grade I, II and III?

- Rubber Band Ligation: Grade I, II and III

- Sutured hemorrhoidopexy: Grade I, II and III

- Stapled hemorrhoidopexy: Grade I, II and III 
- Traditional hemorrhoidectomy: Grade I, II and III

- Other: Grade I, II and III

- Treatment of grade IV incarcerated hemorrhoids :

- Conservative

- Lidocaine ointment

- ISDN ointment

- Directly surgical treatment

- Other

\section{BARRON LIGATION}

- $\quad$ Rubber Band Ligation is performed by the:

- Consultant

- Fellow

- Resident

- PA of Nurse Practitioner

- $\quad$ Treatment strategy after failed RBL for grade I-IV hemorrhoidal disease

- One attempt with Barron ligation

- 2- 3 attempts with Barron ligation

- 3-4 attempts with Barron ligation

- 5 or more attempts with Barron ligation

- Surgical procedure

- Other

\section{FIRST TREATMENT}

- Which treatment did you perform in grade I-IV?

- Barron ligation: Grade I, II, III, IV

- Laser therapy: Grade I, II, III, IV

- Sutured hemorrhoidopexy: Grade I, II, III, IV

- Stapled hemorrhoidopexy (PPH/ STARR): Grade I, II, III, IV

- Doppler-guided hemorrhoidal artery ligation (DGHAL): Grade I, II, III, IV

- Doppler-guided hemorrhoidal artery ligation with Recto-Anal Repair (DG-HAL+RAR): Grade I, II, III, IV

- Traditional hemorrhoidectomy Grade I, II, III, IV

- Otherwise (Referral to another hospital) 


\section{TREATMENT AFTER RECURRENCE}

- Which surgical treatment did you perform when RBL failed in grade I, II, III and IV:

- Laser therapy: Grade I, II, III, IV

- Sutured hemorrhoidopexy: Grade I, II, III, IV

- Stapled hemorrhoidopexy (PPH/ STARR): Grade I, II, III, IV

- Doppler-guided hemorrhoidal artery ligation (DGHAL) : Grade I, II, III, IV

- Doppler-guided hemorrhoidal artery ligation with Recto-Anal Repair (DG-HAL+RAR): Grade I, II, III, IV

- Classical hemorrhoidectomy (Milligan-Morgan or Fergusson): Grade I, II, III, IV

- Otherwise (Referral to another hospital)

- Which treatment did you perform when surgical treatment failed in grade I, II, III and IV?

- Barron ligation: Grade I, II, III, IV

- Laser therapy: Grade I, II, III, IV

- Sutured hemorrhoidopexy: Grade I, II, III, IV

- Stapled hemorrhoidopexy (PPH/ STARR): Grade I, II, III, IV

- Doppler-guided hemorrhoidal artery ligation (DGHAL): Grade I, II, III, IV

- Doppler-guided hemorrhoidal artery ligation with Recto-Anal Repair (DG-HAL+RAR): Grade I, II, III, IV

- Classical hemorrhoidectomy (Milligan-Morgan or Fergusson): Grade I, II, III, IV

- Reference to another hospital

- Otherwise

- When did you perform the traditional hemorrhoidectomy?

- Regularly performed for all grades of hemorrhoids

- Only performed at grade III and IV hemorrhoids

- Only performed at incarcerated hemorrhoids

- Only performed when other therapies fail

- Never performed 


\section{COMPLICATIONS}

\section{Mild complications}

- The reported minor complications after use of different surgical treatment options for hemorrhoidal disease:

- Rubber band ligation

o Perianal hematoma

o Delayed wound healing

o $\quad$ Mild bleeding

o Mild pain

o Urinary retention

o Not applicable

- Laser therapy

o Perianal hematoma

o Delayed wound healing

o $\quad$ Mild bleeding

o Mild pain

o Urinary retention

o Not applicable

- Sutured hemorrhoidopexy

o Perianal hematoma

o Delayed wound healing

o $\quad$ Mild bleeding

o Mild pain

o Urinary retention

o Not applicable

- Doppler-guided hemorrhoidal artery ligation (DG-HAL)

o Perianal hematoma

o Delayed wound healing

o $\quad$ Mild bleeding

o Mild pain

o Urinary retention

o Not applicable

- Doppler-guided hemorrhoidal artery ligation with Recto-Anal Repair (DG-HAL+RAR)

o Perianal hematoma

o Delayed wound healing

o $\quad$ Mild bleeding

o Mild pain

o Urinary retention 
o Not applicable

- Stapled hemorrhoidopexy (PPH/ STARR)

o Perianal hematoma

o Delayed wound healing

o $\quad$ Mild bleeding

o Mild pain

o Urinary retention

o Not applicable

- Traditional hemorrhoidectomy

o Perianal hematoma

o Delayed wound healing

o Mild bleeding

o Mild pain

o Urinary retention

o Not applicable

- Most reported mild complication was:

- Perianal hematoma

- Delayed wound healing

- Mild bleeding

- Mild pain

- Urinary retention

- Otherwise

- How often did you see mild complications?

- $1-5 \%$

- $5-10 \%$

- $10-20 \%$

- $>20 \%$

\section{Major complications}

- The reported major complications after use of different surgical treatment options for hemorrhoidal disease:

- Rubber band ligation

$\begin{array}{ll}\text { o } & \text { Sepsis } \\ \text { o } & \text { Fasciitis necroticans } \\ \text { o } & \text { Severe bleeding } \\ \text { o } & \text { Admission IC/MC } \\ \text { o } & \text { Creating a stoma } \\ \text { o } & \text { Severe pain } \\ \text { o } & \text { Incontinence } \\ \text { o } & \text { Not applicable }\end{array}$


- Laser therapy

o Sepsis

o Fasciitis necroticans

o Severe bleeding

o Admission IC/MC

o Creating a stoma

o Severe pain

o Incontinence

o Not applicable

- Sutured hemorrhoidopexy

o Sepsis

o Fasciitis necroticans

o Severe bleeding

o Admission IC/MC

o Creating a stoma

o Severe pain

o Incontinence

o Not applicable

- Doppler-guided hemorrhoidal artery ligation (DG-HAL)

o Sepsis

o Fasciitis necroticans

o Severe bleeding

o Admission IC/MC

o Creating a stoma

o Severe pain

o Incontinence

o Not applicable

- Doppler-guided hemorrhoidal artery ligation with Recto-Anal Repair (DG-HAL+RAR)

$\begin{array}{ll}\text { o } & \text { Sepsis } \\ \text { o } & \text { Fasciitis necroticans } \\ \text { o } & \text { Severe bleeding } \\ \text { o } & \text { Admission IC/MC } \\ \text { o } & \text { Creating a stoma } \\ \text { o } & \text { Severe pain } \\ \text { o } & \text { Incontinence } \\ \text { o } & \text { Not applicable }\end{array}$

- Stapled hemorrhoidopexy (PPH/ STARR)

o Sepsis

o Fasciitis necroticans 


$\begin{array}{ll}\text { o } & \text { Severe bleeding } \\ \text { o } & \text { Admission IC/MC } \\ \text { o } & \text { Creating a stoma } \\ \text { o } & \text { Severe pain } \\ \text { o } & \text { Incontinence } \\ \text { o } & \text { Not applicable } \\ \text { Traditional hemorrhoidectomy } \\ \text { o } & \text { Sepsis } \\ \text { o } & \text { Fasciitis necroticans } \\ \text { o } & \text { Severe bleeding } \\ \text { o } & \text { Admission IC/MC } \\ \text { o } & \text { Creating a stoma } \\ \text { o } & \text { Severe pain } \\ \text { o } & \text { Incontinence } \\ \text { o } & \text { Not applicable }\end{array}$

- How often did you see a major complication?

- $\quad 1-5 \%$

- $\quad 5-10 \%$

- $10-20 \%$

$-\quad>20 \%$

\section{FOLLOW UP}

- What do you use as primary outcome?

- Absence of complaints

- Satisfaction of patient

- Patient does not return to outpatient clinic

- No further treatment is necessary

- No abnormalities visible at control proctology

- $\quad$ First visit outpatient clinic after (surgical) treatment:

(Fill in the number of weeks)

- Second visit outpatient clinic after (surgical) treatment:

(Fill in the number of weeks) 
A national evaluation of the management practices of hemorrhoidal disease in the Netherlands 


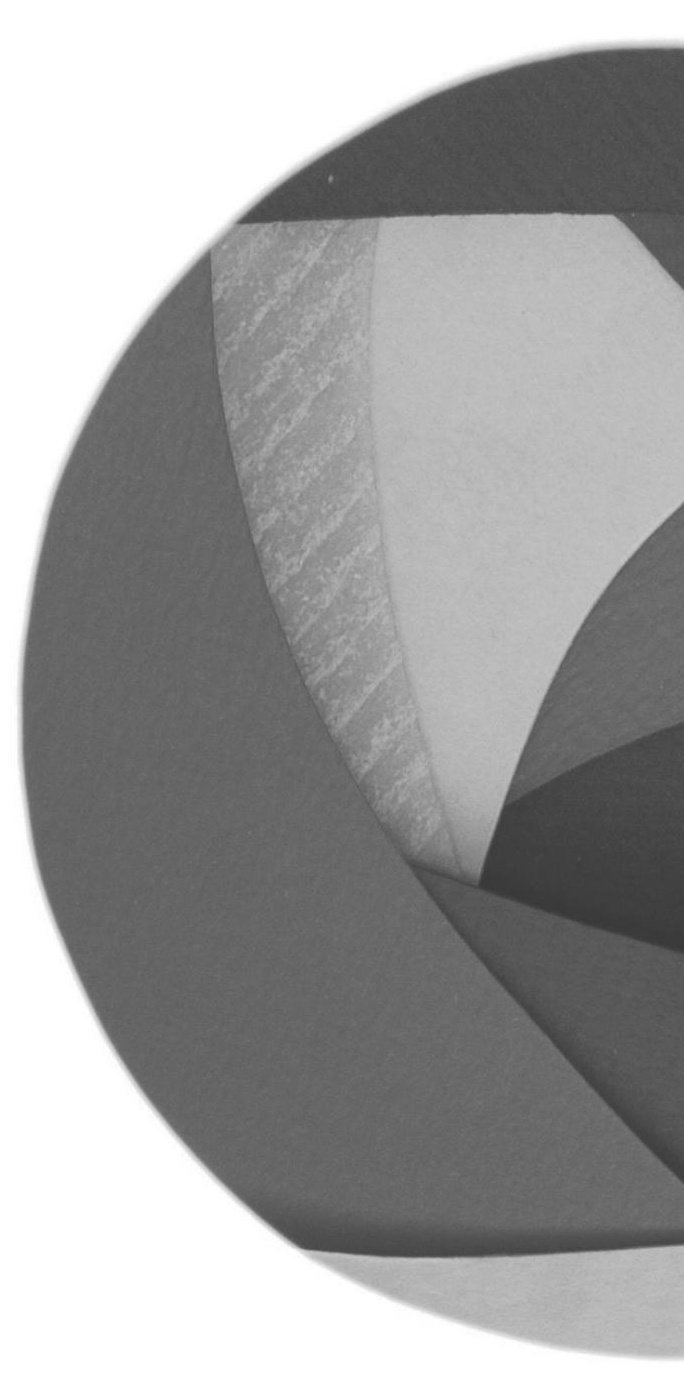




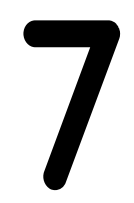

\title{
EUROPEAN SOCIETY OF COLOPROCTOLOGY (ESCP): GUIDELINE FOR HAEMORRHOIDAL DISEASE
}

\author{
ADDENDUM THE DEVELOPMENT \\ OF THE EUROPEAN SOCIETY \\ OF COLOPROCTOLOGY \\ (ESCP) GUIDELINE FOR \\ HAEMORRHOIDAL DISEASE
}




\section{Abstract}

Aim: The goal of this European Society of ColoProctology (ESCP) project was to establish a multidisciplinary, international guideline for haemorrhoidal disease (HD) and to provide guidance on the most effective (surgical) treatment for patients with HD. Methods: The development process consisted of six phases. In phase one we defined the scope of the guideline. The patient population included patients with all stages of haemorrhoids. The target group for the guideline was all practitioners treating patients with haemorrhoids and in addition, healthcare workers and patients who desire information regarding the treatment management of HD. The guideline needed to address both the diagnosis of and the therapeutic modalities for HD. Phase two consisted of the compilation of the guideline development group (GDG). All clinical members needed to have affinity with the diagnosis and treatment of haemorrhoids. Further, attention was paid to geographical distribution of the clinicians. Each GDG member identified at least one patient in their country who could read English to comment on the draft guideline. In phase three review questions were formulated, using a reversed process, starting with possible recommendations based on the GDG's knowledge. In phase four a literature search was performed in MEDLINE (Ovid), PubMed, EMBASE (Ovid), and the Cochrane Database of Systematic Reviews. The search was focused on existing systematic reviews addressing each review question, supplemented by other studies published after the time frame covered by the systematic reviews. In phase five data of the included papers were extracted by the surgical resident (RT) and checked by the methodologist (JK) and the GDG. If needed, meta-analysis of the systematic reviews was updated by the surgical resident and the methodologist using Review Manager (RevMan). During phase six the GDG members decided what recommendations could be made based on the evidence found in literature using GRADE.

Results: Six sections: 1) symptoms, diagnosis \& classification, 2) basic treatment, 3) outpatient procedures, 4) surgical interventions, 5) special situations, 6) other surgical techniques.34 recommendations were formulated.

Conclusion: This international, multidisciplinary guideline provides an up to date and evidence based summary of the current knowledge of the management of HD and may serve as a useful guide for patients and clinicians. 


\section{Introduction}

Haemorrhoidal disease (HD) is one of the most frequent anorectal disorders. The prevalence rates vary between 4,4 and $45 \%$ (1-4).

Over the past decades, an enormous amount of HD research, including several national guidelines, has been conducted (5-7). The most recently published national guideline is from the German guideline committee published in March 2019 (https://www.awmf. org/leitlinien/detail/1//081-007.html. There is a newly updated guideline from the American Society of Colon and Rectal Surgeons (ASCRS) (7). These guidelines could be improved with more robust methodology on how the recommendations were formulated. The AGREE Enterprise developed the first instrumentto assess the quality and reporting of guidelines (8). According to the AGREE checklist, existing national HD guidelines do not describe rigorous development methodology. The guidelines often do not report their review questions or the methods used for formulating their recommendations.

The aim of this guideline was to develop an international, multidisciplinary, high quality guideline in collaboration with the European Society of Coloproctology (ESCP) addressing both the diagnosis of and the therapy for HD.

\section{Methodology}

The full methodology has been published on the ESCP website https://www.escp. eu.com/images/guidelines/documents/Development-ESCP-Guideline-HaemorrhoidalDisease.pdf. The development process consisted of six phases.

\section{Phase one: setting the scope}

In phase one we defined the scope of the guideline taking into account the patient, the target group and the different treatment modalities.

We decided that the guideline should apply to patients with all stages of HD in whom (surgical) interventions are being considered. The target audience is all practitioners treating patients with HD (e.g. general practitioners, surgeons, gastroenterologists, dermatologists), healthcare workers and patients who desire information about the management of HD. The guideline needed to address both the diagnosis of and therapy for haemorrhoids..

\section{Phase two: compilation of guideline development group (GDG)}

In phase two we created the guideline development group (GDG). All clinical members of the GDG had to have an affinity with the diagnosis and treatment of patients with haemorrhoids. In addition, a geographical spread of clinicians from Europe was wished for, as the guideline is aimed at an international audience. We asked all international representatives of the ESCP to participate. Most representatives replied that they did not 
treat $\mathrm{HD}$ or they felt that they were not experienced enough to provide input. Following their recommendations, healthcare professionals with an in-depth understanding of HD and/or development of guidelines were invited using the so-called "snowball method". The guideline development group (GDG) included members from six European countries (Denmark, Italy, France, Germany, the Netherlands and the UK) and it consisted of five colorectal surgeons ( $\mathrm{SB}, \mathrm{DA}, \mathrm{JJ}, \mathrm{NQ}, \mathrm{AW}$ ), one gastroenterologist (TH), one general practitioner (JM), one surgical resident (RT) and one methodologist (JK) with extensive experience in guideline development. One dermatologist $(\mathrm{CH})$ commented on the guideline drafts, but was not a member of the GDG. Each GDG member identified at least one patient in their country who could read English to comment on the draft guideline.

The GDG members were assisted by a team of methodologists (staff at Kleijnen Systematic Reviews Ltd).

\section{Phase three: formulating review questions}

In phase three we developed the first set of review questions. The review questions were built up using a reverse process, starting with possible recommendations based on the GDG's knowledge of practice. Budgetary constraints necessitated an efficient and pragmatic process. The review questions functioned as a framework for the design of the literature searches, informed the planning and process of the evidence review, and acted as a guide for the development of recommendations by the GDG. Review questions were altered and clustered into the following 6 sections: 1) symptoms, diagnosis \& classification, 2) basic treatment, 3) outpatient procedures, 4) surgical interventions, 5) special situations (e.g. thrombosed haemorrhoids, coagulation defect, immunodeficiency and pregnant women) and 6 ) other surgical techniques

\section{Phase four: literature searches}

In phase four, we performed literature searches based on the review questions in MEDLINE, PubMed, EMBASE, and the Cochrane Database of Systematic Reviews. There were no restrictions concerning publication format or language. The search was limited by date $(<25$ years) and conducted in August 2017. See appendix X for the complete search.

Titles and abstracts were screened for inclusion by the surgical resident (RT). All GDG members added relevant studies from their own knowledge, to the search.

Inclusion focused on the available systematic reviews addressing each review question, supplemented by further studies published after the time frame covered by the systematic reviews. We used a hierarchy of best available evidence for study selection, i.e. well performed systematic reviews with or without meta-analyses, randomized trials, controlled observational studies, case series and expert opinion. If evidence of a higher level was available, no lower level of evidence was sought or included. 


\section{Phase five: reviewing evidence of literature}

In phase five, data of the included papers were extracted by the surgical resident (RT) and checked by the methodologist (JK) and the GDG.

If needed, we updated high quality systematic reviews, or included the primary studies of the review, to create a new review. Meta-analysis from the systematic reviews were updated by the surgical resident and the methodologist using Review Manager (RevMan) [Computer program] version 5.3 software.

Quality assessment of the included papers consisted of a systematic process using the ROBIS tool to assess bias by considering the appropriateness of the study design and the methods of the study. The full ROBIS tool and guidance documents are available on the ROBIS website (www.robis-tool.info) or using the link www.jclinepi.com. We used the Cochrane checklist for assessing risk of bias of randomized trials.

\section{Phase six: developing and wording recommendations}

In phase six, the GDG members decided what recommendations could be made based on the evidence found in literature using GRADE (9). In case of high evidence, the term 'must', was implemented in the guideline. Concerning moderate evidence, we used the wording 'should or could'. For low graded evidence we used 'could or may', and for very low evidence 'can be considered'. No Delphi process was conducted, GDG reached consensus on all recommendations. In case of minority dissent, we planned to explicitly report this; however, full consensus was reached on all recommendations. This process is also stated in the development paper (https://www.escp.eu.com/images/guidelines/ documents/Development-ESCP-Guideline-Haemorrhoidal-Disease.pdf).

The draft version of the guideline was posted on the ESCP website for one month for consultation. In addition, Dutch, British, German, Italian and French patients were asked to read the guideline in its final form and were asked to give feedback.

The ESCP Guideline for the management of HD will be updated on an annual basis starting in 2020. This will involve an update of searches and consideration whether recommendations need to be adapted or changed. The guideline group plans to reconvene at annual ESCP conferences to discuss an updated version of the guideline. 


\section{Results}

This guideline includes the following 6 sections: 1) symptoms, diagnosis $\&$ classification, 2) basic treatment, 3) outpatient procedures, 4) surgical interventions, 5) special situations (e.g. thrombosed haemorrhoids, coagulation defect, immunodeficiency and pregnant women) and 6) other surgical techniques. For the extended version of the guideline we want to refer to: https://www.escp.eu.com/images/guidelines/documents/ ESCP-Guidelines-Haemorrhoidal-Disease-2019-02.pdf.

This guideline includes 34 recommendations which provide guidance of the most effective management of patients having HD.

\section{Evaluation: symptoms, diagnosis and classification}

We found little useful evidence for this chapter and the recommendations were predominantly based on expert opinion. The strongest wording used in the recommendations was "should".

1.1 Healthcare providers should make a provisional diagnosis of HD based on the clinical history whilst also thinking about the presence of other diseases like colorectal cancer and IBD.

Expert opinion, upgraded by guideline development group.

1.2 Inspection and physical examination of the anorectal region should be performed to exclude other anorectal pathology.

Expert opinion, upgraded by guideline development group.

1.3 A procedure (e.g. rigid anoscope, proctoscope or rectoscope) to visualize the entire anal canal must be performed in order to diagnose and to classify the severity of haemorrhoidal disease and to exclude other anal pathology.

Expert opinion, upgraded by guideline development group.

1.4 If there are any indications found during history taking or physical examination of colorectal cancer or IBD, the relevant (inter)national guidelines for these conditions should be applied.

Expert opinion, upgraded by guideline development group. 
1.5 Physical examination should be performed in a position that facilitates reliable diagnosis and comfort for the patient; i.e. the left lateral position. Lithotomy and knee-chest position may be alternatives.

Expert opinion, upgraded by guideline development group.

1.6 If a provisional diagnosis of haemorrhoidal disease has been made, basic treatment (i.e. toilet training, laxatives, local anaesthetics and phlebotonics) can be started. Patients with refractory symptoms should be referred.

Expert opinion, upgraded by guideline development group.

See the following chapter 'basic treatment' for evidence regarding toilet training, dietary changes (specifically high fiber diet), topical and pharmacological treatments which may include phlebotonics such as flavonoids.

1.7 For documentation and classification, the Goligher classification has been used most widely and could be used in order to help healthcare providers choose the best therapeutic option for each patient.

Expert opinion, upgraded by guideline development group.

Other recently developed classifications include PATE, the Single Pile Classification (SPC) and a classification by Lunniss et al.(10-12). These classifications might be interesting, but clinically less usable than the Goligher classification. Altogether, we found no evidence favoring one classification over another.

\section{Basic treatment}

When a patient visits the outpatient clinic with anorectal symptoms which may include bleeding, pain, prolapse, itching and/or soiling and the healthcare provider has diagnosed haemorrhoids and excluded the presence of colorectal cancer or inflammatory bowel disease, patients can be first reassured that surgical treatment is not mandatory. Indeed, the first management step should consist of basic treatments and advice for all grades of haemorrhoidal disease.

Basic treatments could be used for symptom relief and to prevent prolapse and includes toilet training, dietary changes (specifically high fiber diet), topical and pharmacological treatments which may include phlebotonics such as flavonoids. In addition, it will be important to manage the patients' expectations about symptom control. 
These interventions are given in addition to advice about adequate water intake, healthy diet and encouraging physical activity.

2.1 Healthy life style measures, like sufficient water intake, a healthy diet and physical activity should be encouraged.

Expert opinion, upgraded by guideline development group.

No systematic reviews or (randomised) trials were found regarding healthy life style measures.

2.2 Toilet training, including adopting the correct body position during defecation should be advised. Straining and prolonged defecation sessions should be avoided.

Expert opinion, upgraded by guideline development group.

No systematic reviews or (randomised) trials were found regarding toilet training.

2.3 The use of laxatives could be considered for symptom relief and to reduce bleeding.

Low level of evidence.

Analysis of the literature revealed only one systematic review evaluating the use of laxatives (fiber: high fiber diet or bulking agents such as bran, ispaghula, psyllium, stimulant laxatives: senna and bisacodyl, faecal softeners: liquid paraffin, seed oils, osmotic agents: lactulose, magnesium hydroxide, sorbitol and lactitol) (13). In this systematic review seven RCTs and a total of 378 patients were evaluated.

2.4 Phlebotonics could contribute to symptom reduction.

Low level of evidence.

The analysis of the literature revealed 2 systematic reviews regarding the use of phlebotonics $(14,15)$. The first systematic review included 14 trials (of which 4 trials 
are not reported in the review of Perera Nirmal) with a total of 1,514 patients (15). The other systematic review included 24 RCTs with a total of 2,344 patients (14).

\subsection{NSAIDs and non-opioids analgesics could be prescribed for pain.} Expert opinion.

There are no scientific data evaluating NSAIDs, cortisone and its derivates for the treatment of haemorrhoids.

\section{Outpatient procedures}

In patients where basic treatment has not resulted in acceptable symptom reduction, further procedures should be considered. As some treatments are less invasive, have fewer and/or less serious reported complications and are quicker and cheaper than others, we propose that clinicians first consider outpatient procedures (i.e. Rubber Band Ligation (RBL), Sclerotherapy (SCL) or Infrared Coagulation (IRC)). Nevertheless, patients with circular prolapsing grade III and especially grade IV haemorrhoidal disease (HD) may be treated with primary surgical interventions like Haemorrhoidectomy, Stapled Haemorrhoidopexy (SH) or Doppler Guided-Haemorrhoidal Artery Ligation + mucopexy (DG-HAL). However, it seems justifiable to use repeat RBL for Grade III prolapsing haemorrhoids, recognizing that surgical procedures will be necessary for patients whose symptoms are not relieved with RBL and those with circular prolapse. Equally, outpatient procedures could be performed in patients with grade III and IV HD when primary surgery is contra-indicated or the patient refuses primary surgery. This is represented in the figure 1 .

3.1 Choice of the outpatient procedure (i.e. rubber band ligation, injection sclerotherapy and infrared coagulation) should be informed by shared-decision making, taking into account patient preferences, availability of procedures and fitness for further procedures. Expert opinion, upgraded by guideline development group.

3.2 Rubber band ligation should be performed in grade I-III haemorrhoidal disease. Repeat banding may be necessary.

Moderate level of evidence. 
Figure I: Flow diagram for grade I-IV HD.

Evidence based treatment algorithm for haemorrhoids

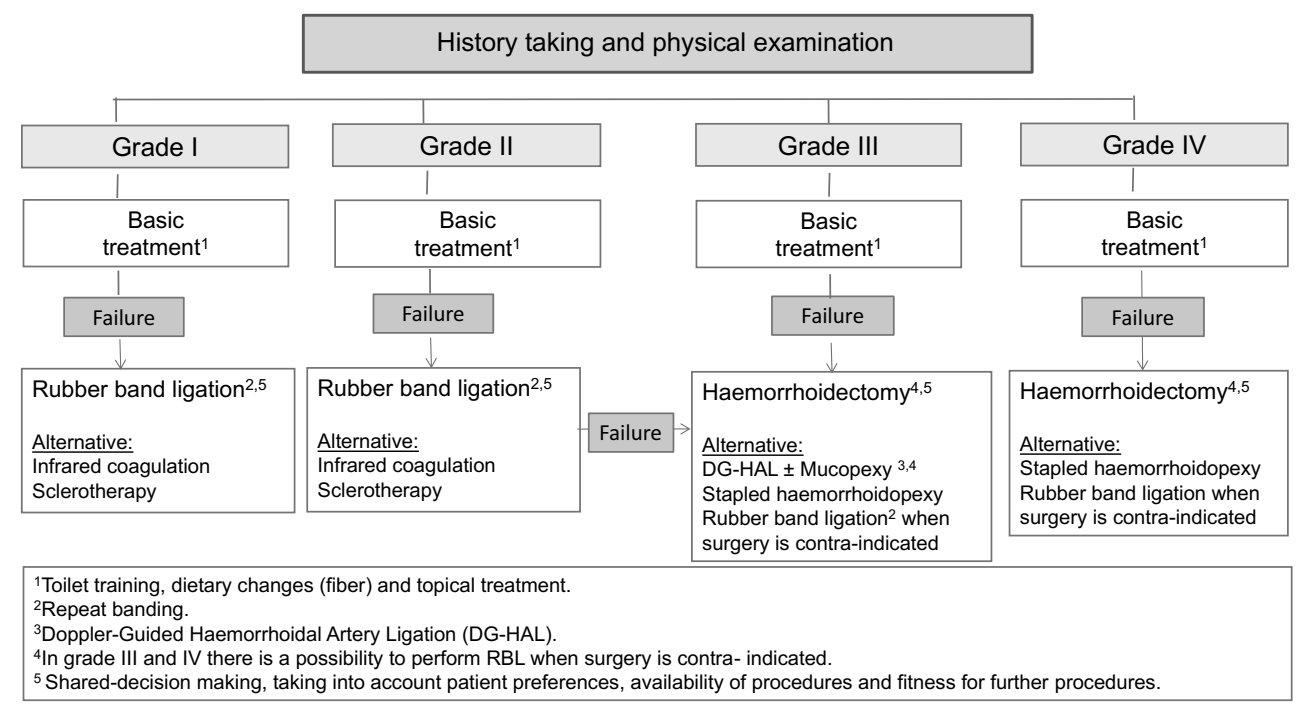

Analysis of the literature revealed one meta-analysis (MacRae and McLeod (16)) comparing RBL, IRC and SCL and included 18 RCTs and observational studies. The following comparisons were made: RBL versus surgical haemorrhoidectomy (3 observational studies), Lord-procedure (e.g. manual dilatation) versus surgical haemorrhoidectomy (6 observational studies), sclerotherapy versus infrared coagulation (one RCT and one observational study), sclerotherapy versus RBL (3 observational studies and one RCT) and RBL versus infrared coagulation (3 RCTs) (16).

The meta-analysis (Shanmugam 2005), including three trials (Murie 1980 (17), Cheng 1981 (18) and Lewis 1983 (19)) and 216 patients, compared RBL with haemorrhoidectomy (20).

Two RCTs (Shanmugam 2010 and Peng 2003) including a total of 105 patients compared RBL with the $\mathrm{SH}(21,22)$.

One RCT (Brown 2016), including 372 patients, compared RBL with DG-HAL (23).

\subsection{Infrared coagulation could be used as the first option in bleeding grade I haemorrhoids.}

Low level of evidence. 
Analysis of the literature revealed five RCTs comparing RBL and IRC. These RCTs included a total of 680 patients (24-28).

3.4 Injection sclerotherapy could be used in patients with grade I-II haemorrhoidal disease.

Low level of evidence.

Analysis of the literature revealed three RCTs comparing RBL versus SCL. These RCTs included a total of 606 patients (29-31).

\section{$4 \quad$ Surgical treatment}

In patients where basic treatment and/or outpatient procedures have not resulted in acceptable outcomes or in grade III and IV haemorrhoidal disease, surgical procedures could be considered. These include Haemorrhoidectomy, Stapled Haemorrhoidopexy (SH) and/or a mucopexy with or without Doppler-Guided Haemorrhoidal Artery ligation (DG-HAL).

4.1 Choice of surgical treatment should be informed by shared-decision making, taking into account patient preferences, availability of procedures and fitness for surgical procedures.

Expert opinion, upgraded by guideline development group. 
Analysis of the literature revealed two RCTs that assessed the efficacy of the Doppler transducer, the addition of a mucopexy and ligation under visual control followed by a mucopexy $(32,33)$.

Two systematic reviews compared DG-HAL and SH. The first systematic review (Pucher 2013) included 28 trials and 2904 patients (6 trials were RCTs). Another systematic review (Sajid 2012) included three randomised trials (two of these were also reported in the review mentioned above) and 150 patients (34-36).

One meta-analysis (Xu 2016), including four RCTs and 316 patients, and one RCT (Bursics 2004) including 60 patients, compared DG-HAL + mucopexy with the haemorrhoidectomy $(37,38)$.

4.3 Stapled haemorrhoidopexy could be used in patients with grade II-III haemorrhoids and/or in patients who are refractory to outpatient procedures. Low level of evidence.

4.4 Haemorrhoidectomy could be used in patients with grade II-III haemorrhoids and/or should be used in patients who are refractory to outpatient procedures.

Moderate level of evidence.

4.5 Haemorrhoidectomy should be used for grade IV haemorrhoids. Moderate level of evidence.

Three meta-analyses, four systematic reviews and one RCT were found comparing haemorrhoidectomy with SH (39-46).

\section{Special situations}

\section{Thrombosed haemorrhoids}

In the anocutaneous junction there is a venous plexus (anatomically called "plexus haemorrhoidalis externa") and here perianal thromboses or perianal haematomata may develop, which can cause severe pain and swelling. In these cases, the thrombosed vessels are covered by skin and there is no prolapsed mucosa. We suggest this phenomenon is called "perianal thrombosis" to make it distinguishable from thrombosed haemorrhoids since it is also possible for haemorrhoids to become incarcerated/ thrombosed. This may happen with grade II, III and /or IV haemorrhoids. In this guideline, we focus on thrombosed haemorrhoids. 
5.1 In patients with thrombosed haemorrhoids, treatment should be informed by shared-decision making, taking into account patient preferences, availability of procedures and fitness for further procedures.

Expert opinion, upgraded by guideline development group.

There is a remarkable paucity of studies reporting on thrombosed haemorrhoids and even fewer studies provided high level of evidence. No systematic reviews were found regarding this subject.

5.2 Primarily, basic treatment (i.e. toilet training, laxatives, NSAIDS and non-opioid analgesics) can be considered in patients with thrombosed haemorrhoids (expert opinion). Phlebotonics could be considered in patients with thrombosed haemorrhoids (low level of evidence). In selected cases, surgical options may be discussed with the patient.

Very low level of evidence.

There were no scientific data evaluating NSAIDs for the treatment of thrombosed haemorrhoids. However, analgesics could be prescribed for pain.

The analysis of the literature revealed one RCT (Giannini 2015), including 134 patients, assessing the efficacy of the oral intake of flavonoids versus placebo in patients with acute 'haemorrhoidal crisis' (47).

\subsection{Surgicalprocedures(i.e.stapledhaemorrhoidopexyandhaemorrhoidectomy) can be considered in patients with thrombosed haemorrhoids. Very low level of evidence.}

Three RCT's compared SH with haemorrhoidectomy. The first RCT (Lai 2007) included 80 patients (48). The second RCT (Brown 2001) included 35 patients (49). The third RCT (Wong 2008) included 41 patients (50).

\section{Immunodeficiency}

Immunocompromised patients have an increased risk of anorectal sepsis and poor tissue healing after any intervention. Therefore an operation should be avoided, or should be 
performed only after careful consideration (51). Also, antibiotic prophylaxis should be given before performing any intervention.

5.4 Outpatient procedures (including rubber band ligation and sclerotherapy) in immunocompromised patients seem to be safe, but very limited data are available. Very low level of evidence.

The analysis of the literature revealed that two studies assessed if SCL can be safely performed in patients with acquired immunodeficiency syndrome (HIV).

One observational study included 22 patients with HIV who underwent SCL (52). Another observational study included a total of 76 patients with haemorrhoids (36 positive HIV and 40 negative HIV) (53).

One observational study assessed if RBL can be safely performed in select HIV-positive patients (54).

\section{Pregnant women}

(Thrombosed) haemorrhoids are a common condition in pregnant women due to an increased endopelvic pressure. The exact prevalence is unknown. One study reported that $8 \%$ of women during the last trimester pregnancy and $20 \%$ of women immediately after delivery develop thrombosed haemorrhoids $(55,56)$. A survey, including 165 obstetricians, showed that only $42 \%$ of obstetricians refer these females to the consultant for HD treatment (57). For many women, symptoms will resolve spontaneously soon after birth, and so the primary goal of treatment is to relief acute symptoms mostly by means of dietary and lifestyle modification (Abramowitz 2011) (56).

\subsection{In pregnant and postpartum women basic treatment (i.e. laxatives, topical treatments, phlebotonics and analgesics) should be used. \\ Expert opinion, upgraded by the guideline development group.}

The analysis of the literature revealed one review, including 2 trials and 150 pregnant females, that compared oral hydroxyl ethilrutosides, a flavonoid drug given to improve the microcirculation in venous insufficiency, with placebo (58).

Two studies evaluated the effectiveness of Proctofoam- $\mathrm{HC}^{\mathrm{R}}$, a combination of corticosteroid and a local anaesthetic in 292 pregnant females $(59,60)$. 
One observational study, including 495 pregnant females, compared three times per day salty warm Sitz bath (using $20 \mathrm{~g}$ of commercial salt) ( $\mathrm{n}=284$ ) with topical cream (containing corticoid and anaesthetic) twice daily (61).

\subsection{In pregnant and postpartum women with thrombosed haemorrhoids unresponsive to basic treatment, surgical procedures to treat thrombosis can be considered. \\ Expert opinion.}

One cohort study assessed the efficacy of haemorrhoidectomy among 25 pregnant women with HD (62).

\section{Inflammatory Bowel Disease (IBD)}

Haemorrhoids are relatively uncommon in Inflammatory Bowel Disease (IBD) patients (63). However, this anal problem could be underestimated, because of a bias due to the higher attention paid to the other clinical features of IBD.

\subsection{In patients with Inflammatory Bowel Disease (IBD), outpatient procedures and/or surgical procedures can only be considered when there is no sign of active disease. \\ Expert opinion, upgraded by the guideline development group.}

The analysis of literature revealed one prospective study (D'Ugo 2013) which included 86 patients with Crohn's disease and compared outpatient and surgical procedures (64). Another retrospective study (Cracco 2014) included eleven retrospective studies including 135 patients with IBD (65).

\section{Irradiation}

Radiation therapy has a major role in the treatment of a number of malignancies arising in the pelvis (i.e. carcinoma of the prostate, bladder, rectum and gynecological malignancies). 


\subsection{Outpatient/ and or surgical procedures in patients who have undergone pelvic radiotherapy can generally not be considered. \\ Expert opinion.}

In the literature, there is no evidence regarding the outcome of haemorrhoidal treatment in irradiated patients. However, there are some papers indicating that surgical treatment in patients who have undergone pelvic radiotherapy can have catastrophic sequelae. The study of Hayne et al. showed that more than three-quarters of patients receiving pelvic radiotherapy, experience acute anorectal symptoms and up to one-fifth suffer from late phase radiation proctitis (66).

\section{Coagulation disorder}

Conservative measures are the mainstay of treatment for patients with a coagulation disorder.

\subsection{If an outpatient procedure and/or surgical procedure is scheduled, appropriate cessation of anticoagulant therapy should be followed according to national guidance. \\ Very low level of evidence, upgraded by guideline development group.}

One retrospective review identified 364 patients undergoing RBL while on antithrombotic therapy (AT) (67).

One controlled study, including 37 patients having $\mathrm{HD}$, compared patients undergoing SCL while on AT versus patients who were not on AT (68).

One retrospective cohort study compared AT patients $(\mathrm{n}=36)$ versus non-AT patients $(\mathrm{n}=70)$ with symptomatic haemorrhoids who underwent DG-HAL (69). 


\section{Other surgical techniques (closed/open haemorrhoidectomy, LigasureR etc)}

6.1 Both the closed and open haemorrhoidectomy (not using energy devices) could be used (low level of evidence). The closed haemorrhoidectomy is associated with less pain and bleeding.

Low level of evidence.

One meta-analysis (Xu 2015), including 5 RCTs and 318 patients, compared the Ligasure $^{\mathrm{R}}$ with the Ferguson (closed) haemorrhoidectomy (70).

6.2 Surgical energy devices $\left(\right.$ Ligasure $^{\mathrm{R}}$ and Harmonic scalpel ${ }^{\mathrm{R}}$ ) could be used for haemorrhoidectomy.

Low level of evidence.

The analysis of the literature revealed one meta-analysis (Mushaya 2014), including 8 studies and 468 patients, that compared the Harmonic scalpel ${ }^{\mathrm{R}}$ haemorrhoidectomy with the Haemorrhoidectomy (71).

6.3 Alternative procedures (Laser and Radiofrequency ablation procedures) could be used/can be considered.

Low level of evidence.

Three RCTs (Naderan 2017, Maloku 2014 and Giamundo 2011), including a total of 160 patients, compared the outcomes of intra-haemorrhoidal coagulation with 980-nanometer ( $\mathrm{nm})$ diode laser with the Haemorrhoidectomy (72-74).

6.4 Rectal resection using a stapler device (including STARR $^{\mathrm{R}}$ ) should not be used to treat haemorrhoids.

Low level of evidence, downgraded by the experts. 
Three RCTs (Corsale 2014, Zanella 2014 and Boccasanta 2006), including a total of 691 patients, compared stapled haemorrhoidopexy $(\mathrm{SH})$ with the STARR procedure (75-77) .

One RCT (Renzi 2011), including 425 patients, compared the clinical and functional results of STARR performed with 2 staplers (PPH-01 vs. PPH-03) (78).

\section{Discussion}

This is multidisciplinary, international guideline for the management of HD. According to this guideline, for grade I and II haemorrhoids, RBL appears to be the treatment of choice, because patients who undergo RBL showed a significantly better response compared to patients treated with SCL and/or IRC. In addition, patients treated by RBL have significantly less recurrence compared to patients treated with SCL or IRC. IRC may be the first treatment option in bleeding grade I haemorrhoids because it causes less pain and complications (28). Complication rates were similar between RBL, IRC and SCL (79-81). For grade III and IV haemorrhoids, haemorrhoidectomy remains the treatment of choice. Comparing $\mathrm{SH}$ and haemorrhoidectomy, the efficacy of $\mathrm{SH}$ is generally lower than haemorrhoidectomy (82), especially in grade IV HD (82). The DG-HAL + mucopexy may be considered in patients with grade II-III HD. However, more research regarding this technique is necessary. The additional effect of the Doppler is currently being questioned since two studies showed that significantly more complications and unscheduled postoperative events were reported in the DG$\mathrm{HAL}+$ mucopexy group compared to the mucopexy alone group $(32,33)$.

To date, several national guidelines have been published, including the American Society of Colon and Rectal Surgeons guideline (7) and the Italian (83)- and French HD guideline (6). The overall methodological quality of these guidelines for HD is suboptimal. In most guidelines, the review questions and methods for formulating their recommendations are not reported. The AGREE Enterprise is the first initiative which developed an instrument diminishing variability in practice guideline quality (84-87). The extensive processes following the AGREE II instrument and using GRADE are the main strengths of this guideline (88-90).

However, several limitations remain present. The first limitation of this guideline was that patients were only partially involved in the development of this guideline. We invited two patients to be GDG members, but they were unable to attend any of the meetings. Besides, we have asked, Dutch, British, German, Italian and French patients to read the guideline in its final concept and asked them for feedback. The patients did not have substantial comments which resulted in a change of the guideline. For the coming update, which is planned in 2020, a patient will be member of the guideline development group. A separate patient information chapter describing the different techniques, was added 
to the current guideline. Further, we asked all international representatives of the ESCP to participate. Most representatives replied that they did not treat HD or they felt that they were not experienced enough to provide input. Following their recommendations, healthcare professionals with an in-depth understanding of HD and/or development of guidelines were invited using the so-called "snowball method". This strategy resulted in a dedicated group of experts with knowledge of the field, but smaller in size than initially planned, which may be a limitation of the study. The third limitation of this guideline was the minimal guidance regarding economic data. The financial reimbursement for HD is different for each country. Therefore, it is difficult to indicate what the best economic option is per country. The guideline development group chose to give an overview of the published economic data, so that these data can inform local decisions. The fourth limitation was that debate regarding the best treatment option for each grade of HD remains as high level of evidence is lacking. Despite the large volume of HD research that has been conducted over the past decade, only a few studies are of high quality. New procedures emerge with often the same low quality evidence. For future guidelines to have more robust recommendations, new interventions need to be evaluated with more rigorous methodologies.

In addition, the lack of uniform outcome, measurement and reporting in HD research data hampers the ability to compare studies and the creation of optimal treatment guidelines $(20,91,92)$. A Core Outcome Set (COS) was recently developed in cooperation with the European Society of Coloproctology (ESCP) (93).

Furthermore, since the evaluation of patient experiences can be very useful in several decision-making contexts, there is a growing chorus of support from clinicians and researchers to embrace patient-reported outcome measures (PROMs) in clinical care (94-96). In a clinical setting, PROMs can provide a more complete understanding of the impact of a therapy on a patient's life and aid treatment choices (97). In addition, it could also provide scientific evidence for guideline development that incorporates the patient's perspective (98-100). Attempts have been made to develop such a tool. Examples include the Symptom-based Severity Score of Pucher et al. (101), the Haemorrhoid Severity Score (HSS) introduced by Nystrom $(102,103)$, the Haemorrhoid Symptom Score recently used in the eTHoS trial (104) and the Hemorrhoidal Disease Symptom Score (HDSS) and Short Health Scale HD (SHS) by Rørvik et al. (105). However, these scoring systems have not gained wide acceptance in the clinical and research setting which may be due to a lack of robust validation and or the extensive length of the instrument.

We plan to update the guideline on a regular basis starting in 2020. This will involve update of all searches and assessment of any relevant research found in relation to the current recommendations. 


\section{Declarations}

\section{Collaborators}

Dr. C.J.M. Henquet, Department of Dermatology, Maastricht University Medical Centre (MUMC+), 6202 AZ Maastricht, the Netherlands

\section{Ethics approval}

Since this study does not use health data of individuals, ethics approval was not required according to the Dutch federal act on research involving human beings.

\section{Conflicts of interest}

All GDG members including Dr. Henquet declared that they had no conflicts of interest. Jos Kleijnen (Kleijnen Systematic Reviews Ltd) has cooperated in the development and is co-author of the ROBIS, PRISMA, QUADAS, STARD and PROBAST tools.

\section{Financial disclosure}

Jan Jongen - received money for a nomination at a satellite conference from Ethicon Endosurgery.

\section{Funding}

An unrestricted grant was received from the guideline committee of the ESCP, enabling GDG members to meet and a surgical resident (RT) to work with the methodologist (JK). The GDG had full control over the wording of the guideline and there was no influence from the funding body.

\section{Availability of data and materials}

All data generated are available in the guideline document and the appendices. 


\section{References}

1. Lohsiriwat V. Hemorrhoids: from basic pathophysiology to clinical management. World J Gastroenterol. 2012;18(17):2009-17.

2. Riss S, Weiser FA, Schwameis K, Riss T, Mittlbock M, Steiner G, et al. The prevalence of hemorrhoids in adults. Int J Colorectal Dis. 2012;27(2):215-20.

3. Haas PA, Haas GP. The prevalence of hemorrhoids and chronic constipation. Gastroenterology. 1990;99(6):1856-7.

4. Johanson JF, Sonnenberg A. The prevalence of hemorrhoids and chronic constipation. An epidemiologic study. Gastroenterology. 1990;98(2):380-6.

5. Trompetto M, Clerico G, Cocorullo GF, Giordano P, Marino F, Martellucci J, et al. Evaluation and management of hemorrhoids: Italian society of colorectal surgery (SICCR) consensus statement. Tech Coloproctol. 2015;19(10):567-75.

6. Higuero T, Abramowitz L, Castinel A, Fathallah N, Hemery P, Laclotte Duhoux C, et al. Guidelines for the treatment of hemorrhoids (short report). J Visc Surg. 2016;153(3):213-8.

7. Davis BR, Lee-Kong SA, Migaly J, Feingold DL, Steele SR. The American Society of Colon and Rectal Surgeons Clinical Practice Guidelines for the Management of Hemorrhoids. Dis Colon Rectum. 2018;61(3):284-92.

8. Cartabellotta A. [AGREE II: assessing the quality of practice guidelines]. Recenti Prog Med. 2011;102(5):217-9.

9. Neumann I, Pantoja T, Penaloza B, Cifuentes L, Rada G. [The GRADE system: a change in the way of assessing the quality of evidence and the strength of recommendations]. Rev Med Chil. 2014;142(5):630-5.

10. Gaj F, Trecca A. [New "PATE 2006" system for classifying hemorrhoidal disease: advantages resulting from revision of "PATE 2000 Sorrento"]. Chir Ital. 2007;59(4):521-6.

11. Elbetti C, Giani I, Novelli E, Fucini C, Martellucci J. The single pile classification: a new tool for the classification of haemorrhoidal disease and the comparison of treatment results. Updates Surg. 2015;67(4):421-6.

12. Lunniss PJ, Mann CV. Classification of internal haemorrhoids: a discussion paper. Colorectal Dis. 2004;6(4):226-32.

13. Alonso-Coello P, Guyatt G, Heels-Ansdell D, Johanson JF, Lopez-Yarto M, Mills E, et al. Laxatives for the treatment of hemorrhoids. Cochrane Database Syst Rev. 2005(4):CD004649.

14. Perera N, Liolitsa D, Iype S, Croxford A, Yassin M, Lang P, et al. Phlebotonics for haemorrhoids. Cochrane Database Syst Rev. 2012(8):CD004322.

15. Alonso-Coello P, Zhou Q, Martinez-Zapata MJ, Mills E, Heels-Ansdell D, Johanson JF, et al. Meta-analysis of flavonoids for the treatment of haemorrhoids. Br J Surg. 2006;93(8):909-20.

16. MacRae HM, McLeod RS. Comparison of hemorrhoidal treatments: a meta-analysis. Can J Surg. 1997;40(1):14-7.

17. Murie JA, Mackenzie I, Sim AJ. Comparison of rubber band ligation and haemorrhoidectomy for second- and third-degree haemorrhoids: a prospective clinical trial. Br J Surg. 1980;67(11):786-8. 


\section{Chapter 7}

18. Cheng FC, Shum DW, Ong GB. The treatment of second degree haemorrhoids by injection, rubber band ligation, maximal anal dilatation, and haemorrhoidectomy: a prospective clinical trial. Aust N Z J Surg. 1981;51(5):458-62.

19. Lewis AA, Rogers HS, Leighton M. Trial of maximal anal dilatation, cryotherapy and elastic band ligation as alternatives to haemorrhoidectomy in the treatment of large prolapsing haemorroids. $\mathrm{Br}$ J Surg. 1983;70(1):54-6.

20. Shanmugam V, Thaha MA, Rabindranath KS, Campbell KL, Steele RJ, Loudon MA. Systematic review of randomized trials comparing rubber band ligation with excisional haemorrhoidectomy. Br J Surg. 2005;92(12):1481-7.

21. Shanmugam V, Muthukumarasamy G, Cook JA, Vale L, Watson AJ, Loudon MA. Randomized controlled trial comparing rubber band ligation with stapled haemorrhoidopexy for Grade II circumferential haemorrhoids: long-term results. Colorectal Dis. 2010;12(6):579-86.

22. Peng BC, Jayne DG, Ho YH. Randomized trial of rubber band ligation vs. stapled hemorrhoidectomy for prolapsed piles. Dis Colon Rectum. 2003;46(3):291-7; discussion 6-7.

23. Brown SR, Tiernan JP, Watson AJM, Biggs K, Shephard N, Wailoo AJ, et al. Haemorrhoidal artery ligation versus rubber band ligation for the management of symptomatic second-degree and thirddegree haemorrhoids (HubBLe): a multicentre, open-label, randomised controlled trial. Lancet. 2016;388(10042):356-64.

24. Ricci MP, Matos D, Saad SS. Rubber band ligation and infrared photocoagulation for the outpatient treatment of hemorrhoidal disease. Acta Cir Bras. 2008;23(1):102-6.

25. Marques CF, Nahas SC, Nahas CS, Sobrado CW, Jr., Habr-Gama A, Kiss DR. Early results of the treatment of internal hemorrhoid disease by infrared coagulation and elastic banding: a prospective randomized cross-over trial. Tech Coloproctol. 2006;10(4):312-7.

26. Poen AC, Felt-Bersma RJ, Cuesta MA, Deville W, Meuwissen SG. A randomized controlled trial of rubber band ligation versus infra-red coagulation in the treatment of internal haemorrhoids. Eur J Gastroenterol Hepatol. 2000;12(5):535-9.

27. Templeton JL, Spence RA, Kennedy TL, Parks TG, Mackenzie G, Hanna WA. Comparison of infrared coagulation and rubber band ligation for first and second degree haemorrhoids: a randomised prospective clinical trial. Br Med J (Clin Res Ed). 1983;286(6375):1387-9.

28. Ambrose NS, Hares MM, Alexander-Williams J, Keighley MR. Prospective randomised comparison of photocoagulation and rubber band ligation in treatment of haemorrhoids. Br Med J (Clin Res Ed). 1983;286(6375):1389-91.

29. Kanellos I, Goulimaris I, Christoforidis E, Kelpis T, Betsis D. A comparison of the simultaneous application of sclerotherapy and rubber band ligation, with sclerotherapy and rubber band ligation applied separately, for the treatment of haemorrhoids: a prospective randomized trial. Colorectal Dis. 2003;5(2):133-8.

30. Gartell PC, Sheridan RJ, McGinn FP. Out-patient treatment of haemorrhoids: a randomized clinical trial to compare rubber band ligation with phenol injection. Br J Surg. 1985;72(6):478-9. 
31. Greca F, Hares MM, Nevah E, Alexander-Williams J, Keighley MR. A randomized trial to compare rubber band ligation with phenol injection for treatment of haemorrhoids. Br J Surg. 1981;68(4):250-2.

32. Aigner F, Kronberger I, Oberwalder M, Loizides A, Ulmer H, Gruber L, et al. Doppler-guided haemorrhoidal artery ligation with suture mucopexy compared with suture mucopexy alone for the treatment of Grade III haemorrhoids: a prospective randomized controlled trial. Colorectal Dis. 2016;18(7):710-6.

33. Gupta PJ, Kalaskar S, Taori S, Heda PS. Doppler-guided hemorrhoidal artery ligation does not offer any advantage over suture ligation of grade 3 symptomatic hemorrhoids. Tech Coloproctol. 2011;15(4):439-44.

34. Pucher PH, Sodergren MH, Lord AC, Darzi A, Ziprin P. Clinical outcome following Dopplerguided haemorrhoidal artery ligation: a systematic review. Colorectal Dis. 2013;15(6):e284-94.

35. Sajid MS, Parampalli U, Whitehouse P, Sains P, McFall MR, Baig MK. A systematic review comparing transanal haemorrhoidal de-arterialisation to stapled haemorrhoidopexy in the management of haemorrhoidal disease. Tech Coloproctol. 2012;16(1):1-8.

36. Lehur PA, Didnee AS, Faucheron JL, Meurette G, Zerbib P, Siproudhis L, et al. Cost-effectiveness of New Surgical Treatments for Hemorrhoidal Disease: A Multicentre Randomized Controlled Trial Comparing Transanal Doppler-guided Hemorrhoidal Artery Ligation With Mucopexy and Circular Stapled Hemorrhoidopexy. Ann Surg. 2016;264(5):710-6.

37. Xu L, Chen H, Lin G, Ge Q, Qi H, He X. Transanal hemorrhoidal dearterialization with mucopexy versus open hemorrhoidectomy in the treatment of hemorrhoids: a meta-analysis of randomized control trials. Tech Coloproctol. 2016;20(12):825-33.

38. Bursics A, Morvay K, Kupcsulik P, Flautner L. Comparison of early and 1-year follow-up results of conventional hemorrhoidectomy and hemorrhoid artery ligation: a randomized study. Int J Colorectal Dis. 2004;19(2):176-80.

39. Nisar PJ, Acheson AG, Neal KR, Scholefield JH. Stapled hemorrhoidopexy compared with conventional hemorrhoidectomy: systematic review of randomized, controlled trials. Dis Colon Rectum. 2004; 47(11):1837-45.

40. Jayaraman S, Colquhoun PH, Malthaner RA. Stapled hemorrhoidopexy is associated with a higher long-term recurrence rate of internal hemorrhoids compared with conventional excisional hemorrhoid surgery. Dis Colon Rectum. 2007;50(9):1297-305.

41. Jayaraman S, Colquhoun PH, Malthaner RA. Stapled versus conventional surgery for hemorrhoids. Cochrane Database Syst Rev. 2006(4):CD005393.

42. Tjandra JJ, Chan MK. Systematic review on the procedure for prolapse and hemorrhoids (stapled hemorrhoidopexy). Dis Colon Rectum. 2007;50(6):878-92.

43. Burch J, Epstein D, Sari AB, Weatherly H, Jayne D, Fox D, et al. Stapled haemorrhoidopexy for the treatment of haemorrhoids: a systematic review. Colorectal Dis. 2009;11(3):233-43; discussion 43. 


\section{Chapter 7}

44. Giordano P, Gravante G, Sorge R, Ovens L, Nastro P. Long-term outcomes of stapled hemorrhoidopexy vs conventional hemorrhoidectomy: a meta-analysis of randomized controlled trials. Arch Surg. 2009;144(3):266-72.

45. Yang J, Cui PJ, Han HZ, Tong DN. Meta-analysis of stapled hemorrhoidopexy vs LigaSure hemorrhoidectomy. World J Gastroenterol. 2013;19(29):4799-807.

46. Lee $\mathrm{KC}$, Chen $\mathrm{HH}$, Chung $\mathrm{KC}, \mathrm{Hu} \mathrm{WH}$, Chang $\mathrm{CL}$, Lin SE, et al. Meta-analysis of randomized controlled trials comparing outcomes for stapled hemorrhoidopexy versus LigaSure hemorrhoidectomy for symptomatic hemorrhoids in adults. Int J Surg. 2013;11(9):914-8.

47. Giannini I, Amato A, Basso L, Tricomi N, Marranci M, Pecorella G, et al. Flavonoids mixture (diosmin, troxerutin, hesperidin) in the treatment of acute hemorrhoidal disease: a prospective, randomized, triple-blind, controlled trial. Tech Coloproctol. 2015;19(6):339-45.

48. Lai HJ, Jao SW, Su CC, Lee MC, Kang JC. Stapled hemorrhoidectomy versus conventional excision hemorrhoidectomy for acute hemorrhoidal crisis. J Gastrointest Surg. 2007;11(12):1654-61.

49. Brown SR, Ballan K, Ho E, Ho Fams YH, Seow-Choen F. Stapled mucosectomy for acute thrombosed circumferentially prolapsed piles: a prospective randomized comparison with conventional haemorrhoidectomy. Colorectal Dis. 2001;3(3):175-8.

50. Wong JC, Chung CC, Yau KK, Cheung HY, Wong DC, Chan OC, et al. Stapled technique for acute thrombosed hemorrhoids: a randomized, controlled trial with long-term results. Dis Colon Rectum. 2008;51(4):397-403.

51. Morandi E, Merlini D, Salvaggio A, Foschi D, Trabucchi E. Prospective study of healing time after hemorrhoidectomy: influence of HIV infection, acquired immunodeficiency syndrome, and anal wound infection. Dis Colon Rectum. 1999;42(9):1140-4.

52. Scaglia M, Delaini GG, Destefano I, Hulten L. Injection treatment of hemorrhoids in patients with acquired immunodeficiency syndrome. Dis Colon Rectum. 2001;44(3):401-4.

53. Wei G, Hua X, Zhao Y, Hu M, Gou F, Liu L, et al. [Clinical study of Ruiyun procedure for hemorrhoids combined with Xiaozhiling injections in treatment of hemorrhoids complicated with human immunodeficiency virus infection]. Zhonghua Wei Chang Wai Ke Za Zhi. 2014;17(12):1201-4.

54. Moore BA, Fleshner PR. Rubber band ligation for hemorrhoidal disease can be safely performed in select HIV-positive patients. Dis Colon Rectum. 2001;44(8):1079-82.

55. Abramowitz L. [Management of hemorrhoid disease in the pregnant woman]. Gastroenterol Clin Biol. 2008;32(5 Pt 2):S210-4.

56. Abramowitz L, Batallan A. [Epidemiology of anal lesions (fissure and thrombosed external hemorroid) during pregnancy and post-partum]. Gynecol Obstet Fertil. 2003;31(6):546-9.

57. Gaj F, Trecca A. [Thoughts on hemorrhoid disease in pregnancy and the postpartum period]. Chir Ital. 2006;58(3):407.

58. Quijano CE, Abalos E. Conservative management of symptomatic and/or complicated haemorrhoids in pregnancy and the puerperium. Cochrane Database Syst Rev. 2005(3):CD004077. 
59. Ebrahimi N, Vohra S, Gedeon C, Akoury H, Bernstein P, Pairaudeau N, et al. The fetal safety of hydrocortisone-pramoxine (Proctofoam-HC) for the treatment of hemorrhoids in late pregnancy. J Obstet Gynaecol Can. 2011;33(2):153-8.

60. Vohra S, Akoury H, Bernstein P, Einarson TR, Pairaudeau N, Taddio A, et al. The effectiveness of Proctofoam-HC for treatment of hemorrhoids in late pregnancy. J Obstet Gynaecol Can. 2009;31(7):654-9.

61. Shirah BH, Shirah HA, Fallata AH, Alobidy SN, Hawsawi MMA. Hemorrhoids during pregnancy: Sitz bath vs. ano-rectal cream: A comparative prospective study of two conservative treatment protocols. Women Birth. 2017.

62. Saleeby RG, Jr., Rosen L, Stasik JJ, Riether RD, Sheets J, Khubchandani IT. Hemorrhoidectomy during pregnancy: risk or relief? Dis Colon Rectum. 1991;34(3):260-1.

63. Lewis RT, Maron DJ. Anorectal Crohn's disease. Surg Clin North Am. 2010;90(1):83-97, Table of Contents.

64. D’Ugo S, Franceschilli L, Cadeddu F, Leccesi L, Blanco Gdel V, Calabrese E, et al. Medical and surgical treatment of haemorrhoids and anal fissure in Crohn's disease: a critical appraisal. BMC Gastroenterol. 2013;13:47.

65. Cracco N, Zinicola R. Is haemorrhoidectomy in inflammatory bowel disease harmful? An old dogma re-examined. Colorectal Dis. 2014;16(7):516-9.

66. Hayne D, Vaizey CJ, Boulos PB. Anorectal injury following pelvic radiotherapy. Br J Surg. 2001;88(8):1037-48.

67. Nelson RS, Thorson AG. Risk of bleeding following hemorrhoidal banding in patients on antithrombotic therapy. Gastroenterol Clin Biol. 2009;33(6-7):463-5.

68. Yano T, Nogaki T, Asano M, Tanaka S, Kawakami K, Matsuda Y. Outcomes of case-matched injection sclerotherapy with a new agent for hemorrhoids in patients treated with or without blood thinners. Surg Today. 2013;43(8):854-8.

69. Atallah S, Maharaja GK, Martin-Perez B, Burke JP, Albert MR, Larach SW. Transanal hemorrhoidal dearterialization (THD): a safe procedure for the anticoagulated patient? Tech Coloproctol. 2016;20(7):461-6.

70. Xu L, Chen H, Lin G, Ge Q. Ligasure versus Ferguson hemorrhoidectomy in the treatment of hemorrhoids: a meta-analysis of randomized control trials. Surg Laparosc Endosc Percutan Tech. 2015;25(2):106-10.

71. Mushaya CD, Caleo PJ, Bartlett L, Buettner PG, Ho YH. Harmonic scalpel compared with conventional excisional haemorrhoidectomy: a meta-analysis of randomized controlled trials. Tech Coloproctol. 2014;18(11):1009-16.

72. Naderan M, Shoar S, Nazari M, Elsayed A, Mahmoodzadeh H, Khorgami Z. A Randomized Controlled Trial Comparing Laser Intra-Hemorrhoidal Coagulation and Milligan-Morgan Hemorrhoidectomy. J Invest Surg. 2017;30(5):325-31.

73. Maloku H, Gashi Z, Lazovic R, Islami H, Juniku-Shkololli A. Laser Hemorrhoidoplasty Procedure vs Open Surgical Hemorrhoidectomy: a Trial Comparing 2 Treatments for Hemorrhoids of Third and Fourth Degree. Acta Inform Med. 2014;22(6):365-7. 


\section{Chapter 7}

74. Giamundo P, Salfi R, Geraci M, Tibaldi L, Murru L, Valente M. The hemorrhoid laser procedure technique vs rubber band ligation: a randomized trial comparing 2 mini-invasive treatments for second- and third-degree hemorrhoids. Dis Colon Rectum. 2011;54(6):693-8.

75. Corsale I, Rigutini M, Francioli N, Panicucci S, Mori PA, Aloise F. Stapled anopexy and STARR in surgical treatment of haemorrhoidal disease. Updates Surg. 2014;66(3):217-22.

76. Zanella S, Spirch S, Scarpa M, Ricci F, Lumachi F. Long-term outcome of stapled transanal rectal resection (STARR) versus stapled hemorrhoidopexys (STH) for grade III-IV hemorrhoids: preliminary results. In Vivo. 2014;28(6):1171-4.

77. Boccasanta P, Venturi M, Roviaro G. Stapled transanal rectal resection versus stapled anopexy in the cure of hemorrhoids associated with rectal prolapse. A randomized controlled trial. Int J Colorectal Dis. 2007;22(3):245-51.

78. Renzi A, Brillantino A, Di Sarno G, D’Aniello F, Giordano A, Stefanuto A, et al. PPH-01 versus PPH-03 to perform STARR for the treatment of hemorrhoids associated with large internal rectal prolapse: a prospective multicenter randomized trial. Surg Innov. 2011;18(3):241-7.

79. Walker AJ, Leicester RJ, Nicholls RJ, Mann CV. A prospective study of infrared coagulation, injection and rubber band ligation in the treatment of haemorrhoids. Int J Colorectal Dis. 1990;5(2):113-6.

80. Johanson JF, Rimm A. Optimal nonsurgical treatment of hemorrhoids: a comparative analysis of infrared coagulation, rubber band ligation, and injection sclerotherapy. Am J Gastroenterol. 1992;87(11):1600-6.

81. Charua Guindic L, Chirino Perez AE, Navarrete Cruces T, Osorio Hernandez RM, Avendano Espinosa O. [Non-surgical alternative management of hemorrhoidal disease]. Rev Gastroenterol Mex. 2005;70(3):284-90.

82. Watson AJ, Hudson J, Wood J, Kilonzo M, Brown SR, McDonald A, et al. Comparison of stapled haemorrhoidopexy with traditional excisional surgery for haemorrhoidal disease (eTHoS): a pragmatic, multicentre, randomised controlled trial. Lancet. 2016;388(10058):2375-85.

83. Altomare DF, Roveran A, Pecorella G, Gaj F, Stortini E. The treatment of hemorrhoids: guidelines of the Italian Society of Colorectal Surgery. Tech Coloproctol. 2006;10(3):181-6.

84. Dans AL, Dans LF. Appraising a tool for guideline appraisal (the AGREE II instrument). J Clin Epidemiol. 2010;63(12):1281-2.

85. Burls A. AGREE II-improving the quality of clinical care. Lancet. 2010;376(9747):1128-9.

86. Brouwers MC, Kho ME, Browman GP, Burgers JS, Cluzeau F, Feder G, et al. Development of the AGREE II, part 1: performance, usefulness and areas for improvement. CMAJ. 2010;182(10):104552.

87. Brouwers MC, Kho ME, Browman GP, Burgers JS, Cluzeau F, Feder G, et al. Development of the AGREE II, part 2: assessment of validity of items and tools to support application. CMAJ. 2010;182(10):E472-8.

88. Collaboration A. Development and validation of an international appraisal instrument for assessing the quality of clinical practice guidelines: the AGREE project. Qual Saf Health Care. 2003;12(1):18-23. 
89. Levin RF, Ferrara L. Using the Appraisal of Guidelines for Research and Evaluation II to assess clinical practice guidelines. Res Theory Nurs Pract. 2011;25(3):160-2.

90. Andrews J, Guyatt G, Oxman AD, Alderson P, Dahm P, Falck-Ytter Y, et al. GRADE guidelines: 14. Going from evidence to recommendations: the significance and presentation of recommendations. J Clin Epidemiol. 2013;66(7):719-25.

91. Shao WJ, Li GC, Zhang ZH, Yang BL, Sun GD, Chen YQ. Systematic review and metaanalysis of randomized controlled trials comparing stapled haemorrhoidopexy with conventional haemorrhoidectomy. Br J Surg. 2008;95(2):147-60.

92. Simillis C, Thoukididou SN, Slesser AA, Rasheed S, Tan E, Tekkis PP. Systematic review and network meta-analysis comparing clinical outcomes and effectiveness of surgical treatments for haemorrhoids. Br J Surg. 2015;102(13):1603-18.

93. van Tol RR, Kimman ML, Melenhorst J, Stassen LPS, Dirksen CD, Breukink SO, et al. European Society of Coloproctology Core Outcome Set for haemorrhoidal disease: an international Delphi study among healthcare professionals. Colorectal Dis. 2019;21(5):570-80.

94. Bredart A, Marrel A, Abetz-Webb L, Lasch K, Acquadro C. Interviewing to develop PatientReported Outcome (PRO) measures for clinical research: eliciting patients' experience. Health Qual Life Outcomes. 2014;12:15.

95. Black N. Patient reported outcome measures could help transform healthcare. BMJ (Clinical research ed). 2013;346:f167.

96. Marshall S, Haywood K, Fitzpatrick R. Impact of patient-reported outcome measures on routine practice: a structured review. Journal of evaluation in clinical practice. 2006;12(5):559-68.

97. Wijsenbeek M, van Manen M, Bonella F. New insights on patient-reported outcome measures in idiopathic pulmonary fibrosis: only PROMises? Curr Opin Pulm Med. 2016;22(5):434-41.

98. Dirksen CD. The use of research evidence on patient preferences in health care decisionmaking: issues, controversies and moving forward. Expert Rev Pharmacoecon Outcomes Res. 2014;14(6):785-94.

99. Barry CA, Bradley CP, Britten N, Stevenson FA, Barber N. Patients' unvoiced agendas in general practice consultations: qualitative study. BMJ. 2000;320(7244):1246-50.

100. Kinnersley P, Stott N, Peters TJ, Harvey I. The patient-centredness of consultations and outcome in primary care. Br J Gen Pract. 1999;49(446):711-6.

101. Pucher PH, Qurashi M, Howell AM, Faiz O, Ziprin P, Darzi A, et al. Development and validation of a symptom-based severity score for haemorrhoidal disease: the Sodergren score. Colorectal Dis. 2015;17(7):612-8.

102. Brown S, Tiernan J, Biggs K, Hind D, Shephard N, Bradburn M, et al. The HubBLe Trial: haemorrhoidal artery ligation (HAL) versus rubber band ligation (RBL) for symptomatic secondand third-degree haemorrhoids: a multicentre randomised controlled trial and health-economic evaluation. Health Technol Assess. 2016;20(88):1-150.

103. Nystrom PO, Qvist N, Raahave D, Lindsey I, Mortensen N, Stapled or Open Pile Procedure trial study g. Randomized clinical trial of symptom control after stapled anopexy or diathermy excision for haemorrhoid prolapse. Br J Surg. 2010;97(2):167-76. 


\section{Chapter 7}

104. Watson AJ, Cook J, Hudson J, Kilonzo M, Wood J, Bruhn H, et al. A pragmatic multicentre randomised controlled trial comparing stapled haemorrhoidopexy with traditional excisional surgery for haemorrhoidal disease: the eTHoS study. Health Technol Assess. 2017;21(70):1-224.

105. Rorvik HD, Styr K, Ilum L, McKinstry GL, Dragesund T, Campos AH, et al. Hemorrhoidal Disease Symptom Score and Short Health ScaleHD: New Tools to Evaluate Symptoms and HealthRelated Quality of Life in Hemorrhoidal Disease. Dis Colon Rectum. 2019;62(3):333-42.

\section{Appendix X}

\section{Search strategies}

Medline (Pubmed):

\#1,"Search $(((($ haemorrhoid*[Title/Abstract]) OR hemorhoid*[Title/Abstract] $)$ OR haemorhoid*[Title/Abstract]) OR hemorroid*[Title/Abstract]) OR haemorroid*[Title/ Abstract]) OR hemoroid*[Title/Abstract]",

1761,06:11:16

\#2,"Search hemorrhoid[MeSH Terms]",

4871,06:12:15

\#3,"Search ((((treatment[MeSH Subheading]) OR therapy) OR treatment) OR therapeutics[MeSH Terms]) OR therapeutics"

9498187,06:16:05

\section{Cochrane:}

1. \#1, "hemorrhoid*":ti,ab,kw (Word variations have been searched)

2. \#2, haemorrhoid*

3. $\# 3$, hemorrhoid*

4. \#4, haemorroid*

5. $\# 5$, hemorroid*

6. \#6, haemorhoid*

7. \#7, hemorhoid*

8. $\# 8$, haemoroid*

9. \#9, hemoroid*

10. $\# 1$ or $\# 2$ or $\# 3$ or $\# 4$ or $\# 5$ or $\# 6$ or $\# 7$ or $\# 8$ or $\# 9$

11. \#14, procedures

12. \#15, treatment

13. \#16, therapy

14. \#17, therapeutics 
15. $\# 14$ or $\# 15$ or $\# 16$ or \#17

16. \#10 and \#15

Ovid (Embase):

1. \#1, hemorrhoid*.mp. or exp hemorrhoid/

2. \#2, haemorrhoid.mp. or exp hemorrhoid/

3. $\# 3$, hemorroid.mp.

4. \#4, haemorroid.mp.

5. $\quad \# 5$, hemoroid.mp.

6. \#6, haemorhoid.mp.

7. \#7, hemorhoid.mp.

8. $\# 1$ or $\# 2$ or $\# 3$ or $\# 4$ or $\# 5$ or $\# 6$ or \#7

9. $\quad \# 8$, treatment.mp.

10. \#9, exp therapy/ or therapy.mp.

11. \#8 or \#9

12. \#8 and \#11 


\section{Abstract}

Aim The European Society of Coloproctology (ESCP) aims to establish international guidelines for the treatment of grade I-IV haemorrhoidal disease (HD), using the best available evidence. The guidelines provides guidance on the most effective (surgical) treatment and management of patients with HD. By providing this information, the ESCP hopes to improve outcomes after treatment such as, recurrence of disease, complications, symptoms and patient satisfaction. This paper describes the processes and methods used to develop and update a guidelines for HD.

Methods and analysis In composing the guideline development group (GDG), all clinical members had to have an affinity with the diagnosis and treatment of hemorrhoids. The GDG were assisted by a team of methodologists (staff at Kleijnen Systematic Reviews Ltd) whose work covered input from information specialists, quality assurance, and evidence review and support. The processes and methods are based on internationally recognized guideline development methodology. These include criteria of quality, as detailed in the Appraisal of Guidelines for Research and Evaluation II (AGREE II) instrument, primary methodological research and evaluation undertaken by the GDG. This study is being conducted over 12-20 months from March 2017 to December 2018. 


\section{Setting the scope}

After invitation by the European Society of ColoProctology (ESCP), one of the colorectal surgeons (SB) of the GDG was asked to establish an international guideline for HD. The ESCP functioned as the stakeholder with an interest in the guideline topic. During the guideline development, the ESCP was informed of progress by email. These guidelines were supported by a small grant from the ESCP enabling GDG-members to meet and a surgical resident (RT) to work with the methodologist (JK). The GDG had full control over the wording of the guideline and there was no influence from the funding body.

We first considered the aim of the guidelines, taking into account the health problems to be addressed, the patient group and the target audience.

It was decided that the guidance would apply to patients with all stages of HD in whom (surgical) interventions are being considered. HD is mostly classified according to the grading system developed by Goligher et al. [1-3] and therapeutic options are generally based on the HD grade.

This guideline needed to address both the diagnostic and therapeutic modalities for use in the management of HD and included the following sections: diagnosis, basic treatment, outpatient procedures, surgical interventions, special situations (i.e. thrombosed haemorrhoids, coagulation defect, immunodeficiency and pregnant women) and follow-up.

The guideline is intended for use by all practitioners treating patients with HD (e.g. general practitioners, surgeons, gastroenterologists, dermatologists), healthcare workers and patients who desire information about the management of HD.

The process of considering the aim of the guideline, defining the target group and describing the users, was compacted into a guideline scope. In the scope we also enlisted key issues to be addressed in the guidelines. The key issues function as the foundation for which possible recommendations are made, which in turn allowed the creation of the review questions.

\section{Invitation guideline development group (GDG)}

The guideline was prepared by a guideline development group (GDG) which included members from six European countries (i.e. Denmark, Italy, France, Germany, the Netherlands and the UK). First we contacted the international representatives of the European Society of Coloproctology (ESCP). On the recommendation of these representatives (i.e. snow ball method) healthcare professionals with an in-depth understanding of outcomes relevant for treatment of $\mathrm{HD}$ and experience with the development of a COS were invited. The aim was to include as many panel members as possible $(18,20)$, to increase the reliability of the group judgment $[4,5]$. 
In composing the GDG, we considered several factors. First, all clinical members had to have an affinity with the diagnosis and treatment of hemorrhoids, considering that clinical knowledge on the subject is key. Second, distribution of geographical differences between surgeons was wished for, as the guideline is aimed at an international audience. The GDG consisted of five colorectal surgeons ( $\mathrm{SB}, \mathrm{DA}, \mathrm{JJ}, \mathrm{NQ}, \mathrm{AW}$ ), one gastroenterologist $(\mathrm{TH})$, one general practitioner $(\mathrm{JM})$ who specialises in the treatment of haemorrhoidal disease, one surgical resident (RT) and one methodologist (JK) with extensive experience of guideline development [table 1]. One dermatologist $(\mathrm{CH})$ commented on the guideline drafts, but was not a member of the GDG. Two Dutch patients were invited by their treating physician (SB) for participation if they experienced a previous episode of HD. The patients were contacted by email to inform them about the study and they were asked for their written consent prior to participation.

The GDG-members were assisted by a team of methodologists (staff at Kleijnen Systematic Reviews Ltd) whose work covered input from information specialists, quality assurance, and evidence review and support.

Table I: guideline development group (GDG) members.

\begin{tabular}{|c|c|c|}
\hline Guideline members & Institution & Country \\
\hline Angus Watson, Colorectal surgeon & Raigmore Hospital & Scotland \\
\hline $\begin{array}{l}\text { Johannes Jongen, Colorectal } \\
\text { surgeon }\end{array}$ & Park Klinik Kiel & Germany \\
\hline $\begin{array}{l}\text { Donato Altomare, Colorectal } \\
\text { surgeon }\end{array}$ & University Aldo Moro of Bari & Italy \\
\hline Niels Qvist, Colorectal surgeon & Odense University Hospital & Denmark \\
\hline $\begin{array}{l}\text { Stephanie Breukink, Colorectal } \\
\text { surgeon }\end{array}$ & $\begin{array}{l}\text { Maastricht University Medical } \\
\text { Center (MUMC+) }\end{array}$ & The Netherlands \\
\hline $\begin{array}{l}\text { Thierry Higuero, } \\
\text { Gastroenterologist }\end{array}$ & Clinique a Beausoleil & France \\
\hline Jean Muris, General practitioner & CAPHRI & The Netherlands \\
\hline Jos Kleijnen, Methodologist & $\begin{array}{l}\text { KSR Ltd \& Maastricht University } \\
\text { Medical Center (MUMC+) - } \\
\text { CAPHRI }\end{array}$ & $\begin{array}{l}\text { UK \& The } \\
\text { Netherlands }\end{array}$ \\
\hline Robin van Tol, Surgical resident & $\begin{array}{l}\text { Maastricht University Medical } \\
\text { Center (MUMC+) }\end{array}$ & The Netherlands \\
\hline
\end{tabular}




\section{Formulating review questions}

Two researchers (RT and JK) developed a set of review questions assessing the key issues listed in the scope. The review questions were built up using a reversed process, starting with possible recommendations based on the GDG's knowledge of practice shortcomings and practice variations. Budgetary constraints necessitated an efficient and pragmatic process.

The review questions were formulated using the PICO (population, intervention, comparator and outcome) framework to assess the effectiveness of an intervention and similar frameworks for other types of questions e.g. about diagnosis. The PICO framework is a helpful and structured approach for developing questions about interventions (table 2).

Table 2: Formulating a review question on the effectiveness of an intervention using the PICO framework.

Population: Which population are we interested in? How best can it be described? Are there subgroups that need to be considered?

Intervention: Which intervention, treatment or approach should be used?

Comparators: Are there alternative(s) to the intervention being considered? If so, what are these (for example, other interventions, standard active comparators, usual care or placebo)?

Outcome: Which outcomes should be considered to assess how well the intervention is working? What is really important for people using services? Core outcome sets may be used where appropriate; one source is the COMET database.

A draft scope including the review questions was distributed by email to the GDG members for their input. Review questions were altered and clustered into chapters (i.e. basic treatment; outpatient procedures; surgical treatment) according to the comments and feedback of the GDG-members, creating major premises and subjects for the guideline. Further, the GDG discussed and agreed on a set of outcomes critical and important for making decisions in clinical settings, including operational procedures and recommendations for diagnostic assessment [table 3]. These are crucial for application of GRADE for assessment of the strength of the evidence, which in turn leads to appropriate wording of the recommendations. 
Table 3: set of outcomes critical and important for making decisions.

\begin{tabular}{l}
\hline Outcome measures \\
\hline 1. General complications \\
2. (Remaining) symptoms \\
3. Postoperative pain \\
4. Recurrence \\
5. Satisfaction \\
6. Quality of life \\
7. Time to return to normal \\
8. Re-operation \\
9. Costs of operation \\
10. Anatomical difference \\
11. Duration of operation \\
12. Duration of hospitalization \\
\hline
\end{tabular}

\section{Literature search}

The review questions functioned as a framework for the design of the literature searches, informed the planning and process of the evidence review, and acted as a guide for the development of recommendations by the GDG members. The GDG members provided expertise (for example, when a condition is described in many different ways in the literature).

A literature search was performed in MEDLINE (Ovid), PubMed, EMBASE (Ovid), and the Cochrane Database of Systematic Reviews through August 2017. Key word combinations included haemorrhoid, haemorrhoidal disease, interventions, techniques (Rubber Band Ligation, h(a)emorrhoidopexy, h(a)emorrhoidectomy, Procedure for Prolapse and Hemorrhoids (PPH), Milligan-Morgan, Ferguson, Doppler guided, and stapled hemorrhoidopexy). There were no restrictions concerning publication format or language. The search was limited by date $(<25$ years) and good-quality published reviews followed by controlled trials followed by observational studies. The searches in databases were supplemented by checking references in the reviews and primary studies that we found. In addition, the GDG-members identified relevant studies from their collections. The search strategy was designed and implemented by the surgical resident (RT) with help from an information specialist (JK and SK).

Inclusion focused on available systematic reviews addressing each question, supplemented by further studies published after the time frame covered by the systematic reviews. We used a hierarchy of best available evidence for study selection, i.e. well performed 
systematic reviews, meta-analyses, randomized trials, controlled observational studies, case series and expert opinion (figure 1). If evidence of a higher level was available, no lower level of evidence was sought or included.

Figure I: The pyramid of evidence.

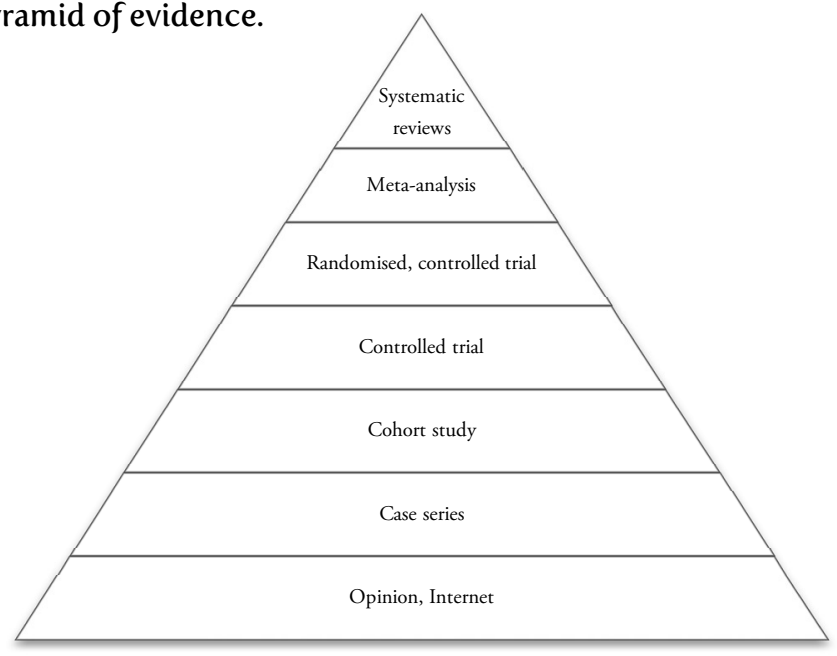

\section{Reviewing research evidence}

Data were extracted by the surgical resident (RT) and checked by the methodologist (JK) and the GDG-members. Inclusion focused on available meta-analyses, systematic reviews addressing each question, supplemented by further studies published after the time frame covered by the systematic reviews.

Quality assessment was a critical stage in reviewing the evidence. It required a systematic process of assessing bias through considering the appropriateness of the study design and the methods of the study. We used the ROBIS-tool to assess the risk of bias in systematic reviews [6] [table 4]. The full ROBIS-tool and guidance documents are available from the ROBIS Web site (www.robis-tool.info) and as Appendices at www.jclinepi.com. We used the Cochrane checklist for assessing risk of bias of randomized trials [7]. 
Table 4: ROBIS Domains and signaling questions [6].

\begin{tabular}{|c|c|c|c|c|c|}
\hline & \multicolumn{4}{|c|}{ Phase 2} & \multirow{2}{*}{$\begin{array}{c}\text { Phase } 3 \\
\text { Risk of bias in the review }\end{array}$} \\
\hline & $\begin{array}{l}\text { 1. Study eligibility } \\
\text { criteria }\end{array}$ & $\begin{array}{l}\text { 2. Identification and } \\
\text { selection of studies }\end{array}$ & $\begin{array}{l}\text { 3. Data collection and } \\
\text { study appraisal }\end{array}$ & 4. Synthesis and findings & \\
\hline \multirow[t]{5}{*}{$\begin{array}{l}\text { Signaling } \\
\text { questions }\end{array}$} & $\begin{array}{l}\text { 1.1 Did the review adhere } \\
\text { to predefined objectives } \\
\text { and eligibility criteria? }\end{array}$ & $\begin{array}{l}2.1 \text { Did the search } \\
\text { include an appropriate } \\
\text { range of databases/ } \\
\text { electronic sources for } \\
\text { published and } \\
\text { unpublished reports? }\end{array}$ & $\begin{array}{l}\text { 3.1. Were efforts made } \\
\text { to minimize error in } \\
\text { data collection? }\end{array}$ & $\begin{array}{l}\text { 4.1. Did the synthesis } \\
\text { include all studies } \\
\text { that it should? }\end{array}$ & $\begin{array}{l}\text { A. Did the interpretation } \\
\text { of findings address all } \\
\text { of the concerns } \\
\text { identified in domains } 1 \\
\text { to } 4 \text { ? }\end{array}$ \\
\hline & $\begin{array}{l}1.2 \text { Were the eligibility } \\
\text { criteria appropriate for } \\
\text { the review question? }\end{array}$ & $\begin{array}{l}2.2 \text { Were methods } \\
\text { additional to database } \\
\text { searching used to } \\
\text { identify relevant } \\
\text { reports? }\end{array}$ & $\begin{array}{l}\text { 3.2. Were sufficient } \\
\text { study characteristics } \\
\text { available for both } \\
\text { review authors and } \\
\text { readers to be able to } \\
\text { interpret the results? }\end{array}$ & $\begin{array}{l}\text { 4.2. Were all predefined } \\
\text { analyses reported or } \\
\text { departures explained? }\end{array}$ & $\begin{array}{l}\text { B. Was the relevance of } \\
\text { identified studies to the } \\
\text { review's research } \\
\text { question appropriately } \\
\text { considered? }\end{array}$ \\
\hline & $\begin{array}{l}1.3 \text { Were eligibility } \\
\text { criteria unambiguous? }\end{array}$ & $\begin{array}{l}2.3 \text { Were the terms and } \\
\text { structure of the search } \\
\text { strategy likely to } \\
\text { retrieve as many } \\
\text { eligible studies as } \\
\text { possible? }\end{array}$ & $\begin{array}{l}\text { 3.3. Were all relevant } \\
\text { study results collected } \\
\text { for use in the } \\
\text { synthesis? }\end{array}$ & $\begin{array}{l}\text { 4.3. Was the synthesis } \\
\text { appropriate given the } \\
\text { nature and similarity } \\
\text { in the research } \\
\text { questions, study } \\
\text { designs, and outcomes } \\
\text { across included } \\
\text { studies? }\end{array}$ & $\begin{array}{l}\text { C. Did the reviewers avoid } \\
\text { emphasizing results on } \\
\text { the basis of their } \\
\text { statistical significance? }\end{array}$ \\
\hline & $\begin{array}{l}\text { 1.4 Were all restrictions } \\
\text { in eligibility criteria } \\
\text { based on study } \\
\text { characteristics } \\
\text { appropriate? }\end{array}$ & $\begin{array}{l}2.4 \text { Were restrictions } \\
\text { based on date, } \\
\text { publication format, or } \\
\text { language appropriate? }\end{array}$ & $\begin{array}{l}\text { 3.4. Was risk of bias (or } \\
\text { methodologic quality) } \\
\text { formally assessed } \\
\text { using appropriate } \\
\text { criteria? }\end{array}$ & $\begin{array}{l}\text { 4.4. Was between-study } \\
\text { variation minimal or } \\
\text { addressed in the } \\
\text { synthesis? }\end{array}$ & \\
\hline & $\begin{array}{l}1.5 \text { Were any restrictions } \\
\text { in eligibility criteria } \\
\text { based on sources of } \\
\text { information } \\
\text { appropriate? }\end{array}$ & $\begin{array}{l}2.5 \text { Were efforts made } \\
\text { to minimize error in } \\
\text { selection of studies? }\end{array}$ & $\begin{array}{l}\text { 3.5. Were efforts made } \\
\text { to minimize error } \\
\text { in risk of bias } \\
\text { assessment? }\end{array}$ & $\begin{array}{l}\text { 4.5. Were the findings } \\
\text { robust, for example, } \\
\text { as demonstrated } \\
\text { through funnel plot } \\
\text { or sensitivity analyses? } \\
\text { 4.6. Were biases in } \\
\text { primary studies } \\
\text { minimal or addressed } \\
\text { in the synthesis? }\end{array}$ & \\
\hline Judgment & $\begin{array}{l}\text { Concerns regarding } \\
\text { specification of study } \\
\text { eligibility criteria }\end{array}$ & $\begin{array}{l}\text { Concerns regarding } \\
\text { methods used to } \\
\text { identify and/or select } \\
\text { studies }\end{array}$ & $\begin{array}{l}\text { Concerns regarding } \\
\text { methods used to } \\
\text { collect data and } \\
\text { appraise studies }\end{array}$ & $\begin{array}{l}\text { Concerns regarding } \\
\text { the synthesis }\end{array}$ & Risk of bias in the review \\
\hline
\end{tabular}

\section{Developing and wording recommendations}

The quality of the evidence was summarized using the GRADE-approach, by outcome across all relevant studies [table 5] [8,9].

The GRADE-system assesses the quality of the evidence for intervention studies by looking at features of the evidence found for each 'critical' and 'important' outcome. We aimed to only do the GRADE-assessments once the recommendations were at an advanced stage, so that this laborious process was kept as efficient as possible. An advanced stage was reached when research evidence and GDG-members supported the recommendation.

If needed, we updated high-quality systematic reviews or their primary studies used as evidence for informing a new review.

The quality of evidence is classified as high, moderate, low or very low. 
Table 5: quality of the evidence according to GRADE [9].

\begin{tabular}{lll}
\hline High & $\begin{array}{l}\text { Further research is very unlikely to change our confidence in the estimate of } \\
\text { effect. }\end{array}$ & Grade ++++ \\
Moderate & $\begin{array}{l}\text { Further research is likely to have an important impact on our confidence in } \\
\text { the estimate of effect and may change the estimate. }\end{array}$ & Grade +++ \\
Low & $\begin{array}{l}\text { Further research is very likely to have an important impact on our } \\
\text { confidence in the estimate of effect and is likely to change the estimate. }\end{array}$ & Grade ++ \\
Very low & Any estimate of effect is very uncertain. & Grade + \\
\hline
\end{tabular}

According to the classification mentioned above, the specific wording of 'must', 'should', 'could', 'may', or 'may not', has been used for the recommendations. In case of high evidence, the term 'must', was implemented in the guideline. Concerning moderate evidence, this was recommended using 'should or could'. The low graded evidence was interpreted as 'could or may', and very low evidence was implemented in the recommendations as 'can be considered'.

The following sections were included in the evidence review [table 6]:

o summary of the evidence, including the 'summary of findings' table from the GRADE profile (if this improves readability and the GRADE system has been used)

o evidence statements

o full GRADE profiles

o evidence tables 
Table 6: Example of a GRADE table.

\begin{tabular}{|c|c|c|c|c|c|c|c|c|c|c|c|c|}
\hline \multicolumn{7}{|c|}{ Certainty assessment } & \multicolumn{2}{|c|}{ № of patients } & \multicolumn{4}{|l|}{ Effect } \\
\hline $\begin{array}{l}\text { № of } \\
\text { studies }\end{array}$ & $\begin{array}{l}\text { Study } \\
\text { design }\end{array}$ & $\begin{array}{l}\text { Risk of } \\
\text { bias }\end{array}$ & $\begin{array}{l}\text { Inconsist- } \\
\text { ency }\end{array}$ & $\begin{array}{l}\text { Indirect- } \\
\text { ness }\end{array}$ & $\begin{array}{l}\text { Impreci- } \\
\text { sion }\end{array}$ & $\begin{array}{l}\text { Other } \\
\text { considera- } \\
\text { tions }\end{array}$ & $\begin{array}{l}\text { phlebot- } \\
\text { onics }\end{array}$ & $\begin{array}{l}\text { no phlebo- } \\
\text { tonics }\end{array}$ & $\begin{array}{l}\text { Relative } \\
(95 \% \mathrm{CI})\end{array}$ & $\begin{array}{l}\text { Absolute } \\
(95 \% \text { CI })\end{array}$ & Certainty & $\begin{array}{l}\text { Impor- } \\
\text { tance }\end{array}$ \\
\hline \multicolumn{13}{|c|}{ Remaining symptoms (bleeding) } \\
\hline 2 & $\begin{array}{l}\text { ran- } \\
\text { domised } \\
\text { trials }\end{array}$ & $\begin{array}{l}\text { not } \\
\text { serious a }\end{array}$ & serious $^{b}$ & not serious & not serious & $\begin{array}{l}\text { publica- } \\
\text { tion bias } \\
\text { strongly } \\
\text { suspect- } \\
\text { ed c }^{\text {c }}\end{array}$ & $\begin{array}{l}4 / 99 \\
(4.0 \%)\end{array}$ & $\begin{array}{l}23 / 91 \\
(25.3 \%)\end{array}$ & $\begin{array}{l}\text { RR 0.15 } \\
(0.05 \text { to } \\
0.44)\end{array}$ & $\begin{array}{l}215 \text { fewer } \\
\text { per } \mathbf{1 , 0 0 0} \\
\text { (from } \\
142 \text { fewer } \\
\text { to } 240 \\
\text { fewer) }\end{array}$ & $\begin{array}{l}\oplus \oplus \circ \mathrm{O} \\
\text { LOW }\end{array}$ & $\begin{array}{l}\text { CRITI- } \\
\text { CAL }\end{array}$ \\
\hline \multicolumn{13}{|c|}{ Remaining symptoms (overall symptom improvement) } \\
\hline 5 & $\begin{array}{l}\text { ran- } \\
\text { domised } \\
\text { trials }\end{array}$ & $\begin{array}{l}\text { not } \\
\text { serious }\end{array}$ & serious $^{\mathrm{c}}$ & not serious & not serious & $\begin{array}{l}\text { publica- } \\
\text { tion bias } \\
\text { strongly } \\
\text { suspect- } \\
\text { ed c }^{\text {c }}\end{array}$ & $\begin{array}{l}181 / 193 \\
(93.8 \%)\end{array}$ & $\begin{array}{l}99 / 175 \\
(56.6 \%)\end{array}$ & $\begin{array}{l}\text { RR 1.69 } \\
(1.57 \text { to } \\
1.74)\end{array}$ & $\begin{array}{l}390 \text { more } \\
\text { per } \mathbf{1 , 0 0 0} \\
\text { (from } 322 \\
\text { more to } \\
419 \text { more) }\end{array}$ & $\begin{array}{l}\oplus \oplus O O \\
\text { LOW }\end{array}$ & $\begin{array}{l}\text { CRITI- } \\
\text { CAL }\end{array}$ \\
\hline \multicolumn{13}{|c|}{ Remaining symptoms (pain assessed with: dosis analgesics) } \\
\hline 2 & $\begin{array}{l}\text { ran- } \\
\text { domised } \\
\text { trials }\end{array}$ & $\begin{array}{l}\text { not } \\
\text { serious } f\end{array}$ & serious $^{b}$ & not serious & not serious & $\begin{array}{l}\text { publica- } \\
\text { tion bias } \\
\text { strongly } \\
\text { suspect- } \\
\text { ed }^{c}\end{array}$ & $\begin{array}{l}11 / 99 \\
(11.1 \%)\end{array}$ & $\begin{array}{l}48 / 91 \\
(52.7 \%)\end{array}$ & $\begin{array}{l}\text { RR 0.21 } \\
(0.02 \text { to } \\
1.05)\end{array}$ & $\begin{array}{l}\mathbf{4 1 7} \text { fewer } \\
\text { per } \mathbf{1 , 0 0 0} \\
\text { (from } \\
26 \text { more } \\
\text { to } 517 \\
\text { fewer) }\end{array}$ & $\begin{array}{l}\oplus \oplus 00 \\
\text { LOW }\end{array}$ & $\begin{array}{l}\text { CRITI- } \\
\text { CAL }\end{array}$ \\
\hline \multicolumn{13}{|c|}{ Complications } \\
\hline 7 & $\begin{array}{l}\text { ran- } \\
\text { domised } \\
\text { trials }\end{array}$ & not serious & not serious & not serious & not serious & $\begin{array}{l}\text { publica- } \\
\text { tion bias } \\
\text { strongly } \\
\text { suspect- } \\
\text { ed c }^{\text {c }}\end{array}$ & $\begin{array}{l}10 / 246 \\
(4.1 \%)\end{array}$ & $\begin{array}{l}10 / 265 \\
(3.8 \%)\end{array}$ & $\begin{array}{l}\text { RR 0.00 } \\
(-0.04 \text { to } \\
0.04)\end{array}$ & $\begin{array}{l}\text {-- per } \\
\mathbf{1 , 0 0 0} \\
\text { (from } 36 \\
\text { fewer to } \\
39 \text { fewer) }\end{array}$ & $\begin{array}{l}\oplus \oplus O O \\
\text { MODER- } \\
\text { ATE }\end{array}$ & $\begin{array}{l}\text { CRITI- } \\
\text { CAL }\end{array}$ \\
\hline
\end{tabular}

Prior to the first face-to-face meeting of the GDG, all members were sent an overview of the review questions with applied evidence from the literature search. This gave all members the opportunity to assess the evidence and review questions before meeting up. The first face-to-face meeting was carried out at the twelfth ESCP conference in Berlin in September 2017.

During this meeting, review questions were altered and optimized according to the experts' interpretations of the evidence found in the literature search [table 7]. Both the surgical resident (RT) and the methodologist (JK) adjusted the review questions and by email permission was obtained from the GDG. 


\section{Table 7: Final set of review questions for the guideline of HD.}

\begin{tabular}{|c|c|}
\hline $\begin{array}{l}\operatorname{Pr} \\
\text { ph }\end{array}$ & $\begin{array}{l}\text { o Which factors should be assessed during history taking? } \\
\text { o In which position should physical examination be performed? (knee-chest-, lithotomy- or } \\
\text { left lateral position) } \\
\text { o How should haemorrhoidal disease be classified? }\end{array}$ \\
\hline & $\begin{array}{l}\text { o What are the effects of toilet training versus no toilet training on occurrence and symptoms } \\
\text { in patients with haemorrhoidal disease? } \\
\text { o What are the effects of laxatives versus no laxatives on occurrence and symptoms in patients } \\
\text { with haemorrhoidal disease? } \\
\text { o What are the effects of local treatments versus no local treatments on occurrence and } \\
\text { symptoms in patients with haemorrhoidal disease? } \\
\text { o What are the effects of phlebotonics versus no phlebotonics on occurrence and symptoms } \\
\text { in patients with haemorrhoidal disease? }\end{array}$ \\
\hline & $\begin{array}{l}\text { o What are the effects of rubber band ligation versus sclerotherapy versus infrared coagulation } \\
\text { on symptoms, recurrence and complications in patients with haemorrhoids which are } \\
\text { suitable outpatient treatment options? } \\
\text { o What are the effects of rubber band ligation versus DG-HAL versus stapled haemorrhoidopexy } \\
\text { versus traditional haemorrhoidectomy on symptoms, recurrence and complications in } \\
\text { patients with haemorrhoids which are suitable outpatient treatment options? }\end{array}$ \\
\hline
\end{tabular}

Surgical procedures o What are the effects of DG-HAL + mucopexy versus muxopexy alone on symptoms, recurrence and complications in patients with haemorrhoidal disease which are suitable for surgical treatment options?

o What are the effects of DG-HAL + mucopexy versus stapled haemorrhoidopexy on symptoms, recurrence and complications in patients with haemorrhoidal disease which are suitable for surgical treatment options?

o What are the effects of DG-HAL + mucopexy versus traditional haemorrhoidectomy on symptoms, recurrence and complications in patients with haemorrhoidal disease which are suitable for surgical treatment options?

o What are the effects of stapled haemorrhoidopexy versus traditional haemorrhoidectomy on symptoms, recurrence and complications in patients with haemorrhoidal disease which are suitable for surgical treatment options?

$\begin{aligned} & \text { Special } \\ & \text { situations }\end{aligned}$
o What are the effects and side effects of basic treatment (i.e. analgesics, flavonoids, heparin
and nifedipin) versus surgical treatment (i.e. stapler and traditional haemorrhoidectomy)?
o What are the effects and side effects of stapled haemorrhoidopexy versus the traditional
haemorrhoidectomy?
o How should we treat haemorrhoids in patients with coagulation defects?
o What are the effects and side effects of RBL in patients with coagulation defects compared
to patients who underwent RBL without coagulation defect? $\rightarrow$ no literature found
o What are the effects and side effects of sclerotherapy in patients with coagulation defects
compared to patients who underwent sclerotherapy without coagulation defect?
o What are the effects and side effects of stapled haemorrhoidopexy in patients with
coagulation defects compared to patients who underwent stapled haemorrhoidopexy
without coagulation defect?
o How should haemorrhoids be treated in patients with immune deficiencies?
o What are the effects and side effects of RBL in patients with immune deficiencies
compared to patients who underwent RBL with no immune deficiencies?
o How should we treat pregnant women with internal and/or external haemorrhoids?
o What are the effects and side effects of basic treatment (i.e. sit bath and flavonoids) versus
the traditional haemorrhoidectomy?


During a second face-to-face meeting in Amsterdam, in January 2018, the GDG members used their judgment to decide what the evidence meant in the context of the guideline referral and decided what recommendations could be made to practitioners, commissioners of services and others. No Delphi process was conducted, GDG members reached consensus on all recommendations. In case of minority dissent, we planned to explicitly report this, however, full consensus was reached on all recommendations. Some recommendations are 'strong' in that the GDG members believe that the vast majority of practitioners or commissioners and people using services would choose a particular intervention if they considered the evidence in the same way as the GDG. Similarly, if the GDG believe that the vast majority of practitioners or commissioners and people using services would not choose a particular intervention if they considered the evidence in the same way as the GDG, a negative recommendation was made ('Do not offer').

If evidence of effectiveness for an intervention was either lacking or too weak for firm conclusions to be reached, the GDG used expert opinion; or it made no recommendation.

\section{The validation process for draft guidelines}

The draft version of the guideline will be posted on the ESCP website for consultation with registered stakeholders and respondents. The ESCP informs registered stakeholders and respondents that the draft is available and invites them to comment by the deadline. Questions for stakeholders are posted with the draft guideline. The ESCP will also ask stakeholders to comment on recommendations identified as likely to substantially increase costs, and their justification, and to consider whether any other draft recommendations are expected to add substantial costs.

A 4-week consultation will be used.

\section{Finalizing and publishing the guideline}

The development time for guideline is between 12 and 20 months from March 2017 to December 2018

\section{Updating guidelines}

The formal process for updating the guideline will begin 3 years after publication. 


\section{References}

1. Dans, A.L. and L.F. Dans, Appraising a tool for guideline appraisal (the AGREE II instrument). J Clin Epidemiol, 2010. 63(12): p. 1281-2.

2. Banov, L., Jr., et al., Management of hemorrhoidal disease. J S C Med Assoc, 1985. 81(7): p. 398401.

3. Gaj, F., et al., The new classification of hemorrhoids: PATE 2000-Sorrento. History of the scientific debate. Minerva Chir, 2002. 57(3): p. 331-9.

4. Elbetti, C., et al., The single pile classification: a new tool for the classification of haemorrhoidal disease and the comparison of treatment results. Updates Surg, 2015. 67(4): p. 421-6.

5. Boers, M., et al., Developing core outcome measurement sets for clinical trials: OMERACT filter 2.0. J Clin Epidemiol, 2014. 67(7): p. 745-53.

6. Sinha, I.P., R.L. Smyth, and P.R. Williamson, Using the Delphi technique to determine which outcomes to measure in clinical trials: recommendations for the future based on a systematic review of existing studies. PLoS Med, 2011. 8(1): p. e1000393.

7. Whiting, P., et al., ROBIS: A new tool to assess risk of bias in systematic reviews was developed. J Clin Epidemiol, 2016. 69: p. 225-34.

8. Savovic, J., et al., Evaluation of the Cochrane Collaboration's tool for assessing the risk of bias in randomized trials: focus groups, online survey, proposed recommendations and their implementation. Syst Rev, 2014. 3: p. 37.

9. Kong, Y., et al., Rating the quality of evidence: the GRADE system in systematic reviews/metaanalyses of AKI. Ren Fail, 2015. 37(7): p. 1089-93.

10. Neumann, I., et al., [The GRADE system: a change in the way of assessing the quality of evidence and the strength of recommendations]. Rev Med Chil, 2014. 142(5): p. 630-5. 


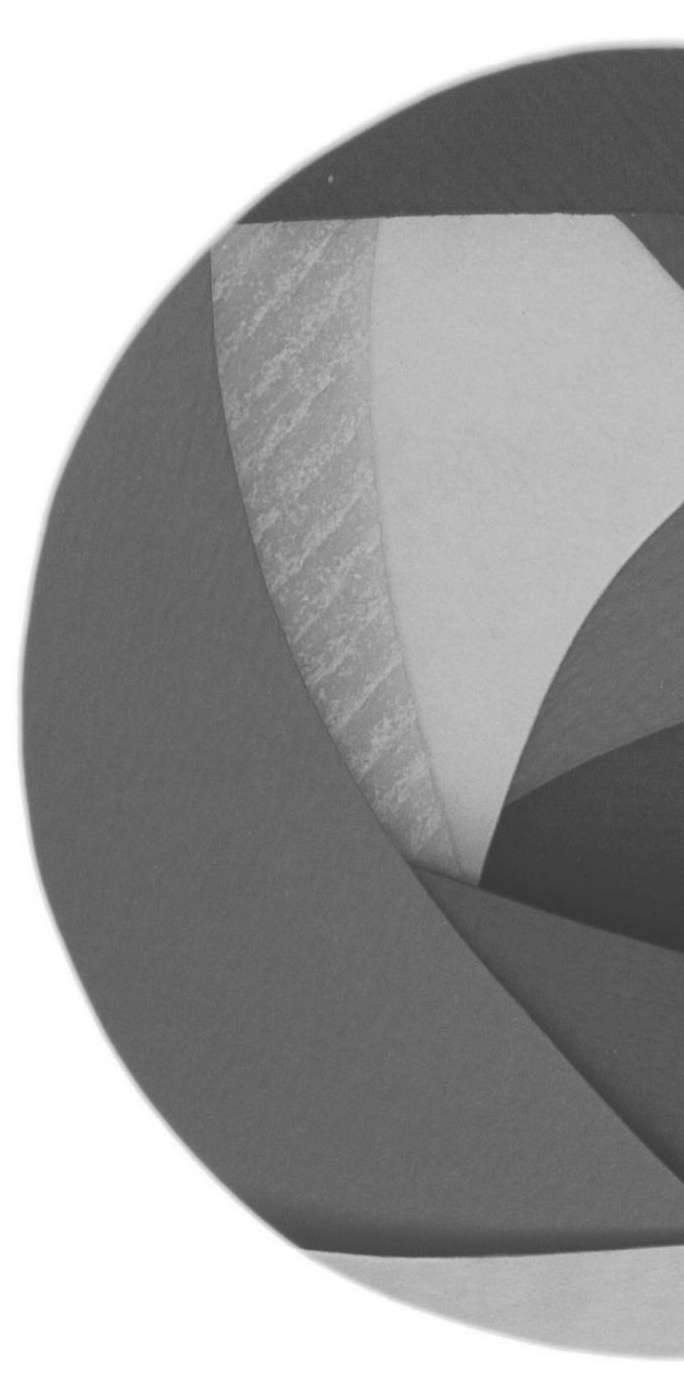




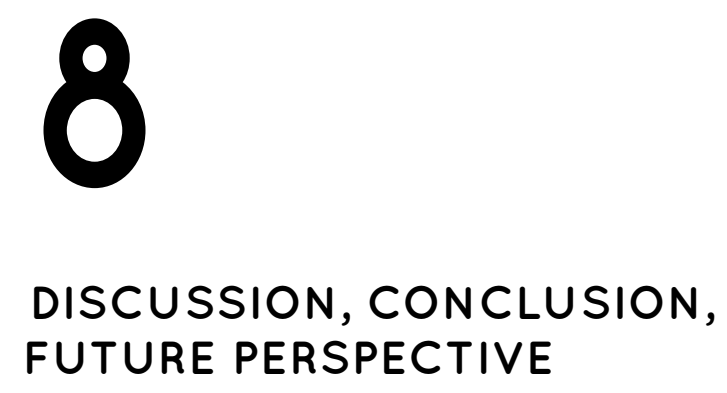




\section{DISCUSSION}

This chapter first repeats the aims and research questions, and then provides a short overview of the studies conducted and the results found.

The overview is followed by a reflection of our findings compared to current literature. Subsequently the conclusions and recommendations are presented.

\section{Outline}

Haemorrhoidal disease (HD) is the most frequent anorectal disorder with prevalence rates up to $45 \%(1-4)$. In the Netherlands, the prevalence is estimated to be around 8.6 per 1000 individuals.

HD is mostly classified according to the grading system of Goligher et al. (5-7). Grade I describes blood loss or haemorrhoidal prolapse through the proctoscope, grade II describes haemorrhoidal prolapse during straining which reduces spontaneously, grade III describes haemorrhoidal prolapse occurring during straining and requires manual reduction back into the anal canal and grade IV describes irreducible haemorrhoidal prolapse.

Till recently, limited level of evidence was available in literature regarding the best treatment options for each grade of HD. Fortunately, in 2016 two high level of evidence trials were published. The HubBLe trial compared RBL with DG-HAL in grade II-IV HD (8). The eTHoS trial was designed to establish the clinical effectiveness and costeffectiveness of stapled haemorrhoidopexy compared with traditional excisional surgery in grade II-IV HD (9). The results of these two studies have not yet been implemented in (inter) national guidelines.

Another problem in HD literature is the fact that high heterogeneity in outcome reporting exists. There is lack of uniformity in outcome definition, measurement, and reporting. Consequently, optimal evidence synthesis is hampered and guidelines can only provide moderate or low level of evidence recommendations (10-12). The development of a core outcome set (COS) has been suggested as a solution in case of high heterogeneity. A COS aims to enable selective reporting and to reduce outcome irrelevance, and inconsistency (13). A COS represents a consensus derived minimum set of outcome parameters that should be reported in all clinical trials within a particular disease area (14). Since no COS for HD exists, we aimed to develop a COS for HD in the first part of this thesis. The first step in the development process of a COS is a systematic review of the currently used outcomes in HD studies.

To incorporate the patient's perspective in the COS, qualitative patient interviews were added to the development process of the $\operatorname{COS}(15,16)$.

Next to the issue of heterogeneity in HD literature, evidence is also hampered by the fact that there are no recently developed HD guidelines which follow the latest international 
adapted methodology like AGREE and GRADE. The AGREE (II) instrument is a validated and internationally most widely used instrument for guideline assessment (1720). The GRADE-approach is used for grading the quality of evidence and strength of recommendations, which is now considered the standard in guideline development (21, 22). Besides, in the current existing guidelines the core recommendations are difficult to identify due to long and bulky documents (35-37). Therefore, we aimed at developing an international HD guideline following AGREE and using GRADE which process is described in the second part of this thesis. Preceding this process, we wanted to explore current practice in the treatment of HD in the Netherlands; a national survey was performed among Dutch colorectal consultants, fellows and residents.

In conclusion, the first aim of this thesis was to develop a COS for HD. The second aim was to develop an international, multidisciplinary guideline for HD following AGREE and using GRADE.

For this purpose, the following research questions were formulated:

- What kind of outcomes are reported in clinical trials on HD?

- How to develop a Core Outcome Set (COS) for HD?

- How to obtain a better understanding of the patients' experiences with HD, impact on their daily life and the patient reported effect of HD treatment?

- What is current practice in the Netherlands regarding HD treatment?

- How to develop an international guideline for HD following GRADE and AGREE?

\section{Summary of the main results}

A solution to improve homogeneity in outcome reporting for $\mathrm{HD}$ was the development of a Core Outcome Set (COS) for HD. The development process of the COS consisted of two main phases (chapter two): 1) a literature review to assess which outcomes are commonly used in clinical trials for HD (chapter three) and 2) a consensus study according to the Delphi methodology (chapter four).

The outcomes reported in the literature review were categorized according to the framework of OMERACT, a practical framework to develop and validate domains and outcomes for any health condition (23-25). In total, 59 different outcomes were found in the 34 included studies. On average, 5.8 different outcomes (2-8) were assessed per study. For the consensus study, the outcomes, that had been identified in the literature review (10), were operationalized into a questionnaire for healthcare professionals and a separate questionnaire for patients. Thereafter, two sequential rounds of the questionnaire for healthcare professionals and one patient round aimed to prioritize these different outcomes. Eventually this resulted in the first international COS for HD with 'symptoms' as primary endpoint and 'complications', 'recurrence' and 'patient satisfaction' as secondary endpoints. The consensus study also underlined the need to 
integrate Patient Reported Outcomes (PROs) in a COS, next to traditional clinical outcomes. Healthcare professionals agreed that the Domain 'symptoms' should be a PRO and include the Outcomes 'pain', 'prolapse', 'itching', 'soiling' and 'blood loss'. This was supported by the qualitative interviews with patients (chapter five) $(26,27)$. The qualitative interviews confirmed that certain aspects relevant to the patient are overlooked when treatment effectiveness is assessed by only traditional endpoints such as prolapse, recurrence and complications.

A national survey (chapter 6 ) regarding the treatment of HD showed that, despite the availability of published national guidelines, considerable practice variation was present in the Netherlands. Grades I and II hemorrhoidal disease were mostly treated conservatively or with Rubber Band Ligation (RBL). This is in accordance with several studies and guidelines describing the optimal treatment for low-grade HD (35-37). However, especially for grade III and IV HD treatment variability was seen. For example, in grade III HD healthcare professionals used the sutured hemorrhoidopexy in $24 \%$ and the DG-HAL in $15 \%$ of the patients. Regarding invasive treatment, respondents used the stapled hemorrhoidopexy in $19 \%$ and traditional hemorrhoidectomy in 31\%.

The above described variation in Dutch HD practice may be explained by suboptimal readability of existing guidelines. Over the last decades several national HD guidelines have been published (28-30). The Dutch guideline was published in 2015 (published:https://richtlijnendatabase.nl/richtlijn/proctologie/behandelalgoritme_ symptomatische_hemorroiden.html). The most recently updated guideline is the one published by the American Society of Colon and Rectal Surgeons (ASCRS) in 2018 (28). In these published guidelines, core recommendations were mostly difficult to identify and the documents were long and bulky. Besides, the current HD guidelines did not follow international adapted methods. These survey results underlined the need to develop a new guideline for daily practice in HD. Since the development of guidelines is expensive and time-consuming we decided to cooperate with the European Society of Coloproctology (ESCP). This international setting improved diversity of the guideline development group and limited loss of time since the face-to-face meetings were conducted during the ESCP congresses. This guideline development process strictly followed the AGREE instrument (17-20) and used $\operatorname{GRADE}(21,22)$ (chapter 7).

\section{Overcoming challenges}

This section discusses the main issues we encountered during our research, and reflects on the findings of this thesis in light of recent literature. These issues relate to the development of a COS, including: categorizing outcomes, methodological approach, stakeholder involvement, patient inclusion and implementation of a COS.

The second part relates to the guideline process, the guideline development tools and the implementation strategies of guidelines. 


\section{Development of a COS}

\section{Categorizing outcomes}

The review in this thesis showed that in $34 \mathrm{HD}$ studies, as much as 59 different outcomes were used. In order to be able to reduce this number of outcomes to a consensus based Core Outcome Set (COS) a rigorous process should be followed. Since 1992, the Outcome Measures in Rheumatology (OMERACT) group developed many Core Outcome Sets (COS) according to a framework and methodology (i.e. the OMERACT Filter) (31). Also the COMET (Core Outcome Measures in Effectiveness Trials) (32) and ICHOM (the International Consortium for Health Outcomes Measurement) (33, 34) initiatives have developed guidelines for developing a COS. We chose to follow the OMERACT working group, since their OMERACT filter has resulted in successful development and implementation of core Domain and Measurement sets for many different diseases (35-41). In addition, they recently provided the OMERACT Filter 2.0, a practical framework to develop and validate domains and measures for any health condition (25). OMERACT uses a conceptual framework based on the International Classification of Functioning to define Core areas, Domains and Outcomes in which study outcomes first should be categorized (25).

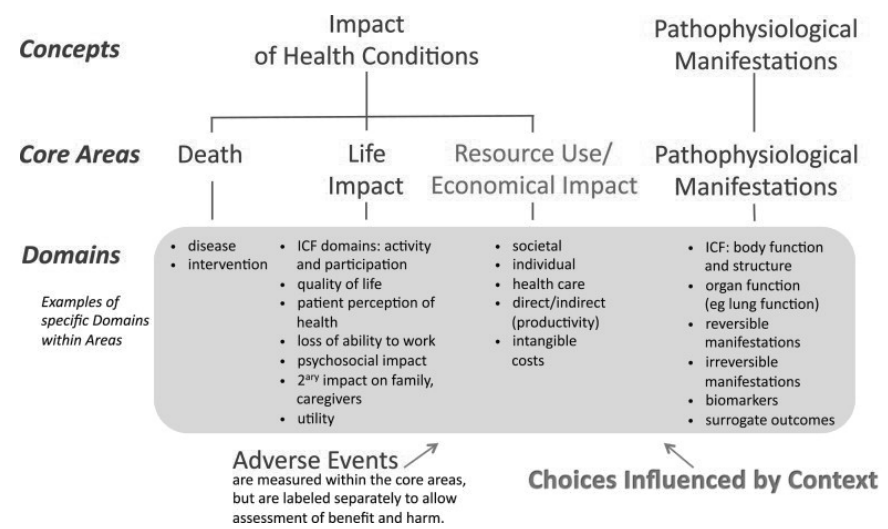

Figure I: Concepts, Core Areas, \& Domains for Outcome Measurement in Health Intervention Studies (Boers 20I4).

However, by categorizing HD outcomes into OMERACT Core areas, Domains and Outcomes, we encountered two problems in the application of the conceptual framework: 1) which outcomes are Domains and/or Outcomes and 2) Outcomes can be assigned to more than one Core area and Domain. OMERACT defined a Domain as component of a Core Area: 'a concept to be measured, a further specification of an 
aspect of health, categorized within a Core Area'. Outcomes are 'any identified result in a Domain or Sub-domain arising from exposure to a causal factor or a health intervention'. We chose to categorize the HD outcomes into the following Domains: 'symptoms', 'complications', 'recurrence' and 'patient satisfaction' and Outcomes: 'pain', 'prolapse', 'blood loss', 'itching', 'soiling', 'urgency', 'constipation', 'abscess', 'incontinence', 'anal stenosis', 'stricture', 'urinary retention', 'thrombosis' and 'edema', 'fistula', 'nodule' and 'severe pain and bleeding.' However, in the literature the outcomes 'prolapse' and 'pain' were also often used as primary endpoints in studies. Therefore, 'prolapse' and 'pain' were also added as Domains. This is one example where an outcome could potentially be assigned to more than one Core area and Domain. Another example is 'repeat procedure' that can be considered in the context of (ongoing) 'Pathophysiological Manifestations', or within 'Resource Use'.

The question is whether a different categorization of the outcomes would have resulted in a different COS. We think that important Domains, like symptoms and complications would also have been chosen as primary and secondary endpoint(s) if another subdivision was chosen. Other COS studies do not report these issues as a limitation $(42,43)$.

\section{Methodological approach}

Different methods for reaching consensus exist. These methods include unstructured group discussions (e.g., task forces, work groups, expert panels), semi-structured group discussions (e.g., nominal group technique), or structured surveys (e.g., Delphi technique) $(44,45)$. With the nominal group technique (NGT), participants write down their ideas silently and independently, followed by brainstorming and reaching consensus on the issues, problems, or solutions which encourages contributions from everyone. With the Delphi method, several rounds of questionnaires are sent out to the group of experts, and the anonymous responses are aggregated and shared with the group after each round. In a face-to-face meeting, final agreement can be achieved. Comparing both techniques, the NGT allows incorporation of many individual perspectives which may increase the number of solutions generated by the group. However, with the NGT the many opinions may not converge in the group discussion. With the Delphi technique dominance of certain persons in face-to-face group meetings are avoided (46) and feedback is provided in a controlled manner. Besides, with the Delphi a clearer description of the level of agreement is thought to be given (47).

Other COS development studies considered the Delphi methodology to be most appropriate to determine a $\operatorname{COS}(45,48)$. While many papers support the use of the Delphi method $(42,49)$, there are also papers criticizing the technique (50-52). One of the major critiques of the Delphi method is that it is associated with limited reproducibility. E.g. if the same information was given to two or more panels there is no guarantee that the same results are obtained. The technique has also been criticised in 
relation to validity. However, if the panels participating in the study are representative of the group or the area of knowledge, then content validity can be assumed. Since other COS development studies have also considered the Delphi methodology to be most appropriate to determine a COS $(45,48)$ and recently the Core Outcome SetStandards for Reporting (COS-STAR) stated that a clear and transparent reporting of a COS development is fundamental (53) we chose for the Delphi methodology for the development of a HD COS.

\section{Stakeholder involvement}

The results of a Delphi study are highly dependent on the composition of the panel. Researchers should aim for a sample of true experts that represents diverse institutes, is multidisciplinary and demonstrates expertise in their field. Besides, the quality of the Delphi study will augment if organizations with geographical differences are incorporated which is described in the book of Surowiecki J. (2004) 'The Wisdom of Crowds: Why the Many Are Smarter Than the Few'. The HD COS was developed with the support of the ESCP, a large and pan-European surgical society. All international representatives of the ESCP were asked to participate in the COS development. Most representatives replied that they did not treat HD or they felt that they were not experienced enough to provide input for a COS. Following their recommendations, healthcare professionals were invited with an in-depth understanding of HD and/or development of a COS using the so-called snowball method. This strategy resulted in a dedicated group of experts with knowledge of the field, but smaller in size than initially planned. The latter we consider as a limitation of the study. The geographical diversity on the other hand is an advantage from the perspective that we strived for international applicability of the COS. By comparison, the recent COS for Crohn's anal fistula secured responses from 120 clinicians (54). The question is whether involvement of a larger group of healthcare professionals would have resulted in a different COS. The literature describes no guidance regarding the minimum required sample size of stakeholder groups and only recommends a sample of experts that represents diverse institutes and organizations with geographical differences (55).

\section{Patient perspective}

The patient perspective is increasingly considered important on all levels of healthcare decision making $(56,57)$. This view is reflected in several international patient participation initiatives in healthcare research and decision-making; e.g. the initiatives Patient Centered Outcomes Research Institute (PCORI) and the PROM-toolbox from the Dutch Healthcare institute. There are also initiatives that embrace the implementation of patient outcomes in healthcare, for example the International Consortium for Health Outcomes Measurement (ICHOM). 
Much of the literature on the patient perspective in healthcare policy decisions focuses on direct and active participation (e.g. membership of committees, participating in face-to-face meetings). Also in COS and guideline development patients should play an active role and bring their experiential knowledge to the table $(58,59)$. However, in both studies we encountered several issues regarding patient involvement. First, in our opinion some questions and issues posed to the healthcare professionals were irrelevant and not conceivable for patients; therefore, during the development of the COS, patients received a modified questionnaire. As a result, patients did not receive the same questionnaire as clinicians, but instead they were asked specifically what symptoms they would like to discuss with the clinician during the outpatient clinic visit. Secondly, in both the COS and guideline development, the presence of patients at the meetings was hampered by the fact that they were either not able to attend, or they did not want to attend because they were intimidated by the fact that a group of doctors would sit in front of them and ask difficult questions (60). Thirdly, they demanded financial compensation which was not available.

Recently a study is published that used semi structured qualitative interviews to explore patients' and health professionals' experiences of participating in COS Delphi surveys. They also described above mentioned issues and identified ways to enhance Delphi surveys for future patient participants in COS studies. They emphasize that patient participants should have the information and support they need $(61,62)$. Several options are available for this patient involvement like; visual, written and auditory methods, infographics and/or visual metaphors, digital stories and other narrative forms.

The COMET website provides resources to help developers facilitate patient participation, including documents explaining COS in plain English and an animation video (http:// www.comet-initiative.org/resources/PlainLanguageSummary), coproduced with members of the public. This may also be applicable for patients who participate in the development of guidelines.

\section{Implementation of a COS}

Worldwide, the implementation of COS in grant applications of clinical trials is actively promoted by the COMET (Core Outcome Measures in Effectiveness Trials) initiative. This initiative believes that using high-quality core outcome sets will ultimately improve the conduct and reporting of clinical trials. As a result, it will enhance the value of evidence synthesis by reducing heterogeneity between trials, and may reduce outcome reporting bias. To assess how well RCTs include the OMERACT COS, a literature search was undertaken for Ankylosing Spondylitis. They showed that 20\% of the articles included the COS domains two years after publication (63). One of the major challenges associated with the development of a COS is ensuring impact, uptake and implementation. However, the lack of implementation of a COS in studies may be due to fact that core outcome sets are of recent date. Still there are many clinical conditions 
for which a COS has not been developed yet. In this respect, a recent initiative of the National Institute for Health Research (NIHR) is helpful; they stated 'Where established Core Outcomes exist, they should be included among the list of outcomes unless there is good reason to do otherwise'. So more clinical societies should develop and advocate implementation of a COS in their work field.

\section{Development of a guideline}

\section{Process}

In the nineties, the evidence-base medicine paradigm came oversea from Ontario to The Netherlands: evidence-based medicine is 'the conscientious, explicit and judicious use of current best practice in making decisions about the care of individual patient" (64). To facilitate this translation of the most recent evidence into clinical practice, guidelines were born. Several (inter)national agencies, institutions, experts, and health care providers have specialized in the guideline field. One of the leading institutions is the National Institute for Health and Care Excellence (NICE) who provides guidance and advice for guideline development. Also in the Netherlands, the Knowledge Institute (Federatie Medisch Specialisten) is concerned with guideline development and implementation. On international level the AGREE Collaboration (Appraisal of Guidelines, Research and Evaluation) is known $(65,66)$. During a meeting of the AGREE Collaboration it was decided to establish an International Guidelines Network (GIN) to promote information sharing, cooperation and collaboration between guideline agencies, programs, and individuals working in the field. According to these institutions appropriate methods and rigorous strategies in the guideline development process are important to develop high quality guidelines with clear recommendations. This resulted in various guidance documents on how to develop trustworthy guidelines and standards. The AGREE collaboration established a generic instrument, to assess the process of guideline development and to reduce confusion from multiple systems $(65,66)$. They developed the AGREE (II) Instrument, an easy online tool to assess the quality and reporting of practice guidelines (67). Currently, this instrument is broadly used for the guideline development process. Besides, it is a useful online tool to assess the quality of existing guidelines $(68,69)$. Therefore, we also chose to follow the AGREE instrument for the development of the ESCP HD guideline.

\section{Development tools}

Besides an optimal and standardized process which should be followed (for example the AGREE II instrument) in guideline development nowadays, development tools should become more aligned and standardized (70). According to a recent review, the following 
guideline development tools are often used for the guideline development: GRADE, CAN-IMPLEMENT $\odot$, Doctor Evidence platforms, RevMan 5, ROBIS, CREBP SRA Systematic Review Creator and Covidence (70). According to this review the tools should be selected according to their support of the guideline development process. The Cochrane Community recommends RevMan5 and GRADE. With Revman one can perform meta-analysis of the data entered, and present the results graphically. GRADE is used to classify the direction and strength of recommendations (22). GRADE has chosen a simple four-category classification of recommendations, a binary classification of recommendations as strong or weak recommendations for or against a management approach. It offers a transparent and structured process for developing and presenting evidence summaries and for carrying out the steps involved in developing recommendations. Since both resulted in successful development of guidelines, we also chose to use Revman and GRADE for the HD guideline.

\section{Implementation}

To be successful, a guideline has to be developed, disseminated to the right target audience and finally be implemented. Without being adopted in daily practice, even the guideline of highest quality is useless. Nowadays, hospitals, healthcare institutions, IGZ (Dutch Health Care Inspectorate) and healthcare providers have to deal with multiple guidelines and external requirements. Since 2010 more than 2400 guidelines have been introduced in Dutch hospitals and it is not always clear what their impact is on clinical practice (71). A scoping review of Fisher et al. showed that guidelines are often not applied $(72,73)$. It is estimated that about $30 \%-40 \%$ of patients receive treatment that is not based on scientific evidence, and $20 \%-25 \%$ receive treatments that are either not needed or potentially harmful (74). Perhaps, clinicians are overwhelmed by the sheer number of guidelines. In the Netherlands, researchers from NIVEL (Nederlands instituut voor onderzoek van de gezondheidszorg), IQ (Scientific Center for Qualitative Healthcare) and ZIN (The National Health Care Institute) concluded that there is room for improvement regarding the implementation of guidelines. They described the following reasons for suboptimal use of guidelines in daily practice:

- The core recommendations are often difficult to identify, especially with long, bulky guideline documents.

- There is little attention for communication and implementation of guidelines and how the key messages can best be brought to the attention of the users.

Future guidelines should focus on above mentioned items. Regarding the content and methodology, guidelines should be as short as possible, with clear recommendations. Regarding the implementation, guideline producers should develop implementation tools to encourage the adoption of new guidelines. A recently conducted review showed the following implementation tools: a memorandum pocket card, a test request form to implement guidelines, paper-based educational materials or reminders, a detail 
sheet in the patient's medical record and/or a toolkit which was a collection of printed educational materials sent to general practitioners. According to this review these tools probably lead to greater adherence to guidelines (median absolute risk difference (ARD) $13.5 \%)$ at an average four weeks follow-up (moderate-quality evidence) (75). For the HD guideline, we created awareness by presenting the guideline on the ESCP congress to the ESCP members, Besides, we published the guideline on the ESCP website. In this way it is accessible for everyone. However, in our opinion, more research is needed to support the translation of the content of guidelines into daily practice. Nevertheless, a combination of above mentioned strategies is most certainly needed to overcome these barriers of implementation (74).

\section{Conclusion}

This thesis encountered two problems in HD research, the heterogeneity in study outcomes and the poor methodology of current HD guidelines. First we addressed the lack of homogeneity in study outcomes by developing a COS. Secondly, by following AGREE and using GRADE, we were able to develop the first international HD guideline; a concise document with clear recommendations.

It remains important to emphasize that both a COS and guideline are dynamic processes and can (and should) be reviewed regularly due to new evidence.

\section{Recommendations for research and practice}

Efforts should be taken to overcome the heterogeneity in study outcomes. Core outcome sets should be used and when lacking, these should be developed. The COMET Initiative provides a freely accessible database with all published core outcomes sets. Each researcher should check the database before conducting a clinical trial. Regarding the development: a Delphi method is generally considered the appropriate method to determine a COS and should be used (45). Another major challenge is ensuring impact and uptake of the COS. Its accessibility is facilitated by the COMET database but we also need to keep in mind that the development of a COS is a dynamic process, and once established, it needs to be evaluated and updated regularly. Nowadays, Patient Reported Outcomes (PROs) are becoming more important since these PROs can provide a more complete understanding of the impact of a therapy on the patient's life (26-28). Besides, they have become an increasingly important component of assessing treatment response [34]. Our Delphi study underlined the need to integrate PROs (Patient Reported Outcomes) next to the traditional clinical outcomes. In the field of focus of this thesis, attempts have been made to develop such patient tools. Examples 
include the Symptom-based Severity Score of Pucher et al. (76), the Haemorrhoid Severity Score (HSS) introduced by Nystrom (77), the Haemorrhoid Symptom Score recently used in the eTHoS trial (78) and the Hemorrhoidal Disease Symptom Score (HDSS) and Short Health Scale HD (SHS) by Rørvik et al. (79). Yet these scoring systems often do not gain wide acceptance in the clinical and research setting. This may be due to a lack of robust validation, the extensive length of the instruments, the fact that the PRO is often sought for multiple purposes (both for individual patient care and for internal and external quality information) and that it takes multiple levels in account (local, regional, national and international). In our opinion a PRO should be short and easy to complete. Therefore, efforts should be made for (inter)national validation of a PRO for HD examing the psychometric properties of the instrument and following from bodies as the 'PROM-Toolbox' and the ICHOM, OECD and PROMIS who are working on the development and implementation of PROs. At the moment, we are developing a disease specific PROM for haemorrhoids that will be based on the results of this Delphi study. We will incorporate the results of a qualitative study with patients in this PROM.

Further, more effort on the implementation of clinical guidelines is needed to support their translation into daily practice and the uptake of their recommendations. Therefore, in the future we should develop concise clinical guidelines with clear recommendations. And by using a memorandum pocket card or a detailed sheet in the patient's medical record these guidelines can be implemented in daily practice.

In the process of establishing these guidelines, knowledge gaps in the literature will be revealed. These knowledge gaps may stimulate new research. Likewise, our ESCP HD guideline gives an overview of the gaps in literature regarding the best treatment option for each grade of HD. A moderate level of evidence for grade II and III HD was found, but a knowledge gap was revealed for the best treatment algorithm in case of recurrent grade II and III HD. To our knowledge no high quality randomized trials have been performed assessing effectiveness and cost-effectiveness of different treatment option in these patients. Such trials need to be conducted. Recently two study groups received a grant to conduct a RCT in the Dutch setting (Grant by ZonMW, the Dutch Institute for Health related research and Innovation of Care; https://www.zonmw.nl/nl/). One of these RCT's, the Napoleon Trial, includes patients with recurrent symptomatic HD grade II and III and aims to provide high level of evidence regarding the costeffectiveness and effectiveness of rubber band ligation versus sutured mucopexy versus haemorrhoidectomy in patients with recurrent haemorrhoidal disease. This study will start inclusion in March 2020 (zorgevaluatie.nl/napoleon-trial). In addition to the Napoleon Trial, another dedicated HD centre has launched a RCT, the HollAND Trial (zorgevaluatie.nl/holland). This RCT aims to provide high level evidence regarding best treatment outcome for patients with symptomatic haemorrhoids grade III by comparing 
Discussion, conclusion, and future perspectives

haemorrhoidectomy with rubber band ligation. In this study clinical effectiveness and cost-utility of both treatments will be compared and the primary outcome is quality of life at 24 months. 


\section{References}

1. Lohsiriwat V. Hemorrhoids: from basic pathophysiology to clinical management. World J Gastroenterol. 2012;18(17):2009-17.

2. Riss S, Weiser FA, Schwameis K, Riss T, Mittlbock M, Steiner G, et al. The prevalence of hemorrhoids in adults. Int J Colorectal Dis. 2012;27(2):215-20.

3. Haas PA, Haas GP. The prevalence of hemorrhoids and chronic constipation. Gastroenterology. 1990;99(6):1856-7.

4. Johanson JF, Sonnenberg A. The prevalence of hemorrhoids and chronic constipation. An epidemiologic study. Gastroenterology. 1990;98(2):380-6.

5. Banov L, Jr., Knoepp LF, Jr., Erdman LH, Alia RT. Management of hemorrhoidal disease. J S C Med Assoc. 1985;81(7):398-401.

6. Gaj F, Trecca A, Busotti A, Brugiotti C, Carboni M. The new classification of hemorrhoids: PATE 2000-Sorrento. History of the scientific debate. Minerva Chir. 2002;57(3):331-9.

7. Elbetti C, Giani I, Novelli E, Fucini C, Martellucci J. The single pile classification: a new tool for the classification of haemorrhoidal disease and the comparison of treatment results. Updates Surg. 2015;67(4):421-6.

8. Brown SR, Tiernan JP, Watson AJM, Biggs K, Shephard N, Wailoo AJ, et al. Haemorrhoidal artery ligation versus rubber band ligation for the management of symptomatic second-degree and thirddegree haemorrhoids (HubBLe): a multicentre, open-label, randomised controlled trial. Lancet. 2016;388(10042):356-64.

9. Watson AJ, Hudson J, Wood J, Kilonzo M, Brown SR, McDonald A, et al. Comparison of stapled haemorrhoidopexy with traditional excisional surgery for haemorrhoidal disease (eTHoS): a pragmatic, multicentre, randomised controlled trial. Lancet. 2016;388(10058):2375-85.

10. Shanmugam V, Thaha MA, Rabindranath KS, Campbell KL, Steele RJ, Loudon MA. Systematic review of randomized trials comparing rubber band ligation with excisional haemorrhoidectomy. Br J Surg. 2005;92(12):1481-7.

11. Shao WJ, Li GC, Zhang ZH, Yang BL, Sun GD, Chen YQ. Systematic review and metaanalysis of randomized controlled trials comparing stapled haemorrhoidopexy with conventional haemorrhoidectomy. Br J Surg. 2008;95(2):147-60.

12. Simillis C, Thoukididou SN, Slesser AA, Rasheed S, Tan E, Tekkis PP. Systematic review and network meta-analysis comparing clinical outcomes and effectiveness of surgical treatments for haemorrhoids. Br J Surg. 2015;102(13):1603-18.

13. Clarke M. Standardising outcomes for clinical trials and systematic reviews. Trials. 2007;8:39.

14. Klokker L, Tugwell P, Furst DE, Devoe D, Williamson P, Terwee CB, et al. Developing an OMERACT Core Outcome Set for Assessing Safety Components in Rheumatology Trials: The OMERACT Safety Working Group. J Rheumatol. 2017;44(12):1916-9.

15. Ubel PA, Angott AM, Zikmund-Fisher BJ. Physicians recommend different treatments for patients than they would choose for themselves. Arch Intern Med. 2011;171(7):630-4. 
16. Stalmeier PF, van Tol-Geerdink JJ, van Lin EN, Schimmel E, Huizenga H, van Daal WA, et al. Doctors' and patients' preferences for participation and treatment in curative prostate cancer radiotherapy. J Clin Oncol. 2007;25(21):3096-100.

17. Dans AL, Dans LF. Appraising a tool for guideline appraisal (the AGREE II instrument). J Clin Epidemiol. 2010;63(12):1281-2.

18. Burls A. AGREE II-improving the quality of clinical care. Lancet. 2010;376(9747):1128-9.

19. Brouwers MC, Kho ME, Browman GP, Burgers JS, Cluzeau F, Feder G, et al. Development of the AGREE II, part 1: performance, usefulness and areas for improvement. CMAJ. 2010;182(10):104552.

20. Brouwers MC, Kho ME, Browman GP, Burgers JS, Cluzeau F, Feder G, et al. Development of the AGREE II, part 2: assessment of validity of items and tools to support application. CMAJ. 2010;182(10):E472-8.

21. Andrews JC, Schunemann HJ, Oxman AD, Pottie K, Meerpohl JJ, Coello PA, et al. GRADE guidelines: 15. Going from evidence to recommendation-determinants of a recommendation's direction and strength. J Clin Epidemiol. 2013;66(7):726-35.

22. Andrews J, Guyatt G, Oxman AD, Alderson P, Dahm P, Falck-Ytter Y, et al. GRADE guidelines: 14. Going from evidence to recommendations: the significance and presentation of recommendations. J Clin Epidemiol. 2013;66(7):719-25.

23. Kirwan JR, Boers M, Tugwell P. Updating the OMERACT filter at OMERACT 11. J Rheumatol. 2014;41(5):975-7.

24. Kirwan JR, Boers M, Hewlett S, Beaton D, Bingham CO, 3rd, Choy E, et al. Updating the OMERACT filter: core areas as a basis for defining core outcome sets. J Rheumatol. 2014;41(5):9949 .

25. Boers M, Kirwan JR, Wells G, Beaton D, Gossec L, d'Agostino MA, et al. Developing core outcome measurement sets for clinical trials: OMERACT filter 2.0. J Clin Epidemiol. 2014;67(7):745-53.

26. Wu YP, Thompson D, Aroian KJ, McQuaid EL, Deatrick JA. Commentary: Writing and Evaluating Qualitative Research Reports. J Pediatr Psychol. 2016;41(5):493-505.

27. Keeley RD, West DR, Tutt B, Nutting PA. A qualitative comparison of primary care clinicians' and their patients' perspectives on achieving depression care: implications for improving outcomes. BMC Fam Pract. 2014;15:13.

28. Davis BR, Lee-Kong SA, Migaly J, Feingold DL, Steele SR. The American Society of Colon and Rectal Surgeons Clinical Practice Guidelines for the Management of Hemorrhoids. Dis Colon Rectum. 2018;61(3):284-92.

29. Altomare DF, Roveran A, Pecorella G, Gaj F, Stortini E. The treatment of hemorrhoids: guidelines of the Italian Society of Colorectal Surgery. Tech Coloproctol. 2006;10(3):181-6.

30. Higuero T, Abramowitz L, Castinel A, Fathallah N, Hemery P, Laclotte Duhoux C, et al. Guidelines for the treatment of hemorrhoids (short report). J Visc Surg. 2016;153(3):213-8.

31. Boers M, Brooks P, Strand CV, Tugwell P. The OMERACT filter for Outcome Measures in Rheumatology. J Rheumatol. 1998;25(2):198-9. 


\section{Chapter 8}

32. Prinsen CA, Vohra S, Rose MR, King-Jones S, Ishaque S, Bhaloo Z, et al. Core Outcome Measures in Effectiveness Trials (COMET) initiative: protocol for an international Delphi study to achieve consensus on how to select outcome measurement instruments for outcomes included in a 'core outcome set'. Trials. 2014;15:247.

33. Ong WL, Schouwenburg MG, van Bommel ACM, Stowell C, Allison KH, Benn KE, et al. A Standard Set of Value-Based Patient-Centered Outcomes for Breast Cancer: The International Consortium for Health Outcomes Measurement (ICHOM) Initiative. JAMA Oncol. 2017;3(5):677-85.

34. McNamara RL, Spatz ES, Kelley TA, Stowell CJ, Beltrame J, Heidenreich P, et al. Standardized Outcome Measurement for Patients With Coronary Artery Disease: Consensus From the International Consortium for Health Outcomes Measurement (ICHOM). J Am Heart Assoc. 2015;4(5).

35. Hall NJ, Kapadia MZ, Eaton S, Chan WW, Nickel C, Pierro A, et al. Outcome reporting in randomised controlled trials and meta-analyses of appendicitis treatments in children: a systematic review. Trials. 2015;16:275.

36. Schmitt J, Spuls PI, Thomas KS, Simpson E, Furue M, Deckert S, et al. The Harmonising Outcome Measures for Eczema (HOME) statement to assess clinical signs of atopic eczema in trials. J Allergy Clin Immunol. 2014;134(4):800-7.

37. Mackie SL, Twohig H, Neill LM, Harrison E, Shea B, Black RJ, et al. The OMERACT Core Domain Set for Outcome Measures for Clinical Trials in Polymyalgia Rheumatica. J Rheumatol. 2017.

38. Toupin-April K, Barton J, Fraenkel L, Li LC, Brooks P, De Wit M, et al. Toward the Development of a Core Set of Outcome Domains to Assess Shared Decision-making Interventions in Rheumatology: Results from an OMERACT Delphi Survey and Consensus Meeting. J Rheumatol. 2017.

39. Hatemi G, Meara A, Ozguler Y, Direskeneli H, Mahr A, Easley E, et al. Developing a Core Set of Outcome Measures for Behcet Disease: Report from OMERACT 2016. J Rheumatol. 2017.

40. Singh JA, Dowsey M, Choong PF. Patient Endorsement of the Outcome Measures in Rheumatology (OMERACT) Total Joint Replacement (TJR) clinical trial draft core domain set. BMC Musculoskelet Disord. 2017;18(1):111.

41. Singh JA, Dowsey MM, Dohm M, Goodman SM, Leong AL, Scholte Voshaar MM, et al. Achieving Consensus on Total Joint Replacement Trial Outcome Reporting Using the OMERACT Filter: Endorsement of the Final Core Domain Set for Total Hip and Total Knee Replacement Trials for Endstage Arthritis. J Rheumatol. 2017.

42. Hodgson CL, Burrell AJC, Engeler DM, Pellegrino VA, Brodie D, Fan E, et al. Core Outcome Measures for Research in Critically Ill Patients Receiving Extracorporeal Membrane Oxygenation for Acute Respiratory or Cardiac Failure: An International, Multidisciplinary, Modified Delphi Consensus Study. Crit Care Med. 2019;47(11):1557-63.

43. Rowe FJ, Hepworth LR, Kirkham JJ. Development of core outcome sets for vision screening and assessment in stroke: a Delphi and consensus study. BMJ Open. 2019;9(9):e029578. 
44. Gargon E, Gurung B, Medley N, Altman DG, Blazeby JM, Clarke M, et al. Choosing important health outcomes for comparative effectiveness research: a systematic review. PLoS One. 2014;9(6):e99111.

45. Chiarotto A, Ostelo RW, Turk DC, Buchbinder R, Boers M. Core outcome sets for research and clinical practice. Braz J Phys Ther. 2017;21(2):77-84.

46. Sinha IP, Smyth RL, Williamson PR. Using the Delphi technique to determine which outcomes to measure in clinical trials: recommendations for the future based on a systematic review of existing studies. PLoS Med. 2011;8(1):e1000393.

47. McMillan SS, King M, Tully MP. How to use the nominal group and Delphi techniques. Int J Clin Pharm. 2016;38(3):655-62.

48. Gorst SL, Gargon E, Clarke M, Blazeby JM, Altman DG, Williamson PR. Choosing Important Health Outcomes for Comparative Effectiveness Research: An Updated Review and User Survey. PLoS One. 2016;11(1):e0146444.

49. Webbe JWH, Duffy JMN, Afonso E, Al-Muzaffar I, Brunton G, Greenough A, et al. Core outcomes in neonatology: development of a core outcome set for neonatal research. Arch Dis Child Fetal Neonatal Ed. 2019.

50. Keeney S, Hasson F, McKenna HP. A critical review of the Delphi technique as a research methodology for nursing. Int J Nurs Stud. 2001;38(2):195-200.

51. Crisp J, Pelletier D, Duffield C, Adams A, Nagy S. The Delphi method? Nurs Res. 1997;46(2):1168.

52. Goodman CM. The Delphi technique: a critique. J Adv Nurs. 1987;12(6):729-34.

53. Kirkham JJ, Gorst S, Altman DG, Blazeby JM, Clarke M, Devane D, et al. Core Outcome SetSTAndards for Reporting: The COS-STAR Statement. PLoS Med. 2016;13(10):e1002148.

54. Sahnan K, Tozer PJ, Adegbola SO, Lee MJ, Heywood N, McNair AGK, et al. Developing a core outcome set for fistulising perianal Crohn's disease. Gut. 2019;68(2):226-38.

55. Hasson F, Keeney S, McKenna H. Research guidelines for the Delphi survey technique. J Adv Nurs. 2000;32(4):1008-15.

56. van der Weijden T, Post H, Brand PLP, van Veenendaal H, Drenthen T, van Mierlo LA, et al. Shared decision making, a buzz-word in the Netherlands, the pace quickens towards nationwide implementation. Z Evid Fortbild Qual Gesundhwes. 2017;123-124:69-74.

57. Dirksen CD, Utens CM, Joore MA, van Barneveld TA, Boer B, Dreesens DH, et al. Integrating evidence on patient preferences in healthcare policy decisions: protocol of the patient-VIP study. Implement Sci. 2013;8:64.

58. Supple D, Roberts A, Hudson V, Masefield S, Fitch N, Rahman M, et al. Erratum to: From tokenism to meaningful engagement: best practices in patient involvement in an EU project. Res Involv Engagem. 2015;1:12.

59. Ocloo J, Matthews R. From tokenism to empowerment: progressing patient and public involvement in healthcare improvement. BMJ Qual Saf. 2016;25(8):626-32.

60. Young B, Bagley H. Including patients in core outcome set development: issues to consider based on three workshops with around 100 international delegates. Res Involv Engagem. 2016;2:25. 


\section{Chapter 8}

61. Hall DA, Smith H, Heffernan E, Fackrell K, Core Outcome Measures in Tinnitus International Delphi Research Steering G. Recruiting and retaining participants in e-Delphi surveys for core outcome set development: Evaluating the COMiT'ID study. PLoS One. 2018;13(7):e0201378.

62. Turnbull AE, Dinglas VD, Friedman LA, Chessare CM, Sepulveda KA, Bingham CO, 3rd, et al. A survey of Delphi panelists after core outcome set development revealed positive feedback and methods to facilitate panel member participation. J Clin Epidemiol. 2018;102:99-106.

63. Bautista-Molano W, Navarro-Compan V, Landewe RB, Boers M, Kirkham JJ, van der Heijde D. How well are the ASAS/OMERACT Core Outcome Sets for Ankylosing Spondylitis implemented in randomized clinical trials? A systematic literature review. Clin Rheumatol. 2014;33(9):1313-22.

64. Evidence-Based Medicine Working G. Evidence-based medicine. A new approach to teaching the practice of medicine. JAMA. 1992;268(17):2420-5.

65. Collaboration A. Development and validation of an international appraisal instrument for assessing the quality of clinical practice guidelines: the AGREE project. Qual Saf Health Care. 2003;12(1):18-23.

66. Levin RF, Ferrara L. Using the Appraisal of Guidelines for Research and Evaluation II to assess clinical practice guidelines. Res Theory Nurs Pract. 2011;25(3):160-2.

67. Cartabellotta A. [AGREE II: assessing the quality of practice guidelines]. Recenti Prog Med. 2011;102(5):217-9.

68. Ferrara F, Parini D, Bondurri A, Veltri M, Barbierato M, Pata F, et al. Italian guidelines for the surgical management of enteral stomas in adults. Tech Coloproctol. 2019.

69. Hou X, Li M, He W, Wang M, Yan P, Han C, et al. Quality assessment of kidney cancer clinical practice guidelines using AGREE II instrument: A critical review. Medicine (Baltimore). 2019;98(40):e17132.

70. Khodambashi S, Nytro O. Reviewing clinical guideline development tools: features and characteristics. BMC Med Inform Decis Mak. 2017;17(1):132.

71. Blume LH, van Weert NJ, Delnoij DM. How to manage external demands in hospitals--the case of atrium MC. Healthc (Amst). 2015;3(3):157-9.

72. Grol R. Successes and failures in the implementation of evidence-based guidelines for clinical practice. Med Care. 2001;39(8 Suppl 2):II46-54.

73. Fischer F, Lange K, Klose K, Greiner W, Kraemer A. Barriers and Strategies in Guideline Implementation-A Scoping Review. Healthcare (Basel). 2016;4(3).

74. Grol R, Grimshaw J. From best evidence to best practice: effective implementation of change in patients' care. Lancet. 2003;362(9391):1225-30.

75. Flodgren G, Hall AM, Goulding L, Eccles MP, Grimshaw JM, Leng GC, et al. Tools developed and disseminated by guideline producers to promote the uptake of their guidelines. Cochrane Database Syst Rev. 2016(8):CD010669.

76. Pucher PH, Qurashi M, Howell AM, Faiz O, Ziprin P, Darzi A, et al. Development and validation of a symptom-based severity score for haemorrhoidal disease: the Sodergren score. Colorectal Dis. 2015;17(7):612-8. 
Discussion, conclusion, and future perspectives

77. Brown S, Tiernan J, Biggs K, Hind D, Shephard N, Bradburn M, et al. The HubBLe Trial: haemorrhoidal artery ligation (HAL) versus rubber band ligation (RBL) for symptomatic secondand third-degree haemorrhoids: a multicentre randomised controlled trial and health-economic evaluation. Health Technol Assess. 2016;20(88):1-150.

78. Watson AJ, Cook J, Hudson J, Kilonzo M, Wood J, Bruhn H, et al. A pragmatic multicentre randomised controlled trial comparing stapled haemorrhoidopexy with traditional excisional surgery for haemorrhoidal disease: the eTHoS study. Health Technol Assess. 2017;21(70):1-224.

79. Rorvik HD, Styr K, Ilum L, McKinstry GL, Dragesund T, Campos AH, et al. Hemorrhoidal Disease Symptom Score and Short Health ScaleHD: New Tools to Evaluate Symptoms and HealthRelated Quality of Life in Hemorrhoidal Disease. Dis Colon Rectum. 2019;62(3):333-42. 


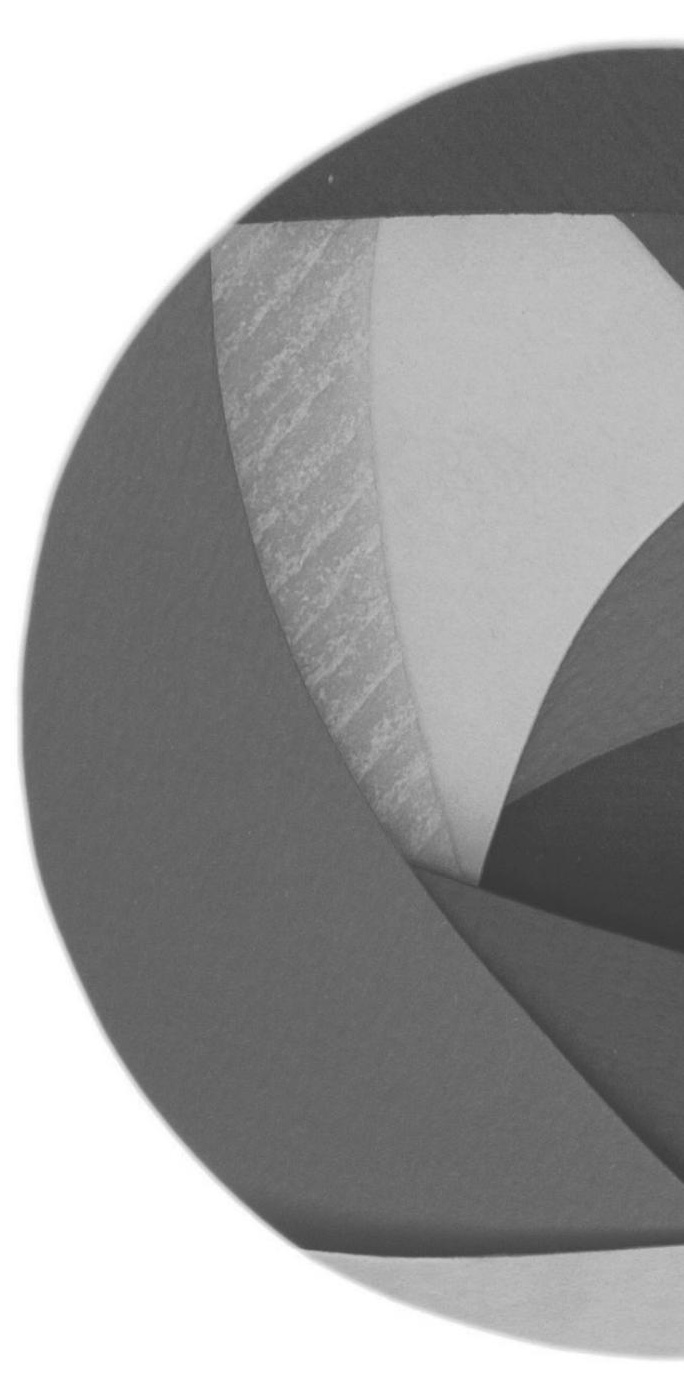




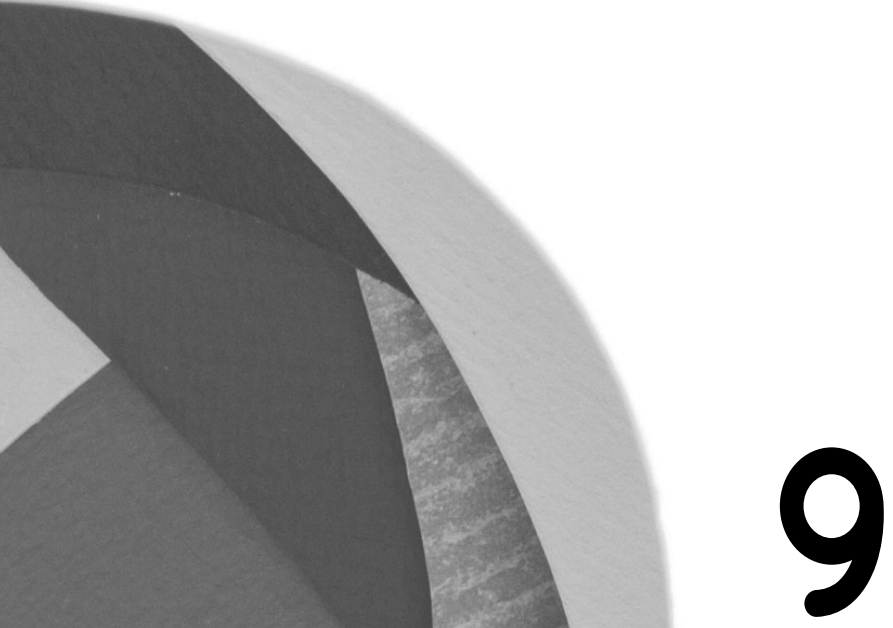

APPENDICES

SUMMARY

SAMENVATTING

VALORIZATION

DANKWOORD

CURRICULUM VITAE 
Chapter 9 


\section{SUMMARY}

This thesis consisted of two aims. The first aim of this thesis was to address heterogeneity in study outcomes in haemorrhoidal disease (HD) research and find solutions to improve homogeneity in outcome reporting. The second aim was to prepare and develop an international, high quality, multidisciplinary guideline for $\mathrm{HD}$.

Systematic reviews of the effectiveness of HD treatments highlighted the lack of uniform outcome definition, -measurement and -reporting in research data, hindering optimal evidence synthesis (1-3). A solution to improve homogeneity in outcome reporting was the development of a Core Outcome Set (COS). A COS represents a consensus-derived minimum set of outcome parameters that should be reported in all studies that report on a particular condition (4). Since no COS for HD existed yet, a logical next step was the development of such a COS for HD.

A detailed protocol (chapter 2) described the development process of the COS consisting of two main phases: 1) a literature review to ascertain which outcomes are commonly used in clinical trials for HD and 2) a consensus study according to the Delphi methodology. Additionally, qualitative interviews (chapter 5) were conducted to gain a deeper understanding and obtain information directly from the patients about their experiences with HD and treatment preferences $(5,6)$.

For the literature review (chapter 3) Medline (Pubmed), Embase (OVID) and Cochrane were searched for interventional studies for adult patients with HD. Two authors independently identified and reviewed eligible studies and finally 34 studies were included. The outcomes used in the studies were categorized according to the framework of OMERACT 2.0 filter $(7,8)$ a practical framework to develop and validate domains and outcomes for any health condition (9). This resulted in three Core Areas, 10 Domains and 59 different types of outcomes. Core Areas included Life impact, Pathophysiological manifestations, Resource use/economic impact and Death. No outcome could be placed into the Core Area Death. Apparently, death was not an outcome of interest in HD studies.

The Core Area Life impact included the following three Domains: patient satisfaction, time to return to normal and quality of life. The Core Area Pathophysiological manifestations consisted of three Domains: symptoms, complications and recurrence. The Core Area Resource use/ economical impact included four Domains: duration of operation, duration of hospitalization, re-operation and costs.

The most reported Domains were symptoms (100\%), complications (91\%), recurrence (59\%) and patient satisfaction (41\%) [table 1,2 and 3]. 
Table I: Outcome Domains in 42 studies included according to OMERACT 2.0 filter Core "Life impact"

\begin{tabular}{lcc}
\hline Domain & $\begin{array}{c}\text { Number of outcomes reported } \\
\text { within Domain }\end{array}$ & $\begin{array}{c}\text { Number of studies reporting } \\
\text { outcomes in Domain (\%) }\end{array}$ \\
\hline Patient satisfaction & 1 & $14(41)$ \\
Time to return to normal & 6 & $12(35)$ \\
Quality of life & 2 & $8(24)$ \\
\hline
\end{tabular}

Table 2: Outcome Domains in 42 studies included according to OMERACT 2.0 filter Core "Pathophysiological manifestations"

\begin{tabular}{lcc}
\hline Domain & $\begin{array}{c}\text { Number of outcomes reported } \\
\text { within domain }\end{array}$ & $\begin{array}{c}\text { Number of studies reporting } \\
\text { outcomes in Domain (\%) }\end{array}$ \\
\hline Symptoms & 22 & $34(100)$ \\
Complications & 18 & $31(91)$ \\
Recurrence & 2 & $20(59)$ \\
\hline
\end{tabular}

Table 3: Outcome Domains in 42 studies included according to OMERACT 2.0 filter Core "Resource use/ economical impact"

\begin{tabular}{lcc}
\hline Domain & $\begin{array}{c}\text { Number of outcomes reported } \\
\text { within domain }\end{array}$ & $\begin{array}{c}\text { Number of studies reporting } \\
\text { outcomes in Domain (\%) }\end{array}$ \\
\hline Duration of operation & 3 & $10(29)$ \\
Duration of hospitalization & 2 & $13(38)$ \\
Re-operation & 2 & $13(38)$ \\
Costs & 1 & $5(15)$ \\
\hline
\end{tabular}

Twenty-two different outcomes were used in the Domain 'symptoms'. Most reported outcomes were pain $(91 \%)$, blood loss (94\%) and prolapse (71\%). Eighteen different outcomes were used in the Domain 'complications'. Recurrence was used in 20 studies (59\%). Patient satisfaction was used in 14 studies (41\%) using non-validated questionnaires. On average, 5.8 different outcomes (2-8) were assessed per study. With this review, we derived potentially relevant Domains and Outcomes for the development of a COS for HD (47).

For the COS development, the Delphi methodology was followed (chapter 4). In collaboration with the European Society of Coloproctology (ESCP) 43 national representatives were invited to participate in the study. Besides, Dutch-speaking male 
and female participants ( $>18$ years) $(\mathrm{n}=30)$ having HD were asked to participate in the study. The Delphi process consisted of four phases.

In phase one, the outcomes, which were identified in the literature review (10), were operationalized into a questionnaire for healthcare professionals and a separate questionnaire for patients.

Phase two involved two sequential rounds of the questionnaire for healthcare professionals and one patient round, aiming to prioritize the different outcomes (11). Participants were asked to rate the appropriateness of each Domain and Outcome on a 9-point Likert scale. In round one, the first part of the questionnaire regarding the question 'What domains should we use as primary and secondary end-points in the COS for HD?', the domains (in order of level of appropriateness) 'symptoms', 'patient satisfaction', 'recurrence', 'complications', 'prolapse' and 'pain' were rated appropriate as primary endpoint options. In the same round, the domains 'patient satisfaction', 'complications' and 'recurrence' were rated as appropriate as secondary end-points and 'symptoms', 'prolapse' and 'pain' were rated as unsure. In the second part of questionnaire, regarding the question 'Which outcomes should be included in the domains?', most outcomes (i.e. 'pain', 'prolapse', 'itching', 'soiling', 'blood loss', 'abscess', 'incontinence', 'anal stenosis', 'stricture', 'fistula', 'severe bleeding', 'severe pain', 'urinary retention', 'thrombosis') were rated as appropriate. The Outcomes 'urgency' and 'constipation' were rated as unsure. The Outcomes 'edema' and 'nodule' were rated as inappropriate and were omitted.

The following definitions of recurrence were rated as appropriate: 'recurrent prolapse after a symptom free period', 'reappearance of initial symptoms' and 'further intervention necessary'. The definition 'residual symptoms in relation to degree of satisfaction' was rated as unsure and 'histological proved recurrence' was rated as inappropriate. In round two, healthcare professionals rated the Domains 'symptoms', 'patient satisfaction', 'recurrence' and 'complications' as primary endpoints. As secondary endpoints, all Domains (i.e. 'patient satisfaction', 'recurrence', 'prolapse', 'complications', 'symptoms' and 'pain') were rated as appropriate. Regarding the question: "Which Outcomes should be included in the Domains", 'constipation', 'urgency', 'urinary retention' and 'thrombosis' were rated as unsure. 'Pain', 'prolapse', 'itching', 'soiling', 'blood loss', 'abscess', 'incontinence', 'anal stenosis', 'fistula', 'stricture', 'severe pain' and 'severe bleeding' were rated as appropriate outcomes.

To define recurrence the following options were rated as appropriate: 'further intervention necessary', 'recurrent prolapse after symptom free period', 'reappearance of initial symptoms', and 'residual symptoms in relation to degree of satisfaction'. In conclusion, the questionnaire rounds did not result in a clear-cut selection of primary and secondary endpoints for HD. Most Domains and Outcomes were considered important and only three Outcomes were excluded. Patients rated 'symptoms' as most important to discuss during the outpatient clinic. They reported the following complaints: 'pain', 'prolapse', 'itching', 'soiling' and 'blood loss'. 
In phase three a face-to-face consensus meeting was conducted with 16 healthcare professionals in order to get consensus on the final endpoints of the COS [table 4]. Healthcare professionals rated the Domain 'symptoms' as the most appropriate primary endpoint in the COS. Further, healthcare professionals reached consensus that the Domains 'complications', 'recurrence' and 'patient satisfaction' should all be used as secondary endpoints in the COS for HD.

Besides uniformity in reporting, this Delphi study underlined the need to integrate Patient Reported Outcome Measures (PROMs) next to traditional clinical outcomes. PROMs have become an increasingly important component of assessing treatment response. Healthcare professionals agreed that the Domain 'symptoms' should be a Patient Reported Outcome Measure (PROM) and include the Outcomes 'pain', 'prolapse', 'itching', 'soiling' and 'blood loss'.

In phase four a short survey was sent to the healthcare professionals in order to reach consensus on 'how' the selected endpoints should be assessed and at which time points preand post-procedure. 'Incontinence' should be assessed by the Wexner Fecal Incontinence Score, 'abscess' by physical examination, 'urinary retention' by ultrasonography, 'anal stenosis' by physical examination, and 'fistula' by MR-imaging if physical examination is inconclusive [table 4]. During follow-up, the Outcome 'symptoms' should be assessed at baseline (i.e. before the procedure) and at 7 days, 6 weeks (arguably by telephone) and one-year post-procedure. The Outcomes 'abscess' and 'urinary retention' should be assessed 7 days' post-procedure, and 'rectal stenosis', 'incontinence' and 'fistula' one year post-procedure [table 5].

This resulted in the first international COS for HD based on an international Delphi study. Use of this COS will improve the quality and uniformity of future research and enhance evidence synthesis for meta-analyses and guidelines. 
Table 4: Summary of the core Domains for haemorrhoidal disease

\begin{tabular}{|c|c|}
\hline \multicolumn{2}{|l|}{ Core Outcome Set } \\
\hline \multicolumn{2}{|l|}{ PRIMARY OUTCOME } \\
\hline $\begin{array}{ll}\text { - } & \text { Patient reported symptoms } \\
\text { - } & \text { Blood loss } \\
\text { - } & \text { Pain } \\
\text { - } & \text { Prolapse } \\
\text { - } & \text { Itching } \\
\text { - } & \text { Soiling }\end{array}$ & Patient Reported Outcome Measure (PROM) \\
\hline \multicolumn{2}{|l|}{ SECONDARY OUTCOME } \\
\hline $\begin{array}{ll}\text { - } & \text { Complications } \\
\text { - } & \text { Incontinence } \\
\text { - } & \text { Abscess } \\
\text { - } & \text { Fistula } \\
& \\
\text { - } & \text { Urinary retention } \\
\text { - } & \text { Anal stenosis }\end{array}$ & $\begin{array}{l}\text { Wexner Fecal Incontinence Score } \\
\text { Physical examination } \\
\text { MR imaging after inconclusive physical } \\
\text { examination } \\
\text { Ultrasonography } \\
\text { Physical examination }\end{array}$ \\
\hline Recurrence & The reappearance of initial symptoms \\
\hline Patient satisfaction & This endpoint will be included in the PROM. \\
\hline
\end{tabular}

Table 5: Follow-up scheme.

\begin{tabular}{llcccc}
\hline & Outcomes & Baseline & 7 days & 6 weeks & 1 year \\
\hline Primary endpoint & Symptoms (PROM) & $\mathrm{X}$ & $\mathrm{X}$ & $\mathrm{X}$ & $\mathrm{X}$ \\
Secondary endpoints & Abscess & & $\mathrm{X}$ & & \\
& Urinary retention & & $\mathrm{X}$ & & \\
& Anal stenosis & & & $\mathrm{X}$ \\
& Incontinence & & & $\mathrm{X}$ \\
& Fistula & & & $\mathrm{X}$ \\
\hline
\end{tabular}

Since these traditional clinical outcomes - mostly selected by healthcare professionals - may not include all relevant benefits and harms as experienced by patients. However, differences in such preferences are difficult to predict and may vary between conditions (21-25).

During individual interviews $(\mathrm{n}=15)$, patients were encouraged to describe their experiences and symptoms they encounter having HD. Blood loss and anal pain were the most commonly reported symptoms. Participants indicated that these symptoms were directly associated with emotional burden, daily adjustments, and social impact. For example, in patients having blood loss before the diagnosis was known, this symptom resulted in feelings of fear. Besides, blood loss resulted in embarrassment and 
avoidance of social activities. Participants were not always completely satisfied with the process and outcomes of treatment. They expected greater openness and exchange of information regarding the different treatment options and the expected outcomes from their healthcare professionals.

This was the first study that showed that certain aspects relevant to the patient were overlooked when HD-treatment effectiveness was assessed by only traditional endpoints such as prolapse, recurrence and complications. Furthermore, this study showed that patients had different preferences regarding the treatment options compared to the preferences of the clinician.

In the second part of the thesis the development of the first international guideline for HD in collaboration with the European Society of Coloproctology (ESCP) is described. Up till now, only country-specific guidelines have been published, including the American Society of Colon and Rectal Surgeons guideline (12), the Italian (13)- and the French HD guideline (14). The methodological quality of these guidelines could be improved by being much more specific regarding the methods used to formulate the recommendations.

To see how the current Dutch situation was before the introduction of the new guideline, a nationwide survey (chapter 6) was conducted using a validated web based program. The survey was distributed among 619 officially registered Dutch colorectal consultants, fellows and residents and contained questions regarding the treatment options for each grade of $\mathrm{HD}$.

Grade I and II HD were most often treated conservatively or with Rubber Band Ligation (RBL). Respondents chose for more invasive treatment options like DopplerGuided Haemorrhoidal Artery Ligation (DG-HAL), stapled haemorrhoidopexy and haemorrhoidectomy in case of grade III and IV HD. In case of recurrent HD, they often preferred basic treatment and RBL. This study showed that there is considerable variability in treatment of HD in the Netherlands.

In a protocol (addendum) the seven steps of the guideline development were described using the AGREE II instrument [21]. We started with defining the scope of the guideline in phase one. The target group of the guideline consisted of all physicians treating patients with HD, healthcare workers and patients who desire information regarding the treatment management of HD. The patient population included patients with all stages of HD. The guideline needed to address both the diagnostic and therapeutic modalities for HD management.

In phase two the guideline development group (GDG) was composed and consisted of five colorectal surgeons, one gastroenterologist and proctologist (TH), one general practitioner (JM) specializing in the treatment of HD, one surgical resident (RT) and one methodologist $(\mathrm{JK})$ with extensive experience in guideline development. 
In phase three the first set of review questions were developed. The review questions were built up using a reversed process, starting with possible recommendations based on the GDG's knowledge.

In phase four a literature search was performed in MEDLINE (Ovid), PubMed, EMBASE (Ovid), and the Cochrane Database of Systematic Reviews. The search was focused on existing systematic reviews addressing each review question, supplemented by other studies published after the time frame covered by the systematic reviews.

In phase five data of the included papers were extracted by the surgical resident (RT) and checked by the methodologist (JK) and the GDG.

In phase six the GDG decided what recommendations could be made based on the evidence found in literature. GRADE was used to indicate the quality of the evidence (15).

This resulted in the first international guideline for HD (chapter 7) including 34 recommendations covering six sections: 1) evaluation: symptoms, diagnosis \& classification, 2) basic treatment, 3) outpatient procedures, 4) surgical interventions, 5) special situations and 6) other surgical techniques [figure 1].

For grade I and II HD, RBL appears to be the treatment of choice, because patients who undergo RBL showed a significantly better response compared to patients treated with sclerotherapy (SCL) and/or infrared coagulation (IRC). Besides patients treated by RBL have significantly less recurrence compared to patients treated with SCL or IRC. IRC may be the first treatment option in bleeding grade I HD because it causes less pain and complications (16). However, complication rates were similar in higher grade HD between RBL, IRC and SCL (17-19).

For grade III and IV HD, haemorrhoidectomy remains the treatment of choice. Comparing stapled haemorrhoidopexy $(\mathrm{SH})$ and haemorrhoidectomy, the efficacy of $\mathrm{SH}$ is generally lower than haemorrhoidectomy (20), especially in grade IV HD (20). The DG-HAL + mucopexy may be considered in patients with grade II-III HD. However, more research regarding this technique is necessary. The additional effect of the Doppler is currently being questioned since two studies showed that significantly more complications and unscheduled postoperative events were reported in the DG$\mathrm{HAL}+$ mucopexy group compared to the mucopexy alone group $(21,22)$.

The flow diagram for all degrees of haemorrhoids is shown below (figure 1).

This international multidisciplinary guideline provides an up to date and evidence based summary and may serve as a useful guidance for patients and clinicians. 


\section{Chapter 9}

History taking and physical examination

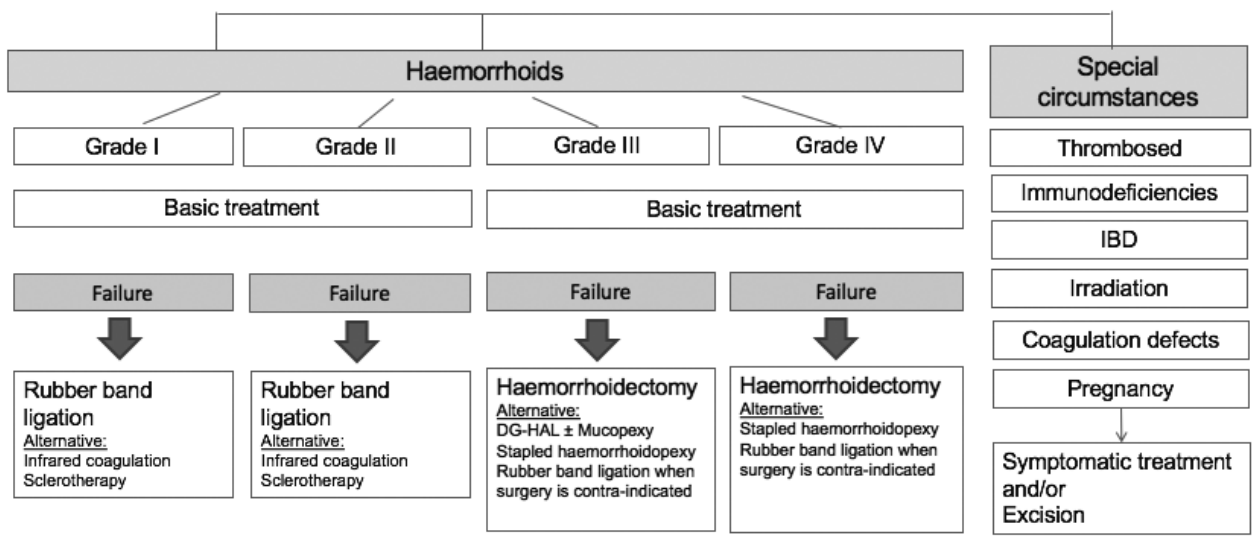

Figure I: flow diagram grade I-IV HD. 


\section{References}

1. Shanmugam V, Thaha MA, Rabindranath KS, Campbell KL, Steele RJ, Loudon MA. Systematic review of randomized trials comparing rubber band ligation with excisional haemorrhoidectomy. Br J Surg. 2005;92(12):1481-7.

2. Shao WJ, Li GC, Zhang ZH, Yang BL, Sun GD, Chen YQ. Systematic review and metaanalysis of randomized controlled trials comparing stapled haemorrhoidopexy with conventional haemorrhoidectomy. Br J Surg. 2008;95(2):147-60.

3. Simillis C, Thoukididou SN, Slesser AA, Rasheed S, Tan E, Tekkis PP. Systematic review and network meta-analysis comparing clinical outcomes and effectiveness of surgical treatments for haemorrhoids. Br J Surg. 2015;102(13):1603-18.

4. Klokker L, Tugwell P, Furst DE, Devoe D, Williamson P, Terwee CB, et al. Developing an OMERACT Core Outcome Set for Assessing Safety Components in Rheumatology Trials: The OMERACT Safety Working Group. J Rheumatol. 2017;44(12):1916-9.

5. Wu YP, Thompson D, Aroian KJ, McQuaid EL, Deatrick JA. Commentary: Writing and Evaluating Qualitative Research Reports. J Pediatr Psychol. 2016;41(5):493-505.

6. Keeley RD, West DR, Tutt B, Nutting PA. A qualitative comparison of primary care clinicians' and their patients' perspectives on achieving depression care: implications for improving outcomes. BMC Fam Pract. 2014;15:13.

7. Kirwan JR, Boers M, Tugwell P. Updating the OMERACT filter at OMERACT 11. J Rheumatol. 2014;41(5):975-7.

8. Kirwan JR, Boers M, Hewlett S, Beaton D, Bingham CO, 3rd, Choy E, et al. Updating the OMERACT filter: core areas as a basis for defining core outcome sets. J Rheumatol. 2014;41 (5):9949 .

9. Boers M, Kirwan JR, Wells G, Beaton D, Gossec L, d'Agostino MA, et al. Developing core outcome measurement sets for clinical trials: OMERACT filter 2.0. J Clin Epidemiol. 2014;67(7):745-53.

10. van Tol RR, van Zwietering E, Kleijnen J, Melenhorst J, Stassen LPS, Dirksen CD, et al. Towards a core outcome set for hemorrhoidal disease-a systematic review of outcomes reported in literature. Int J Colorectal Dis. 2018.

11. Steurer J. The Delphi method: an efficient procedure to generate knowledge. Skeletal Radiol. 2011;40(8):959-61.

12. Davis BR, Lee-Kong SA, Migaly J, Feingold DL, Steele SR. The American Society of Colon and Rectal Surgeons Clinical Practice Guidelines for the Management of Hemorrhoids. Dis Colon Rectum. 2018;61(3):284-92.

13. Altomare DF, Roveran A, Pecorella G, Gaj F, Stortini E. The treatment of hemorrhoids: guidelines of the Italian Society of Colorectal Surgery. Tech Coloproctol. 2006;10(3):181-6.

14. Higuero T, Abramowitz L, Castinel A, Fathallah N, Hemery P, Laclotte Duhoux C, et al. Guidelines for the treatment of hemorrhoids (short report). J Visc Surg. 2016;153(3):213-8. 


\section{Chapter 9}

15. Neumann I, Pantoja T, Penaloza B, Cifuentes L, Rada G. [The GRADE system: a change in the way of assessing the quality of evidence and the strength of recommendations]. Rev Med Chil. 2014;142(5):630-5.

16. Ambrose NS, Hares MM, Alexander-Williams J, Keighley MR. Prospective randomised comparison of photocoagulation and rubber band ligation in treatment of haemorrhoids. Br Med J (Clin Res Ed). 1983;286(6375):1389-91.

17. Walker AJ, Leicester RJ, Nicholls RJ, Mann CV. A prospective study of infrared coagulation, injection and rubber band ligation in the treatment of haemorrhoids. Int J Colorectal Dis. 1990;5(2):113-6.

18. Johanson JF, Rimm A. Optimal nonsurgical treatment of hemorrhoids: a comparative analysis of infrared coagulation, rubber band ligation, and injection sclerotherapy. Am J Gastroenterol. 1992;87(11):1600-6.

19. Charua Guindic L, Chirino Perez AE, Navarrete Cruces T, Osorio Hernandez RM, Avendano Espinosa O. [Non-surgical alternative management of hemorrhoidal disease]. Rev Gastroenterol Mex. 2005;70(3):284-90.

20. Watson AJ, Hudson J, Wood J, Kilonzo M, Brown SR, McDonald A, et al. Comparison of stapled haemorrhoidopexy with traditional excisional surgery for haemorrhoidal disease (eTHoS): a pragmatic, multicentre, randomised controlled trial. Lancet. 2016;388(10058):2375-85.

21. Aigner F, Kronberger I, Oberwalder M, Loizides A, Ulmer H, Gruber L, et al. Doppler-guided haemorrhoidal artery ligation with suture mucopexy compared with suture mucopexy alone for the treatment of Grade III haemorrhoids: a prospective randomized controlled trial. Colorectal Dis. 2016;18(7):710-6.

22. Gupta PJ, Kalaskar S, Taori S, Heda PS. Doppler-guided hemorrhoidal artery ligation does not offer any advantage over suture ligation of grade 3 symptomatic hemorrhoids. Tech Coloproctol. 2011;15(4):439-44. 


\section{SAMENVATTING}

Dit proefschrift is geschreven met twee doelen:

1. Het eerste doel van het proefschrift was om de heterogeniteit in onderzoeksuitkomsten aan te pakken in hemorrhoiden onderzoek en om oplossingen te vinden om de homogeniteit in de rapportage van de resultaten te verbeteren.

2. Het tweede doel was het opstellen en ontwikkelen van een internationale multidisciplinaire richtlijn voor de behandeling van hemorrhoiden.

Hemorrhoiden is een van de meest voorkomende anorectale aandoeningen. De werkelijke prevalentie van aambeien is echter niet bekend; ziekenhuisstudies zijn niet representatief voor de totale populatie met hemorrhoiden en community-gebaseerde studies hebben alleen op zelfrapportage vertrouwd. Dit heeft geleid tot gerapporteerde prevalentie percentages variërend van 4,4-45\% (1-4). In Nederland wordt de prevalentie geschat op ongeveer 8,6 per 1000 personen. De piek incidentie lijkt tussen de leeftijd van 45-65 jaar te liggen $(5,6)$. In de algemene bevolking is de prevalentie vergelijkbaar bij mannen en vrouwen $(2,7)$. Hoge oestrogeenreceptorniveaus zijn geïdentificeerd in aambeien, wat hemorroïdale symptomen tijdens de zwangerschap kan verklaren (8). Er is een verhoogde prevalentie onder hogere sociaaleconomische groepen, maar dit kan gezondheidsgerelateerd gedrag weerspiegelen (9).

Met de voortdurende evolutie van verschillende behandelingen voor de zorg van hemorrhoiden is het belangrijk dat de effectiviteit van (chirurgische) behandelingen op een systematische manier wordt geanalyseerd. Klinische onderzoeken naar de effectiviteit van interventies voor hemorrhoiden hebben een breed scala aan uitkomsten en uitkomstmaten gebruikt. Verschillende richtlijnen wezen op het gebrek aan uniformiteit van de definitie, meting en rapportage van uitkomsten. Hierdoor wordt optimale bewijssynthese belemmerd en ontbreken richtlijnen van hoge kwaliteit (1012).

Een oplossing om de homogeniteit in de resultaat rapportage over hemorrhoiden te verbeteren, is het ontwikkelen en gebruiken van een gestandardiseerde uitkomstenset. Een uitkomstenset vertegenwoordigt een uit consensus verkregen minimale set uitkomstparameters die moet worden gerapporteerd in alle studies die over een bepaalde aandoening rapporteren (13). Een overeengekomen uitkomstenset zal het vermogen verbeteren om toekomstige studies te vergelijken en om een optimaal behandelingsalgoritme voor hemorrhoiden te ontwikkelen. Aangezien er nog geen 
uitkomstenset voor hemorrhoiden bestaat, is een belangrijke stap voor het verbeteren van hemorrhoiden onderzoek de ontwikkeling van een gestandardiseerde uitkomstenset voor dergelijk onderzoek.

De afgelopen tien jaar zijn verschillende nationale richtlijnen voor de behandeling van hemorrhoiden gepubliceerd (35-37). De meest recent bijgewerkte richtlijn is van de Amerikaanse colorectale chirurgen (14). De methodologische kwaliteit van deze richtlijnen kan worden verbeterd door veel specifieker te zijn over de methoden die worden gebruikt om hun anbevelingen te formuleren. Daarom willen we een internationale, multidisciplinaire, hoogwaardige richtlijn ontwikkelen in samenwerking met de European Society of Coloproctology (ESCP) die zowel diagnostische als therapeutische modaliteiten voor het beheer van hemorrhoiden aanpakt.

\section{Doel I}

Hoofdstuk 2: een protocol voor het ontwikkelen van een gestandardiseerde uitkomstenset voor hemorrhoiden.

Hoofdstuk 3: literatuuroverzich van de verschillende uitkomsten in hemorrhoiden studies

Hoofdstuk 4: een Delphi proces om een internationale uitkomstenset te ontwikkelen voor hemorrhoiden.

Hoofdstuk 5: een kwalitatieve studie naar de ervaringen van patienten met hemorrhoiden.

\section{Doel 2}

Hoofdstuk 6: een nationale enquete naar het behandelalgortime onder de Nederlandse chirurgen.

Hoofdstuk 7: de richtlijn van hemorrhoiden.

Bijlage: de methodiek achter de richtlijn.

Voor de ontwikkeling van een gestandaardiseerde uitkomstenset moet een stapsgewijze aanpak worden gevolgd die in een protocol wordt beschreven (hoofdstuk 2). Een van de eerste pogingen om de resultaten te standardiseren werd in de jaren zeventig door de Wereldgezondheidsorganisatie uitgevoerd met betrekking tot kankeronderzoeken. Dit resulteerde in een WHO-handboek met richtlijnen die de minimumvereisten voor gegevensverzameling in kankeronderzoek aanbevelen (15). Het meest opmerkelijke werk tot nu toe met betrekking tot standaardisatie van resultaten sindsdien is uitgevoerd door de OMERACT-samenwerking (Outcome Measures in Rheumatology) (16). Sinds OMERACT zijn er andere voorbeelden (d.w.z. HOME, IMMPACT) van 
vergelijkbare initiatieven om aanbevelingen te ontwikkelen over de resultaten die in klinische onderzoeken moeten worden gemeten $(17,18)$. De OMERACT-gemeenschap heeft echter onlangs de OMERACT-filter 2.0 gepubliceerd, die een zorgvuldige uitleg geeft over hoe deze in andere subspecialiteiten kan worden geïmplementeerd (19). In dit proefschrift hebben we besloten deze methode te volgen. In navolging van het OMERACT-initiatief is de eerste fase bij het ontwikkelen van een uitkomstenset een literatuuronderzoek naar de soorten uitkomsten en uitkomstmaten die zijn gebruikt in eerder gepubliceerd onderzoek naar hemorrhoiden (hoofdstuk 3). In hemorrhoiden onderzoek worden verschillende uitkomsten (bijvoorbeeld verzakking, recidief, complicaties en duur van de operatie) gebruikt als primaire en secundaire uitkomsten. Deze heterogeniteit in de rapportage van uitkomsten bemoeilijkt de juiste vergelijking tussen onderzoeken. Zelfs twee recent uitgevoerde gerandomiseerde gecontroleerde studies van een onderzoeksgroep uit Engeland gebruiken verschillende primaire uitkomsten. In de eerste studie, de HubBLe-studie, wordt rubber band ligatie (RBL) vergeleken met de doppler (DG-HAL). De auteurs gebruiken 'herhaling na één jaar na de procedure' als primaire uitkomst. De tweede studie, de eTHoS-studie, waarbij geniete hemorroïdopexy wordt vergeleken met de traditionele hemorroïdectomie, wordt 'een gebied onder de curve van de kwaliteit van leven' gemeten als primaire uitkomst met behulp van het beschrijvende systeem EQ-5D-3L (20-22).

De tweede fase bij het ontwikkelen van een uitkomstenset is een Delphi proces. Eerst zullen de resultaten die in de literatuurstudie zijn geïdentificeerd, worden geoperationaliseerd in een vragenlijst voor artsen en een afzonderlijke vragenlijst voor patiënten. Daarna volgen twee opeenvolgende rondes van de vragenlijst om deze uitkomsten te prioriteren. Fase drie bestaat uit een vergadering met artsen om overeenstemming te bereiken over de eindpunten van de uitkomstenset. Dit wordt beschreven in hoofdstuk 4.

Door een uitkomstenset voor hemorrhoiden te ontwikkelen, moeten we echter voorzichtig zijn dat behandelvoorkeuren en -uitkomsten aanzienlijk kunnen verschillen tussen patiënten met hemorrhoiden (23). Kwalitatieve interviews bij patiënten met hemorrhoiden kunnen worden uitgevoerd om een dieper inzicht te krijgen en rechtstreeks van de patiënten informatie te verkrijgen over hun ervaringen met hemorrhoiden en behandelingsvoorkeuren (hoofdstuk 5) $(24,25)$.

Richtlijnen dienen het doel om klinische (gedeelde) besluitvorming met betrekking tot behandelingskeuzes te ondersteunen, volgens het beste beschikbare bewijs. Verschillende nationale HD-richtlijnen zijn gepubliceerd $(14,26,27)$. De Nederlandse richtlijn is in 2015 gepubliceerd.

Om de huidige praktijk in de behandeling van hemorrhoiden in Nederland te verkennen voordat een internationale richtlijn wordt geïntroduceerd, zullen we een nationale enquête onder Nederlandse colorectale consultants, fellows en arts-assistenten 
uitvoeren (hoofdstuk 6). Deze resultaten dienen als richting voor de volgende fase van het ontwikkelen van een internationale richtlijn voor hemorrhoiden.

Verschillende initiatieven (d.w.z. NICE, GIN-McMaster) ontwikkelden checklists voor de ontwikkeling van richtlijnen en beschreven dat een richtlijn moet worden ontwikkeld volgens een proces dat begint bij het gekozen onderwerp en zich uitstrekt tot toekomstige updates van richtlijnen. De AGREE Enterprise ontwikkelde het AGREE-instrument, een online tool om de kwaliteit en rapportage van praktijkrichtlijnen te beoordelen (28). Bestaande hemorrhoiden richtlijnen beschrijven geen duidelijke ontwikkelingsmethode zoals voorgesteld door de AGREE-checklist. Ze rapporteren vaak hun beoordelingsvragen en methoden voor het formuleren van hun aanbevelingen niet. In samenwerking met de European Society of Coloproctology (ESCP) zal een internationale kwaliteitsrichtlijn voor hemorrhoiden worden ontworpen. In hoofdstuk 7 worden de resultaten van de definitieve ESCP richtlijn voor de behandeling van hemorrhoiden gepresenteerd. In de bijlage worden de ontwikkelingsprocessen en -methoden volgens het AGREE IIinstrument beschreven. 


\section{Referenties}

1. Lohsiriwat V. Hemorrhoids: from basic pathophysiology to clinical management. World J Gastroenterol. 2012;18(17):2009-17.

2. Riss S, Weiser FA, Schwameis K, Riss T, Mittlbock M, Steiner G, et al. The prevalence of hemorrhoids in adults. Int J Colorectal Dis. 2012;27(2):215-20.

3. Haas PA, Haas GP. The prevalence of hemorrhoids and chronic constipation. Gastroenterology. 1990;99(6):1856-7.

4. Johanson JF, Sonnenberg A. The prevalence of hemorrhoids and chronic constipation. An epidemiologic study. Gastroenterology. 1990;98(2):380-6.

5. Medich DS, Fazio VW. Hemorrhoids, anal fissure, and carcinoma of the colon, rectum, and anus during pregnancy. Surg Clin North Am. 1995;75(1):77-88.

6. Madoff RD, Fleshman JW, Clinical Practice Committee AGA. American Gastroenterological Association technical review on the diagnosis and treatment of hemorrhoids. Gastroenterology. 2004;126(5):1463-73.

7. Haas PA, Haas GP, Schmaltz S, Fox TA, Jr. The prevalence of hemorrhoids. Dis Colon Rectum. 1983;26(7):435-9.

8. Pares D, Iglesias M, Pera M, Pascual M, Torner A, Baro T, et al. Expression of estrogen and progesterone receptors in the anal canal of women according to age and menopause. Dis Colon Rectum. 2010;53(12):1687-91.

9. Burkitt DP. Varicose veins, deep vein thrombosis, and haemorrhoids: epidemiology and suggested aetiology. Br Med J. 1972;2(5813):556-61.

10. Shanmugam V, Thaha MA, Rabindranath KS, Campbell KL, Steele RJ, Loudon MA. Systematic review of randomized trials comparing rubber band ligation with excisional haemorrhoidectomy. Br J Surg. 2005;92(12):1481-7.

11. Shao WJ, Li GC, Zhang ZH, Yang BL, Sun GD, Chen YQ. Systematic review and metaanalysis of randomized controlled trials comparing stapled haemorrhoidopexy with conventional haemorrhoidectomy. Br J Surg. 2008;95(2):147-60.

12. Simillis C, Thoukididou SN, Slesser AA, Rasheed S, Tan E, Tekkis PP. Systematic review and network meta-analysis comparing clinical outcomes and effectiveness of surgical treatments for haemorrhoids. Br J Surg. 2015;102(13):1603-18.

13. Klokker L, Tugwell P, Furst DE, Devoe D, Williamson P, Terwee CB, et al. Developing an OMERACT Core Outcome Set for Assessing Safety Components in Rheumatology Trials: The OMERACT Safety Working Group. J Rheumatol. 2017;44(12):1916-9.

14. Davis BR, Lee-Kong SA, Migaly J, Feingold DL, Steele SR. The American Society of Colon and Rectal Surgeons Clinical Practice Guidelines for the Management of Hemorrhoids. Dis Colon Rectum. 2018;61(3):284-92.

15. Miller AB, Hoogstraten B, Staquet M, Winkler A. Reporting results of cancer treatment. Cancer. 1981;47(1):207-14. 


\section{Chapter 9}

16. Boers M, Brooks P, Strand CV, Tugwell P. The OMERACT filter for Outcome Measures in Rheumatology. J Rheumatol. 1998;25(2):198-9.

17. Turk DC, Dworkin RH, McDermott MP, Bellamy N, Burke LB, Chandler JM, et al. Analyzing multiple endpoints in clinical trials of pain treatments: IMMPACT recommendations. Initiative on Methods, Measurement, and Pain Assessment in Clinical Trials. Pain. 2008;139(3):485-93.

18. Schmitt J, Spuls PI, Thomas KS, Simpson E, Furue M, Deckert S, et al. The Harmonising Outcome Measures for Eczema (HOME) statement to assess clinical signs of atopic eczema in trials. J Allergy Clin Immunol. 2014;134(4):800-7.

19. Boers M, Kirwan JR, Wells G, Beaton D, Gossec L, d'Agostino MA, et al. Developing core outcome measurement sets for clinical trials: OMERACT filter 2.0. J Clin Epidemiol. 2014;67(7):745-53.

20. Watson AJ, Hudson J, Wood J, Kilonzo M, Brown SR, McDonald A, et al. Comparison of stapled haemorrhoidopexy with traditional excisional surgery for haemorrhoidal disease (eTHoS): a pragmatic, multicentre, randomised controlled trial. Lancet. 2016;388(10058):2375-85.

21. Brown SR, Bradburn M. The HubBle trial: a word of caution - Authors' reply. Lancet. 2016;388(10063):2996.

22. Leung ALH, Cheung TPP, Tung K, Tsang YP, Cheung H, Lau CW, et al. A prospective randomized controlled trial evaluating the short-term outcomes of transanal hemorrhoidal dearterialization versus tissue-selecting technique. Tech Coloproctol. 2017;21(9):737-43.

23. Brown SR, Watson A. Comments to 'Rubber band ligation versus excisional haemorrhoidectomy for haemorrhoids'. Tech Coloproctol. 2016;20(9):659-61.

24. Wu YP, Thompson D, Aroian KJ, McQuaid EL, Deatrick JA. Commentary: Writing and Evaluating Qualitative Research Reports. J Pediatr Psychol. 2016;41(5):493-505.

25. Keeley RD, West DR, Tutt B, Nutting PA. A qualitative comparison of primary care clinicians' and their patients' perspectives on achieving depression care: implications for improving outcomes. BMC Fam Pract. 2014;15:13.

26. Altomare DF, Roveran A, Pecorella G, Gaj F, Stortini E. The treatment of hemorrhoids: guidelines of the Italian Society of Colorectal Surgery. Tech Coloproctol. 2006;10(3):181-6.

27. Higuero T, Abramowitz L, Castinel A, Fathallah N, Hemery P, Laclotte Duhoux C, et al. Guidelines for the treatment of hemorrhoids (short report). J Visc Surg. 2016;153(3):213-8.

28. Cartabellotta A. [AGREE II: assessing the quality of practice guidelines]. Recenti Prog Med. 2011;102(5):217-9. 


\section{VALORIZATION}

The process of disseminating scientific knowledge, and making it available for society, is called valorization of knowledge. This chapter describes the valorization potentials of this thesis. The results described in this thesis are relevant for patients, healthcare professionals, the scientific community and the government.

\section{To patients}

Patients become more and more empowered, and are eager to learn about available treatment options and the impact of therapies on their quality of life. Besides, there is a growing trend to include patients in advisory groups and decision-making processes to incorporate their opinions and ideas.

This thesis showed that several patient relevant aspects are overlooked if HD treatment is only assessed by traditional doctor's endpoints. In the majority of HD studies treatment success is mainly based on quantitative measurement of parameters such as prolapse, recurrence, complications and duration of operation (1-3). However, in this thesis qualitative interviews with patients showed that beside these traditional endpoints, patients are more concerned about the bothersomeness of the symptoms and the impact of HD on their daily life.

We developed a Core Outcome Set (COS) for HD. Patients participated in its development process. This collaboration between patients and healthcare professionals resulted in a COS with 'Patient Reported Symptoms' as primary endpoint. This outcome should be assessed by a Patient Reported Outcome Measure (PROM). PROMs are questionnaires that measure the patient's experiences regarding health (outcomes) and well-being (4). Several PROMs for HD have been published like the Symptom-based Severity Score of Pucher et al. (5), the Haemorrhoid Severity Score (HSS) introduced by Nystrom (6), the Hemorrhoidal Disease Symptom Score (HDSS), the Short Health Scale HD (SHS) by Rørvik et al. (7) and the Haemorrhoid Symptom Score recently used in the eTHoS trial (8). Yet, these scoring systems have not gained wide acceptance in the clinical and research setting which may be due to a lack of robust development and validation process. Moreover, some questionnaires were not derived from patients' experiences with haemorrhoidal disease. Recently, our research team developed the PROM Haemorrhoidal Impact and Severity Score (PROM-HISS), which is based on the outcomes of Delphi study and qualitative interviews reported in this thesis (9). Apart from symptoms, the PROM-HISS takes impact of HD symptoms on daily life and satisfaction with treatment into account. The above illustrates the impact the research from this thesis has on strengthening the patients' perspective in $\mathrm{HD}$ and on inspiring further research on this topic. 


\section{To healthcare professionals}

One of the deliverables of this thesis is an international guideline. This filled in an existing gap for healthcare professionals. A Dutch survey, published in this thesis, confirmed the need to develop such a guideline as its results showed considerable practice variation in HD treatment in the Netherlands despite the already existing Dutch guideline. Besides the Dutch guideline, other national guidelines for $\mathrm{HD}$ are available as well $(10-12)$. In these guidelines, core recommendations are mostly difficult to identify and the documents are long and bulky. Moreover, these national HD guidelines did not follow the AGREE instrument (Appraisal of Guidelines for Research \& Evaluation), an international adapted development method (13-16). In this thesis the development of an international, multidisciplinary $\mathrm{HD}$ guideline is described incorporating AGREE (13-16) and $\operatorname{GRADE}(17,18)$. We believe this guideline has the potential to contribute to a standardized treatment algorithm for patients to be used by healthcare professionals. Furthermore, this thesis is valuable for healthcare professionals since it revealed new knowledge gaps in the literature of HD. For example, a knowledge gap for the best treatment algorithm in case of recurrent grade II and III HD was discovered. There are no existing randomized trials assessing (cost)effectiveness of different treatment options in patients with this manifestation of HD. Recently, our research group received a grant to conduct a RCT in the Dutch setting (Grant by ZonMw, the Netherlands Organisation for Health Research and Development; https://www.zonmw.nl/nl/). This RCT, named the Napoleon Trial, will include patients with recurrent symptomatic HD grade II and III and aims to provide high level evidence regarding the (cost)effectiveness of rubber band ligation versus sutured mucopexy versus haemorrhoidectomy. This study will start inclusion in March 2020 (zorgevaluatie.nl/napoleon-trial).

Therefore, this thesis has not only offered valuable information for current healthcare givers, but also contributes to obtaining further knowledge by new scientific work.

\section{To researchers}

For researchers, the development processes of the COS and guideline presented in this thesis might be of interest. The methods and protocols are published in peer reviewed international journals. Such protocols provide researchers a detailed and step by step overview of the development processes which may be insightful for future COS and/ or guidelines developments in other clinical fields. Moreover, this development process may also be useful for researchers to recognize the challenges to involve patients and healthcare professionals in a balanced manner in such processes. Another insight from this thesis is that in both the COS and guideline development, the involvement of patients could be optimized. This can be enhanced for example by installing a Patient Advisory Board (PAB). A PAB includes a group of patients experiencing HD. One person can be appointed chairman and representative in the scientific project group, adding the patient's perspective of the PAB. Throughout the process close collaboration 
can be maintained with the PAB following a jointly prepared participation plan. Budget should be reserved to reimburse the patient advocates for every meeting. All members of the PAB fulfill the role of partner according to the participation matrix, meaning there is an equal cooperation with the investigators $(19,20)$.

Moreover, the HD COS in this thesis gives guidance for future researchers as to which minimum set of outcomes should be included in future HD studies. Broad use of the COS in future research will enhance optimal evidence synthesis which will result in future guidelines with higher level of evidence recommendations.

Finally, it is important to emphasize that both a COS and a guideline are dynamic constructs which should be reviewed regularly by researchers based on new evidence. An update will be conducted by our research group. For the guideline this will involve updated searches and assessment of any relevant research topic found in relation to the current recommendations and considerations leading to adaptation and change of the guideline.

\section{To the government}

Around the world, health care systems are struggling with rising healthcare costs. As a result, there is an increasing interest in maximizing the efficiency of health care. Annually 50.000 patients are referred to the Dutch hospital because of persistent HD symptoms (21), hence there is a profit to be gained by improving effectiveness and decreasing the budget impact of treatment of HD.

The HD guideline decribed in this thesis contributes to improving of the costeffectiveness of care for HD by presenting the best available evidence for each degree of this disease. Moreover, for grade I and II HD RBL is recommended and for grade III and IV HD the traditional haemorrhoidectomy. These are both techniques that are less expensive than sclerotherapy and infrared coagulation (for grade I and II) and stapled hemorroidectomy (for grade III and IV).

In the guideline a separate chapter is dedicated to the economic evidence. In our opinion the HD guideline in this thesis could greatly improve the quality of care and reduce treatment costs for HD. 


\section{References}

1. Watson AJ, Hudson J, Wood J, Kilonzo M, Brown SR, McDonald A, et al. Comparison of stapled haemorrhoidopexy with traditional excisional surgery for haemorrhoidal disease (eTHoS): a pragmatic, multicentre, randomised controlled trial. Lancet. 2016;388(10058):2375-85.

2. Brown SR, Tiernan JP, Watson AJM, Biggs K, Shephard N, Wailoo AJ, et al. Haemorrhoidal artery ligation versus rubber band ligation for the management of symptomatic second-degree and thirddegree haemorrhoids (HubBLe): a multicentre, open-label, randomised controlled trial. Lancet. 2016;388(10042):356-64.

3. Leung ALH, Cheung TPP, Tung K, Tsang YP, Cheung H, Lau CW, et al. A prospective randomized controlled trial evaluating the short-term outcomes of transanal hemorrhoidal dearterialization versus tissue-selecting technique. Tech Coloproctol. 2017;21(9):737-43.

4. Wiering B, de Boer D, Delnoij D. Patient involvement in the development of patient-reported outcome measures: a scoping review. Health Expect. 2017;20(1):11-23.

5. Pucher PH, Qurashi M, Howell AM, Faiz O, Ziprin P, Darzi A, et al. Development and validation of a symptom-based severity score for haemorrhoidal disease: the Sodergren score. Colorectal Dis. 2015;17(7):612-8.

6. Brown S, Tiernan J, Biggs K, Hind D, Shephard N, Bradburn M, et al. The HubBLe Trial: haemorrhoidal artery ligation (HAL) versus rubber band ligation (RBL) for symptomatic secondand third-degree haemorrhoids: a multicentre randomised controlled trial and health-economic evaluation. Health Technol Assess. 2016;20(88):1-150.

7. Rorvik HD, Styr K, Ilum L, McKinstry GL, Dragesund T, Campos AH, et al. Hemorrhoidal Disease Symptom Score and Short Health ScaleHD: New Tools to Evaluate Symptoms and HealthRelated Quality of Life in Hemorrhoidal Disease. Dis Colon Rectum. 2019;62(3):333-42.

8. Watson AJ, Cook J, Hudson J, Kilonzo M, Wood J, Bruhn H, et al. A pragmatic multicentre randomised controlled trial comparing stapled haemorrhoidopexy with traditional excisional surgery for haemorrhoidal disease: the eTHoS study. Health Technol Assess. 2017;21(70):1-224.

9. van Tol RR, Kimman ML, Melenhorst J, Stassen LPS, Dirksen CD, Breukink SO, et al. European Society of Coloproctology Core Outcome Set for haemorrhoidal disease: an international Delphi study among healthcare professionals. Colorectal Dis. 2019;21(5):570-80.

10. Davis BR, Lee-Kong SA, Migaly J, Feingold DL, Steele SR. The American Society of Colon and Rectal Surgeons Clinical Practice Guidelines for the Management of Hemorrhoids. Dis Colon Rectum. 2018;61(3):284-92.

11. Altomare DF, Roveran A, Pecorella G, Gaj F, Stortini E. The treatment of hemorrhoids: guidelines of the Italian Society of Colorectal Surgery. Tech Coloproctol. 2006;10(3):181-6.

12. Higuero T, Abramowitz L, Castinel A, Fathallah N, Hemery P, Laclotte Duhoux C, et al. Guidelines for the treatment of hemorrhoids (short report). J Visc Surg. 2016;153(3):213-8.

13. Dans AL, Dans LF. Appraising a tool for guideline appraisal (the AGREE II instrument). J Clin Epidemiol. 2010;63(12):1281-2.

14. Burls A. AGREE II-improving the quality of clinical care. Lancet. 2010;376(9747):1128-9. 
15. Brouwers MC, Kho ME, Browman GP, Burgers JS, Cluzeau F, Feder G, et al. Development of the AGREE II, part 1: performance, usefulness and areas for improvement. CMAJ. 2010;182(10):104552.

16. Brouwers MC, Kho ME, Browman GP, Burgers JS, Cluzeau F, Feder G, et al. Development of the AGREE II, part 2: assessment of validity of items and tools to support application. CMAJ. 2010;182(10):E472-8.

17. Andrews JC, Schunemann HJ, Oxman AD, Pottie K, Meerpohl JJ, Coello PA, et al. GRADE guidelines: 15. Going from evidence to recommendation-determinants of a recommendation's direction and strength. J Clin Epidemiol. 2013;66(7):726-35.

18. Andrews J, Guyatt G, Oxman AD, Alderson P, Dahm P, Falck-Ytter Y, et al. GRADE guidelines: 14. Going from evidence to recommendations: the significance and presentation of recommendations. J Clin Epidemiol. 2013;66(7):719-25.

19. Dreesens D, Stiggelbout A, Agoritsas T, Elwyn G, Flottorp S, Grimshaw J, et al. A conceptual framework for patient-directed knowledge tools to support patient-centred care: Results from an evidence-informed consensus meeting. Patient Educ Couns. 2019;102(10):1898-904.

20. van der Weijden T, Dreesens D, Faber MJ, Bos N, Drenthen T, Maas I, et al. Developing quality criteria for patient-directed knowledge tools related to clinical practice guidelines. A development and consensus study. Health Expect. 2019;22(2):201-8.

21. Janssen LW. [Consensus hemorrhoids (Dutch Society for Surgery)]. Ned Tijdschr Geneeskd. 1994;138(42):2106-9. 
Chapter 9 


\section{DANKWOORD}

Dit proefschrift is tot stand gekomen dankzij hulp en steun van vele mensen. Ik wil iedereen die heeft bijgedragen aan dit onderzoek graag bedanken, waarvan een aantal in het bijzonder.

Dr. S.O Breukink, geachte copromotor, beste Stéphanie. Jouw energie en enthousiasme werken aanstekelijk. Ik ben ervan overtuigd dat de combinatie van jouw enthousiasme en mijn ietwat 'drammerige' trekjes hebben geresulteerd in een vlotte voltooiing van dit promotietraject. Ik heb jou leren kennen als een uitgelaten, enthousiaste, wijze en vooral lieve vrouw. Wekelijks zat jij met mij om de tafel om mij van wijze lessen te voorzien. Niet alleen op werk gebied maar ook privé. Daar ben ik je enorm dankbaar voor. Samen hebben we het gepresteerd om naast mijn studie en werk binnen 4 jaar een PhD-traject te voltooien.

Prof. Carmen Dirksen, beste Carmen, met jou ervaring en expertise binnen de methodologie is het gelukt om dit proefschrift tot een mooi resultaat te verwerken. Menig keer zat ik bij je aan tafel en wilde ik het onderzoek opnieuw uitvoeren omdat ik het opschrijven van de limitaties maar moeilijk vond. Gelukkig hield je mij tegen. Ik wil je dan ook bedanken voor al je hulp bij het schrijven van dit proefschrift.

Prof. Dr. Laurents Stassen, ik wil u ontzettend bedanken voor uw kritische blik en snelle revisies van mijn stukken. $U$ zorgde voor het tegenwicht dat de stukken nodig hadden om beter te worden. Daarnaast wil ik u bedanken voor uw steuntje in de rug om mijn carriere buiten de regio voort te zetten.

Dr. Merel Kimman, beste Merel, jij was een waardevol onderdeel van mijn promotieteam. Ondanks je drukke schema vond je altijd tijd om mijn stukken te bekijken. Daar ben ik je erg dankbaar voor. Verder wil ik je bedanken voor de gezellige koffie sessies en het mogen gebruik maken van jouw stempelkaart als ik weer eens geen cash geld bij mij had.

Dr. Jarno Melenhorst, beste Jarno, jij zorgde voor een heldere en nuchtere kijk op dingen. Enorm bedankt!

Geachte leden van de beoordelingscommissie, bestaande uit Prof. dr. N. Bouvy (voorzitter), Prof. dr. A. Masclee, Prof. dr. T.van der Weijden, Prof. dr. E. Consten en Dr. F.J. Vogelaar. Bedankt voor het beoordelen van mijn proefschrift en het plaatsnemen in de commissie. 
Alle collega-onderzoekers van de chirurgie in Maastricht (Yvonne Roebroek, Marissa Vane, Romy Aarnoutse, Britt Hupkens) ontzettend bedankt voor de gezellige onderzoekstijd. Van iedere ochtend koffiedrinken tot eten bij Dadawan, een prachtige bruiloft van Yvonne en het niet te vergeten jumping fitnessen. Jullie hebben ervoor gezorgd dat het een mooi jaar is geworden.

Verder wil ik de overige auteurs bedanken voor hun bijdrage aan de hoofdstukken van dit proefschrift met in het bijzonder Sara Kuiper. Jij bent de toekomst van de aambeien, heel veel succes! Hopelijk kan ik mijn steentje blijven bijdragen.

Gedurende mijn onderzoeksperiode werkte ik zes maanden als ANIOS op de afdeling heelkunde van het MUMC+ onder hoede van Dr. Ronald van Dam en Dr. Daemen. Verder werkte ik 1 jaar in het Diakonessenhuis onder hoede van Dr. Thijs van Dalen. Hierbij wil ik jullie en de assistenten met wie ik heb samengewerkt tijdens deze periode bedanken voor de leerzame tijd en natuurlijk de gezelligheid!

Lieve vrienden, bedankt voor jullie geduld en interesse in aambeien de afgelopen jaren. Jullie zorgden voor de broodnodige ontspanning. Hierbij wil ik in het bijzonder Judith bedanken. Menig keer kwam ik gestrest thuis en was jij degene die mijn verhalen moest aanhoren van die dag. Jij zorgde dat het eten klaar stond en sleepte mij vervolgens mee naar de sportschool. Dit werd afgewisseld met etentjes in de stad en de bioscoop of het theater. Ik ben trots op je dat je je werk nog even voortzet in Maastricht zodat daar iets heel moois uit voort gaat komen.

Lieve Andrea en Doreen: 200 km afstand, gelukkig zegt frequentie niks over gevoel.

Natuurlijk wil ik mijn ouders en broer bedanken voor al hun steun de afgelopen jaren. Ouders wonend in Spanje is ideaal als je een week compensatie hebt. Niemand snapte dat ik het hele jaar zo bruin was. Ook wil ik mijn schoonouders bedanken voor het support. In de weekenden was ik veel bij jullie te vinden. Ik bof met een familie zoals jullie. En Caroline, wat komt het goed van pas om een creatieve in de familie te hebben, bedankt voor het ontwerpen van de omslag van dit boek!

Lieve Nils, ik ben erg blij dat wij samen door het leven gaan. Bedankt voor je onvoorwaardelijke steun, energie en geduld. Ik prijs mij ontzettend gelukkig met jou en ik kijk uit naar al het moois wat we nog samen gaan meemaken. 


\section{CURRICULUM VITAE}

Robin R. Van Tol was born on March the 11th 1992, in Blaricum, The Netherlands. She grew up in Naarden en attended pre-university education (Gymnasium) at the Willem de Zwijger College in Bussum were she graduated in 2010. The same year she moved to Maastricht to start Medical school at Maastricht University. Robin developed an interest in medical research during her first surgical internship in 2013. She has been working on various research projects since. Also the thesis on endpoints in haemorrhoidal disease studies, which is the

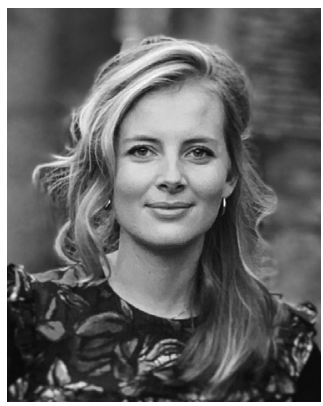
foundation on which this $\mathrm{PhD}$ project was built. After obtaining her medical doctor degree in 2016, she started working as surgical resident (not in training) under supervision of dr. J.W.H.C. Daemen and dr. R.M. van Dam at Maastricht UMC+. In february 2017 she worked during one year as fulltime $\mathrm{PhD}$ student under supervision of dr. Stephanie Breukink, Prof. dr. Laurents Stassen and Prof. Carmen Dirksen, which resulted in the current dissertation. From March 2018-2019, she was employed as a surgical resident at the Diakonessenhuis Utrecht, under supervision of dr. Th. Van Dalen. Currently, Robin works as a urology resident (not in training) at the Diakonessenhuis and St. Antonius Hospital under supervision of drs. O.J.D. Snieders and dr. H.H.E. van Melick. Robin lives with Nils in Utrecht. 

